\title{
Regulación de Protección de Datos y de Sociedades de Información: Una Comparación de Países Seleccionados de América Latina, los Estados Unidos, Canadá y la Unión Europea.*
}

\author{
Rafael del Villar \\ Alejandro Díaz de León \\ Johanna Gil Hubert
}

Octubre de 2001

Documento de Investigación No. 2001-07

\footnotetext{
* Agradecemos los muy valiosos comentarios y sugerencias de Armando Baqueiro y Margaret Miller, a los participantes de la Conferencia Internacional sobre Sistemas de Reporte de Crédito organizada por el Banco Mundial en junio de 2000, así como la asistencia de Clara de la Cerda y Luis Treviño en la elaboración de este documento. Los autores trabajan en la Dirección General de Investigación Económica del Banco de México. Las opiniones contenidas en este trabajo corresponden exclusivamente a los autores y no necesariamente representan el punto de vista del Banco de México.
} 


\title{
Regulación de Protección de Datos y de Sociedades de Información: Una Comparación de Países Seleccionados de América Latina, los Estados Unidos, Canadá y la Unión Europea.*
}

\author{
Rafael del Villar \\ Alejandro Díaz de León \\ Johanna Gil Hubert
}

Octubre de 2001

Documento de Investigación No. 2001-07

\begin{abstract}
Resumen
En este estudio se argumenta que la protección de datos personales y la promoción del flujo de información no son objetivos necesariamente incompatibles y que no deben analizarse ni regularse de manera aislada. La protección de la privacidad de las personas es un derecho fundamental del ser humano. La privacidad en cuanto a datos personales es congruente con el desarrollo económico cuando la regulación además de proteger los datos personales, contempla el surgimiento de sociedades de información (término genérico que se refiere a empresas que facilitan el flujo de información). En el estudio se comparan ambos tipos de regulaciones para seis países de América Latina: Argentina, Brasil, Colombia, Chile, México y Perú. Se incluyen como referencia las regulaciones en los Estados Unidos, Canadá y los países de la Unión Europea. La tesis de este estudio no es nueva, la OCDE ya había considerado ambos objetivos hace 21 años en las directrices sobre la protección de datos personales. No obstante, el tema es particularmente importante para los países de América Latina, pues generalmente carecen tanto de una regulación de protección de datos personales como de una regulación general para las sociedades de información. Así, es recomendable contar con un marco que promueva el flujo de información bajo un esquema que proteja la privacidad del individuo y elaborar leyes de protección de datos que consideren el desarrollo de las sociedades de información.
\end{abstract}




\section{INDICE}

Uso de Términos 1

I. Introducción 2

A. El fluio de datos personales como factor determinante del desarrollo y su balance con relación a la protección de la privacidad

B. Experiencia Internacional en la Regulación de Protección de Datos Personales y Objetivos del Presente Trabajo

C. Estructura del Presente Trabajo

II. Marco Regulatorio en Materia de Protección de Datos

A. Directrices de Organismos Multinacionales sobre la Protección de Personales

1. Derechos del consumidor o sujeto

2. Especificación del Fin

3. Límites a la Recolección

4. Limitaciones al Uso y Transmisión

5. Límites a la Retención de Datos

6. Calidad de los datos (exactos y actualizados)

7. Medidas de Seguridad

8. Sanciones y Remedios

9. Responsabilidad del controlador de datos

10. Transparencia del Controlador de Datos

11. Excepciones

B. Protección de Datos Personales en los Estados Unidos, Canadá, la América Latina

1. Derechos establecidos en las constituciones

2. Legislación de Protección de Datos: Ámbito y Objetivos en Distintos Países

3. Derechos de los Consumidores Respecto a la Información sobre su Persona

\section{Mercados de Información y la Regulación de las Sociedades de}

Información

A. Beneficios del Flujo de la Información y el Papel de las Sociedades

de Información

1. Incentivos económicos de los consumidores cumplidos para dar a conocer su información

2. Incentivos Económicos a Compartir Información entre Empresas

B. Consideraciones para el Desarrollo de Sociedades de Información Latina

1. Elaboración de un marco regulatorio para la protección de datos y para el Desarrollo de las SIs

2. Regulación de las Sociedades de Información en los países analizados de América Latina, los Estados Unidos, Canadá y la Unión Europea 
3. Tipos de Datos tratados por las Sociedades de Información en los países de América Latina, Los Estados Unidos, Canadá y la Unión Europea

IV. El Marco Institucional en los Países Analizados

A. Comparación Internacional del Marco Institucional para la Personales

1. Autoridades Administrativas en los Estados Unidos

2. Autoridades de Control en la Unión Europea

3. Autoridad Administrativa Federal en Canadá

4. Autoridades en los Países de América Latina

B. Análisis de las Responsabilidades de las Autoridades

Administrativas

1. Vigilar la Aplicación de la Ley

2. Facultades Regulatorias de la Autoridad Administrativa

3. Rendición de Cuentas

C. Comparación de las Responsabilidades de las Autoridades

Administrativas

V. Recomendaciones

A. Recomendaciones sobre la Protección de Datos Personales 78

B. Recomendaciones para Facilitar el Desarrollo de Sociedades de Información

ANEXOS

Argentina $\quad 89$

Brasil $\quad 98$

$\begin{array}{ll}\text { Chile } & 105\end{array}$

Colombia 113

México 121

Perú 128

Estados Unidos

Canadá 147

Unión Europea 154 


\section{INDICE DE CUADROS}

Cuadro 1 La Existencia y Acceso a la Información es un Instrumento Fundamental.

Cuadro 2 Instrumentos Internacionales para la protección de los datos Personales.

Cuadro 3 Fundamentos Constitucionales.

Cuadro 4 Derechos de los Consumidores Respecto a la Información sobre su Persona.

Cuadro 5 Costo para las Personas Físicas de Accesar y Rectificar su Propia Información en Poder de Sociedades de Información

Cuadro 6 El Flujo de Información de Datos Personales desde la. Perspectiva del Individuo

Cuadro 7 El Flujo de Información de Datos Personales desde la Perspectiva de las Empresas.

Cuadro 8 Regulación de las Sociedades de Información

Cuadro 9 Tipo de Información Tratada por las Sociedades de Información.

Cuadro 10 Marco Institucional.

Cuadro 11 Responsabilidades y Facultades de las Autoridades Administrativas con Respecto a los Burós de Crédito 



\section{Uso de Términos}

\section{Controlador de Datos}

Término genérico que se refiere a toda persona, física o moral, pública o privada, que lleva a cabo el tratamiento de datos personales.

\section{Tratamiento de Datos}

La definición de tratamiento de datos es muy amplia y se refiere a cualquier operación o conjunto de operaciones, efectuadas o no mediante procedimientos automatizados aplicadas a datos personales, como la recolección, registro, organización, conservación, modificación, extracción, consulta, utilización, comunicación por transmisión, difusión o cualquier otra forma que facilite el acceso a los mismos, cotejo o interconexión, así como su bloqueo, supresión o destrucción.

\section{Datos Personales}

Los datos personales se definen como toda información sobre una persona física identificada o identificable sobre sus características físicas, fisiológicas, psíquicas, económicas, culturales o sociales. (por ejemplo, información crediticia, de seguros, de arrendamiento, de empleo, médica etc.).

\section{Sociedades de Información (SIs)}

Controladores de datos, empresas públicas o privadas, que venden reportes con datos personales de las personas, tales como el historial crediticio, de empleo, médico, de pago de bienes y servicios y de arrendamientos, etc.

\section{$\underline{\text { SIS privadas }}$}

Sociedades de información operadas por el sector privado. El presente documento se concentra en la regulación de las Sociedades de Información Privadas.

\section{$\underline{\text { SIs Públicas }}$}

Sociedades de información operadas por el gobierno como Registros Públicos (Comercio, propiedad, etc), y Centrales de Riesgo Públicas (comúnmente operadas por los bancos centrales o las superintendencias bancarias).

\section{Reporte de datos personales}

Es toda comunicación de datos personales de una SI que se refiere al historial crediticio, características o reputación de un individuo. Dicha comunicación es comúnmente utilizada para evaluar el otorgamiento de crédito o seguro a dicho individuo o para propósitos de empleo u otros propósitos. 


\section{Introducción}

En este estudio se argumenta ampliamente a favor del desarrollo de marcos regulatorios en materia de protección de datos personales basados en los principios establecidos por la Organización de las Naciones Unidas, la Organización para la Cooperación y el Desarrollo Económico y el Consejo Europeo. Adicionalmente, se ha identificado que la experiencia de los Estados Unidos, de más de un siglo y medio con burós de crédito o sociedades de reportes del consumidor privadas (que en este documento se denominan genéricamente Sociedades de Información, SIs), es particularmente importante para los países de América Latina. El punto central de este documento es que en los países de América Latina las medidas que promuevan la protección de datos personales deben venir acompañadas de otras que posibiliten y fomenten el sano desarrollo de las SIs.

\section{A. El flujo de datos personales como factor determinante del desarrollo económico y su balance con relación a la protección de la privacidad.}

Para la prestación de bienes y servicios y, en general, para la realización de transacciones económicas es de gran utilidad contar con información adecuada sobre las partes involucradas. Lo anterior permite que los contratos se realicen con menores costos y riesgos. Por ello, tanto los proveedores de bienes y servicios como los consumidores obtienen beneficios al operar con mejor información.

\section{Cuadro 1}

La existencia y acceso a la información de las personas es un instrumento fundamental para:

(i) mejorar la toma de decisiones (políticas, sociales y de negocios);

(ii) fomentar la cultura de pago y el cumplimiento de todo tipo de obligaciones;

(iii) propiciar el desarrollo de la economía, aumentar la productividad, reducir precios y favorecer la provisión de nuevos servicios (el no conocer información relevante y verdadera de las personas, entorpece y hace más riesgosa la toma de decisiones);

(iv) reducir los costos de transacción en que incurren los agentes que requieren de este tipo de información. De no contar con dicha información, los agentes tienen que utilizar mecanismos más onerosos para obtenerla, completarla y hacerla más precisa; y

(v) fomentar el comercio interno e internacional. 
Cuando se analiza el papel en la economía de los datos de las personas, es importante tener en cuenta dos intereses fundamentales: la protección a la privacidad y el libre flujo de la información. La protección de la información personal contenida en bases de datos se relaciona con el derecho individual de respeto a la vida privada. Por otra parte, el libre flujo de información está claramente relacionado con los derechos individuales de libertad de expresión y libertad de prensa.

Los esfuerzos por fortalecer y preservar la privacidad del individuo pueden restringir el funcionamiento eficiente de la economía el cual requiere que fluya la información. A este respecto, la legislación y regulación de las bases de datos personales debe buscar proteger la privacidad y propiciar el flujo de información en beneficio tanto de los consumidores como de las empresas prestadoras de servicios. Pareciera que existe un conflicto permanente entre estos dos objetivos, pero no es así. Si bien el proteger la privacidad impone algunos costos reales, principalmente a las empresas, la protección de los datos personales fomenta la confianza de los consumidores y de las empresas de que la información no será utilizada injustamente. Ello facilita el desarrollo de bases de datos personales y, por ende, el flujo de información y la mejor toma de decisiones. No se debe perder de vista que consumidores y empresas incurren en costos elevados al tener que tomar decisiones sin contar con información actualizada, veraz y completa.

\section{B. Experiencia Internacional en la Regulación de Protección de Datos Personales y Objetivos del Presente Trabajo}

Por lo que toca a la experiencia internacional en materia de protección de datos personales, se presentan las recomendaciones de tres instrumentos de organismos multinacionales: las directrices de la Organización para la Cooperación y el Desarrollo Económico (OCDE), la Convención del Consejo Europeo y las Directrices de las Naciones Unidas. Como muestra del esfuerzo del sector privado en esta materia, también se incluye el Código Modelo para la Protección de Información Personal de la Asociación Canadiense de Estándares, que ya es parte de la ley de protección de datos de dicho país. Si bien el manejo de datos 
personales parecería ser un tema nuevo, asociado al desarrollo de medios de comunicación como Internet y el comercio electrónico, los instrumentos mencionados no son recientes. Las directrices de la OCDE y del Consejo Europeo fueron emitidas a principio de los años ochenta, mientras que las directrices de las Naciones Unidas se remontan al inicio de la década de los noventa.

Posteriormente, se comparan las regulaciones y los marcos institucionales existentes en materia de protección de datos personales y de las SIs en seis países de América Latina: Argentina, Brasil, Chile, Colombia, México y Perú. Para efectuar dicha comparación se examina adicionalmente el contexto regulatorio e institucional de los Estados Unidos, Canadá y los miembros de la Unión Europea, países con los que América Latina mantiene relaciones comerciales y de cooperación económica muy cercanas.

\section{Estructura del Presente Trabajo}

En el capítulo II se presenta la experiencia internacional en la regulación de protección de datos. En particular, se incluyen seis países de América Latina (Argentina, Brasil, Colombia, Chile, México y Perú), los Estados Unidos y la Unión Europea.

En el capítulo III se presenta un ángulo distinto del mismo tema. Se describen los incentivos que tanto consumidores como empresas tienen para compartir información de consumidores con terceros. Adicionalmente, se discute la importancia de que las SIs obtengan la confianza de los consumidores y empresas y se identifican los impedimentos que existen en algunos países de América Latina para que este importante mercado se desarrolle. Se examina la regulación de las SIs, en el contexto de los principios internacionales mencionados, el tipo de información que tratan y la conveniencia de que exista competencia entre las SIs.

Finalmente, en el capítulo IV se analiza el papel asignado a las autoridades y tribunales de los distintos países en la materia objeto de este documento. En el último capítulo se 
presentan las principales recomendaciones en los ámbitos regulatorio y de diseño institucional que se desprenden de este estudio. 


\section{Marco Regulatorio en Materia de Protección de Datos}

\section{A. Directrices de Organismos Multinacionales sobre la Protección de Bases de Datos Personales}

Por lo que toca a la experiencia internacional relativa a los principios de protección de datos personales destacan los instrumentos de tres organismos multinacionales, las directrices de la OCDE, la Convención del Consejo Europeo y las Directrices de las Naciones Unidas. Por su relevancia y por ser resultado de un esfuerzo del sector privado en esta materia, también se ha incluido en el análisis al Código Modelo para la Protección de Información Personal de la Asociación Canadiense de Estándares. Son notables las coincidencias entre los objetivos o principios que buscan atender las directrices estudiadas, los cuales se discuten a continuación.

\section{Derechos del consumidor o sujeto}

Un individuo debe tener el derecho de:

a) obtener de un controlador de datos, o de su representante, confirmación de si tiene datos relacionados con su persona;

b) que el controlador de datos le comunique cualquier dato en relación con su persona, con las siguientes características:

(i) Dentro de un plazo razonable;

(ii) Con un costo, si alguno, que no sea excesivo;

(iii) De una manera razonable;

(iv) En una forma que sea claramente inteligible para él;

c) que se le informen las razones cuando se le niegue uno de los requerimientos que haga bajo los incisos a) y b), y poder disputar dicha negativa;

d) Disputar datos que se relacionen con su persona, y si dicha disputa es exitosa, que se borren, rectifiquen, completen o enmienden dichos datos.

El derecho de los individuos a accesar y disputar datos personales es una de las medidas más importantes para la protección de la privacidad. El alcance de disputar los datos incluye desde una primera instancia frente al controlador de datos hasta acciones en los tribunales, órganos administrativos o profesionales y otras instituciones, de acuerdo a las regulaciones nacionales. 


\section{Especificación del Fin}

Se deben especificar los fines para los cuáles se recaban los datos personales a más tardar en la fecha de la recolección. Su uso subsecuente debe estar limitado a alcanzar dichos fines u otros que no sean incompatibles con éstos. Es preciso, asimismo, avisar al sujeto en cada ocasión que se modifique el fin. Además, los datos no deben abarcar más información que la necesaria para los fines para los que se van a utilizar dichos datos. No se deben introducir arbitrariamente nuevos fines; la libertad de hacer cambios debe implicar una compatibilidad con los fines originales. 


\section{Cuadro 2}

Instrumentos Internacionales para la Protección de los Datos Personales

\begin{tabular}{|c|c|c|c|c|}
\hline & $\begin{array}{l}\text { Septiembre de } 1980 \\
\text { OCDE }\end{array}$ & $\begin{array}{l}1981 \\
\text { Consejo Europeo }\end{array}$ & $\begin{array}{l}\text { Diciembre de } 1990 \\
\text { Organización de las } \\
\text { Naciones Unidas }\end{array}$ & $\begin{array}{l}\text { Marzo de } 1996 \\
\text { Asociación } \\
\text { Canadiense de } \\
\text { Estándares }\end{array}$ \\
\hline Instrumento Internacional & \begin{tabular}{|l} 
Directrices para la \\
Protección de la \\
Privacidad y el \\
Flujo \\
Transfronterizo de \\
Datos Personales
\end{tabular} & $\begin{array}{l}\text { Convención para la } \\
\text { Protección de los } \\
\text { Individuos con } \\
\text { Relación al } \\
\text { Procesamiento } \\
\text { Automatizado de } \\
\text { Datos Personales } \\
\end{array}$ & $\begin{array}{l}\text { Directrices en } \\
\text { Relación con los } \\
\text { Archivos } \\
\text { Computarizados de } \\
\text { Datos Personales }\end{array}$ & $\begin{array}{l}\text { Código Modelo para } \\
\text { la Protección de } \\
\text { Datos Personales }\end{array}$ \\
\hline \multicolumn{5}{|l|}{ Ambito } \\
\hline \multicolumn{5}{|l|}{ Datos personales } \\
\hline Sector público & SI & SI & SI & NO \\
\hline Sector privado & SI & SI & SI & SI \\
\hline \multicolumn{5}{|l|}{ Objetivos } \\
\hline $\begin{array}{|lll|}\begin{array}{l}\text { Proteger la privacidad } \\
\text { libertades individuales }\end{array} & \text { las } \\
\end{array}$ & SI & SI & SI & SI \\
\hline $\begin{array}{l}\text { Facilitar la libre circulación de } \\
\text { datos personales }\end{array}$ & SI & SI & SI & SI \\
\hline \multicolumn{5}{|l|}{ Principios } \\
\hline 1. $\begin{array}{l}\text { Derechos de Acceso y de } \\
\text { Rectificación }\end{array}$ & SI & SI & SI & SI \\
\hline 2. Especificación del Fin & SI & SI & SI & SI \\
\hline 3. Limites a la Recolección & SI & SI & SI & SI \\
\hline 4. Límites al Uso & SI & SI & SI & SI \\
\hline $\begin{array}{l}\text { 5. Límites a la Retención de } \\
\text { datos }\end{array}$ & SI & SI & SI & SI \\
\hline $\begin{array}{l}\text { 6. Calidad de los datos (exactos } \\
\text { y actualizados) }\end{array}$ & SI & SI & SI & SI \\
\hline 7. Medidas de Seguridad & SI & SI & SI & SI \\
\hline $\begin{array}{l}\text { 8. Sanciones y Remedios en las } \\
\text { leyes nacionales }\end{array}$ & SI & SI & SI & NO \\
\hline $\begin{array}{l}\text { Responsabilidad de los } \\
\text { controladores de datos }\end{array}$ & SI & NO & NO & SI \\
\hline 10. Transparencia del controlado & SI & NO & NO & SI \\
\hline 11. Excepciones & & SI & SI & NO \\
\hline
\end{tabular}

\section{Límites a la Recolección}

Deben existir límites a la recolección de datos personales. Cualquier dato debe ser obtenido por medios legítimos y justos y, cuando sea apropiado, con el conocimiento o consentimiento del sujeto a quién se refieran los datos. 
Los datos personales que revelen el origen racial, opiniones políticas o religiosas, u otras creencias, así como los datos personales concernientes a la salud o vida sexual, no podrán ser procesados automáticamente, a menos que la ley nacional provea las medidas de seguridad apropiadas.

\section{Limitaciones al Uso y Transmisión}

Los datos personales no se deben divulgar, hacer disponibles, transmitir o utilizar para fines diferentes de los especificados, excepto:

a) con el consentimiento del sujeto a quién se refieren los datos; o

b) por la autoridad de la ley.

\section{Límites a la Retención de Datos}

Para proteger al consumidor o cuando los datos ya no sirvan al fin para el cual fueron recolectados puede ser necesario borrarlos.

\section{Calidad de los datos (exactos y actualizados)}

Los datos personales deben ser exactos, completos y actualizados.

\section{Medidas de Seguridad}

Los datos personales se deben proteger con medidas de seguridad razonables contra riesgos como pérdida, acceso no autorizado, destrucción, uso, modificación o divulgación de los datos. Las medidas de seguridad pueden ser físicas (tarjetas de identificación), de organización (diferentes niveles de acceso a los datos) o de informática.

\section{Sanciones y Remedios}

Cada país se encargará de establecer las sanciones y remedios apropiados por violaciones a la legislación, de tal manera que los controladores de datos cumplan con los principios internacionales para la protección de datos que aquí se mencionan.

\section{Responsabilidad del controlador de datos}

El controlador de datos es responsable de la información personal bajo su control y del cumplimiento de estos principios y de las reglas y decisiones que se establezcan para la protección de la privacidad. El controlador de datos no es relevado de esta responsabilidad al traspasar su información a un tercero para su procesamiento. 
$\mathrm{Al}$ respecto, dentro de los estándares canadienses destaca lo siguiente:

a) El controlador de datos debe designar a un individuo o individuos para vigilar el cumplimiento de los principios dentro de la organización.

b) A solicitud del sujeto, la identidad de los individuos designados para vigilar el cumplimiento de los principios debe hacerse pública.

\section{Transparencia del Controlador de Datos}

El controlador de datos debe mantener una política de transparencia frente a los individuos al hacer disponible información específica con relación a los desarrollos, políticas y prácticas relacionados con la administración de los datos personales. Además, se deben establecer medios para que el sujeto pueda constatar la existencia y naturaleza de los datos personales y los fines principales para su uso, así como la identidad y residencia del controlador de datos.

\section{Excepciones}

Se autorizan excepciones a la aplicación de estos principios sólo si son necesarias para proteger la seguridad nacional, el orden público, la moral o la salud pública.

* * *

La descripción de los principales lineamientos internacionales en cuanto a la protección de datos personales (Directrices de la OCDE, Convención del Consejo Europeo, Directrices de las Naciones Unidas y el Código de la Asociación Canadiense de Estándares (ACE)), hace evidente la marcada similitud entre los principios y objetivos que plantean como necesarios para lograr la protección efectiva de la privacidad y para promover la circulación de datos personales. Asimismo, destaca la recomendación conjunta a favor de contar con legislación a nivel nacional que permita el cumplimiento de dichos objetivos.

\section{B. Protección de Datos Personales en los Estados Unidos, Canadá, la Unión Europea y América Latina}

A continuación se describen en detalle los objetivos, el ámbito, los fundamentos legales y otras características de la protección de datos personales en distintos países de América 
Latina (Argentina, Brasil, Chile, Colombia, México y Perú). Esta descripción incluye como referencia la de los Estados Unidos, Canadá y la Unión Europea.

\section{Derechos establecidos en las constituciones}

En algunos de los países analizados se establecen a nivel constitucional tres derechos estrechamente relacionados con la protección de datos personales (Cuadro 5).

\section{a) Derecho a la privacidad}

Este derecho incluye el derecho de las personas a no ser molestadas en su vida privada y a que se respete su honra, imagen o buen nombre, así como al secreto y a la inviolabilidad de sus comunicaciones y documentos privados. En estos términos generales las constituciones de todos los países estudiados garantizan este derecho. Adicionalmente, las constituciones de algunos países señalan explícitamente que el derecho a la privacidad incluye la protección de los datos personales. En las constituciones de Colombia y Perú, se establece explícitamente que el tratamiento de datos debe respetar la privacidad de las personas.

\section{b) Derecho del individuo a accesar y rectificar su información en poder de cualquier controlador de datos}

En algunos países la constitución establece explícitamente el derecho de las personas a conocer, actualizar y rectificar la información que se haya obtenido sobre ellas de cualquier banco de datos público o privado. Tal es el caso de Colombia. En Argentina la constitución establece dicho derecho en cuanto a los bancos de datos públicos. Sin embargo, respecto de bancos de datos privados el derecho está limitado a aquéllos que proveen informes. En la constitución peruana y en la brasileña el derecho de acceso está establecido únicamente en relación con la información que el sujeto requiera de las entidades u órganos públicos. Adicionalmente, en Perú y Chile, se señala que toda persona afectada por afirmaciones inexactas por algún medio de comunicación social tiene derecho a una rectificación gratuita. En el caso de México, la constitución no hace una referencia explícita a este tema. 


\section{c) Derecho del individuo a acudir a los tribunales para exigir la protección de sus derechos en relación con el tratamiento de datos personales (Acción de Habeas Data)}

Para garantizar la observancia de los derechos consagrados en las constituciones en relación con el tratamiento de datos personales, las de Argentina, Brasil, Chile y Perú establecen una acción judicial expedita al respecto (Habeas Data). Dicha acción puede llevarse a cabo por las personas con el fin de defender sus derechos de privacidad, así como de acceso y rectificación de sus datos. Cabe señalar que si bien en Colombia no se establece explícitamente en la constitución la acción de Habeas Data, en el artículo 86 se establece la "tutela", el cual es un procedimiento preferente y sumario (en ningún caso pueden transcurrir más de 10 días entre la solicitud de "tutela" y su resolución) frecuentemente utilizado por los colombianos para solicitar la modificación o exclusión de su información reportada en los burós de crédito.

\section{Cuadro 3}

\section{Fundamentos Constitucionales}

\begin{tabular}{|c|c|c|c|c|c|c|c|}
\hline & & Argentina & Brasil & Chile & Colombia & México & Perú \\
\hline 1) & $\begin{array}{lll}\text { Derecho } & \text { a } & \text { la } \\
\text { Privacidad } & & \end{array}$ & & & & & & \\
\hline & $\begin{array}{l}\text { Principio General de } \\
\text { Intimidad o Privacidad }\end{array}$ & $\begin{array}{c}\text { SI } \\
\text { Art. } 19\end{array}$ & $\begin{array}{c}\text { SI } \\
\text { Art. } 5, x\end{array}$ & \begin{tabular}{|c|} 
SI \\
Art. 19 inciso \\
4 y 5
\end{tabular} & \begin{tabular}{|c|} 
SI \\
Art. 15 y 21
\end{tabular} & $\begin{array}{c}\text { SI } \\
\text { Art. } 7\end{array}$ & $\begin{array}{c}\text { SI } \\
\text { Art. } 2 \text { inciso } \\
5 \text { y } 7\end{array}$ \\
\hline & $\begin{array}{l}\text { Referencia específica al } \\
\text { tratamiento de datos o } \\
\text { información de las } \\
\text { personas }\end{array}$ & NO & NO & NO & $\begin{array}{c}\text { SI } \\
\text { Art. } 15\end{array}$ & $\mathrm{NO}$ & $\begin{array}{c}\text { SI } \\
\text { Art.2 } \\
\text { inciso } 6\end{array}$ \\
\hline 2) & $\begin{array}{l}\text { Derecho del individuo } \\
\text { a accesar y rectificar } \\
\text { su información en } \\
\text { poder de cualquier } \\
\text { controlador de datos }\end{array}$ & $\begin{array}{l}\text { A cualquier banco } \\
\text { de datos públicos, } \\
\text { pero sólo a } \\
\text { bancos de datos } \\
\text { privados que } \\
\text { proveen informes. } \\
\text { Art. } 43\end{array}$ & $\begin{array}{l}\text { Sólo de los } \\
\text { órganos } \\
\text { públicos } \\
\text { Art. } 5 \text { XIV y } \\
\text { XXXIII }\end{array}$ & NO & $\begin{array}{c}\text { SI } \\
\text { Art. } 15\end{array}$ & $\mathrm{NO}$ & $\begin{array}{l}\text { Sólo a } \\
\text { bancos de } \\
\text { datos } \\
\text { públicos } \\
\text { Art. 2 } \\
\text { inciso } 5\end{array}$ \\
\hline 3) & $\begin{array}{l}\text { Derecho de Audiencia } \\
\text { Judicial sobre Datos } \\
\text { Personales (Habeas } \\
\text { Data) }\end{array}$ & $\begin{array}{c}\text { SI } \\
\text { Art. } 43\end{array}$ & \begin{tabular}{c|} 
SI \\
Art. 5, LXXII
\end{tabular} & $\begin{array}{c}\text { SI } \\
\text { Art. } 20\end{array}$ & \begin{tabular}{|c|} 
Sí \\
Art. 15 y Art. \\
86
\end{tabular} & $\overline{\mathrm{NO}}$ & $\begin{array}{c}\text { SI } \\
\text { Art. } 200\end{array}$ \\
\hline
\end{tabular}




\section{Legislación de Protección de Datos: Ámbito y Objetivos en Distintos Países}

El nivel de desarrollo de la protección de datos en los distintos ordenamientos legales de los países analizados es muy distinto. El ámbito de la regulación también varía, abarcando al sector privado, al sector público o a ambos. Asimismo, cuando la regulación contempla al sector privado puede ser que incluya a todo tipo de organizaciones, si ésta aplica a todos los sectores e industrias, o bien estar enfocada a un sector en particular.

De los países estudiados, aquéllos que cuentan con una ley general de protección de datos personales son Canadá y los miembros de la Unión Europea, Argentina y Chile. Los Estados Unidos y Perú no cuentan con una ley general de protección de datos, pero sí con una ley general que regula a las SIs. Los Estados Unidos cuentan adicionalmente con más de mil leyes federales y estatales que regulan la protección de datos en todo tipo de sectores.

Con respecto a Canadá, en los últimos 30 años el gobierno federal y los gobiernos provinciales han emitido diversas regulaciones relacionadas con la privacidad del individuo. La Personal Information Protection and Electronic Documents Act (PIPEDA) de abril de 2000, la cual incorpora los Principios establecidos por la Asociación Canadiense de Estándares en 1996, es un esfuerzo por cerrar las brechas existentes en el conjunto de regulaciones federales y provinciales. La PIPEDA es una legislación federal de protección de datos que es aplicable únicamente a organizaciones del sector privado ${ }^{1}$. Las entidades e instituciones del sector público que actualmente ya están reguladas por el Privacy Act de 1983, así como aquellas áreas bajo jurisdicción provincial exclusiva, como son las universidades, escuelas y hospitales, no están sujetas a la PIPEDA. Además, se establece un esquema de transición para la adopción de la ley por parte del sector privado. Con la

\footnotetext{
${ }^{1}$ La PIPEDA aplica a toda organización con respecto a la información personal que dicha organización recolecte, use o transmita en el curso de sus actividades comerciales. No obstante, no aplica a:

$\hat{\text { I }}$ Las instituciones de gobierno a las cuales se aplica el Privacy Act.

Î El individuo que recolecte, use o transmita información para uso personal o doméstico y no la recolecte, use o transmita para cualquier otro propósito.

Î Cualquier organización que recolecte, use o transmita la información personal para propósitos periodísticos, artísticos y literarios y no la recolecte, use o transmita para otros propósitos.
} 
entrada en vigor de la PIPEDA en enero del 2001 se obligó a su cumplimiento inmediato por bancos, el sector de las telecomunicaciones, la teledifusión, las aerolíneas, las compañías de transporte y cualquier compañía que venda información personal dentro de las fronteras de las provincias. A partir de enero de 2004, la PIPEDA deberá aplicarse a todas las actividades comerciales del sector privado, incluyendo compañías bajo jurisdicción provincial o territorial. Debido a que ésta es una regulación federal, queda en manos de las provincias y de los territorios el promulgar una legislación "substancialmente similar" en los 3 años posteriores la fecha en que entró en vigor. Terminados esos 3 años, en caso que las provincias o territorios no contaran con una ley de protección de datos, la PIPEDA se les aplicaría automáticamente.

La Directiva de la Unión Europea está construida sobre los principios adoptados por los organismos multinacionales discutidos anteriormente. Esta directiva establece un marco legal general que abarca tanto a las bases de datos en poder del sector público como el privado. Destaca la variedad de entidades del sector privado que deben cumplir con estas disposiciones, ya que se regula el tratamiento de datos personales de todo controlador de bases de datos ${ }^{2}$, con excepción de actividades fuera del alcance de la Ley Comunitaria, tales como seguridad nacional, ley criminal y el tratamiento de datos por una persona natural en el ejercicio de actividades exclusivamente personales o domésticas. No obstante lo anterior, no se regula de manera específica el funcionamiento y la operación de las SIs.

Cabe destacar que los objetivos de la regulación de protección de datos en Canadá ${ }^{3}$ y la Unión Europea ${ }^{4}$, así como de la regulación de privacidad y de las SIs en los Estados

\footnotetext{
${ }^{2}$ En la Unión Europea se define a un controlador de datos como aquella entidad, física o moral, pública o privada, que realiza el tratamiento de datos personales. Dicho tratamiento se define como: "cualquier operación o conjunto de operaciones, efectuadas o no mediante procedimientos automatizados, y aplicadas a datos personales, como la recolección, registro, organización, conservación, elaboración o modificación, extracción, consulta, utilización, comunicación por transmisión, difusión o cualquier otra forma que facilite el acceso a los mismos, cotejo o interconexión, así como su bloqueo, supresión o destrucción."

3 El objetivo de la PIPEDA es establecer reglas para la recolección, uso y transmisión de información personal, de manera que se reconozcan el derecho de privacidad del individuo con respecto a su información, así como la necesidad de las organizaciones de recolectar, usar y transmitir información personal para propósitos apropiados.

${ }^{4}$ Los objetivos de la Directiva de la Unión Europea (1995) son: i) la protección de las libertades y de los derechos fundamentales de las personas físicas, y, en particular, del derecho a la intimidad, en lo que respecta al tratamiento de los datos personales; y ii) los Estados miembros no podrán restringir ni prohibir la
} 
Unidos, como se describirá más adelante, se enfocan no sólo a la protección de la privacidad, sino a apoyar el comercio y el mejor funcionamiento de los mercados, a través de promover el flujo de información. En la Unión Europea este último objetivo se circunscribe básicamente a eliminar barreras al flujo de datos personales y, por tanto, al comercio, entre los países de la Unión y aquellos otros países que cuenten con un nivel de protección de datos similar al ofrecido en la Unión.

Argentina y Chile, países de América Latina que tienen leyes generales en materia de protección de datos, se han concentrado en la protección de las libertades individuales y de los derechos fundamentales de las personas (privacidad). La ley chilena de Protección de Datos de Carácter Personal ${ }^{5}$ de 1999 y la Ley de Protección de Datos Personales de Argentina de $2000^{6}$ no incluyen explícitamente el objetivo de apoyar el flujo de información. En contraste, la Ley que regula las Centrales Privadas de Información de Riesgos y de Protección al titular de la Información de Perú de 2001 es una regulación general enfocada en las SIs y en la que destaca el objetivo de promover el flujo de información, respetando los derechos individuales. ${ }^{7}$

A semejanza de la Directiva de la Unión Europea, el ámbito de la ley de protección de datos chilena incluye a todos los controladores de datos en los sectores público y privado, mientras que la ley de Argentina incorpora al sector público y al privado sólo en cuanto a las bases de datos de las SIs. En Perú el ámbito de la ley de las SIs es aún más restringido y solamente se aplica a las bases de datos del sector privado. No obstante lo anterior, Perú

libre circulación de datos personales entre los Estados miembros por motivos relacionados con la protección de la privacidad de las personas, en virtud de estar garantizada por dicha directiva.

${ }^{5}$ En Chile la Ley de Protección de Datos de Carácter Personal (1999) propone dar una adecuada protección a las personas en cuanto al derecho a la privacidad, previniendo eventuales intromisiones ilegítimas que pudieran afectarlo, para lo cual se regula el uso que terceros puedan hacer de sus datos de carácter personal. En el Título Preliminar, Artículo $1^{\circ}$ se establece que "Toda persona puede efectuar el tratamiento de datos personales... En todo caso deberá respetar el pleno ejercicio de los derechos fundamentales de los titulares de los datos."

${ }^{6}$ El objetivo de la ley es la protección integral de los datos personales asentados en archivos, registros, bancos de datos, u otros medios técnicos de tratamiento de datos, sean éstos públicos o privados, destinados a dar informes, para garantizar el derecho al honor y a la intimidad de las personas, así como también el acceso a la información que sobre las mismas se registre, de conformidad a lo establecido en el artículo 43, párrafo tercero de la Constitución Nacional (el cual se refiere a la Acción de Habeas Data). 
cuenta con la Ley No.26301 que norma el proceso de Habeas Data que aplica a cualquier controlador de datos en el sector público y a las SIs, en los sectores privado y público. Además de una ley general, los tres países han emitido disposiciones particulares para el sector financiero y tienen autoridades que administran un registro de deudores (la Superintendencia Bancaria en Chile y Perú y el Banco Central en el caso de Argentina).

Los Estados Unidos no cuentan con una ley general de protección de datos, pero sí con más de mil ordenamientos legales que tienen que ver con esta materia. La regulación en los Estados Unidos ha ido evolucionando a partir de las decisiones y controversias judiciales que se han suscitado en relación con la operación de las SIs. La legislación, por tanto, ha asimilado estas experiencias principalmente en dos vertientes: el acceso a bases de datos personales del sector público a través del Freedom of Information Act (FOIA) y el procesamiento de datos personales por parte de las agencias de reportes sobre consumidores (consumer reporting agencies) a través del Fair Credit Reporting Act ${ }^{8}$ (FCRA). Entre las leyes sectoriales que regulan la protección de datos personales destacan las del sistema financiero, particularmente el título V del Gramm-Leach-Bliley Act de 1999 y el Financial Information Privacy Protection Act de 2000 que enmienda el título V de la ley GrammLeach-Bliley. Adicionalmente, entre las numerosas otras leyes sectoriales que tratan sobre el tema de protección de datos en los Estados Unidos se encuentra la Ley del Seguro Social, la cual tiene un capítulo sobre la protección de datos relativos a información médica.

Es importante destacar que el FCRA, que ha sido reformado numerosas veces, es una disposición que regula a la industria privada de información sobre consumidores y la cual realiza todo tipo de reportes sobre personas físicas. Esta industria incluye a los Burós de

\footnotetext{
${ }^{7}$ En Perú la ley (2001) tiene como objetivo regular el suministro de información de riesgos en el mercado, garantizando el respeto a los derechos reconocidos por la legislación a los titulares de la misma y promoviendo la veracidad, confidencialidad y uso apropiado de dicha información.

8 Dentro de los múltiples ordenamientos legales que existen en los Estados Unidos respecto a la protección de datos personales, destaca el Fair Credit Reporting Act (FCRA) de 1971, cuyos principales objetivos son: i) proteger la privacía de la información de los reportes del consumidor; ii) garantizar que la información que ofrecen las SIs (denominadas en el FCRA como "consumer reporting agencies") sea tan veraz y precisa como sea posible, y; iii) fomentar que las SIs adopten procedimientos razonables para apoyar el comercio permitiendo el flujo del crédito, las decisiones de contratación de personal, las de los seguros y otras necesidades de información, de tal forma que la información proporcionada por las SIs sea justa para el consumidor, y se respete la confidencialidad, veracidad, relevancia y uso apropiado de la misma.
} 
Crédito. En los Estados Unidos se utiliza el término información del consumidor para englobar un universo que además de información crediticia incluye la de empleo, salud, arrendamientos de vivienda, etc. El concepto de agencia de reportes sobre consumidores que se utiliza en el FCRA incluye básicamente a toda empresa que vende datos personales o servicios de información de los consumidores. ${ }^{9}$

En el sector financiero, la ley Gramm-Leach-Bliley, modificada por el Financial Information Privacy Protection Act, regula la protección de datos de las personas en sus operaciones con instituciones financieras, las cuáles, bajo la definición de dicha ley, incluyen, entre otras, a bancos, compañías de ahorro y préstamo, compañías de tarjetas de crédito y aseguradoras. Estas leyes, además de establecer ciertas condiciones para la transmisión de la información, permiten la autorregulación de las instituciones financieras, dándoles libertad para que éstas definan sus políticas en relación con la transferencia de información personal no pública de sus clientes. El consumidor cuenta con el derecho a que su información no sea transmitida a terceros bajo dichas políticas. Cabe destacar que las instituciones son sancionadas si no se sujetan a las políticas que ellas han definido. Además, estas leyes establecen un régimen estricto en caso de acceso fraudulento a información personal.

Los Estados Unidos tienen el mercado más desarrollado de las SIs. Esta situación facilita el flujo de información en la economía y la realización de todo tipo de transacciones, siendo por ello un importante factor de progreso económico. A pesar de no contar con una ley general de protección de datos que aplique a todo controlador de datos, los Estados Unidos dan al individuo el derecho de accesar y corregir su información en poder de una gran cantidad de controladores de bases de datos personales. Dicho derecho se encuentra disperso en numerosas leyes y en otras regulaciones sectoriales.

\footnotetext{
${ }^{9}$ El concepto de las Sociedades de Información (SIs) que se utiliza en este documento es similar al de las agencias de reportes del consumidor del FCRA.
} 
Brasil, Colombia y México no cuentan con una ley de protección de datos personales, como tampoco con una ley general que regule el mercado de las SIs, si bien han emitido algunas normas sectoriales en la materia.

En adición a la disposición constitucional que establece el derecho de acceso a la información y el proceso Habeas Data, Brasil tiene la Ley ordinaria 9.507 de 1997, que regula el procedimiento de Habeas Data, estableciendo los plazos para accesar y rectificar los datos y los procedimientos judiciales. Además, la ley 8.159 establece disposiciones sobre el tratamiento de archivos públicos y privados identificados por el Estado como de interés público y social.

El Código de Protección y Defensa del Consumidor de Brasil, en sus artículos 43 y 44 , también establece ciertas reglas y derechos en relación con la información que se encuentra en los bancos de datos o registros de los consumidores. Adicionalmente, Brasil cuenta con una Central de Riesgo de Crédito operada por el Banco Central.

En Colombia, existe Jurisprudencia de la Corte Constitucional, en relación con el derecho constitucional de la acción de Habeas Data respecto de información en bancos de datos de entidades públicas y privadas. Este país dispone de una ley similar al Freedom of Information Act de los Estados Unidos, la Ley 57 de 1985, la cual tiene como fin que el público pueda conocer e informarse sobre el manejo de los asuntos públicos y ejercer eficaz control sobre la conducta de las autoridades. Asimismo, ordena el acceso a la información relativa a actos y documentos oficiales.

El tipo de información bancaria que pueden registrar y ceder los burós de crédito en Colombia es el que, según la Superintendencia Bancaria y de conformidad con el artículo 15 de la Constitución, se considere relevante para evaluar la solvencia económica de sus titulares. La Superintendencia proporciona a los burós de crédito información relacionada con la calificación y clasificación del endeudamiento de las personas con entidades del sector financiero. A cambio, la Superintendencia recibe de los bancos información adicional sobre el comportamiento de las personas usuarias del sistema financiero, por 
ejemplo, información de inmobiliarias respecto a los hábitos de pago de sus arrendatarios, etc.

México no cuenta con una legislación específica de Habeas Data, ni con una que garantice el acceso a la información bajo control del sector público. Existen pocas disposiciones de protección de datos en la materia. Las normas aplicables al sector financiero regulan la operación de los burós de crédito y la información crediticia que éstos obtienen, tanto de personas físicas como morales. Adicionalmente, han comenzado a aparecer disposiciones sectoriales en materia de datos personales, por ejemplo, en el sector de telecomunicaciones. Estas disposiciones no consideran los derechos de los consumidores e inhiben el flujo de información a otros sectores ${ }^{10}$.

\section{Derechos de los Consumidores Respecto a la Información sobre su Persona}

Si bien existe consenso internacional sobre el derecho que debe tener el individuo para conocer y rectificar la información que de él tengan las SIs, existen muy diferentes niveles de desarrollo y de cobertura de estos derechos en los casos analizados. En algunos países el individuo tiene derecho a conocer su información en poder de cualquier controlador de datos, ya sea público o privado, pero en otros ni siquiera se incluye a los burós de crédito. Generalmente, se facilita al individuo ejercer sus derechos de rectificación, actualización y, cuando corresponda, supresión de los datos. Esta es una responsabilidad que comparten las SIs.

De igual manera existen otros derechos que no todos los países han establecido, como el de conocer quien ha recibido un reporte sobre su persona. Las leyes de los Estados Unidos, Europa, Argentina y Chile dan al individuo la posibilidad de revisar quién ha obtenido reportes de las SIs acerca de su persona. Debido a que en la mayoría de los países sólo pueden accesarse reportes de las SIs con el consentimiento del individuo o si existe otro "propósito permisible", las personas pueden identificar las situaciones en que se obtuvieron

\footnotetext{
${ }^{10}$ La Ley Federal de Protección al Consumidor regula parcialmente algunos aspectos de los datos personales que administran empresas con fines de mercadotecnia. En la práctica no es clara la relevancia de esta disposición. Los burós de crédito se rigen por las leyes del sistema financiero.
} 
dichos reportes en contravención con lo dispuesto en la ley. Cabe destacar que el derecho del individuo a revisar quién o quiénes han obtenido reportes de su persona es uno de los mecanismos más efectivos de garantizar que se salvaguarden las disposiciones de confidencialidad de la ley.

En los Estados Unidos los individuos también tienen el derecho a que cuando un tercero toma una acción adversa en su contra, se le informe cual SI proporcionó el reporte así como requerir un reporte gratis de la $\mathrm{SI}^{11}$ en dicho caso. La protección contra acciones adversas también está contemplada en la directiva de la Unión Europea, aunque su significado difiere del que tiene en los Estados Unidos. En la Directiva de la Unión Europea se establece que un individuo tiene el derecho a no verse sometido a una decisión con efectos jurídicos sobre él o que le afecte de manera significativa y que se base únicamente en un tratamiento automatizado de datos destinado a evaluar determinados aspectos de su personalidad (rendimiento laboral, crédito, fiabilidad, conducta, etc.).

Otro derecho importante que tienen los individuos en algunos países es el de poder excluirse de listados de personas que se utilizan con fines promocionales o para realizar ofertas en firme a posibles clientes. A continuación se resumen las características particulares de la legislación en cada uno de los países estudiados.

11 Además de lo establecido en el FCRA, en los Estados Unidos el Equal Credit Opportunity Act (ECOA) obliga a que los acreedores especifiquen porque fue tomada esa acción si el consumidor pregunta. Además, el ECOA también obliga a los acreedores a tomar en cuenta información adicional que el consumidor pudiera facilitarles acerca de su historial crediticio. 


\section{Cuadro 4}

\section{Derechos de los Consumidores Respecto a la Información sobre su Persona}

\begin{tabular}{|c|c|c|c|c|c|c|c|c|c|}
\hline & Argentina & Brasil & Chile & $\begin{array}{l}\text { Colom- } \\
\text { bia }\end{array}$ & México & Perú & $\begin{array}{l}\text { Estados } \\
\text { Unidos }\end{array}$ & Canadá & $\begin{array}{c}\text { Unión } \\
\text { Europea }\end{array}$ \\
\hline \multicolumn{10}{|l|}{ Acceso a su Información } \\
\hline De burós de crédito & SI & SI & SI & SI & $\mathrm{NO}$ & SI & SI & SI & SI \\
\hline $\begin{array}{l}\text { De cualquier controlador de } \\
\text { Datos Públicos }\end{array}$ & SI & SI & SI & SI & NO & SI & SI & SI & SI \\
\hline $\begin{array}{l}\text { De cualquier controlador de } \\
\text { Datos Privados }\end{array}$ & $\mathrm{NO}$ & SI & SI & SI & $\mathrm{NO}$ & $\mathrm{NO}$ & SI & SI & SI \\
\hline $\begin{array}{l}\text { Se regula el costo y plazo de } \\
\text { entrega }\end{array}$ & SI & NO & SI & $\mathrm{NO}$ & NO & SI & SI & SI & SI \\
\hline $\begin{array}{l}\text { Conocer quienes han } \\
\text { obtenido reportes con } \\
\text { información sobre su persona }\end{array}$ & SI & $\mathrm{NO}$ & SI & SI & $\mathrm{NO}$ & SI & SI & SI & SI \\
\hline \multicolumn{10}{|l|}{ Rectificar su información } \\
\hline Con los burós de crédito & SI & SI & SI & SI & $\mathrm{NO}$ & SI & SI & SI & SI \\
\hline $\begin{array}{l}\text { Con los usuarios de la } \\
\text { información o acreedores }\end{array}$ & NO & SI & SI & SI & SI & NO & SI & SI & n.a. \\
\hline $\begin{array}{l}\text { Con cualquier controlador de } \\
\text { datos }\end{array}$ & NO & SI & SI & SI & NO & NO & SI & SI & SI \\
\hline $\begin{array}{l}\text { A ser excluido de listados de } \\
\text { ofertas }\end{array}$ & SI & NO & SI & $\mathrm{NO}$ & SI & NO & SI & $\mathrm{NO}$ & SI \\
\hline Protección de acción adversa & $\mathrm{NO}$ & $\mathrm{NO}$ & $\mathrm{NO}$ & $\mathrm{NO}$ & $\mathrm{NO}$ & $\mathrm{NO}$ & SI & $\mathrm{NO}$ & SI \\
\hline
\end{tabular}

n.a. significa no aplica

De los países analizados, el consumidor cuenta con los más amplios derechos de acceso y rectificación de la información sobre su persona en Brasil $^{12}$, Canadá $^{13}$, Chile $^{14}$, Colombia $^{15}$,

${ }^{12}$ En Brasil, el acceso a bases de datos en poder de entidades u organismos públicos está establecido a nivel constitucional en el artículo $5^{\circ}$ LXXII y es regulado por la ley Ley 8.159 ( $\operatorname{art} 4^{\circ}, 22^{\circ}$ y 230 ). Adicionalmente, el derecho de acceso se extendió a las bases de datos del sector privado a raíz de que en el artículo 43 del Código de Protecao e Defesa do Consumidor se estableció que "El consumidor tiene acceso a la información existente en catastros, fichas, registros, y a los datos personales y de consumo archivados sobre él, así como sobre sus respectivas fuentes."

${ }^{13}$ Bajo el principio $9^{\circ}$, la PIPEDA indica que las personas deberán de tener acceso a su información personal, por lo que necesitan solicitar el acceso por escrito a la organización. La PIPEDA aplica a toda organización que recolecte, use o transmita información personal en el curso de sus actividades comerciales, y por organización se entiende una asociación, sociedad, persona o asociación de comercio.

${ }^{14}$ En la Ley de Protección de Datos de Chile se señala que toda persona tiene derecho a exigir a quien sea responsable de un banco de datos que se dedique en forma pública o privada al tratamiento de datos personales, información sobre los datos relativos a su persona. 
los Estados Unidos, y en los miembros de la Unión Europea. En estos países el consumidor tiene el derecho de acceso y rectificación de todo controlador de datos, público o privado.

Como se señaló, los Estados Unidos no cuentan con una ley general de protección de datos. El derecho del individuo para accesar y corregir la información sobre su persona está disperso en numerosas leyes federales y estatales. Así, por ejemplo, la ley Gramm-Leach Bliley (modificada por el Financial Information Privacy Protection Act) establece que a solicitud del consumidor toda institución financiera tiene que hacer disponible a éste la información sobre su persona que esté bajo su control y esté razonablemente disponible en la institución financiera. El derecho de acceso y rectificación respecto a las SIs se encuentra en el Fair Credit Reporting Act. La persona también tiene acceso a las bases de datos del sector público según lo establecido por el Freedom of Information Act.

Las constituciones de Argentina y Perú establecen que la persona física tiene el derecho de accesar y rectificar la información sobre su persona en poder de las SIs, así como la información sobre su persona bajo el control del sector público. El consumidor no puede ejercer dicho derecho ante cualquier controlador de datos privado. De acuerdo con dicho ámbito, la ley de protección de datos en Argentina además de establecer el derecho de acceso por la vía administrativa, detalla el procedimiento bajo el cual se ejerce el derecho judicial de acción de protección de datos o Habeas Data. En Perú la ley que regula las SIs se refiere a la tutela judicial ${ }^{16}$ en su articulo 17 , aunque no con el detalle de la ley de Argentina.

En México el derecho de acceso y rectificación que tiene el consumidor es limitado. El consumidor no tiene el derecho de accesar directamente la información que de su persona tiene un buró de crédito. La Ley Federal de Protección al Consumidor únicamente concede

\footnotetext{
${ }^{15}$ En Colombia el derecho de acceso está establecido a nivel constitucional en el artículo 15, el cual aplica a bancos de datos y archivos de entidades públicas y privadas. Dicho derecho se ejerce a través de la "tutela" establecida en el artículo 86 de la constitución.

${ }^{16}$ En Perú la acción de Habeas Data está establecida en el artículo 200 de la constitución . La acción de Habeas Data procede contra el hecho u omisión, por parte de cualquier autoridad, funcionario o persona, que vulnera o amenaza los derechos a que se refiere el Art. 2 inciso 5) y 6) de la constitución. Dichos artículos aplican tanto a entidades pública como a servicios informáticos computarizados (públicos o privados). Además la Ley 26301 que regula el Habeas Data señala que se puede ejercer frente a una persona natural o jurídica (pública o privada).
} 
el derecho de acceso y rectificación con las empresas que recopilan información con fines de mercadotecnia, las cuales no incluyen a los burós de crédito. Frente a reportes de crédito erróneos o incompletos, el titular de los datos sólo tiene el derecho de acceder y aclarar la información sobre su persona a través de sus acreedores.

En relación con el costo de la rectificación que debe absorber el titular de los datos para accesar y rectificar sus datos, las leyes en Argentina, Perú, los Estados Unidos, Canadá y, como ejemplo de la Unión Europea, España, señalan que la rectificación debe ser gratuita. Por otra parte, el acceso debe ser gratuito en ciertas condiciones y en otras no. En Chile, la ley de protección de datos no establece un acceso gratuito, aunque sí una rectificación sin costo para el titular. En Brasil, México y Colombia el costo no está regulado. En todos los países, en las circunstancias bajo las cuales el acceso no es gratuito, se permite a las SIs determinar el costo. A continuación (Cuadro 5) se puede comparar el costo de acceso y rectificación, tomando como muestra a una SI en cada país. 


\section{Cuadro 5 \\ Costo para las Personas Físicas de Accesar y Rectificar su Propia Información en poder de Sociedades de Información}

\begin{tabular}{|c|c|c|}
\hline & Acceso & Rectificación \\
\hline Argentina & $\begin{array}{c}\text { Por ley, gratuito cada seis meses o bajo interés legítimo. } \\
\text { (Veraz) } \\
\text { Gratuito cada } 6 \text { meses; Otras Consultas \$ } 10 \text { USD }\end{array}$ & $\begin{array}{l}\text { Por ley, } \\
\text { Gratuita }\end{array}$ \\
\hline Brasil & nd & nd \\
\hline Chile & $\begin{array}{c}\text { (Dicom-Equifax) } \\
\text { Gratuito en pantalla de la SI, cuando el titular se presenta en la sucursal } \\
\text { de la SI. \$5.25 USD por reporte completo impreso. }\end{array}$ & $\begin{array}{l}\text { Por ley, } \\
\text { Gratuita }\end{array}$ \\
\hline Colombia & $\begin{array}{l}\text { No está determinado por la legislación } \\
\text { (Covidata) }) \\
\text { Acceso Gratuito en la sucursal del Buró. }\end{array}$ & Gratuita \\
\hline México & No está regulado & $\begin{array}{l}\text { No está } \\
\text { regulado }\end{array}$ \\
\hline Perú & $\begin{array}{l}\text { Por ley, gratuito mediante la visualización de los datos en pantalla } \\
\text { (Inforcorp-Equifax) } \\
\text { Gratuito en pantalla del Buró. } \\
\$ 2.00 \text { USD/minuto por teléfono. } \\
\$ 15.00 \text { USD por el reporte completo impreso. }\end{array}$ & $\begin{array}{l}\text { Por ley, } \\
\text { Gratuita }\end{array}$ \\
\hline $\begin{array}{l}\text { Estados } \\
\text { Unidos }\end{array}$ & $\begin{array}{c}\text { Por Ley: gratuito cada doce meses para personas de escasos recursos. } \\
\text { gratuito ante acción adversa en su contra. } \\
\text { gratuito después de rectificar la información. } \\
\text { Otras consultas de } \$ 0-\$ 8.50 \text { USD depend iendo del Estado. }\end{array}$ & $\begin{array}{l}\text { Por ley, } \\
\text { Gratuita }\end{array}$ \\
\hline Canadá & Por ley, con el mínimo o ningún costo. & $\begin{array}{l}\text { Por ley, } \\
\text { Gratuita }\end{array}$ \\
\hline España & Por ley, gratuito cada doce meses, o bajo interés legítimo. & $\begin{array}{l}\text { Por ley, } \\
\text { Gratuita }\end{array}$ \\
\hline
\end{tabular}

$$
\text { * * * }
$$

El derecho de acceso y rectificación del titular de los datos es crucial para la adecuada protección de los datos de los individuos. Ello, toda vez que permite conservar información actualizada y veraz, así como fomentar la confianza del consumidor en la operación de las SIs. Dicho derecho es uno de los fundamentales contenidos en los principios internacionales mencionados anteriormente. En adición a dicho derecho, diversos países 
han adoptado los demás principios en su regulación. En la siguiente sección se analiza y compara la aplicación de los demás principios internacionales en los países estudiados, en específico, aplicados a la regulación de las SIs.

\section{Mercados de Información y la Regulación de las Sociedades de Información}

En este capítulo se evalúan los beneficios económicos para la sociedad, en particular para los consumidores y las empresas, de contar con información veraz y estandarizada sobre los individuos. El acceso oportuno a información de calidad ayuda a la mejor toma de decisiones por parte de las empresas y a la obtención de mejores precios y servicios por parte del consumidor. En esta sección se arguye que las SIs son intermediarios naturales entre los individuos o consumidores y las empresas, por lo que conviene promover su desarrollo. Finalmente, se examina la regulación de las SIs en países de América Latina, los Estados Unidos, Canadá y la Unión Europea.

\section{A. Beneficios del Flujo de la Información y el Papel de las Sociedades de Información.}

Las SIs son intermediarios naturales entre las necesidades de información de los consumidores y de las empresas. En algunos países, como los Estados Unidos, Argentina y Chile, las SIs han podido conformar amplias bases de datos gracias a que su operación merece la confianza de consumidores y usuarios. Lo anterior se debe en parte a que existen reglas que restringen la transmisión de información contenida en sus bases de datos. El consumidor tiene confianza en las SIs porque sabe que estas empresas no transmiten la información arbitrariamente, sino únicamente cuando existe un derecho o interés legítimo del destinatario de la información. Tal es el caso cuando el destinatario tiene la autorización previa del titular de los datos. Este modelo garantiza que el acceso de las empresas a la información sea efectivamente para fines que benefician al consumidor.

\section{Incentivos económicos de los consumidores cumplidos para dar a conocer su información}


Para obtener bienes y servicios a menores precios y en mejores términos, el consumidor procura demostrar que es una persona confiable y cumplida. Una forma de demostrarlo es presentando información en la que se señala que ha cumplido con las condiciones convenidas en contratos anteriores. Es en beneficio del consumidor cumplido que quienes le proveen bienes y servicios cuenten con este tipo de información. Por ello, este consumidor procura que se pueda transmitir su información a acreedores o proveedores, de tal manera que le sea posible demostrar su buen comportamiento previo (reputación) ${ }^{17}$. Si el consumidor tiene el derecho a exigir una copia de la información que sobre él tienen registrada los controladores de datos, se le facilita comprobar cual ha sido su comportamiento pasado.

Los derechos de los consumidores de solicitar a las empresas y al gobierno información con el historial de sus operaciones y de exigir, en su caso, su corrección, constituyen derechos básicos de los consumidores. Además de dar a la persona el derecho a corregir información incorrecta o errónea sobre su persona evitando que se le discrimine injustamente, estos derechos permiten al consumidor utilizar la información sobre su persona contendida en las distintas bases de datos para realizar transacciones en su propio beneficio ${ }^{18}$. La efectividad de estos derechos depende de que se establezcan mecanismos expeditos y sencillos para que el consumidor pueda ejercerlos directamente o a través de terceros. Para ello, es conveniente establecer un proceso simple y de bajo costo para que el consumidor obtenga la información de su persona y que al mismo tiempo, no resulte indebidamente oneroso para las empresas y el gobierno.

El reconocer que el consumidor tiene este derecho fomenta la competencia y la eficiencia económica, ya que al facilitarse el flujo de información sobre los consumidores se reduce una importante barrera de entrada al mercado a nuevos oferentes de bienes o servicios. El flujo de información se vuelve más necesario entre mayor sea la movilidad de las personas

\footnotetext{
${ }^{17}$ Generalmente, son sólo los consumidores incumplidos los que procuran evitar dar a conocer su historial crediticio. Ello con el fin de recibir un mejor trato que el que obtendrían si se llegara a conocer su verdadero historial.

${ }^{18}$ Con esto no se pretende otorgar al consumidor el control para eliminar o suprimir información a su antojo, lo cual tendría repercusiones graves sobre la calidad y uso de la información. Se trata simplemente de otorgarle la capacidad de ser él quien en primera instancia pueda beneficiarse de dicha información.
} 
y en la medida en que aumenta la prestación de servicios en la economía que involucran créditos (directa o indirectamente).

\section{Cuadro 6}

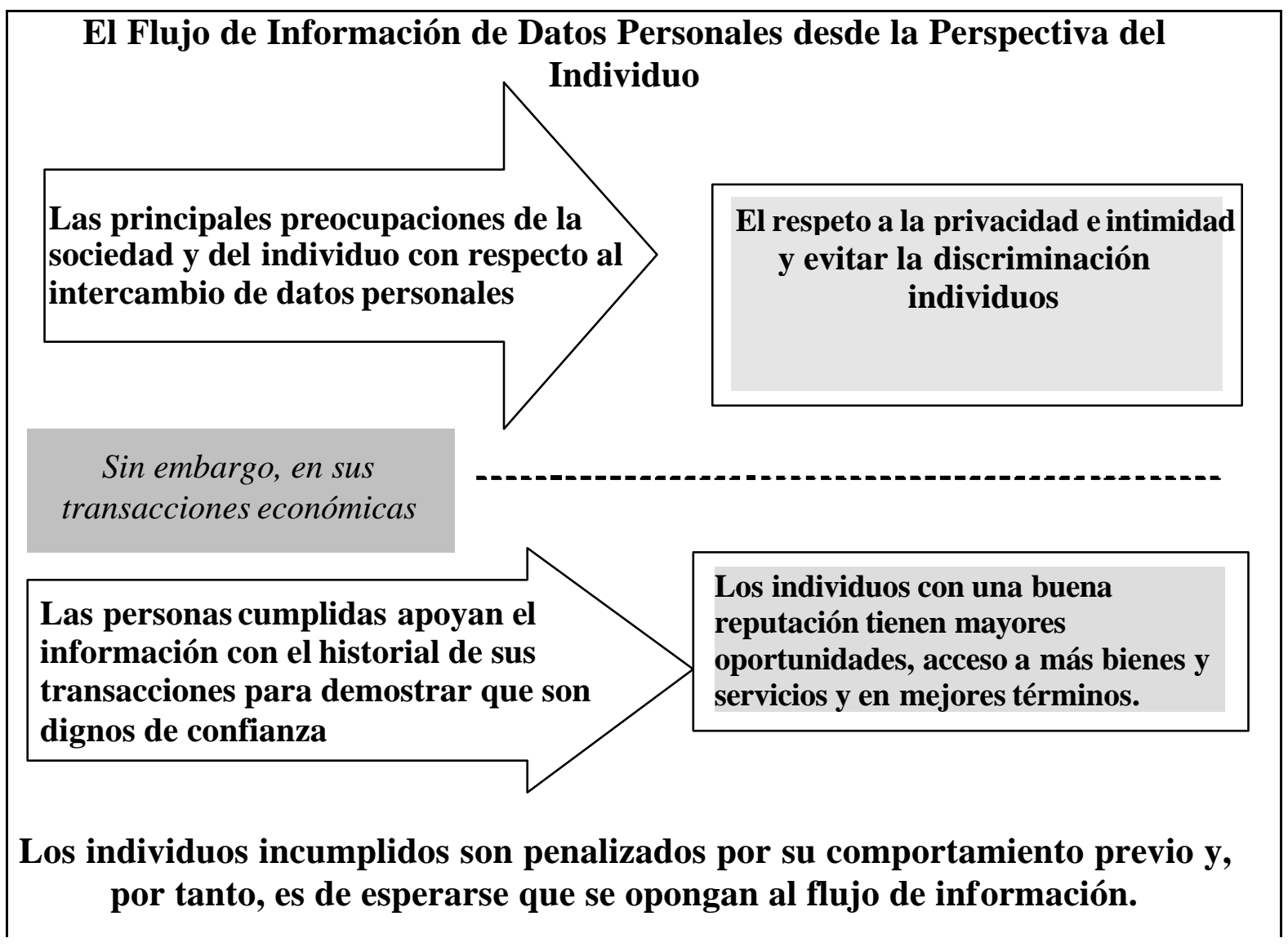

Existe un importante mercado para facilitar al consumidor la comprobación de su historial crediticio. Las empresas en este mercado se especializan en la recolección y el procesamiento de información de muy distintas fuentes. Es natural que sean intermediarios entre el consumidor y otras empresas que les ofrecen bienes y servicios. No obstante, para que este mercado se desarrolle se necesita que las empresas compartan sus bases de datos con las SIs. Esto no siempre sucede ya que la empresa que controla la base de datos no necesariamente tiene incentivos para compartir la información del consumidor. Por ello, es fundamental que la autoridad encargada de aplicar la ley de protección de datos obligue a todo controlador de datos a entregarle la información al consumidor.

Las SIs tienen una función social muy importante: 
- Los reportes de las SIs tienen amplia credibilidad por la imparcialidad con la que construyen sus bases de datos. El individuo, en contraste, tiene un claro incentivo a colectar y transmitir sólo aquella información que le es más favorable.

- Las SIs están en mejores condiciones que los individuos para identificar la conveniencia de efectuar solicitudes de reportes a determinados controladores de datos, ya que conocen mejor las necesidades de información de los posibles destinatarios o usuarios de la información.

- Las SIs agregan valor a esta tarea, ya que presentan la información de tal manera que el destinatario de la información puede evaluar más fácilmente a un individuo especifico.

\section{Incentivos Económicos a Compartir Información entre Empresas}

A las empresas les conviene obtener información adicional a la contenida en su propia base de datos para poder realizar una adecuada evaluación de sus clientes potenciales. Las empresas tienen incentivos para querer identificar a los consumidores cumplidos con el fin de disminuir el riesgo de sus operaciones y aumentar su rentabilidad. En estas circunstancias es natural que las empresas busquen compartir información que les permita tomar mejores decisiones. La ventaja para las empresas de compartir información es reducir la probabilidad de ofrecer un servicio o producto a un cliente que incumplirá su contrato, minimizando con ello las pérdidas de operación esperadas. Además, como el contar con mejor información permite premiar a los consumidores cumplidos y castigar a los incumplidos, la compartición de información induce a los individuos a procurar ser cumplidos.

No obstante lo señalado, lo que más conviene a una empresa es tener acceso a la información de las SIs sin tener que compartir su propia base de datos. Este incentivo a no compartir información pudiera evitar que se desarrolle el mercado de las SIs. Para contrarrestar este equilibro ineficiente, las SIs han encontrado deseable solicitar reciprocidad por parte de sus usuarios. Es decir, para que un usuario pueda consultar las 
bases de datos de la SI, es necesario compartir la información que éste posee. Desafortunadamente, los incentivos para compartir información pueden no ser suficientes, particularmente en mercados con una elevada concentración. Esto se debe a que el compartimiento entre empresas de la información sobre sus clientes tiende a aumentar la competencia en los mercados, ya que los entrantes al mercado pueden identificar mejor las características de riesgo de sus clientes potenciales y, por ende, ofrecer mejores precios y condiciones que los que actualmente proporcionan las empresas dominantes. Lo anterior reduce las rentas que la empresa dominante recibe por el acceso y uso exclusivo de dicha información personal. Para dicha empresa el valor de la información adicional es relativamente pequeño, mientras que la pérdida de las rentas en razón de mayor competencia puede ser sustancial. Por ello, las empresas dominantes pueden no tener incentivos a participar en el intercambio de información con las SIs. En suma, los incentivos a compartir información están influenciados por la estructura del mercado en el que operan las empresas. En un mercado competido es mayor el incentivo a compartir la información sobre sus clientes entre empresas de una misma o similar actividad económica, mientras que en mercados monopólicos el incentivo dominante es generalmente a no compartir información como mecanismo de defensa de las rentas supranormales. 


\section{Cuadro 7}

\section{El Flujo de Información de Datos Personales desde la Perspectiva de las Empresas}

El intercambio de información sobre los consumidores permite a las empresas: a) identificar mejor a los buenos clientes y reducir los costos y riesgos de crédito en la provisión de bienes y servicios y b) reducir el incumplimiento de los consumidores. No obstante lo anterior, dicho intercambio puede no ocurrir naturalmente en mercados concentrados.

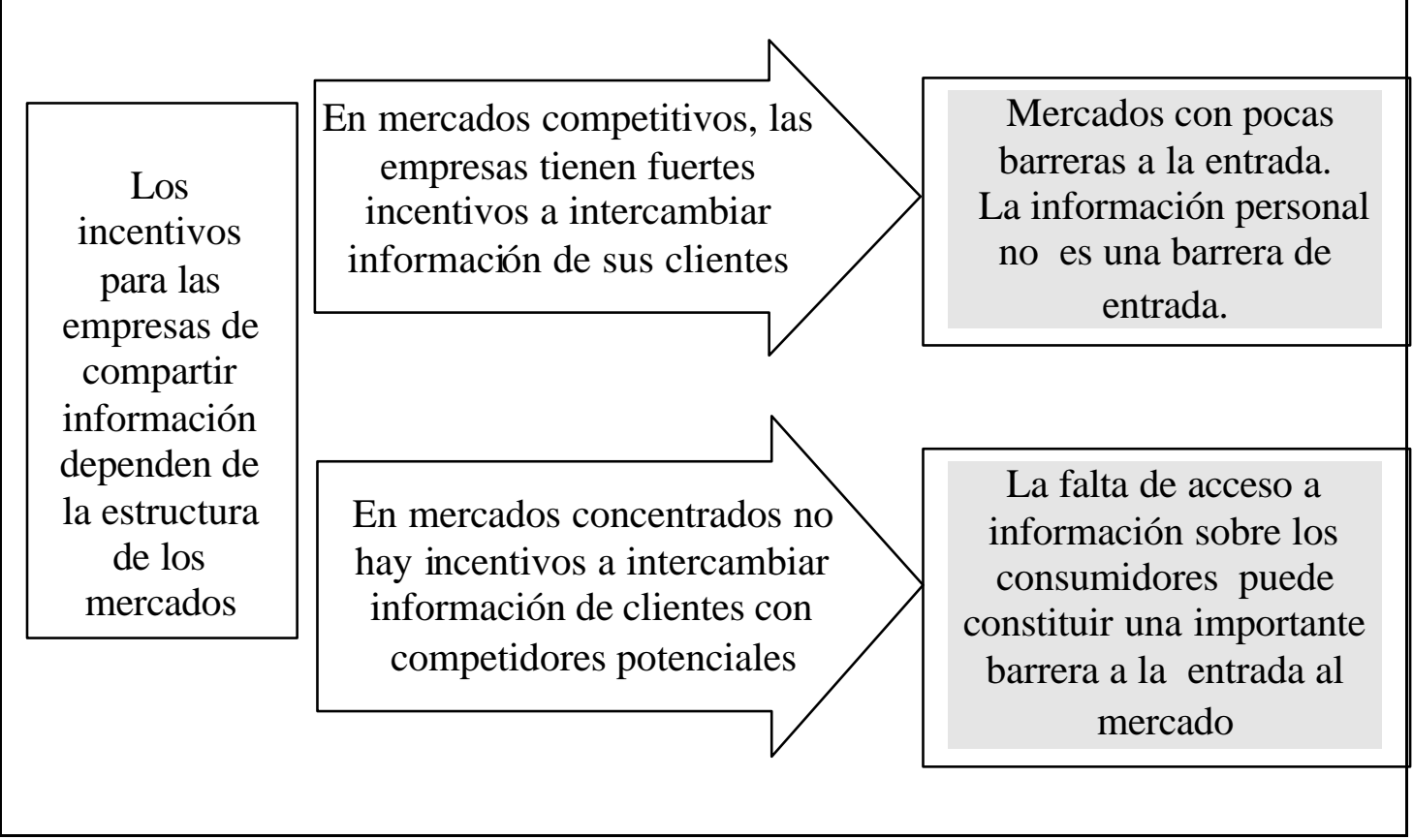

Cabe mencionar que al promoverse la competencia en sectores como telecomunicaciones, gas y electricidad, muchas veces se obliga a las empresas dominantes a compartir información negativa con sus competidores. No compartir esta información posibilita que consumidores morosos o dolosos cambien de proveedor sin haber cumplido con las obligaciones pactadas anteriormente, en detrimento de todos los operadores y del desarrollo económico.

Respecto del tipo de información que se comparte, es evidente que la información negativa, es decir sobre incumplimiento de obligaciones ayuda a las empresas a reducir riesgos y, generalmente, conduce a una mayor eficiencia económica. Sin embargo, el compartir información sobre obligaciones de los consumidores que están siendo cumplidas, es decir, 
información positiva, también resulta conveniente. Por ejemplo, el compartir información del monto de los distintos créditos otorgados al consumidor permite determinar su nivel total de endeudamiento, lo cual a su vez facilita una mejor evaluación de su capacidad de endeudamiento adicional.

En suma, el desarrollo de las SIs es benéfico anto para el consumidor como para los prestadores de servicios, ya que propicia que se lleven a cabo transacciones que ambas partes desean. Las SIs facilitan la ampliación de las bases de datos personales y la mejor toma de decisiones de consumo e inversión.

\section{B. Consideraciones para el Desarrollo de Sociedades de Información en América Latina}

Es particularmente importante estimular el desarrollo de las SIs en América Latina, ya que las deficiencias de los ordenamientos legales ${ }^{19}$ y las marcadas carencias institucionales en algunos países de esta región han causado que prolifere la cultura del no pago. Estas carencias han contribuido tanto al subdesarrollo del sistema financiero de estos países como a limitar la capacidad del gobierno para cobrar impuestos.

El incumplimiento de las obligaciones crediticias ha tenido graves repercusiones sobre los países de la región. La carencia de información actualizada, veraz y completa de los deudores de la banca ha sido un factor que ha incrementado la vulnerabilidad de los sistemas financieros y ha contribuido a la generación de crisis bancarias recurrentes. Éstas han tenido enormes costos para las sociedades y se han presentado en prácticamente la totalidad de los países de la región. Es importante recordar que los intermediarios financieros tienen la gran responsabilidad de evaluar cuidadosamente los riesgos que incurren al conceder créditos, ya que están disponiendo de los recursos de terceros, los depositantes. Para poder efectuar una evaluación diligente requieren contar con información sobre los adeudos de quienes les solicitan créditos y sobre la forma como estas personas las han pagado en el pasado. En la práctica, para poder cumplir con la

\footnotetext{
${ }^{19}$ Tal es el caso de las leyes de quiebras y las normas sobre la ejecución de garantías.
} 
responsabilidad de otorgar crédito sólo a los sujetos confiables, necesitan información adicional a la que poseen. Así, para obtener acceso a ella deben estar dispuestos a compartir la información crediticia en su poder con las SIs.

En contraste con los 170 años de experiencia que tienen las SIs privadas en los Estados Unidos, los países de América Latina generalmente cuentan con pocos años, o en el mejor de los casos unas cuantas décadas de experiencia. En la mayoría de estos países, el mercado de las SIs no se originó y desarrolló naturalmente, como sucedió en los Estados Unidos, debido a que en la región las personas tienden a tener menos movilidad ${ }^{20}$. Además, las economías latinoamericanas se caracterizan por tener elevados niveles de concentración en muchos mercados e industrias. Como se señaló, estos factores propician que las empresas estén menos dispuestas a transmitir información de sus clientes a terceros, inhibiéndose así el desarrollo de las SIs y el flujo de datos en los países de la región.

El surgimiento de las SIs en América Latina en ocasiones se relaciona con el interés de grupos dominantes de una industria por establecer su propia SI. Por ejemplo, los bancos mexicanos son dueños del único buró de crédito que opera en el país. De igual manera, en México las compañías de telecomunicaciones han contratado a una SI para que les provea de información negativa de los usuarios de telefonía de larga distancia. Estos grupos tienden a limitar el uso que dichas SIs pueden dar a la información no tanto para proteger la confidencialidad de los datos personales de sus clientes, sino mas bien para evitar que dicha información caiga en manos de sus competidores. ${ }^{21}$

El control de las SIs por parte de algunas empresas usuarias de la información transmitida por estas sociedades, como es el caso de los bancos en México y en Brasil, puede causar un serio conflicto de interés, lo que restringe la capacidad de estas SIs por conformar bases de datos completas e inhibe el surgimiento de otras SIs. Las empresas que no forman parte del

\footnotetext{
${ }^{20}$ Jappelli, Tulio, "Credit bureaus: effects on market performance and the role of government intervention" mimeo presentado en el Workshop "The role of timely and reliable information in the development of stable financial markets", World Bank and BCRA, Buenos Aires, Argentina, 1997.

21 Adicionalmente, este tipo de control se tiende a justificar también por la inexistencia de una regulación general de protección de datos y de las SIs. De acuerdo con este argumento, las empresas tienden a
} 
grupo de control de dichas SIs consideran que pueden ser discriminadas por las políticas que éstas adopten, es decir, tener acceso a la información en condiciones menos favorables que el acceso provisto a los bancos que forman parte del grupo de control. La mera sospecha de que las SIs no otorgan un trato equitativo a todos los usuarios de sus servicios es un factor que limita su capacidad para atraer empresas que le traspasen sus bases de datos personales. El resultado de ello es que las SIs con este conflicto de interés cuenten con pocos clientes y no puedan contar con bases de datos completas ${ }^{22}$, lo que aumenta el riesgo de la actividad crediticia y limita el desarrollo de los mercados y de la economía. El conflicto de interés ocasiona además que los bancos que son parte del grupo de control decidan no compartir la información de sus clientes con otras SIs. Esta situación puede ocasionar la monopolización del mercado de las SIs, situación que no fomenta una agresiva innovación tecnológica y de servicios y tiende a ocasionar ineficiencias como es el caso de tarifas excesivamente elevadas.

Para estar en mejores posibilidades de integrar bases de datos que contengan información de un gran número de empresas o proveedores que compiten entre sí, es indispensable que éstas tengan confianza en la imparcialidad en el uso de la información por parte de las SIs. Por ello, la estructura corporativa de las SIs que permite su mejor desarrollo en competencia es aquella en que el control de las SIs no recae en empresas que son importantes usuarias de sus servicios. Además, un mercado con estas características requiere una menor regulación y supervisión por parte de las autoridades, gracias a la ausencia de conflictos de interés y a que se elimina un importante obstáculo al desarrollo competitivo del mercado.

Para contrarrestar los efectos negativos de la integración vertical de los bancos en la SI, una medida regulatoria que las autoridades han adoptado en México es requerir que las SIs compartan un subconjunto de información negativa. Esta regulación no tuvo el efecto deseado debido en parte a retrasos en su aplicación y al hecho de que la información que

restringir el uso de la información para proteger los datos personales del mal uso que pudieran darse a éstos debido a que no existe una regulación adecuada en la materia. 
finalmente se compartió fue sólo una pequeña fracción de la información negativa ${ }^{23}$. De hecho, la SI de la que son dueños los bancos en un $70 \%$ se ha consolidado como el único buró de crédito en México, al abandonar este mercado las otras dos SIs autorizadas, la "joint venture" de un grupo de empresarios del estado de Jalisco con TRW (ahora Experian) en 1997 y Equifax a principios de 2000.

Esta experiencia sugiere que el obligar a las SIs a compartir información entre sí tiene importantes inconvenientes. En primer lugar existe la dificultad práctica de que competidores compartan información, en tiempo y forma ante la férrea oposición al intercambio de parte de la SI dominante. Adicionalmente, se puede disminuir el esfuerzo de las SIs por conformar bases de datos, si se ven obligadas a transferir a sus competidores sus bases de datos "gratis". Ello inhibiría el desarrollo de SIs.

Otra medida regulatoria para fomentar el desarrollo del mercado de las SIs es el derecho de las SIs incipientes de adquirir reportes a la SI dominante a tarifas que no sean mayores que las menores tarifas que las SIs ofrecen a sus usuarios. Esta regla para la determinación de tarifas de reventa es comúnmente aceptada en industrias de red con un elevada

${ }^{22}$ El buró de crédito de personas físicas de México tenía a mediados de 2001 menos de 400 usuarios que le proporcionaban información y a los que el buró le vende reportes. En contraste en Argentina alguno delos burós de crédito nacionales tiene alrededor de 100,000 usuarios.

23 La información negativa que se comparte es un subconjunto de datos sobre cartera vencida. En la reforma de 1997 a las "Reglas Generales a que deberán sujetarse las sociedades de información crediticia a que se refiere el artículo 33 de la Ley para Regular las Agrupaciones Financieras”, la Secretaría de Hacienda sustituyó la obligación de compartir información de cartera vencida por la obligación de compartir información relacionada con cartera vencida. De acuerdo con este cambio, la base de datos que los burós deben intercambiar es significativamente menor que la base de datos con información de cartera vencida, ya que:

i) Para financiamiento vía tarjeta de crédito (créditos revolventes) se debe compartir sólo la información del cliente que no haya realizado el pago mínimo requerido durante 120 días naturales. Se considera cartera vencida la de clientes que no hayan realizado el pago mínimo requerido por 2 o más períodos de facturación, es decir 60 días;

ii) Para créditos a la vivienda se debe compartir sólo la información del acreditado después de transcurridos 180 días naturales de la fecha de vencimiento de la primera amortización no liquidada. Se considera cartera vencida una vez transcurridos 90 días naturales de la fecha de vencimiento de la primera amortización no liquidada;

iii) Para la adquisición de bienes de consumo duradero, sólo se debe compartir la información del acreditado después de transcurridos 120 días naturales de la fecha de vencimiento de la primera amortización no liquidada, en vez de los 90 días establecidos en la regulación de cartera vencida. 
concentración $^{24}$. Esta regulación permite a una SI que está iniciando y que por tanto cuenta con una base de datos pequeña, competir con las SIs establecidas en el mercado. No obstante lo señalado, este tipo de regulación puede presentar dificultades similares a las que existen cuando se obliga a las SIs a compartir sus bases de datos, ya que las SIs con las mayores bases de datos tienen incentivos a posponer y complicar la operación técnica de la transmisión de reportes a otras SIs. Por ende, para que dicha política sea viable se requiere de una supervisión efectiva por parte de las autoridades. Cabe insistir que la reventa no resuelve el problema de discriminación de los bancos en contra de las SIs de las que no son dueños.

Se considera que la manera más efectiva para que surja una sana competencia entre las SIs, es que los usuarios de las SIs (particularmente los usuarios de las SIs dominantes con importantes bases de datos, como son los bancos en México o Brasil) no puedan mantener nexos patrimoniales con dichas sociedades. Esta acción eliminaría importantes obstáculos para el desarrollo de las SIs.

\section{Elaboración de un marco regulatorio para la protección de datos y para el desarrollo de las SIs}

El sano desarrollo del mercado de las SIs precisa de un marco regulatorio que establezca con claridad los principios que norman la protección de los datos personales. Dichos principios inciden sobre todos los agentes que participan en el mercado (consumidores, SIs y usuarios). Además, en la medida en que este marco regulatorio tenga una aplicación general para los distintos sectores de la economía, se facilita la conformación de bases de datos que incorporen información de diversas fuentes, propiciando que las bases de datos sean más completas y que las SIs presten una mayor variedad de servicios. Adicionalmente, un marco regulatorio general reduce la incertidumbre jurídica y los riesgos que enfrentan las partes. Estas condiciones propician mayores inversiones para la prestación de servicios de información.

\footnotetext{
${ }^{24}$ Para la reventa de reportes entre las SIs no se debe requerir la autorización del consumidor, puesto que la SI que recibe información no pública de otra SI sólo puede transmitir dicha información a terceros en los casos previstos en la ley o regulación.
} 


\section{Regulación de las Sociedades de Información en los países analizados de América Latina, los Estados Unidos, Canadá y la Unión Europea.}

En esta sección se describe la regulación que rige a las SIs en los países analizados. Para ello, se comentan los requisitos legales que deben cumplir las SIs para iniciar sus operaciones y se estudia la aplicación de los principios internacionales a la operación de las mismas.

\section{a) Requisitos para el Inicio de Operaciones de las SIs}

Si bien los Estados Unidos no tienen un requisito legal que deban cumplir los interesados en constituir SIs, cuenta con una regulación detallada de sus operaciones. Brasil, Chile, Colombia tampoco establecen requisitos para crear SIs. Sin embargo, al contrario de los Estados Unidos, no tienen una regulación detallada de las SIs. En Argentina ${ }^{25}$, Perú y la Unión Europea existe un proceso de registro al que deben sujetarse las SIs. México cuenta con un proceso de autorización discrecional para las $\mathrm{SIs}^{26}$.

\section{b) Datos Recolectados por las SIs}

Como se mencionó en relación con los principios internacionales de protección de datos personales (capítulo II.1), deben existir límites a la recolección de datos personales. Todo dato debe ser obtenido por medios legítimos y justos y, cuando sea apropiado, con el conocimiento o consentimiento del sujeto a quién se refieran los datos ${ }^{27}$. La mayoría de los

\footnotetext{
${ }^{25}$ En Argentina, el registro de archivos de datos debe comprender como mínimo la siguiente información: a) nombre y domicilio del responsable; b) características y finalidad del archivo; c) naturaleza de los datos personales contenidos en cada archivo; d) forma de recolección y actualización de datos; e) destino de los datos y personas físicas o de existencia ideal (personas morales) a las que pueden ser trasmitidos; f) modo de interrelacionar la información registrada; g) medios utilizados para garantizar la seguridad de los datos, debiendo detallarse la categoría de personas con acceso al tratamiento de la información; h) tiempo de conservación de los datos; e i) forma y condiciones en las que las personas pueden acceder a los datos referidos a ellas y los procedimientos a realizar para la rectificación o actualización de los datos.

${ }^{26}$ En México las Sociedades de Información Crediticia necesitan contar con la autorización de la Secretaría de Hacienda, tomando en cuenta la opinión del Banco de México y de la Comisión Nacional Bancaria y de Valores.

27 De acuerdo con la Directiva Europea, cuando los datos no hayan sido recabados directamente del interesado, el responsable del tratamiento deberá, desde el momento del registro o a más tardar en el momento de la primera comunicación de datos, comunicar al interesado: a) la identidad del responsable del tratamiento y, en su caso, de su representante; b) los fines del tratamiento de que van a ser objeto los datos; c) cualquier otra información tal como la ya mencionada. De lo anterior se concluye que se puede recolectar información y no informarle al sujeto hasta que dicha información se vaya a transmitir. No
} 
países contempla expresamente en su regulación el principio de contar con fuentes y medios legítimos de recolección de información, excepto Brasil ${ }^{28}$, México y Colombia. En este último país, aún cuando el principio no está establecido en una ley, la Corte Constitucional ha señalado que los datos conseguidos por medios ilícitos no pueden ser parte de los bancos de datos y tampoco pueden circular.

En varios países, como Argentina, Chile, Colombia ${ }^{29}$ y Canadá $^{30}$, está establecido el principio general de contar con el conocimiento del titular para la recolección de datos. No obstante, se excluye de dicho requerimiento la información crediticia. En los Estados Unidos sólo cierto tipo de información, el cual no incluye la crediticia, requiere el consentimiento del deudor para su recolección. En Perú y México la regulación no establece conocimiento o consentimiento alguno del titular para la recolección de datos.

obstante, se señala que no es necesario imponer esta obligación si el interesado ya está informado, si el registro y la comunicación están expresamente previstos por la ley o si resulta imposible informarle, o ello implica esfuerzos desproporcionados, como puede ser el caso para tratamientos con fines históricos, estadísticos o científicos

${ }^{28}$ En el Artículo 43 del Código de Protecao e Defesa do Consumidor no se señala acerca de la obtención de los datos, pero si se establece que la apertura de un catastro, ficha de registro de datos personales o de consumo deberá de ser comunicada por escrito al consumidor, cuando no sea solicitada por él.

${ }^{29}$ En Colombia el artículo 114 de la Ley 510 establecía que las SIs sólo podían tratar datos personales obtenidos de fuentes accesibles al público o procedentes de informaciones recogidas mediante el consentimiento libre, expreso, informado y escrito de su titular. No obstante lo anterior, dicho artículo se declaró inexequible. Por su parte, la Corte Constitucional señaló que para facilitar el conocimiento de los datos por la persona a quien conciernen, debe notificarse a ésta sobre la inclusión de tales datos en las base de datos, pero se exceptúa la información crediticia por ser de interés general.

30 En Canadá, aunque la PIPEDA no establece explícitamente la excepción relativa a la información crediticia, establece que se puede recolectar información personal sin consentimiento cuando dicho consentimiento comprometería la disposición y precisión de la información. 


\section{Cuadro 8}

\section{Regulación de las Sociedades de Información}

\begin{tabular}{|c|c|c|c|c|c|c|c|c|c|}
\hline & Argentina & Brasil & Chile & $\begin{array}{c}\text { Colom- } \\
\text { bia }\end{array}$ & México & Perú & $\begin{array}{c}\text { Estados } \\
\text { Unidos }\end{array}$ & Canadá & $\begin{array}{c}\text { Unión } \\
\text { Europea }\end{array}$ \\
\hline \multicolumn{10}{|l|}{ Inicio de Operaciones } \\
\hline $\begin{array}{l}\text { No se requiere regis tro } \\
\text { o autorización }\end{array}$ & & SI & SI & SI & & & SI & SI & \\
\hline Se requiere registro & SI & & & & & SI & & & SI \\
\hline Se requiere autorización & & & & & SI & & & & \\
\hline \multicolumn{10}{|l|}{$\begin{array}{l}\text { Principios establecidos } \\
\text { en instrumentos } \\
\text { internacionales }\end{array}$} \\
\hline Especificación del fin & SI & $\mathrm{NO}$ & SI & $\mathrm{NO}$ & SI & SI & SI & SI & SI \\
\hline \multicolumn{10}{|l|}{ 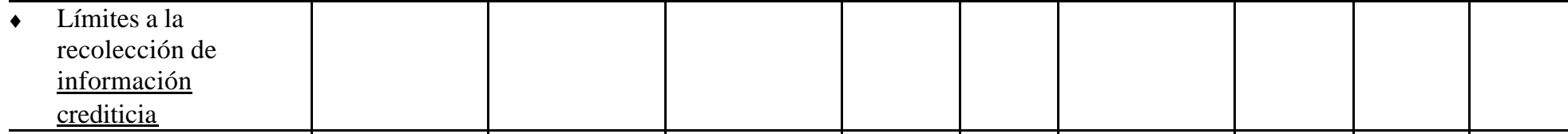 } \\
\hline $\begin{array}{ll}\text { a) } & \text { Obtenidos por medios } \\
\text { legítimos }\end{array}$ & SI & NO & SI & SI & NO & SI & SI & SI & SI \\
\hline $\begin{array}{l}\text { b) Conocimiento del } \\
\text { Consumidor }\end{array}$ & NO & $\begin{array}{l}\text { Sólo info. } \\
\text { negativa sin } \\
\text { consentimien- } \\
\text { to del } \\
\text { consumidor } \\
\end{array}$ & NO & NO & NO & NO & NO & NO & SI \\
\hline $\begin{array}{l}\text { Autorización para la } \\
\text { transmisión de } \\
\text { información } \\
\text { crediticia } \\
\end{array}$ & & & & & & & & & \\
\hline a) Expresa y por escrito & \multirow{3}{*}{$\begin{array}{c}\text { La info. } \\
\text { crediticia es } \\
\text { pública y no } \\
\text { requiere del } \\
\text { consentimien- } \\
\text { to del titular } \\
\text { de los datos } \\
\text { para su } \\
\text { transmisión }\end{array}$} & NO & \multirow{3}{*}{$\begin{array}{c}\text { La info. } \\
\text { crediticia } \\
\text { negativa es } \\
\text { pública y no } \\
\text { requiere del } \\
\text { consentimien- } \\
\text { to del titular } \\
\text { de los datos } \\
\text { para su } \\
\text { transmisión }\end{array}$} & SI & SI & \multirow{3}{*}{\begin{tabular}{|c|} 
La info. \\
crediticia es \\
pública y no \\
requiere del \\
consentimien- \\
to del titular \\
de los datos \\
para \\
transmisión
\end{tabular}} & SI & SI & SI \\
\hline $\begin{array}{l}\text { b) Implícita en } \\
\text { transacciones } \\
\text { iniciadas por el } \\
\text { consumidor } \\
\end{array}$ & & NO & & NO & NO & & SI & SI & SI \\
\hline $\begin{array}{l}\text { c) Propósitos permitidos } \\
\text { o interés legítimo del } \\
\text { usuario de la } \\
\text { información }\end{array}$ & & NO & & NO & NO & & SI & SI & SI \\
\hline $\begin{array}{l}\text { Límites al plazo de } \\
\text { retención de los datos }\end{array}$ & SI & SI & SI & NO & NO & SI & SI & & SI \\
\hline - Calidad de los datos & SI & SI & SI & SI & $\mathrm{NO}$ & SI & SI & SI & SI \\
\hline $\begin{array}{ll} & \begin{array}{l}\text { Regulación de } \\
\text { seguridad }\end{array} \\
\end{array}$ & SI & $\mathrm{NO}$ & SI & $\mathrm{NO}$ & SI & SI & $\mathrm{NO}$ & SI & SI \\
\hline $\begin{array}{l}\text { Responsabilidad del } \\
\text { controlador }\end{array}$ & SI & NO & SI & NO & SI & SI & SI & SI & SI \\
\hline Sanciones & SI & NO & SI & $\mathrm{NO}$ & SI & $\mathrm{NO}$ & SI & $\mathrm{NO}$ & SI \\
\hline
\end{tabular}

*Dada la amplitud con la que se utiliza el término Sociedad de Información (SI) en este documento, conviene especificar, para cada país, cuales entidades se incorporan en el análisis. En Argentina se hace referencia a los bancos públicos o los privados destinados a proveer informes; en Brasil a los bancos de datos o registros de los consumidores, públicos o privados; en Chile y Europa a los bancos de datos de carácter personal en Colombia, México y Perú únicamente a los burós de crédito; y en los Estados Unidos a las agencias de reportes sobre consumidores. 
En Brasil, no obstante que el secreto bancario cubre la información de las operaciones activas de las instituciones financieras, la Ley No. 105 establece que la transmisión a "entidades de protección del crédito" de información contenida en el registro de emisores de cheques sin fondos y de deudores incumplidos no viola el secreto bancario. Así, se concluye que la información crediticia negativa se puede transmitir a las SIs sin consentimiento o conocimiento. En España se requiere notificar al titular de los datos una referencia de los que hubiesen sido incluidos cuando se recabó información personal de sus acreedores sobre cumplimientos o incumplimientos de obligaciones, a los 30 días de registrarse dicha información.

Se considera en este estudio que no es apropiado requerir el conocimiento y consentimiento del deudor para que las SIs puedan recolectar información. Esto permitiría a las SIs conjuntar bases de datos más completas, en beneficio de la calidad de los servicios que ofrecen. Lo anterior no demerita la protección del individuo si las SIs transmiten datos personales sólo en condiciones que salvaguarden los derechos de éste.

\section{c) Transmisión de Datos Personales a Terceras Personas}

De acuerdo con los lineamientos internacionales, el principio básico para transmitir, hacer disponibles o utilizar para fines diferentes a los especificados los datos del consumidor, es que éste otorgue su consentimiento. No obstante, se contemplan diversas excepciones bajo las cuales no se requiere consentimiento para la transmisión. Algunas de las excepciones más comunes respecto de la necesidad de contar con la autorización para la transmisión son los siguientes: i) cuando los datos se hayan obtenido de fuentes accesibles al público y ii) cuando se transmitan a la autoridad, sea esta judicial, tributaria o administrativa, para el ejercicio de funciones.

En los Estados Unidos el Fair Credit Reporting Act contempla, además de la transmisión de datos personales a autoridades y jueces, una serie de propósitos claramente definidos que si bien no requieren del consentimiento expreso del consumidor, no obran en perjuicio de su privacidad. Entre dichos propósitos destacan: i) cuando existe una transacción mercantil iniciada por el consumidor y ii) cuando la SI tiene razones para creer que el tercero tiene la 
intención de usar la información en relación con una transacción crediticia o la adquisición de un seguro. Cabe destacar que para la transmisión a terceros de información sensible y con propósitos de empleo siempre se requiere el consentimiento explícito del consumidor.

La directiva de la Unión Europea y la PIPEDA de Canadá también establecen la autorización explícita, así como la autorización implícita y las excepciones en las cuales no se requiere dicha autorización.

En Argentina y Chile hay dos tipos de información: la que necesita autorización por escrito para su transmisión y la que por su naturaleza pública no requiere autorización. Dentro de éste último tipo se encuentran los incumplimientos de obligaciones de carácter económico, financiero, bancario o comercial en Chile ${ }^{31}$ y la información bancaria activa en Argentina ${ }^{32}$. Por otra parte, la ley de las SIs de Perú no establece la necesidad de contar con ningún tipo de autorización para la transmisión y uso de datos, una vez que éstos se recolectaron por los medios especificados en la ley. En Brasil el intercambio de información entre instituciones financieras para fines de registro, inclusive utilizando como intermediarios a las centrales de riesgo, no viola el secreto bancario.

En contraste, el esquema adoptado en México es más restrictivo que en los anteriores países, toda vez que se obliga a las SIs a contar con la autorización expresa y por escrito del consumidor para poder transmitir información a un tercero. Colombia sigue una política similar a la de México, dado que la Corte Constitucional señaló:

\section{"el derecho a la información y la legitimidad de la conducta de las entidades que solicitan información de sus eventuales clientes, así como la facultad de reportar a quienes incumplan las obligaciones con ellos contraídas, tiene como base fundamental, la autorización que el interesado les otorgue para}

\footnotetext{
${ }^{31}$ El texto de la ley de protección de datos recientemente aprobada en Chile señala que no es necesaria la autorización por escrito del consumidor para la transferencia de información económico financiera. Esto es posible, en parte, debido a que en dicho país sólo se comparte información negativa. Adicionalmente, en Chile se establece que el usuario es responsable de la legalidad de toda solicitud de servicio a un buró de crédito.
} 
disponer de esa información, autorización que debe ser expresa y voluntaria por parte del interesado"33

\section{d) Límites al Plazo de Retención de Datos o "Derecho al Olvido"}

La mayoría de los países analizados, regula el plazo que pueden permanecer los datos en las bases de datos de las SIs. En los Estados Unidos, por regla general, la información sobre incumplimientos se retiene por 7 años en las bases de datos de las SIs. Tal es el caso de juicios y sentencias, incumplimiento de obligaciones fiscales, cuentas por cobrar, registros de arrestos, denuncias y condenas de delitos. En el caso de quiebras personales se conservan hasta por 10 años. Sin embargo, existen importantes excepciones al derecho al olvido. No se puede borrar la información contenida en las bases de datos de SIs relativas a créditos de 150 mil dólares o más, datos de seguros de vida con cobertura igual o superior a 150 mil dólares o datos de empleo con salarios anuales de 75 mil dólares o mayores.

En España los datos de carácter personal que sean determinantes para evaluar la solvencia económica de los interesados no pueden retenerse más de seis años. En los países de América Latina analizados se mantiene un límite de retención de datos generalmente más corto. Por ejemplo, en Brasil, Argentina y Perú se ha establecido un plazo genérico de 5 años. En México, como en Colombia, no se ha establecido en la regulación un límite al plazo de retención de los datos. No obstante, la Corte Constitucional en Colombia al menos señala que el deudor tiene derecho al olvido estableciendo que:

"También hacia el pasado debe fijarse un límite razonable pues no sería lógico ni justo que el buen comportamiento de los últimos años no borrara, la mala conducta pasada. Es razonable el término que evite el abuso del poder informático y preserve las sanas prácticas crediticias. " 34

32 El art. 26 de la ley de protección de datos argentina exenta a los burós de crédito de requerir el consentimiento para transmitir o ceder datos cuando estén relacionados con el giro de las actividades comerciales o crediticias de los cesionarios.

${ }^{33}$ Sentencia Constitucional SU 089/95, Colombia.

${ }^{34}$ Sentencia Constitucional SU 089/95, Colombia. 
Chile, siguiendo el modelo de los Estados Unidos, estableció que la información que verse sobre obligaciones de carácter económico, financiero, bancario o comercial, permanece en las bases de datos de las SIs por siete años, desde que la respectiva obligación se hizo exigible. Si el deudor paga este plazo se reduce a tres años. Este mecanismo de reducción del plazo de retención de datos fue incorporado en la ley de Argentina. De acuerdo con esta ley sólo se pueden archivar, registrar o ceder los datos personales que sean significativos para evaluar la solvencia económico-financiera de los afectados durante los últimos cinco años. Dicho plazo se reduce a dos años cuando el deudor cancela o de otro modo extingue la obligación.

Se considera que lo plazos de retención de datos se deben determinar con un criterio ético, no como una decisión política de corto plazo que intente beneficiar a ciertos consumidores o crear un incentivo adicional para pagar obligaciones actuales. Los acreedores deben contar con información suficiente y apropiada para la toma de decisiones, y no con un historial de pago de sólo dos o tres años. Adicionalmente, diversos problemas de operación pueden surgir para determinar el estado actual de los deudores que han cancelado sus obligaciones con otros créditos o reestructurado sus deudas. Lo anterior llevaría a que se deteriorara aún más la calidad y utilidad de las bases de datos.

Una amnistía en cuanto al periodo de retención de datos personales podría resultar en un tratamiento injusto a distintos consumidores, en una fuerte descapitalización de información (la cual es esencial para el otorgamiento de créditos) y además, contribuiría a que las transacciones en el mercado doméstico fuesen más riesgosas. Más perjudiciales que las amnistías mencionadas son las generales que se han incorporado en algunas leyes. Por ejemplo, el Poder Legislativo argentino (octubre de 2000) aprobó una amnistía general transitoria sobre el plazo de retención, misma subsecuentemente vetada por la Presidencia de la República. El artículo vetado establecía que "los bancos de datos presentadores de servicios de información crediticia deberán suprimir, o en su caso, omitir asentar, todo dato referido al incumplimiento o mora en el pago de una obligación si ésta hubiere sido cancelada al momento de la entrada en vigencia de la presente ley." 
Por otra parte, en Colombia el artículo 76 de la Ley 550 de 1999 "Sobre Intervención Económica" establece que las personas que dentro de los diez (10) meses siguientes a la entrada en vigor de la ley 114/99 se pusieran al día en aquellas obligaciones por cuya causa hubieren sido reportadas a los bancos de datos tendrían un alivio consistente en la caducidad inmediata de la información negativa. Los clientes de entidades financieras que tuvieron moras con sus obligaciones y cancelaron dentro del periodo comprendido entre el 4 de agosto de 1999 y el 4 de junio de 2000, tuvieron el derecho a un alivio consistente en la caducidad inmediata de la información negativa reportada a las Centrales de Riesgo ${ }^{35}$.

\section{e) Disposiciones relacionadas con la seguridad de las bases de datos}

Estas disposiciones generalmente sólo establecen que los datos deben estar protegidos de riesgos de pérdida, destrucción o transmisión indebida. Tal es el caso de los Estados Unidos, cuya regulación no señala obligaciones explícitas a las SIs en materia de seguridad. En dicho país existen estándares de medidas de seguridad adoptados por la industria. De hecho, las compañías compiten también en la dimensión de seguridad promocionando sus políticas al respecto y sus prácticas de privacidad.

El tema de la seguridad en la industria de las SIs se maneja a través de estándares desarrollados por la ACB (Associated Credit Bureaus). La ACB trabajó conjuntamente con las compañías de "software" líderes en el mercado, para desarrollar el ACB Security Certification Program. La certificación es otorgada sólo a aquellas SIs que cumplan con los estándares de seguridad de la $\mathrm{ACB}$ o que tengan controles aceptables que sean equivalentes.

\section{f) Sanciones Adecuadas}

El Fair Credit Reporting Act de los Estados Unidos establece sanciones a las SIs como a sus usuarios en caso de que incumplan lo prescrito por esta ley con respecto a cualquier

\footnotetext{
${ }^{35}$ Otro ejemplo de este tipo de amnistías es el establecido en el Artículo 52 de la Ley 546 de 1,999 "Sobre regulación del sistema de financiación de vivienda". Dicho artículo establece que los deudores de los créditos de vivienda individual a largo plazo que reestructuren sus créditos hipotecarios o entreguen sus viviendas en dación en pago con posterioridad al $1^{\circ}$ de enero de 1997 , tendrán derecho a que las entidades financieras los declaren a paz y en salvo por el crédito respectivo y retiren sus nombres de las centrales de riesgo. En la práctica, el beneficio se adquiere una vez canceladas hs tres primeras cuotas del crédito reestructurado y la obligación de retirar la información de los deudores morosos recae en la entidad financiera y no en el buró de crédito.
} 
individuo. Distingue entre infracciones intencionales y negligentes. En el caso de infracciones intencionales, las sanciones equivalen a la suma de los daños efectivamente ocasionados al consumidor o, en su defecto, un monto que oscila entre cien y mil dólares, el total de “daños punitivos" que el juez determine, las costas judiciales y, adicionalmente, los honorarios "razonables" de los abogados que determine el juez. En el caso de infracciones por negligencia, las sanciones equivalen a la suma de los daños efectivamente ocasionados, las costas judiciales y los honorarios razonables de los abogados que determine el juez.

De acuerdo con la Ley de Protección de Datos de Carácter Personal (1999) de España, constituye una infracción grave o muy grave tratar los datos de carácter personal o usarlos posteriormente quebrantando los principios y garantías establecidos en la ley o incumpliendo los preceptos de protección que impongan las disposiciones regla mentarias. Las infracciones son sancionadas con multas que oscilan entre los 10 y los 100 millones de pesetas (entre 54 y 540 mil dólares de los Estados Unidos). La cuantía de las sanciones es determinada por la Agencia de Protección de Datos atendiendo a lo siguiente: la naturaleza de los derechos personales afectados; el volumen de los tratamientos efectuados; los beneficios obtenidos; el grado de intencionalidad; la reincidencia; los daños y perjuicios causados a las personas interesadas y a terceras personas; así como cualquier otra circunstancia que permita determinar al grado de ilegalidad y culpabilidad presentes en la actuación infractora. Por otra parte, los interesados que, como consecuencia del incumplimiento de lo dispuesto en la ley por una SI o controlador de datos privado, sufran daño o lesión en sus bienes o derechos, tendrán derecho a ser indemnizados. Para ello, deben ejercitar la acción ante los órganos de la jurisdicción ordinaria.

Cabe destacar que las sanciones establecidas en la ley de España son notablemente mayores que las consideradas en la de los Estados Unidos. Esto probablemente se debe a que el objeto de la primera es la protección de datos, mientras que el flujo de información en la economía y el desarrollo de las SIs son objetivos secundarios. En los Estados Unidos ocurre lo contrario. Las sanciones elevadas tienden a desincentivar el flujo de información en la economía e inhiben el desarrollo de las SIs. Esto porque los controladores de datos 
tienden a ser excesivamente cautelosos en el tratamiento y transmisión de datos personales, a fin de evitar elevados costos en caso de cometer errores. Si bien es importante que se sancionen los incumplimientos, intencionales o por descuido, por parte de los controladores de datos y de las SIs, las sanciones no deben ser tan grandes que desincentiven la inversión y el desarrollo de bases de datos personales y de las SIs.

\section{g) Disposiciones Relacionadas con la Transparencia de las SIs}

Estas disposiciones se refieren a que el consumidor tenga acceso a información relativa a la identidad y residencia de las SIs, así como a sus políticas y prácticas relacionadas con la administración de los datos personales. Este es un aspecto que tiene mucha importancia en el Fair Credit Reporting Act de los Estados Unidos.

\section{Tipos de Datos tratados por las Sociedades de Información en los países de América Latina, Los Estados Unidos, Canadá y la Unión Europea.}

Para que las SIs puedan ofrecer servicios que redunden en el mayor beneficio posible para la sociedad es necesario que tengan acceso a diversos tipos de información de los individuos, ya sea que esté en poder del sector público o del privado.

Las SIs generalmente se han concentrado en ofrecer servicios de información tendientes a facilitar las decisiones de otorgamiento de crédito. En adición, las SIs han comenzado a procesar datos personales con fines distintos, entre los cuales destacan los de empleo, médicos y arrendamiento de inmuebles. A continuación se presenta un cuadro resumen y una breve descripción del tipo de información que procesan las SIs en los países analizados. 


\section{Cuadro 9}

\section{Tipo de Información Tratada por las Sociedades de Información*}

\begin{tabular}{|c|c|c|c|c|c|c|c|c|c|}
\hline & Argentina & Brasil & Chile & Colombia & \begin{tabular}{|l|} 
México \\
\end{tabular} & Perú & $\begin{array}{l}\text { Estados } \\
\text { Unidos }\end{array}$ & Canadá & $\begin{array}{c}\text { Unión } \\
\text { Europea }\end{array}$ \\
\hline \multicolumn{10}{|l|}{$\begin{array}{l}\begin{array}{l}\text { Bancaria y de } \\
\text { Seguros** }\end{array} \\
\end{array}$} \\
\hline \multicolumn{10}{|l|}{$\begin{array}{l}\text { Crediticia y Otra } \\
\text { Activa }\end{array}$} \\
\hline \begin{tabular}{|l|} 
Información Positiva \\
\end{tabular} & SI & SI & $\mathrm{NO}$ & SI & SI & SI & SI & SI & SI \\
\hline Información Negativa & SI & SI & SI & SI & SI & SI & SI & SI & SI \\
\hline Bancaria Pasiva & $\mathrm{NO}$ & $\mathrm{NO}$ & $\mathrm{NO}$ & $\mathrm{NO}$ & $\mathrm{NO}$ & NO & $\mathrm{NO}$ & $\mathrm{NO}$ & $\mathrm{NO}$ \\
\hline \multicolumn{10}{|l|}{ Tributaria } \\
\hline Información Positiva & $\mathrm{NO}$ & $\mathrm{NO}$ & $\mathrm{NO}$ & $\mathrm{NO}$ & $\mathrm{NO}$ & NO & $\mathrm{NO}$ & $\mathrm{NO}$ & $\mathrm{NO}$ \\
\hline Información negativa & NO & SI & SI & NO & SI & SI & SI & nd & nd \\
\hline $\begin{array}{l}\text { Para propósitos de } \\
\text { Empleo }\end{array}$ & SI & $\mathrm{NO}$ & SI & NO & NO & SI & SI & SI & SI \\
\hline $\begin{array}{l}\begin{array}{l}\text { Para propósitos de } \\
\text { arrendamiento }\end{array} \\
\end{array}$ & SI & $\mathrm{NO}$ & SI & SI & $\mathrm{NO}$ & -SI & SI & SI & SI \\
\hline \multicolumn{10}{|l|}{\begin{tabular}{|l|} 
Categorías \\
Especiales
\end{tabular}} \\
\hline Médica & SI & $\mathrm{NO}$ & SI & $\mathrm{NO}$ & $\mathrm{NO}$ & NO & SI & SI & SI \\
\hline Datos Sensibles & $\mathrm{NO}$ & $\mathrm{NO}$ & SI & $\mathrm{NO}$ & $\mathrm{NO}$ & NO & SI & $\mathrm{NO}$ & SI \\
\hline
\end{tabular}

*El término Sociedades de Información (SIs) tiene connotaciones diferentes dependiendo del país de que se trate. La regulación de las SIs privadas en Argentina abarca a los bancos de datos privados destinados a proveer informes; en Brasil a los bancos de datos o registros de los consumidores; en Colombia y México únicamente a sociedades de información crediticia; en Perú a las centrales de riesgo privadas; en los Estados Unidos a las agencias de reportes sobre consumidores; y en Chile y Europa a los bancos de datos de carácter personal.

** Incluye crédito otorgado por instituciones no bancarias (por ejemplo, Comerciales).

SI significa que la información es tratada por las SIs; nd significa información que no se obtuvo para la elaboración de este estudio.

\section{a) Información Bancaria y Financiera}

Para propiciar mejores decisiones de otorgamiento de crédito, las SIs generalmente tienen acceso a información de operaciones activas (es decir, los créditos u otro tipo de obligaciones de sus clientes) tanto negativa como positiva, obtenida de los bancos, de otras instituciones financieras o de cualquier acreedor. En la mayoría de los países se establece que dicha información puede provenir de fuentes accesibles al público, ser facilitada por el titular de la misma o proporcionada por el acreedor.

En la mayoría de los países las SIs tratan tanto la información crediticia negativa como la positiva. La excepción es Chile, en donde la ley únicamente permite el tratamiento de 
información crediticia negativa por parte de las SIs, ya que el artículo 18 de la Ley de Protección de Datos de Carácter Personal de Chile (1999) establece que:

“Los responsables de los registros o bancos de datos personales sólo podrán comunicar información que verse sobre obligaciones de carácter económico, financiero, bancario o comercial, cuando éstas consten en letras de cambio y pagarés protestados; cheques protestados por falta de fondos, por haber sido girados contra cuenta corriente cerrada o por otra causa; como asimismo el incumplimiento de obligaciones derivadas de mutuos hipotecarios y de préstamos o créditos de bancos, sociedades financieras, administradoras de mutuos hipotecarios, cooperativas de ahorros y créditos, organismos públicos y empresas del Estado sometidas a la legislación común, y de sociedades administradoras de créditos otorgados para compras en casas comerciales."

No obstante lo anterior, en Chile existen acuerdos o convenios entre los bancos para compartir la información activa positiva de sus clientes, ya que ésta es esencial para llevar a cabo una adecuada evaluación crediticia de los sujetos de crédito. Dicha información no está disponible a otros otorgantes de crédito.

La información de las operaciones pasivas de los bancos o instituciones financieras, es decir, los depósitos, las cuentas de ahorro o de inversión de sus clientes, es un complemento útil para verificar la solvencia económica del sujeto $\mathrm{y}$, por ende, para tomar mejores decisiones de crédito. No obstante, en ninguno de los países analizados se permite a las SIs tratar dicha información. Ello, dado que se estima que el flujo de la misma sería una intromisión inaceptable en la privacidad de la persona (Cuadro 8). Si bien las SIs no tratan dicha información, las entidades financieras de los Estados Unidos, Canadá, países de la Unión Europea, Argentina, Brasil y Perú pueden transmitir información pasiva con consentimiento expreso del titular de los datos. La regulación del secreto bancario se presenta con mayor detalle a continuación. 


\section{(i) Regulación del Secreto Bancario}

El propósito que se persigue con el secreto bancario es proteger la información de los usuarios de servicios provistos por las entidades financieras. La naturaleza de la protección de esta información varía mucho entre los países analizados, lo cual se expone a continuación. Iniciamos la discusión de este tema describiendo la naturaleza del secreto bancario en los Estados Unidos y en España.

\section{Estados Unidos}

El Título V de la ley Gramm-Leach-Bliley de 1999, y su consecuente fortalecimiento con el Financial Information Privacy Protection Act de 2000, sujeta a las instituciones financieras a la obligación de respetar la privacidad de sus clientes y a proteger la confidencialidad y seguridad de la información personal definida como no pública. Además, en estas leyes se regula el uso y la transmisión de información personal no pública a terceros por parte de las instituciones financieras.

La información personal no pública es aquella que identifica a la persona, incluyendo su número del seguro social, cuando esta información sea proporcionada por el consumidor a la institución financiera al solicitar un producto o servicios financiero, resulte de una transacción entre la institución financiera y el usuario o la institución financiera la obtenga como consecuencia de la provisión de un producto o servicio financiero.

La obligación general de respetar la privacidad de sus clientes mo impide a la institución financiera transmitir a terceros información personal no pública de sus clientes. Ello, siempre y cuando se le proporcione al usuario una descripción clara y conspicua de las categorías de información que pueden ser reveladas a erceros. Antes de transmitir por primera vez datos personales, debe darle al consumidor la oportunidad de instruir, a través de medios sencillos para éste, que dicha información no sea divulgada. ${ }^{36}$ Adicionalmente, debe informar al usuario sobre su política de privacidad por lo menos una vez al año, cuando este último lo solicite y cuando demande un producto o servicio de la institución

\footnotetext{
${ }^{36}$ En particular, el consumidor debe poder utilizar el mismo medio de comunicación que el que la institución financiera utiliza para informarle de los datos sobre su persona que pretende revelar a terceros.
} 
financiera o en el caso de que la institución financiera inicie un relación con el consumidor (con periodicidad no mayor a anual).

Lo anterior se traduce en que si una institución financiera hace la notificación requerida por ley y no recibe una negativa por parte del consumidor, puede transmitir la información personal no pública a un tercero (afirmativa ficta). No obstante, a dicha regla se le imponen algunas restricciones. Una institución financiera, que proporciona al consumidor un servicio de envío o recepción de pagos o transferencias, ya sea por cheque, tarjeta de débito o crédito u otro instrumento similar, no puede transferir a un tercero una lista de las transacciones que realiza el consumidor o una descripción de los hábitos de consumo, intereses, preferencias u otras características del mismo. Una institución financiera tampoco puede transmitir a un tercero una lista de consumidores que contenga información de salud que identifique individualmente a un consumidor. Sólo se puede transmitir información de hábitos de consumo o de salud si la institución la requirió y obtuvo el consentimiento expreso y afirmativo del consumidor. Esta consideración es de gran importancia, ya que hace patente que cierta información activa, como la que revela los hábitos de consumo, puede ser tan "sensible” como la información pasiva.

Con fines de mercadotecnia directa, por correo o "telemarketing", una institución financiera no puede transmitir a un tercero, excepto a una SI, el número de una cuenta, o un número o código de acceso a una cuenta de tarjeta de crédito, o a cualquier cuenta de transacción de un consumidor.

Además, la ley explícita diversas circunstancias en las cuales la institución financiera puede divulgar a terceros, información personal no pública de sus clientes, entre las cuales destacan las siguientes (ver anexo para mayor detalle):

1. Cuando existe la orden o el consentimiento del consumidor;

2. Cuando ello es necesario para efectuar, administrar o hacer cumplir una transacción solicitada o autorizada por el consumidor o para servir o procesar un producto o servicio financiero si éste es solicitado por el consumidor; 
3. A entidades de seguro de depósito, calificadoras financieras y a $\mathrm{SIs}^{37}$.

\section{La Unión Europea: El Caso de España}

En España, como en otros países de Europa, no existen disposiciones legales ${ }^{38}$ que con carácter general y explícito obliguen a los intermediarios financieros a guardar secreto sobre sus operaciones (salvo en la zona de las islas Canarias). No obstante ello, existen disposiciones que presuponen el deber de secreto sobre las operaciones de los bancos con sus clientes y el respeto a la información bancaria. Además, existe una tradición de protección de la información de los clientes bancarios inherente en las relaciones bancarias nacionales e internacionales.

La ley de protección de datos de 1999 establece que las SIs que se dediquen a la prestación de servicios de información sobre solvencia patrimonial y crédito sólo pueden tratar información personal obtenida de fuentes públicas, facilitadas por el propio titular o cuando sea relativa al cumplimiento o incumplimiento de obligaciones, facilitadas por el acreedor o por quien actúe por su cuenta o interés. Por ende, las SIs pueden tratar información activa sin autorización, siempre y cuando se le haya notificado al titular que se recogió dicha información. En cambio, para que las SIs puedan tratar información relacionada con los depósitos y los ahorros en las instituciones financieras, se requeriría que los titulares de los datos se las facilitaran.

En España el fisco tiene acceso a la información bancaria. Las instituciones bancarias o crediticias tienen la obligación de colaborar con la Administración Tributaria, a la cual deben proporcionar datos, informes o antecedentes con trascendencia tributaria, no

\footnotetext{
${ }^{37}$ El FCRA establece como propósitos permisibles para proveer un reporte sin el consentimiento expreso del consumidor, entre otros, cuando exista una orden judicial, ante la solicitud de agencias gubernamentales asociadas a programas de apoyo a infantes, cuando se entrega a personas que ya tengan una relación comercial con el consumidor o que intenten iniciar una relación comercial con el consumidor, cuando el consumidor inicie o solicite una transacción comercial, y cuando la transacción consiste en una oferta de crédito en firme (si se cumplen ciertos criterios predefinidos y no discrecionales). También son propósitos permisibles eportes para propósitos de empleo. No obstante, para éstos hay una extensa serie de restricciones y diversas condicionantes y el consumidor tiene que dar anuencia.

${ }^{38}$ Tal es el caso también de otros países europeos, incluyendo a Suiza. La inexistencia de una regulación formal no ha impedido que en estos países exista una protección de la privacidad de las operaciones bancarias de las personas.
} 
pudiendo ampararse las citadas instituciones en el secreto bancario para incumplir la obligación de colaborar. ${ }^{39}$ Sin embargo, todos los datos obtenidos por la Administración Tributaria en el desempeño de sus funciones tienen el carácter de reservados.

${ }^{39}$ Ley General Tributaria (Ley 50/1977), artículos 111 y 112 y Reglamento General de la Inspección de los Tributos. 


\section{Los países de América Latina analizados}

En los países de América Latina analizados el secreto bancario generalmente es normado en la legislación del sistema financiero. La distinción que se hace no es entre información pública y no pública como es el caso en los Estados Unidos, sino que las regulaciones tienden a distinguir entre información bancaria pasiva y activa. La información bancaria pasiva en todos los países estudiados de América Latina está protegida por el secreto bancario, mientras que la información activa tiene un nivel de protección menor, y en algunos casos ninguna protección. En todos los países las centrales de riesgo administradas por las autoridades financieras y las SIs privadas procesan información crediticia.

En Argentina ${ }^{40}$, Chile $^{41}$ y Perú ${ }^{42}$, el secreto bancario sólo cubre las operaciones pasivas. Sin embargo, en Chile, los bancos solamente pueden dar a conocer las operaciones crediticias a quien demuestre un interés legítimo. En cambio en la Ley de Protección de Datos Personales de Argentina ${ }^{43}$ se establece que la prestación de servicios de información crediticia no requerirá el previo consentimiento del titular de los datos para los efectos de su cesión ni para la ulterior comunicación de ésta, cuando estén relacionados con el giro de las actividades comerciales o crediticias de los cesionarios. En Perú, al igual que en Argentina y en Chile, las SIs pueden transmitir información activa sin el consentimiento del titular. No obstante en Chile esto ocurre exclusivamente con la información negativa cuya transmisión no tiene restricción alguna, mientras que la positiva m puede ser transmitida siquiera a las SIs. Por su parte, las instituciones financieras de Argentina ${ }^{44}$ y de Perú

\footnotetext{
${ }^{40}$ La Ley de Entidades Financieras (Ley No. 21.526) de 1977 de Argentina señala bajo el Título V, Art. 39 excepciones, como lo son los informes que requieran los jueces en causas judiciales, el Banco Central de la República Argentina (BCRA) y la Superintendencia de Entidades Financieras y Cambiarias y los organismos recaudadores de impuestos.

${ }^{41}$ En la Ley General de Bancos de 1997, el Art. 154 señala que el secreto bancario abarca los depósitos y captaciones de cualquier naturaleza que reciban los bancos, los cuales no podrán proporcionar antecedentes relativos a dichas operaciones sino a su titular o representante legal. Es decir, las SIs no pueden captar este tipo de información de los bancos aunque cuenten con la autorización del sujeto.

${ }^{42}$ En Perú el Secreto Bancario está regulado en la Ley General del Sistema Financiero y del Sistema de Seguros y la Ley Orgánica de la Superintendencia de Banca y Seguros. No. 26702 (06/12/96, modificada el 06/05/99 - Arts. 140-143). El secreto bancario abarca las operaciones pasivas de las empresas del sistema financiero, las cuáles tienen prohibido suministrar esta información sobre sus clientes a menos que medie autorización escrita de estos.

${ }^{43}$ Artículo 26 de la Ley 25.326 de Protección de los Datos Personales promulgada el 30 de octubre de 2000.

${ }^{44}$ En Argentina, la información pasiva está protegida por el secreto bancario. No se especifica, pero tampoco se prohibe, que dicha información se transmita al propio titular o a un tercero con el consentimiento del
} 
pueden suministrar información sobre las operaciones pasivas de sus clientes si media autorización escrita de éstos. En Chile ello no es posible incluso con la autorización del individuo.

Si bien en Brasil ${ }^{45}$ y en México ${ }^{46}$ el secreto bancario cubre tanto las operaciones pasivas como las activas y otras relacionadas, existen excepciones que comúnmente se encuentran en las legislaciones, como son las relacionadas con investigación de delitos, acceso a dicha información por parte de autoridades financieras y por parte de los jueces. En México y Brasil también es una excepción al secreto bancario el que las instituciones financieras transmitan información crediticia positiva y negativa a las SIs. En Brasil existen importantes excepciones adicionales. Por ejemplo, no constituye violación al secreto bancario la transmisión de información protegida por el secreto en el caso de intercambio de datos entre instituciones financieras siempre que éstas observen las normas establecidas por el Consejo Monetario Nacional o por el Banco Central, así como la transmisión de dicha información al Ministerio de Hacienda, al Poder Legislativo y sus Comisiones Parlamentarias investigadoras para el ejercicio de sus competencias.

En Colombia no existe en materia financiera una ley que expresamente se refiera al secreto bancario. Sin embargo, la doctrina y la jurisprudencia admiten unánimemente la existencia de este deber de discreción y se considera un principio que deben respetar la banca y los profesionales de los negocios bancarios ${ }^{47}$. Además, existen diversos textos $u$ ordenamientos legales, que aún cuando no sean leyes, consagran el secreto bancario. Por ejemplo, la Circular Externa 07 de 1996 de la Superintendencia Bancaria establece la reserva bancaria como una de las obligaciones especiales de las entidades vigiladas por ella

titular. En adición, la ley de protección de datos establece la transmisión de información, dentro de la cual podría estar considerada la información pasiva, con el consentimiento del titular.

${ }^{45}$ El Art. 38 de la Ley No.4.595 de1964 fue revocado por Ley Co mplementaria No. 105 del 10 de enero de 2001. Pese a la reforma, el secreto bancario aún cubre las operaciones activas, pasivas y servicios prestados por las instituciones bancarias. No obstante, establece diversas excepciones bajo las cuales se puede transmitir la información sin violar el secreto.

${ }^{46}$ La Ley de Instituciones de Crédito artículo 117, establece que las instituciones de crédito en ningún caso podrán dar noticias o información de los depósitos, servicios o cualquier tipo de operación sino al consumidor o beneficiario que corresponda. No obstante ello, en la Ley de Agrupaciones Financieras (Art.33) se permite a los burós de crédito (sociedades de información crediticia) obtener y proporcionar información sobre operaciones activas.

${ }^{47}$ Concepto OJ-260 de noviembre 19 de 1982, Colombia. 
y la define como "el deber que tienen los funcionarios de las entidades financieras y aseguradoras de guardar reserva y discreción sobre los datos de sus clientes o sobre aquellos relacionados con la situación propia de la compañía, que conozcan en desarrollo de su profesión u oficio." Sin embargo, la Corte Constitucional de este país ha establecido que el derecho al secreto bancario no debe impedir que fluya información hacia quienes otorgan crédito ${ }^{48}$.

\section{(ii) Modelos de regulación del secreto bancario para América Latina}

En América Latina el secreto bancario generalmente ha sido regulado por disposiciones contenidas en las legislaciones de los sistemas financieros, las cuales anteceden a los principios internacionales de protección de datos. Las leyes generales de protección de datos son un vehículo adecuado para una regulación moderna del secreto bancario. Dichas leyes parten de los principios de protección internacionalmente aceptados, que aplican a todo tipo de datos personales, y no de una diferenciación entre operaciones activas y pasivas de los bancos. Esta última distinción es poco útil para clasificar el grado de protección que se debe dar a los datos personales en poder de las instituciones financieras. Como se señaló, cierta información activa, como la que revela los hábitos de consumo, puede ser tan "sensible" como la información pasiva.

La experiencia de los Estados Unidos muestra que una legislación sectorial del secreto bancario es compatible con los principios internacionales. Por otra parte, la experiencia de Argentina muestra que el contar con una ley general de protección de datos personales no es suficiente para garantizar una adecuada protección de la información en poder de las instituciones financieras. En ese país la transmisión de la información crediticia es posible sin el consentimiento del titular y, en general, sin restricción alguna. La protección de datos personales en poder de instituciones financieras de Chile tampoco es satisfactoria. $\mathrm{La}$ información crediticia negativa y la positiva están sujetas a reglas de transmisión muy distintas. La transmisión de la información crediticia negativa es posible sin restricción alguna. En contraste, los bancos no pueden transmitir información crediticia positiva a las SIs. Esto da lugar a que la calidad de los reportes de las SIs no sea satisfactoria, particularmente para usuarios no bancarios, quienes no tienen otra forma de accesar la información crediticia positiva de los bancos.

\footnotetext{
${ }^{48}$ La Corte Constitucional señaló en la Sentencia T-82/95 que "Las instituciones de crédito, precisamente por manejar el ahorro del público, ejercen una actividad de interés general (...). No tendría sentido pretender que prestaran sus servicios, y en particular otorgaran créditos, a personas de las cuales no tienen información. Por el contrario, un manejo prudente exige obtener la información que permita prever qué suerte correrán los dineros dados en préstamo. El deudor, por su parte, no tiene derecho, en el caso que se examina, a impedir el suministro de la información, principalmente por tres razones: La primera, que se trata de hechos que no tienen que ver solamente con él; la segunda, que no puede oponerse a que la entidad de crédito ejerza un derecho; y la tercera, que no se relaciona con asuntos relativos a su intimidad (...)”.
} 


\section{b) Inclusión de Información Tributaria en reportes de SIs y acceso del fisco a reportes de SIs}

El que las SIs puedan emitir reportes con información tributaria negativa es de gran importancia. La inclusión de la información tributaria permite a las SIs contar con información más completa y por tanto ofrecer reportes que permitan a los usuarios de los mismos obtener un mejor conocimiento de las personas evaluadas. Al otorgarse un crédito a una persona, quienes aportan los recursos se interesan en conocer no sólo las deudas que tiene dicha persona con las instituciones financieras y otras empresas, sino también si el solicitante de crédito tiene obligaciones tributarias pendientes. Adicionalmente, el incorporar la información fiscal incentiva el cumplimiento de las obligaciones fiscales, lo cual es particularmente benéfico para países que tradicionalmente tienen elevados índices de evasión fiscal, como son los países de América Latina.

No es sorprendente, que las autoridades fiscales estén cada vez más concientes que las SIs pueden favorecer la recolección de impuestos. Así, en los últimos años, las SIs de varios países de América Latina han empezado a incorporar en sus bases de datos información tributaria. El Cuadro 9 muestra que dicha información se limita a los incumplimientos fiscales. Para poder transmitir esta información a las SIs, diversos países analizados han estado reformando sus legislaciones sobre el denominado secreto fiscal, de tal manera que no se le aplique a los incumplimientos tributarios.

En Chile, Brasil y Perú el secreto fiscal no incluye a las deudas exigibles de los contribuyentes morosos, por lo que esta información es pública, e incluso está disponible en Internet. En Chile esta información se reporta a través de una página electrónica del Servicio de Impuestos Internos. En dicha página se puede consultar información relativa a la situación tributaria de los contribuyentes que están incluidos en la nómina de difícil fiscalización, no han atendido citatorios por diferencias detectadas en su declaración, no han sido ubicados vía requerimientos hechos a domicilio o no han concurrido a requerimientos notificados por la autoridad. Las SIs de Chile incorporan esta información 
en sus bases de datos $^{49}$. El artículo 198 del Código Fiscal de 1966 de Brasil fue modificado en 2001, con lo cual se estableció que el secreto tributario, que incluye información sobre la situación económica y financiera y sobre la naturaleza y estado de los negocios o actividades de los sujetos pasivos (contribuyente y responsable) o de terceros, no aplica a moratorias. Tampoco abarca las inscripciones en un registro que lleva la Hacienda Pública de Deuda Activa, es decir, la deuda exigible. En Brasil, la Secretaria da Receita Federal les proporciona a algunas SIs esta información.

En Perú, la Superintendencia Nacional de Administración Tributaria (SUNAT) difunde los montos de deuda tributaria exigible (la que da lugar a las acciones de coerción para su cobranza). La SUNAT hizo un convenio de cooperación con los burós de crédito a fin de que éstos hagan públicos los listados de deudores tributarios, ciertos datos del Registro Unico de Contribuyentes y los listados de omisos en la presentación de declaraciones de pago. A su vez, las SIs le permiten a la SUNAT acceso a su base de datos sobre morosidad de los clientes del sistema financiero y de las entidades comerciales. ${ }^{50}$ Asimismo, el secreto bancario y tributario puede levantarse a petición del juez en procedimientos civiles

\footnotetext{
${ }^{49}$ En los servicios prestados por Dicom Chile, se ofrece un informe sobre la situación tributaria de personas naturales o jurídicas que stán impedidas para timbrar boletas por alguna razón. También se publica información fiscal a través de una base de datos que contiene información proveniente de organismos estatales relativa a los antecedentes de contribuciones en cobranza, bienes y raíces en cobranza, deudas, morosos (formulario 21), deudores de crédito fiscal y otras.

En Chile, el Servicio de Impuestos Internos ha desarrollado un sistema a través del cual se puede consultar cierta información acerca de la situación tributaria de los siguientes contribuyentes:

- los que están incluidos en nómina de difícil fiscalización.

- los inconcurrentes a citaciones cursadas por diferencias detectadas en su declaración.

- los no ubicados vía requerimientos hechos a domicilio

- los inconcurrentes a requerimientos, habiendo sido notificados por la autoridad

${ }^{50}$ La deuda tributaria que será reportada es únicamente aquélla que se encuentra en la etapa de la cobranza coactiva y sobre la cual no existe duda respecto de su exigibilidad. La información que la SUNAT remite a las Centrales de Riesgos es:

1) el padrón del Registro Único de Contribuyentes (RUC).

2) el apellido, nombre, razón social, registro, dirección etc.

3) los representantes legales.

4) la deuda tributaria:

a) monto de la deuda, periodo tributario de la deuda, fecha de inicio del proceso de cobranza coactiva, fecha de última información procesada;

b) omisos a la Presentación, y

c) concepto(s) no declarados, periodo(s) omisos, fecha del proceso.
} 
o penales y de la Comisión de Fiscalización o de las Comisiones Investigadoras del Congreso, siempre que la información se refiera al caso investigado ${ }^{51}$.

En México el secreto fiscal también se ha hecho menos estricto recientemente. El Código Fiscal $^{52}$ fue reformado en diciembre de 2000, para permitir que la información sobre las obligaciones fiscales exigibles de los contribuyentes pueda ser proporcionada a las SIs, y para que éstas la transmitan en sus reportes.

En Argentina el secreto fiscal aún protege las infracciones o incumplimientos de las obligaciones fiscales. Sin embargo, cabe mencionar que en 1999 la Administración Federal de Ingresos Públicos presentó un Anteproyecto de Código Tributario en el cual se relajaba el secreto fiscal, al establecer que el secreto fiscal no se extendería a las infracciones o incumplimientos de las obligaciones tributarias detectadas mediante ejercicio de las facultades de verificación, fiscalización e investigación de la Autoridad Tributaria. A septiembre de 2001 esta reforma al Código Tributario todavía no había sido aprobada. En Colombia las SIs todavía no cuentan con ningún tipo de información de los contribuyentes. Tampoco existen convenios entre las autoridades fiscales y las SIs. Sin embargo, actualmente tiene lugar una discusión técnica de carácter legal sobre el alcance del secreto fiscal en este país, por lo que es posible que esta situación cambie en un futuro cercano.

Cabe mencionar que el tratamiento de este tipo de información no es exclusivo de América Latina. Por ejemplo, en los Estados Unidos, la información de deudores fiscales

\footnotetext{
${ }^{51}$ Constitución de Perú, Art. 2, sección $5^{\circ}$ y Código Fiscal (Decreto Legis 816) 20/04/96 Título III, Art.85.

${ }^{52} \mathrm{El}$ artículo 69 establece que el personal oficial que intervenga en los diversos trámites relativos a la aplicación de las disposiciones tributarias estará obligado a guardar absoluta reserva en lo concerniente a las:

- Declaraciones y datos suministrados por los contribuyentes o terceros relacionados, así como los obtenidos en el ejercicio de comprobación.

Dicha reserva no comprenderá la información relativa a los créditos fiscales exigibles de los contribuyentes, que las autoridades fiscales proporcionen a las sociedades de información crediticia que obtengan autorización de la Secretaría de Hacienda y Crédito Público de conformidad con la Ley de Agrupaciones Financieras (agregado en diciembre de 2000) y los casos que señalen las leyes fiscales y aquellos casos en que deban suministrarse datos a:

- Funcionarios encargados de la administración y defensa de los intereses fiscales nacionales;

- Autoridades judiciales en procesos de orden penal;

- Tribunales competentes que conozcan de pensiones alimenticias.
} 
sentenciados por los tribunales es información pública y las SIs la han venido recopilando desde hace muchos años.

No obstante las ventajas que tiene la incorporación de información tributaria negativa en las bases de datos de las SIs, no son claras las condiciones bajo las cuales el fisco debiera poder acceder a la información en poder de las SIs. En particular, no es evidente que la autoridad tributaria deba tener acceso irrestricto a información en las bases de datos de las SIs para llevar a cabo una política de fiscalización agresiva. El objetivo principal de las SIs es facilitar las transacciones en la economía al fomentar la transparencia en los mercados mediante la provisión de información oportuna, veraz y estandarizada. Si las personas perciben que las SIs son utilizadas intensamente por las autoridades fiscales para combatir la evasión, se pudiera frenar el flujo de información en la economía. Por ejemplo, para evitar aparecer en las bases de datos de las SIs, las personas pudieran recurrir a canales de crédito informales que no comparten sus bases de datos con las SIs. Ello daría lugar a una intermediación financiera menos eficiente. Asimismo, es posible que las SIs enfrentaran mayores dificultades para atraer empresas que les compartieran sus bases de datos, lo que frenaría su desarrollo.

\section{c) Información de Empleo}

En materia de información laboral en poder de las SIs, cabe mencionar que en los Estados Unidos, el FCRA establece reglas estrictas para la emisión de los reportes sobre consumidores con propósitos de empleo. El usuario del buró debe informar al consumidor que solicitará un reporte, para lo cual debe obtener la autorización por escrito del sujeto. La SI debe verificar que se cumpla lo anterior y debe obtener del usuario certificación de que la información no se usará en contravención de las leyes laborales. Antes de iniciar una acción en contra del consumidor, el usuario debe entregarle una copia del reporte y una descripción de sus derechos de acuerdo con el FCRA. Cuando la SI utilice información de registros públicos y esta información pudiera tener un efecto adverso sobre la posibilidad del sujeto para obtener empleo, la SI debe notificar al consumidor que va a elaborar un reporte y el nombre de la persona a quien le va a suministrar dicho reporte. 
Adicionalmente, cabe notar que en Canadá la PIPEDA no cubre bs archivos de empleo en manos de sector privado, ya que éstos son regulados por las provincias. ${ }^{53}$ Sin embargo, las SIs en Canadá, por ejemplo Equifax Canadá, recogen y reportan información de empleo. Esta última la obtienen sólo de las solicitudes de crédito, por lo que la información no se actualiza regularmente.

Por lo que toca a los países de América Latina, no existen ordenamientos que regulen el manejo de bases de datos personales con fines de empleo. Cabe destacar, que aún cuando la información de empleo no está regulada en Argentina, Chile y Perú, las SIs en estos países transmiten algunos datos de empleo. Por ejemplo, en Chile y Perú, existen SIs que ofrecen el servicio de registro de trabajos o de verificación de empleo. En Chile se constata la dirección laboral, el cargo y la antigüedad laboral del sujeto. En Perú se incluye información de empresas y de trabajadores dependientes e independientes. En ella se recogen datos del titular como sueldo, antigüedad, cargo y características de la empresa en donde trabaja o de la que es propietario (actividad económica, número de trabajadores, datos de inmueble, etc.) Además, si el sujeto es una persona independiente también se incluyen pagos de AFP, IPSS y la SUNAT, entre otros. La nueva ley que regula las Centrales de Información (julio de 2001) no regula la transmisión de datos relativos al empleo.

\section{d) Información Sensible}

Existe consenso entre los diversos países en cuanto a las restricciones al tratamiento a que debe estar sujeta la información sensible, entendiéndose por ésta aquélla que revele el origen racial y étnico, las opiniones políticas, las convicciones religiosas, filosóficas o morales, la afiliación sindical y la información referente a la salud o a la vida sexual. De acuerdo con los principios internacionales mencionados, en la mayoría de los países esta información sólo puede ser recolectada y transmitida con la autorización de la persona o bajo alguna instancia de ley específica.

\footnotetext{
${ }^{53}$ Bennet, Colin. "Bill C-6: Canada's Answer to Privacy Protection in the Private Sector", University of Victoria, 2001.
} 
La Unión Europea señala que se pueden tratar datos sensibles cuando el titular de los mismos haya otorgado consentimiento explícito. A manera de ilustración conviene mencionar lo establecido en la Constitución y en la ley de protección de datos de España. ${ }^{54}$ De acuerdo con esta ley, los datos de carácter personal que hagan referencia al origen racial, a la salud a la vida sexual sólo pueden ser recabados, tratados y cedidos cuando, por razones de interés general, así lo disponga una Ley o el afectado consienta expresamente. En el caso de los datos de carácter personal que revelen ideología, afiliación sindical, religión y creencias, el apartado 2 del artículo 16 de la Constitución, establece que nadie puede ser obligado a declarar al respecto y que al recabarse el consentimiento, el cual debe ser expreso y por escrito, se advertirá al interesado acerca de su derecho a no permitirlo. La ley prohibe además las bases de datos creadas con la finalidad exclusiva de almacenar datos de carácter personal que revelen la ideología, afiliación sindical, religión, creencias, origen racial o étnico y vida sexual. Se exceptúan de dicha prohibición las bases de datos que los partidos políticos, sindicatos, iglesias, comunidades religiosas y otras entidades no lucrativas y con finalidad política, filosófica, religiosa o sindical, tengan de sus miembros. No obstante, respecto de estas últimas, la cesión de los datos debe contar con el previo consentimiento del titular.

En España los datos de carácter personal sensible pueden ser objeto de tratamiento, cuando dicho tratamiento resulte necesario para la prevención y el diagnóstico médicos, la prestación de asistencia sanitaria o tratamientos médicos o la gestión de servicios sanitarios, siempre que dicho tratamiento de datos se realice por un profesional sanitario sujeto al secreto profesional o por otra persona sujeta asimismo a una obligación equivalente de secreto. En este sentido también es lícito el tratamiento de datos sensibles cuando ello sea necesario para salvaguardar el interés vital del afectado o de otra persona, en el supuesto de que el afectado esté física o jurídicamente incapacitado para dar su consentimiento.

En los Estados Unidos un reporte no puede contener información médica sobre el consumidor a menos de que éste otorgue su consentimiento, si el reporte es con propósitos

\footnotetext{
54 Artículo 7 de la Ley Orgánica de Protección de Datos de Carácter Personal 15/91999, de 13 de diciembre de 1999.
} 
de empleo o transacciones de crédito o seguro. El reporte sólo puede incluir información acerca del carácter, reputación, modo de vida y características personales del consumidor cuando se le informe claramente al consumidor que tal información se va a incluir, el alcance de dicho reporte y éste lo autorice. El sujeto debe recibir una copia del resumen de sus derechos. Además, la ley establece que al tomar la decisión de ofrecer un servicio o producto financiero, una institución financiera no puede obtener o recibir de un tercero afiliado o no-afiliado información de salud que identifique individualmente a un consumidor, excepto cuando la institución financiera ha requerido claramente el consentimiento expreso y afirmativo por escrito del titular de los datos y solicite esa misma información de salud a todos los consumidores como un requerimiento o condición para proveer el producto o servicio financiero correspondiente.

En Canadá existe actualmente un debate acerca de la aplicación de la PIPEDA (2000) relativa a instituciones de salud e información médica. Los partidarios de exceptuar la información de salud de la ley argumentan que el cuidado de la salud es una responsabilidad provincial. ${ }^{55}$ A este respecto, el Senado modificó recientemente la ley para darle al sector salud un año adicional para cumplir con la legislación.

La Ley de Protección de datos de Chile establece que los datos sensibles, incluyendo la información médica, pueden ser objeto de tratamiento solamente si existe consentimiento expreso y por escrito del titular. Asimismo, en dicho país los datos médicos se pueden tratar sin consentimiento si son necesarios para la determinación u otorgamiento de beneficios de salud que correspondan a sus titulares. En contraste en Argentina y Perú queda prohibida la formación de archivos, bancos o registros que almacenen información que directa o indirectamente revele datos sensibles. En Argentina se establece que los datos sensibles sólo pueden ser recolectados y ser objeto de tratamiento cuando medien razones de interés general autorizadas por ley o cuando sean tratados con finalidades estadísticas o científicas si no se identifica a sus titulares. Además, los datos personales relativos a la salud sólo se pueden ceder sin consentimiento si ello resulta necesario por

\footnotetext{
55 Diversas provincias, incluyendo Manitoba, Saskatchewan y Alberta, han aprobado legislación específica relacionada con a la información médica de los individuos.
} 
razones de salud pública, de emergencia o para la realización de estudios epidemiológicos. La Ley de las SIs de Perú no contiene excepciones, por lo que establece que dicha información no puede estar contenida en los bancos de datos de las CEPIRS ni ser difundida en sus reportes de crédito.

En Colombia, en sentencia constitucional se ha establecido que si un banco de datos, abusando de sus funciones, incluye entre la información sobre el deudor, datos que por su contenido pertenecen a la esfera íntima del individuo, la persona cuya intimidad se vulnera podrá exigir la exclusión de tales datos. Y si tal exclusión no se hace voluntariamente, solicitarla a los tribunales. 


\section{El Marco Institucional en los Países Analizados}

Las acciones de las autoridades deben encaminarse a propiciar que exista confianza del público en los controladores de datos y en las SIs, mediante la atención oportuna y eficaz de las quejas de los consumidores y la sanción de los incumplimientos.

En el presente capítulo se describe: (a) el tipo de autoridades que en cada país se encargan de vigilar, supervisar y reglamentar las cuestiones relacionadas con la protección de la información de las personas naturales; (b) las funciones que tienen encomendadas dichas autoridades; y (c) el papel que tiene el poder judicial en garantizar una aplicación efectiva de la ley.

En primer lugar, se describen los marcos institucionales de los Estados Unidos y de los países de la Unión Europea, los cuales si bien son muy distintos entre sí tienen en común el estar ampliamente desarrollados. Esta situación contrasta fuertemente con la de los países de América Latina, donde se tienen serias carencias institucionales.

\section{A. Comparación Internacional del Marco Institucional para la Protección de Datos Personales}

En los Estados Unidos intervienen numerosas autoridades en relación con la protección de datos personales. En el caso de la regulación del sistema financiero, diversas autoridades tienen jurisdicción dependiendo del tipo de institución de que se trate. Por otra parte, en cada uno de los países de la Unión Europea existe una autoridad nacional de control que tiene competencia sobre bases de datos públicas y privadas. Su responsabilidad es aplicar la ley nacional de protección de datos personales. Además, a nivel comunitario existe un cuerpo asesor y la Comisión Europea puede proponer disposiciones comunitarias en la materia apoyándose en un comité integrado por representantes de los países miembros. 


\section{Autoridades Administrativas en los Estados Unidos}

En los Estados Unidos no existe una autoridad de protección de datos contenidos en bases en poder del sector privado o del sector público. La aplicación de las leyes relacionadas con las bases de datos en poder del sector público tradicionalmente se ha delegado en los tribunales. Así, de acuerdo con el Freedom of Information Act (FOIA), cualquier queja o conflicto que surja en relación con el acceso a la información controlada por una autoridad será resuelto por la Corte de Distrito. No obstante ello, en las leyes en las que se regulan las bases de datos en poder del sector privado, se observa una clara tendencia a fortalecer el papel de las autoridades administrativas. Esto es lo que se desprende de las modificacione s al Fair Credit Reporting Act (FCRA) de 1997 y 1999 y con la expedición del GrammLeach-Bliley Act (1999) y del Financial Information Privacy Protection Act (2000). ${ }^{56}$ Con estas reformas legales, el legislador ha dado a las autoridades del Poder Ejecutivo facultades y obligaciones mayores en lo referente a: (i) la aplicación de estas leyes; (ii) la emisión de regulaciones complementarias; (iii) la evaluación del cumplimiento de las leyes; y (iv) la obligación de realizar estudios que permitan mejorar las disposiciones legales en el futuro. Asimismo, el legislador ha fortalecido las disposiciones para facilitar que la industria se autorregule.

En cuanto a las autoridades administrativas federales se refiere, destaca el papel que la Federal Trade Commission (FTC) tiene en relación con la aplicación del FCRA y cuyos objetivos son, por un lado, regular las SIs para su sano desarrollo y, por otro, proteger el uso de la información de los consumidores. La FTC atiende violaciones por parte de las SIs, de sus usuarios y de los proveedores de información. Cuenta con facultades para la resolución de quejas, para requerir la presentación de reportes y documentos e iniciar un juicio en una corte de distrito. Tiene asimismo importantes funciones de difusión y educación. La FTC debe emitir las regulaciones que sean necesarias para dar cumplimiento a sus atribuciones ${ }^{57}$.

\footnotetext{
${ }^{56}$ Las autoridades responsables de aplicar el Gramm-Leach-Bliley Act están especificadas en la sección 505 de esa Ley, párrafo 1, y concuerdan con lo establecido en el FCRA.

57 Específicamente, de acuerdo con el Federal Trade Commission Act, la FTC tiene como misión: (a) prevenir métodos injustos de competencia y actos o prácticas injustas o engañosas de o que afectan al
} 
También son responsables de aplicar el FCRA, el Gramm-Leach-Bliley Act y el Financial Information Privacy Protection Act, las autoridades federales financieras de acuerdo con la jurisdicción que tienen en las distintas leyes del sistema financiero. Para cumplir con los propósitos de dichas leyes, las autoridades financieras mencionadas deben emitir las regulaciones complementarias que sean necesarias. Las autoridades del sistema financiero deben consultarse y coordinarse entre ellas para asegurar que, en la medida de lo posible, las disposiciones secundarias que establezcan sean compatibles y similares. Adicionalmente, el Gramm-Leach-Bliley Act establece que el Secretario del Tesoro debe someter al Congreso un informe sobre el compartimiento de información entre instituciones financieras a más tardar el 1 de enero de 2002.

Por otra parte el FCRA, el Gramm-Leach-Bliley Act y el Financial Information Privacy Protection Act, dan a los gobiernos estatales facultades de procuración de justicia en estas materias. Dichas facultades consisten en realizar denuncias en una corte de distrito a favor de los residentes del estado con el fin de evitar una violación de las disposiciones y obtener el pago por daños y perjuicios. El estado debe avisar por anticipado a la FTC de las acciones que vaya a tomar, teniendo la FTC la facultad de intervenir, de ser escuchada en todas las cuestiones, de trasladar las acciones a una corte de distrito y de presentar recursos de apelación.

\section{Autoridades de Control en la Unión Europea}

Para la aplicación de la Directiva Europea de 1995, existen tres entidades. La primera, el Grupo de Protección a las Personas en lo que respecta al Tratamiento de Datos Personales, es un grupo asesor, a nivel de la Comunidad Europea, entre cuyas funciones está estudiar la aplicación de la Directiva en cada Estado Miembro y el nivel de protección ofrecido en terceros países. La segunda, es la Secretaría del Grupo de Protección, la cual ejecuta las tareas que le encomienda el Grupo. La Secretaría recae en la Comisión de la Comunidad

comercio; (b)procurar obtener compensación monetaria u otra reparación por conductas perjudiciales para los consumidores; (c) prescribir reglas que definan específicamente actos o prácticas que son injustas o engañosas y establecer requerimientos para prevenir tales actos o prácticas; (d) llevar a cabo investigaciones 
Europea y es asistida por un Comité de Representantes de los Estados Miembros. La tercera entidad formada por las Autoridades Nacionales de Control, están encargadas de vigilar en su territorio la aplicación de las leyes nacionales. Dichas autoridades nacionales ejercen sus funciones con plena independencia, elemento esencial del modelo europeo, ya que éstas también tienen amplias facultades en relación con bases de datos públicas. Las decisiones de las Autoridades Nacionales de Control pueden ser disputadas en los tribunales.

\section{Autoridad Administrativa Federal en Canadá}

En Canadá, la PIPEDA establece que la Oficina Federal del Comisionado de Privacidad (Federal Office of the Privacy Commissioner) es la autoridad encargada de aplicar dicha ley federal. La entidad se creó a finales de los años setenta para aplicar el Federal Privacy Act. El PIPEDA, al igual que el Privacy Act, sigue un modelo basado en la recepción y resolución de quejas y se apoya, sobretodo, en el proceso de mediación y conciliación. El Comisionado, por ende, tiene amplias facultades de investigación, tales como llamar a testigos a comparecer e investigar los locales de los negocios. También puede llevar a cabo auditorías de las prácticas de una organización y hacer recomendaciones. Aún cuando puede hacer públicas sus conclusiones, no tiene poder para forzar a las partes a obedecer. Por ello, debe solicitar a la corte federal que haga cumplir la ley, e imponer multas y reposición de daños. Además, puede llevar a cabo programas de difusión y educación en relación a la materia.

\section{Autoridades en los Países de América Latina}

En el caso de Chile los legisladores decidieron no crear una autoridad nacional de control ni asignar responsabilidades en lo referente a la aplicación de la ley a autoridad administrativa alguna $^{58}$. Al contrario de los modelos adoptados en los Estados Unidos, la Unión Europea

relacionadas con la organización, negocio, prácticas y la administración de entidades que se dedican al comercio; y (e) preparar reportes y recomendaciones legislativas al Congreso.

${ }^{58}$ De acuerdo con la Constitución de Chile, las personas pueden ocurrir a la Corte de Apelaciones respectiva, la que adoptará de inmediato las providencias que juzgue necesarias para restablecer el imperio del derecho y asegurar la debida protección del afectado en el caso de infracciones a derechos y garantías fundamentales (artículo 20). Tal es el caso del derecho de respeto y protección a la vida privada y pública y a la honra de la persona y su familia (artículo 19, 4º ), fundamento de la Ley de Protección de Datos de Carácter Personal de 1999. 
y Canadá, la ley chilena delega enteramente la responsabilidad de la aplicación de la ley de protección de datos en las instancias judiciales. Los jueces son responsables de tomar las providencias para hacer efectiva la protección de los derechos en la ley. Las acciones civiles tendientes a ejercer los derechos que la ley establece, incluida la indemnización por los perjuicios asociados a daños materiales o morales causados, se tramitan ante los tribunales de acuerdo con un procedimiento sumario. Las acciones penales se rigen por las reglas generales.

A diferencia de Chile, el diseño institucional en Argentina partió del adoptado por la Unión Europea. La Ley de Protección de los Datos Personales de 2000 creó el órgano de control que debe realizar todas las acciones necesarias para el cumplimiento de la misma. La ley otorga al órgano de control importantes atribuciones, las cuales tienen que ver con la protección de datos y con los burós de crédito. Sin embargo, no es claro que tenga todos los medios para cumplir efectivamente con dichas funciones. De hecho, de acuerdo con la ley, dicho órgano debió de haber sido establecido a los 180 días de la promulgación de la ley, pero ello no ocurrió como resultado de las dificultades de las finanzas públicas por las que atraviesa el país.

Las funciones del órgano de control argentino son: (i) asistir y asesorar a las personas que lo requieran acerca de los alcances de la ley y de los medios legales de que disponen para la defensa de los derechos que ésta garantiza; (ii) dictar normas y reglamentaciones; (iii) realizar un censo de archivos, registros o bancos de datos y mantener el registro permanente de los mismos; (iv) controlar la observancia de las normas sobre integridad y seguridad de datos; (v) solicitar información a las entidades públicas y privadas, las que deberán proporcionar los antecedentes, documentos, programas u otros elementos relativos al tratamiento de los datos personales que se le requieran; (vi) imponer sanciones; (vii) constituirse en querellante en las acciones penales que se promuevan por violaciones a la ley, y; (viii) controlar el cumplimiento de los requisitos y garantías que deben reunir los archivos o bancos de datos privados destinados a suministrar informes (es decir burós de crédito) para obtener la correspondiente inscripción en el Registro creado por la ley. 
En lo referente a la autorregulación, la ley argentina también está a la vanguardia. Permite que las asociaciones o entidades representativas de usuarios o responsables de bancos de datos de titularidad privada puedan elaborar códigos de conducta de práctica profesional, que establezcan normas para el tratamiento de datos personales que tiendan a asegurar y mejorar las condiciones de operación de los sistemas de información en función de los principios establecidos en la ley. Dichos códigos deben ser inscritos en el registro que al efecto administre el órgano de control, el cual puede denegar la inscripción cuando considere que los códigos no se ajustan a las disposiciones legales y reglamentarias sobre la materia.

Al promulgarse la ley, la Presidencia de la República vetó el texto por el que se otorgaba al órgano de control autonomía funcional como órgano descentralizado, en el ámbito del Ministerio de Justicia y Derechos Humanos de la Nación. En dicho texto se señalaba que el órgano debía ser dirigido y administrado por un director designado por cuatro años por el Poder Ejecutivo con acuerdo del Senado de la Nación. El veto presidencial, aunado al hecho de que el Director ahora puede ser removido por el Poder Ejecutivo cuando juzgue que el director tiene un "mal desempeño de sus funciones", debilita al órgano de control. Además, la ley no contempla una evaluación del órgano de control ni que éste tenga que rendir cuentas. Como consecuencia de lo anterior surgen dudas sobre las capacidades reales del órgano de control.

Cabe recordar que en Argentina el secreto bancario no se aplica a los créditos otorgados por las entidades financieras. Esta situación permite a la Central de Deudores del Sistema Financiero, que administra el Banco Central de la República Argentina, poner a disposición del público en general dicha información sin restricciones a través de su página en Internet (www.bcra.gov.ar). El acceso a la información de los deudores cumplidos, es decir, los que reciben clasificación 1 y 2, se puede obtener sólo de manera individual, mientras que el acceso a la base de datos de todos los deudores morosos, aquéllos con clasificación 3 a 6 , y a la base de datos de las personas inhabilitadas para operar con cuenta corriente bancaria por libramiento de cheques sin fondos, se encuentra disponible mensualmente en un 
compact disk a un costo de 10 dólares de los Estados Unidos. Las entidades financieras están obligadas a reportar mensualmente a todos sus deudores cuyo adeudo sea superior a los 50 dólares de los Estados Unidos, por lo que esta base de datos es muy amplia. El banco central utiliza también esta información con fines de análisis de concentración de riesgos, de supervisión de las carteras crediticias de las entidades, así como para evaluar el cumplimiento de las reglas prudenciales y de clasificación de créditos de las mismas. Si bien existen alegatos de competencia desleal, junto con esta central de deudores, coexisten más de 100 burós de cámaras de comercio regionales y tres burós de crédito nacionales privados asociados con burós de crédito de los Estados Unidos.

En Perú, de acuerdo con la Ley que Regula las CEPIRS, el Instituto Nacional de Defensa de la Competencia y de la Protección de la Propiedad Intelectual (INDECOPI), a través de la Comisión de Protección al Consumidor, es el órgano administrativo competente para conocer de las infracciones tipificadas (cuando una SI negara el acceso a un reporte o la revisión ante una reclamación y rehusara hacer la modificación o cancelación de la información cuando así se haya resuelto) e imponer las sanciones administrativas y las medidas correctivas a las que hubiere lugar. La Superintendencia de Banca y Seguros tiene a su cargo la Central de Riesgos Pública.

El marco institucional en Brasil es similar al de Perú, dado que el Departamento de Protección y Defensa del Consumidor (DPDC) de la Secretaría de Derecho Económico del Ministerio de Justicia tiene diversas facultades en la materia. Destaca entre dichas facultades la de mantener registros actualizados de las reclamaciones fundamentadas contra las SIs, debiendo hacerlos públicos anualmente. La divulgación indica si el reclamo fue atendido o no por el proveedor. Adicionalmente, a partir de $1997^{59}$ aplica las sanciones administrativas a aquéllos que: i) impidan o dificulten el acceso gratuito del consumidor a información sobre su persona en bases de datos, así como a sus respectivas fuentes; ii) elaboren bases de datos de consumidores con datos irreales o inexactos; iii) mantengan bases de datos con información negativa por un periodo mas largo que el establecido; y iv)

\footnotetext{
59 Son atribuciones que recibe el Departamento de Protección y Defensa del Consumidor en el Decreto No. 2.181 del 20 de marzo de 1997.
} 
dejen de corregir, inmediatamente y gratuitamente, la inexactitud de los datos en bases de datos cuando el consumidor lo solicite.

Por otra parte, a partir de 1997 el Banco Central de Brasil es responsable de administrar la Central de Riesgo de Créditos, en la cual se inscriben cada mes los créditos mayores que $\$ 25,900$ dólares de los Estados Unidos otorgados por instituciones financieras ${ }^{60}$ a consumidores y personas morales. Debido al elevado monto a partir del cual los créditos se deben registrar, sólo un porcentaje pequeño de los mismos queda incluido en esta base de datos. Las informaciones consolidadas por cliente pueden ser consultadas por las instituciones financieras una vez que obtienen autorización específica del cliente. Esta central también es utilizada por el Banco Central como instrumento de supervisión de las instituciones financieras.

En México intervienen cuatro autoridades distintas solamente en lo referente a la regulación y supervisión de los burós de crédito. La Secretaría de Hacienda y Crédito Público es responsable de autorizar la constitución de estas SIs de objeto limitado y de decidir quienes pueden ser usuarios de sus servicios de información, así como de determinar las cuotas que por inspección y vigilancia deben cubrir a la Comisión Nacional Bancaria y de Valores. El Banco de México es competente para regular sus actividades y determinar las remuneraciones correspondientes a la prestación de sus servicios. También tiene la facultad de solicitarles todo tipo de información. La Comisión Nacional Bancaria y de Valores las supervisa y tiene la facultad de sancionar a los usuarios financieros que no recaban la autorización del consumidor antes de hacer consultas a la SI. Finalmente compete a la Comisión Nacional para la Protección y Defensa de los Usuarios de Servicios Financieros atender y, en su caso, resolver las quejas de las personas en contra de estas SIs.

El Banco de México también es responsable, desde 1954, de administrar la central de riesgos que se denomina Servicio Nacional de Información de Crédito Bancario (Senicreb).

\footnotetext{
60 Incluye información tanto positiva como negativa de bancos múltiples, bancos comerciales, cajas económicas, bancos de inversión bancos de desarrollo, sociedades de crédito inmobiliario, sociedades de crédito, financiamiento e inversión, compañías hipotecarias, agencias de fomento y sociedades de arrendamiento mercantil.
} 
El Senicreb procesa información de créditos vigentes y vencidos de empresas y personas físicas con actividad empresarial mayores que 20 mil dólares. El Senicreb fue utilizado en los años setenta y ochenta para evaluar si estas instituciones cumplían con los cajones obligatorios de crédito, es decir, si satisfacían los porcentajes requeridos de asignación de créditos al sector industrial y al sector comercio. En la década de los noventa Senicreb fue utilizado como un buró de crédito de objeto limitado, dado que su base de datos nunca ha incluido información de adeudos de personas físicas ni las bases de datos de oferentes de crédito no financieros. Hoy en día la operación del Senicreb es marginal toda vez que no existe obligación de consultarlo y los bancos prefieren hacer las consultas a su propio buró de crédito.

En Colombia, al no contarse con una ley de protección de datos, las quejas o acciones de los particulares en contra de los burós de crédito se atienden mediante la acción de Habeas Data ante los tribunales. La Corte Constitucional ha asumido un papel crucial al ir resolviendo las controversias e interpretando y desarrollando las regulaciones principales en esta materia conforme va dictando sentencias, con lo que se ha creado jurisprudencia. Al igual que en Chile, en el caso de que resultara vulnerado el derecho de Habeas Data por cualquier autoridad pública o por particulares, el individuo puede efectuar la acción de "tutela" a través de un procedimiento preferente y sumario ante los tribunales. En elCuadro 12 se resumen las características de los marcos institucionales de los distintos países analizados. 


\section{Cuadro 10 \\ Marco Institucional}

\begin{tabular}{|c|c|c|c|}
\hline & $\begin{array}{c}\text { Autoridad } \\
\text { Independiente de } \\
\text { Protección de } \\
\text { Datos } \\
\end{array}$ & $\begin{array}{l}\text { Autoridades no especializadas con } \\
\text { competencia en la materia de protección } \\
\text { de datos y SIs }\end{array}$ & $\begin{array}{c}\text { Poder Judicial } \\
\text { Acción de Habeas } \\
\text { Data }\end{array}$ \\
\hline Argentina & Organo de Control & -- & $\begin{array}{l}\text { Juzgado local o } \\
\text { federal dependiendo } \\
\text { del caso }\end{array}$ \\
\hline Brasil & -- & $\begin{array}{c}\text { Departamento de Protección y Defensa del } \\
\text { Consumidor } \\
\text { Banco Central }\end{array}$ & $\begin{array}{c}\text { Juzgado Civil } \\
\text { depende de quien sea } \\
\text { el demandado }\end{array}$ \\
\hline Chile & -- & -- & Juzgado Civil \\
\hline Colombia & -- & Superintendencia Bancaria & Juzgado Civil \\
\hline México & -- & $\begin{array}{c}\text { Secretaría de Hacienda y Crédito Público, } \\
\text { Banco de México, Comisión Nacional Bancaria y } \\
\text { de Valores, Comisión Nacional de Defensa de los } \\
\text { Usuarios de Servicios Financieros, } \\
\text { Procuraduría Federal del Consumidor. }\end{array}$ & Juzgado Civil o Penal \\
\hline Perú & - & $\begin{array}{c}\text { La Comisión de Protección al Consumidor del } \\
\text { Instituto Nacional de Defensa de la Competencia } \\
\text { y de la Protección de la Propiedad } \\
\text { Superintendencia de Banca y Seguros }\end{array}$ & Juzgado Civil \\
\hline $\begin{array}{l}\text { Estados } \\
\text { Unidos }\end{array}$ & -- & $\begin{array}{l}\text { Federal Trade Commission, } \\
\text { Autoridades Financieras y } \\
\text { Otras Autoridades Sectoriales }\end{array}$ & Corte de Distrito $^{3}$ \\
\hline Canadá & -- & Office of the Federal Privacy Commissioner & Corte \\
\hline $\begin{array}{l}\text { Unión } \\
\text { Europea }\end{array}$ & $\begin{array}{l}\text { Autoridades } \\
\text { Nacionales de } \\
\text { Control }\end{array}$ & & Autoridad Judicial \\
\hline
\end{tabular}

\section{B. Análisis de las Responsabilidades de las Autoridades Administrativas}

Es conveniente dividir las responsabilidades y atribuciones de las autoridades administrativas en tres categorías: la responsabilidad de vigilar la aplicación de las disposiciones legales en la materia; la facultad regulatoria; y la obligación de presentar informes y rendir cuentas. 


\section{Vigilar la Aplicación de la Ley}

La responsabilidad de vigilar la aplicación de la ley incluye: recibir y resolver quejas; obtener acceso a datos o reportes de los controladores de datos; llevar a cabo u ordenar que se efectúen auditorías a controladores de datos; tener la facultad de demandar en juicio a controladores de datos que incumplan con las disposiciones en materia de protección de datos; tener la facultad de sancionar o imponer remedios en caso de que los controladores de datos incumplan las disposiciones; y dar a conocer al público en general las disposiciones legales que existan en la materia.

\section{a) Resolución de quejas}

La resolución de quejas es un elemento central para la protección de datos personales. Sin embargo, puede ser un proceso muy costoso en términos de tiempo y dinero para las autoridades responsables de aplicar la legislación de protección de datos. Por ello, el diseño de una política para el procesamiento de quejas es importante. Bajo los principios de la Asociación Canadiense de Estándares, incorporados en la PIPEDA, los controladores de datos deben designar a un individuo o individuos responsables del cumplimiento de las directrices, los cuales deben recibir las quejas de las personas. Este principio es conveniente aplicarlo a todo controlador de datos incluyendo el sector público.

\section{b) Acceso a datos o reportes}

Esta facultad es útil para que las autoridades responsables puedan realizar investigaciones cuando no existe una queja formal de un individuo. Dar esta atribución a las autoridades puede ayudarlas a cumplir con otros objetivos, como son los de supervisión en el sector financiero o el combate a la evasión fiscal.

\section{c) Efectuar u ordenar auditorías}

Las auditorías a los controladores de bases de datos pueden ser un mecanismo eficaz para incentivarlos a cumplir con la regulación establecida. Las auditorías son más sistemáticas y de mayor alcance que la investigación de una queja específica. 


\section{d) Iniciar juicios}

Es conveniente que los consumidores y las autoridades de control puedan detonar el inicio de juicios sumarios ante los tribunales por supuestos incumplimientos de los controladores de datos.

\section{e) Sanciones y remedios}

Siempre va a existir la necesidad de incluir en la legislación sanciones pecuniarias para hacer cumplir las normas. En adición a éstas, es conveniente promover que el mercado castigue a aquellas empresas que no proporcionan una protección adecuada a los datos de sus consumidores. Este sería el caso si se establece la obligación de que ciertas empresas obtengan una certificación de parte de terceros de que cumplen con las disposiciones o los estándares establecidos. La publicación por parte de la autoridad de información relativa a cuales empresas cumplen con la certificación anterior puede ser un aliciente para que éstas acaten las regulaciones. Por otra parte, también parece ser necesario que las autoridades tengan la facultad de imponer remedios a los controladores de datos, como ordenarles que modifiquen sus prácticas en cuanto al tratamiento de datos personales.

\section{f) Difusión y educación de los consumidores}

La difusión y educación de los consumidores son factores importantes que contribuyen a un mejor cumplimiento de las disposiciones legales. Es fundamental para el consumidor conocer cuales son sus derechos y qué puede hacer para corregir errores en bases de datos, agregar o, en su caso, borrar información de las mismas, etc. Por ello, conviene que las autoridades tengan una política de difusión que haga más comprensible los objetivos y funciones de las SIs y que se combatan ideas como la de que las SIs son sólo listas negras o culpables del no otorgamiento de crédito. Además, las autoridades deben dar a conocer procedimientos simples para que el consumidor pueda ejercer sus derechos. La educación del público en materia de privacidad puede evitar muchos conflictos e incentivar a los consumidores a protegerse. Adicionalmente, es deseable que la autoridad mantenga informado al público del posible impacto sobre su privacidad derivado del uso de nuevas prácticas o tecnologías. 


\section{Facultades Regulatorias de la Autoridad Administrativa}

En cuanto a las facultades regulatorias se refiere, es importante distinguir entre la facultad de las autoridades de control para emitir regulaciones secundarias en la materia y la facultad de examinar y aprobar códigos o estándares de protección desarrollados por la industria.

\section{a) Facultad para interpretar y emitir regulaciones secundarias que faciliten la aplicación de la ley}

El dotar a las autoridades de control de facultades para emitir disposiciones secundarias permite a éstas interpretar las disposiciones legales según las condiciones particulares que se van presentando. Esto es especialmente importante en el caso de los países de América Latina analizados, debido a que éstos cuentan con relativamente poca experiencia en la materia y es difícil pensar que desde un inicio se puedan establecer regulaciones tan detalladas como las contenidas en las leyes de los Estados Unidos. No obstante estas ventajas, debe tomarse en cuenta que de otorgarse mucha discrecionalidad regulatoria a las autoridades en la materia se corre el riesgo de que éstas sobre o sub regulen o bien que establezcan regulaciones que se aparten del espíritu de la ley.

\section{b) Examinar y aprobar códigos o estándares de la industria}

En el futuro es probable que los códigos operativos o estándares desarrollados por las industrias para el manejo de las bases de datos sean elementos importantes de las políticas de protección de privacidad. Es conveniente que las autoridades de control los aprueben, ya que los códigos o estándares pudieran contener provisiones no compatibles con la ley. No obstante lo anterior, es aconsejable evitar procesos formales de aprobación que sean lentos y burocráticos. A este respecto, es importante concebir la regulación como un estándar mínimo de protección al consumidor, el cual debe ser cumplido cabalmente en todo momento, permitiendo que los estándares industriales ofrezcan mayor protección y beneficios a los consumidores. 


\section{Rendición de Cuentas}

Una autoridad de protección de datos independiente debe tener la obligación de rendir cuentas, de tal manera que la sociedad pueda evaluar su desempeño. Si bien esta obligación puede implicar ciertos costos, permite obtener importantes beneficios. Al explicar la labor que desempeña, la autoridad se gana la confianza y el respaldo de la sociedad, lo cual aumenta la eficacia de sus acciones.

\section{Comparación de las Responsabilidades de las Autoridades Administrativas}

Como se desprende del siguiente cuadro, el marco institucional es el rubro en el que se observa quizás el mayor atraso en los países de América Latina. Las autoridades de control tanto de los Estados Unidos como de la Unión Europea tienen responsabilidades y facultades significativamente mayores que las asignadas a las autoridades de los países de América Latina, con la excepción del órgano de control de Argentina el cual, sin embargo, ha enfrentado enormes problemas para su constitución. Ello probablemente obedece a razones tales como la poca experiencia que existe sobre la materia en la región, así como a la carencia estructural de recursos que caracteriza a los gobiernos de América Latina, lo cual dificulta crear y mantener instituciones sólidas. Conviene recordar que las constituciones de algunos de estos países al igual que en los Estados Unidos y Canadá dan una preeminencia a los tribunales, ya que a través de éstos es como el individuo lleva a cabo la acción de Habeas Data. 


\section{Cuadro 11}

\section{Responsabilidades y Facultades de las Autoridades Administrativas con}

Respecto a los Burós de Crédito

\begin{tabular}{|l|c|c|c|c|c|c|c|c|c|}
\hline & Argentina & Brasil & Chile & $\begin{array}{c}\text { Colombi } \\
\mathbf{a}\end{array}$ & $\begin{array}{c}\text { Méxi } \\
\text { co }\end{array}$ & $\begin{array}{c}\text { Perú } \\
\text { Estado } \\
\text { s } \\
\text { Unidos }\end{array}$ & $\begin{array}{c}\text { Canad } \\
\text { á }\end{array}$ & $\begin{array}{c}\text { Unión } \\
\text { Europea }\end{array}$ \\
\hline $\begin{array}{l}\text { Vigilar la aplicación de la } \\
\text { regulación }\end{array}$ & & & & & & & & & \\
\hline Recibir y resolver quejas & NO & SI & NO & NO & NO & NO & SI & SI & SI \\
\hline $\begin{array}{l}\text { Acceso a datos para } \\
\text { verificar el cumplimiento } \\
\text { de las disposiciones en la } \\
\text { materia }\end{array}$ & SI & NO & NO & NO & NO & NO & SI & SI & SI \\
\hline $\begin{array}{l}\text { Efectuar u ordenar } \\
\text { auditorías a controladores } \\
\text { de datos }\end{array}$ & SI & NO & NO & NO & NO & NO & NO & SI & SI \\
\hline Iniciar juicios & SI & SI & NO & NO & NO & NO & SI & SI & SI \\
\hline Sanciones y remedios & SI & SI & NO & NO & SI & NO & NO & SI & SI \\
\hline Difusión, educación & NO & NO & NO & NO & NO & NO & SI & SI & SI \\
\hline Facultades regulatorias & & & & & & & & & \\
\hline $\begin{array}{l}\text { Organo regulatorio o de } \\
\text { consulta }\end{array}$ & SI & NO & NO & SI & SI & SI & SI & NO & SI \\
\hline $\begin{array}{l}\text { Exámen o aprobación de } \\
\text { códigos o estándares }\end{array}$ & SI & NO & NO & NO & NO & NO & SI & NO & SI \\
\hline $\begin{array}{l}\text { Obligación de presentar } \\
\text { informe de actividades }\end{array}$ & NO & NO & NO & NO & NO & NO & SI & SI & SI \\
\hline
\end{tabular}

De establecerse autoridades de protección de datos y si regulan las bases de datos del sector privado y público, es importante que sean independientes. Lo anterior para evitar que el gobierno pueda obtener un acceso indebido a los datos de las personas, así como para que pueda resolver controversias e imponer sanciones a entidades del sector público. Las funciones de esta autoridad especializada debieran ser: i) supervisar la aplicación de la ley (recibir y resolver quejas, llevar a cabo investigaciones, iniciar juicios, imponer remedios y sanciones, llevar a cabo políticas de difusión y educación de consumidores, controladores de datos y usuarios, etc.); ii) facultades regulatorias (interpretar la regulación, emitir disposiciones secundarias, examinar y aprobar códigos desarrollados por la industria, etc.); y iii) rendir cuentas y presentar informes de actividades periódicamente. 


\section{Recomendaciones}

Este estudio ha permitido identificar una serie de recomendaciones para proteger los datos personales, promover el flujo de información y desarrollar el mercado de las SIs en países de América Latina.

\section{A. Recomendaciones sobre la Protección de Datos Personales}

Conviene que los países de América Latina cuenten con un marco general para la protección de datos y el desarrollo de las SIs que incorpore los principios internacionales que norman la protección de los datos personales (OCDE, ONU, Consejo Europeo, etc.). De acuerdo con estos principios el ámbito de la regulación debe ser el tratamiento de datos personales por parte de todo controlador de datos, tanto en el sector privado como en el sector público. Es recomendable que incluya la regulación que propicie el desarrollo de SIs. Los objetivos de este marco legal deben ser la protección de datos personales, el apoyo al comercio y el mejor funcionamiento de los mercados a través de promover el flujo de información. Al limitar la recolección y transmisión de datos sensibles de las personas se logra un objetivo adicional, evitar la discriminación entre individuos.

En cuanto a los principios de protección de datos personales, destacan: (i) los diversos derechos que debe tener el individuo, en cuanto a conocer, obtener y disputar la información sobre su persona en poder de los controladores de datos; (ii) los límites a la recolección, uso y retención de datos; y (iii) las obligaciones de los controladores de datos en cuanto a especificar el fin del tratamiento, mantener la calidad de la información (exacta y actualizada), adoptar medidas de seguridad pertinentes y ser responsable de los datos bajo su control.

La regulación del secreto bancario que en algunos países de América Latina protege la información de los depositantes, ahorradores e inversionistas (Argentina, Chile, Perú) y que en otros cubre también la información de los deudores de la banca (Brasil y México), ha 
generado diversos problemas. En primer lugar, la distinción entre información bancaria activa (créditos) y pasiva (depósitos) no es muy útil para otorgarles un nivel de protección diferente. Por ejemplo, la información crediticia que permite reconstruir los patrones de consumo detallados de los individuos probablemente debiera recibir un nivel de protección similar al aplicado a la información pasiva.

La regulación del secreto bancario ha ocasionado otros importantes problemas. Por ejemplo, en Argentina y Perú la información crediticia no está sujeta al secreto bancario, por lo cual se considera erróneamente que dicha información es pública y, por tanto, no sujeta a las disposiciones de protección de datos personales. En el caso de Chile la información crediticia negativa se trata como información pública, mientras que la información crediticia positiva recibe una protección tal que ni siquiera las SIs están facultadas para tratar dicha información, lo que innecesariamente reduce el valor de sus servicios y aumenta el riesgo en el otorgamiento de crédito en la economía. Si bien en Chile esta situación se subsana parcialmente, toda vez que existe un acuerdo para compartir información crediticia positiva entre los bancos, un otorgante no bancario de crédito al consumo cuenta con menos información que un banco al decidir otorgar crédito. En Brasil y México el secreto bancario es tan amplio que estos países se han visto en la necesidad de establecer diversas y cada vez mayores excepciones al secreto bancario, en lo que a la información crediticia se refiere, con el fin de relajar las excesivas restricciones al flujo de esta información en la economía. En Brasil a partir de 2001 se permite la transmisión de información crediticia libremente entre bancos. Esta disposición facilita el flujo de información pero sólo entre un reducido grupo de otorgantes de crédito, situación similar a la que existe en Chile. Como consecuencia de ello, los otorgantes de crédito no bancarios cuentan con menos información que los bancos al otorgar crédito al consumo. Por ende, la competencia en este mercado es desigual.

Un modelo basado en la regulación de la protección y transmisión de los datos financieros personales que no están públicamente disponibles, como es el caso en los Estados Unidos, es una mejor alternativa que la regulación actual basada en la distinción entre información bancaria activa y pasiva. Para la información financiera podrían contemplarse dos niveles 
de protección. La información con mayor protección sería la referente a los depósitos, ahorros y patrones de gasto de los individuos. La protección de esta información pudiera ser similar a la protección de la información que generalmente se considera sensible, la cual sólo se puede transmitir con el consentimiento previo y expreso del individuo. Para la transmisión de otra información financiera y, en general, de información no sensible del individuo, se podría establecer un número de "propósitos permisibles" al estilo de la regulación de los Estados Unidos. Este modelo de regulación embonaría bien en una ley general de protección de datos.

En los últimos años, las SIs de varios países de América Latina han empezado a incorporar en sus bases de datos información relativa a incumplimientos con el fisco. Para poder transmitir esta información a las SIs y que éstas la incluyan en sus reportes, diversos países de América Latina han estado reformando el llamado secreto fiscal. En Chile, Brasil y Perú el secreto fiscal ya no incluye a las deudas exigibles de los contribuyentes morosos, por lo que esta información es pública, e incluso está disponible en Internet. En México el secreto fiscal también se ha hecho menos estricto recientemente, ya que el Código Fiscal fue reformado, para permitir que la información sobre las obligaciones fiscales exigibles de los contribuyentes pueda ser proporcionada a las SIs, y para que éstas la incluyan en sus reportes. En los Estados Unidos, la información sobre deudores fiscales sentenciados por los tribunales es información pública y las SIs la han venido recopilando desde hace muchos años.

No obstante las ventajas que tiene la incorporación de los incumplimientos fiscales en las bases de datos de las SIs, pues permite a las SIs contar con información más completa y ofrecer mejores servicios a la vez que incentiva a las personas a cumplir con sus obligaciones fiscales, no es claro que el fisco deba tener acceso irrestricto a información en las bases de datos de las SIs para llevar a cabo una política de fiscalización agresiva. A consecuencia de ello, las personas pudieran recurrir a canales de crédito informales que no compartan sus bases de datos con las SIs, lo que daría lugar a una intermediación financiera menos eficiente. 
Ante la falta de experiencia de América Latina en materia de protección de datos y desarrollo de SIs, en un inicio es probable que las regulaciones de protección de datos personales y de SIs sean generales. Conviene permitir a la iniciativa privada promover el desarrollo de estándares adicionales adaptados a la industria, para así brindar una mayor seguridad a los consumidores, pero sin que ello restrinja el flujo de información en la economía. En la etapa inicial los principios generales de protección juegan un papel fundamental para adecuar y homologar regulaciones que muchas veces se encuentran dispersas. No obstante, es previsible que en el futuro los códigos operativos o estándares desarrollados por la iniciativa privada sobre el manejo de bases de datos sean elementos importantes que contribuyan al desarrollo del marco jurídico.

El diseño institucional debe incluir las herramientas administrativas y judiciales necesarias para que los individuos puedan ejercer sus derechos y tengan acceso a su información de una manera simple y expedita, que no sea indebidamente onerosa para los consumidores y para los controladores de datos. En cuanto a los instrumentos judiciales, existen importantes avances en este sentido. Los individuos en los países de América Latina analizados, con excepción de México, tienen derecho a la acción de Habeas Data, es decir a un proceso judicial breve para resolver controversias sobre los datos que se refieren a su persona.

Si bien existe una gran variedad de modelos administrativos posibles para la efectiva aplicación de las disposiciones en materia de protección de datos personales y fomento de las SIs, resulta conveniente crear una autoridad administrativa especializada, particularmente en aquellos países que no cuenten con experiencia en la materia. Las restricciones presupuestales que enfrentan los países de América Latina dificultan la asignación de recursos públicos para estos fines. Por ello, es indispensable el uso eficiente de dichos recursos. La existencia de una autoridad administrativa tiene diversas ventajas: reduce la carga a los tribunales; facilita una aplicación homogénea de la ley a distintos sectores; realiza una labor de difusión de la ley ante la sociedad; y le da confianza de que las protecciones establecidas se van a respetar. La autoridad debiera ser el vehículo para llevar a cabo las importantes funciones de difusión y educación en la materia, 
principalmente para orientar al consumidor y dar a conocer que las SIs y los burós de crédito no son listas negras, sino que tienen la valiosa función de apoyar a los consumidores cumplidos.

De establecerse dicha autoridad, es importante que tenga un elevado nivel de independencia y que quede sujeta a una completa rendición de cuentas ante la sociedad. La independencia es deseable para evitar que el gobierno pueda obtener un acceso indebido a los datos de las personas, así como para que la autoridad controladora pueda de facto resolver controversias y sancionar las infracciones de las entidades del sector público.

Las funciones de la autoridad de control serían: i) supervisar la aplicación de la ley (recibir $\mathrm{y}$ resolver quejas, llevar a cabo investigaciones, iniciar juicios, imponer remedios y sanciones, llevar a cabo políticas de difusión y educación de consumidores, controladores de datos y usuarios, etc.); ii) ejercer sus facultades regulatorias (interpretar la regulación, emitir disposiciones secundarias, examinar y aprobar códigos desarrollados por la industria, etc.); y iii) rendir cuentas y presentar informes de actividades periódicamente.

\section{B. Recomendaciones para Facilitar el Desarrollo de Sociedades de Información}

El objetivo principal de las SIs es facilitar las transacciones en la economía. Ello al fomentar la transparencia en los mercados mediante la provisión de información oportuna, veraz y estandarizada. Dadas las dificultades que algunos países de América Latina han tenido para que se desarrolle un mercado competitivo de SIs, conviene evaluar las medidas que se requieren para facilitar el desarrollo de estas empresas, entre las cuales destacan:

\section{Promover la competencia en el mercado de las SIs}

En algunos países de América Latina los bancos han formado sus propias SIs. Si bien esto se ha debido en parte a la ausencia de un marco regulatorio general que proteja los datos personales y estimule el desarrollo de las SIs independientes, ello ha impedido que se desarrolle una sana competencia entre las SIs. Usualmente, ha tenido lugar una integración vertical de dichos bancos en una sola SI, lo cual les permite a los bancos mantener el 
control de la información crediticia en la economía y crear una barrera de entrada a posibles competidores. Los bancos que son dueños de la SI dominante discriminan en contra de otras SIs al no compartir con ellas sus bases de datos, lo que les impide a las segundas conformar bases de datos con las cuales puedan ofrecer servicios competitivos. El desarrollo del mercado de las SIs se ve adversamente afectado también por la percepción de que las políticas de la SI dominante favorecen a sus dueños. Como consecuencia de lo anterior, la SI dominante generalmente cuenta con poca información y presta servicios limitados y de baja calidad. Para contrarrestar la monopolización del mercado de las SIs, lo más recomendable es obligar a los bancos a vender su participación accionaria en la sociedad así como establecer esquemas de reventa de reportes entre las SIs. La viabilidad económica de la reventa de reportes entre las SIs depende de que se establezcan tarifas que no sean mayores que las tarifas más bajas que las SIs ofrecen a sus usuarios y se cuente con un mecanismo de supervisión efectivo.

\section{Acceso al mayor universo de datos personales posible}

Para que puedan ofrecer servicios de mayor valor es indispensable que las SIs tengan acceso a información de los individuos en poder de los sectores público y privado. En este sentido es importante evitar que las SIs sean reguladas por leyes sectoriales. Esta situación acotaría innecesariamente el ámbito de la información que pueden tratar las SIs, lo que reduciría la calidad de los servicios prestados y, además, el interés de los agentes privados por invertir y establecer este tipo de empresas. Asimismo, conviene que las SIs puedan transmitir reportes con diversos fines (crédito, seguro, empleo, etc.).

\section{Promover el flujo de información respetando la privacidad}

El tener que contar con la autorización de los consumidores para que las SIs recolecten la información no sensible de las personas limitaría indebidamente la capacidad de las SIs para conformar bases de datos y ofrecer sus servicios. Lo que efectivamente garantiza que no se de un mal uso a la información no pública de las personas que recolectan las SIs, es que éstas sólo transmitan datos personales a terceros en los términos establecidos en la ley. Asimismo, una persona que solicita a una empresa un bien o servicio que conlleva una 
transacción de crédito o seguro está implícitamente autorizando a que esta empresa pueda evaluar si es un sujeto confiable de recibir crédito.

\section{Esquema de sanciones adecuado para las SIs y sus usuarios}

Es conveniente que el marco legal contemple sanciones tanto para las SIs como para sus usuarios en caso de que incumplan lo prescrito. Deben existir sanciones impuestas por la autoridad ya sea que la infracción fuera o no intencional, pues en ambos casos el incumplimiento por parte de la SI o sus usuarios puede ocasionar daño al individuo. Asimismo, las personas que como consecuencia del incumplimiento de lo dispuesto en la ley sufran daño o lesión en sus bienes o derechos, deben tener el derecho a ser indemnizados de acuerdo con lo que establezca el juez. El nivel que se fije en la ley para las sanciones es importante. Las sanciones elevadas como las establecidas en la ley de España pudieran inhibir el desarrollo de las SIs. Las sanciones no deben ser tan grandes que desincentiven la inversión y el desarrollo de las SIs así como el tratamiento de información personal por cualquier controlador de datos personales. 


\section{Referencias}

Argentina, “Constitución Nacional”, 22 de agosto de 1994.

Argentina, "Ley No. 21.526, Ley de Entidades Financieras, Título V”, 21 de febrero de 1977.

Argentina, "Ley 25.326. Ley de Protección de Datos Personales”, 4 de octubre de 2000.

Argentina, "Ley Procedimiento Tributario", 1998 (modificado por el Decreto 821/98, Anexo I, de fecha 13/7/98 (B.O. 20/7/98), con las modificaciones introducidas por el Decreto $\mathrm{N}^{\circ} 1.334 / 98$ y por el Decreto 290 de la Ley 25239 de diciembre de 1999).

Argentina, “Anteproyecto de Código Tributario”, 1999.

Barron, John y Michael Staten "The Value of Comprehensive Credit Reports: Lessons from the US experience", presentado en la Conferencia Internacional de Sistemas de Reportes de Crédito organizada por el Banco Mundial, junio 2000.

Brasil, "Constituição Federal”, 1988.

Brasil, "Decreto No. 2.181, Código de Proteção e Defesa do Consumidor", 20 de Marzo de 1997.

Brasil, "Lei No. 4.595”, 1964.

Brasil, "Lei No. 5.172, Dispõe sobre o Sistema Tributário Nacional e Institui Gerais de Dereito Tributário Aplicáveis a União, Estados e Municipios", 25 de octubre de 1966.

Brasil, "Lei Ordinaria No. 9.507 Regula o Direito de Acceso a la Informações e Disciplina o rito processual do Habeas Data", 12 de noviembre de 1997.

Brasil, "Ley Complementaria No. 105, Disposiciones sobre el secreto de las operaciones de instituciones financieras y de otras providencias", 10 de enero de 2001.

Brasil, "Resolução do Banco Central do Brasil No. 1682”, 31 de enero de 1990.

Brasil, “Resolução do Banco Central do Brasil No. 2.390”, 22 de mayo de 1997.

Cepeda Espinosa, Manuel José. "Concepto sobre la divulgación de información sobre el desempeño de los contribuyentes y de las empresas cotizantes”, Colombia.

Canadá, "An Act to support and promote electronic commerce by protecting personal information that is collected, used or disclosed in certain circumstances, by providing for 
the use of electronic means to communicate or record information or transactions and by amending the Canada Evidence Act, the Statutory Instruments Act and the Statute Revision Act", 13 de abril de 2000

Canadá, Asociación Canadiense de Estándares, "Model Code for the Protection of Personal Data", marzo 1996.

Chile, "Constitución Política de la República de Chile”, 1980 (reformada en el 2001).

Chile, "Decreto Legislativo 830, Código Tributario", 1974 (reformado el 29 de julio de 1998).

Chile, "Ley General de Bancos, Decreto Federal Legislativo 252, Título XVI y Decreto Legislativo 1.097”, diciembre 1997.

Chile , “Ley 19496, Ley de Protección al Consumidor”, 1997.

Chile, Ley 19628, "Ley de Protección de Datos de Carácter Personal”, 28 de agosto de 1999.

Colombia, "Circular Externa 07, Título Primero, Capítulo Primero Numeral 4.1, Superintendencia Bancaria”, 1996.

Colombia, “Constitución Política de la República de Colombia”, 1991.

Colombia, "Ley 510, Ley por la cual se dictan disposiciones en relación con el sistema financiero y asegurador, el mercado público de valores, la Superintendencia Bancaria y de Valores y conceden algunas facultades", 13 de agosto de 1999.

Colombia, "Ley 546”, 1999.

Colombia, "Sentencia No. SU-082/95, Corte Constitucional”, 1995.

Colombia, "Sentencia No. SU-089/95, Corte Constitucional”, 1995.

Colombia, "Sentencia No. T-094/95, Corte Constitucional", 1995.

Consejo Europeo, "Convención para la Protección de los individuos con relación al procesamiento automatizado de Datos Personales", 1981.

Consejo Europeo, "Directiva 95/46/CE del Parlamento Europeo y del Consejo de 24 de octubre de 1995 relativa a la protección de las personas físicas en lo que respecta al tratamiento de datos personales y a la libre circulación de estos datos".

España, “Ley 50, Ley General de Impuestos”, 1977. 
España, "Ley Orgánica 15/91999, Protección de datos de carácter personal”, 13 de diciembre de 1999.

Estados Unidos, "Freedom of Information Act, 5 U.S.C. § 552", 1966 (reformada en 2 de enero de 1991).

Estados Unidos, "Fair Credit Reporting Act”, 30 de Septiembre de 1997.

Estados Unidos, "Constitution of the United States and Amendments".

Estados Unidos, “Gramm-Leach-Bliley Act”, 1999.

Estados Unidos, "Financial Information Privacy Protection Act”, 2000.

México, "Código Fiscal Art.69, 63”, 31 de diciembre de 1981 (última reforma diciembre de 2000).

Jappelli, Tulio, "Credit bureaus: effects on market performance and the role of government intervention" mimeo presentado en el Workshop "The role of timely and reliable information in the development of stable financial markets", World Bank and BCRA, Buenos Aires, Argentina, 1997.

México, “Constitución Política de los Estados Unidos Mexicanos”, 1917.

México, "Disposiciones de carácter general a las que sujetarán las Sociedades de Información Crediticia para proporcionar su base de datos a otras Sociedades de Información Crediticia”, Banco de México, 27 de diciembre de 1996.

México, “Ley de Instituciones de Crédito Título VI, Art. 117”, 18 de julio de 1990 (última reforma 17 de mayo de 1999).

México, "Ley para Regular las Agrupaciones Financieras, Artículo 33”, 18 de julio de 1990 (artículo 33 fue reformado el 23 de julio de 1993, última reforma de la ley 19 de enero de 1999).

México, "Ley del Mercado de Valores Art. 25, 72", 2 de enero de 1975 (última reforma 17 de mayo de 1999).

México, "Reglas Generales a que deberán sujetarse las sociedades de información crediticia a que se refiere el artículo 33 de la Ley para Regular las Agrupaciones Financieras", Secretaría de Hacienda y Crédito Público, 15 de febrero de 1995 (reformadas en septiembre y diciembre 1997).

Naciones Unidas, Secretaría General, "Guidelines for the regulation of computerized personal data files", A/RES/45/95 junta plenaria 68, 14 de diciembre de 1990. 
Neil, Andrea. "Report to the World Bank on the Legal Requirements to establish a Central Information Exchange Directory for Argentina", enero 1998.

Perú, “Circular NB 1931-92, Superintendencia de Banca y Seguros”, diciembre 1992.

Perú, “Constitución Política del Perú”, 1993.

Perú, "Decreto Legislativo 716, Ley de Protección al Consumidor", 9 de noviembre de 1991.

Perú, “Decreto Legislativo 816, Código Fiscal, Libro Segundo, Título II”, 20 de abril 1996.

Perú, “Ley No.0416, Ley que regula las Centrales de Información,” 7 de junio de 2001.

Perú, “Ley No. 26301, Procedimiento del Habeas Data”, 2 de mayo de 1994.

Perú, "Ley No. 26702, Ley General del Sistema Financiero y del Sistema de Seguros y Orgánica de la Superintendencia de Banca y Seguros, Sección Segunda, Capítulo II y Capítulo IV”, 6/ de diciembre de 1996 (reformada 6 de mayo de 1999).

Unión Europea, "Directiva 95/46/CE del Parlamento Europeo y del Consejo Relativa a la protección de las personas físicas en lo que respecta al tratamiento de datos personales y a la libre circulación de estos datos", 24 de octubre de 1995.

Unión Europea, "Directive 97/66/EC of the European Parliament and of the Council Concerning the processing of personal data and the protection of privacy in the telecommunications sector", 15 December 1997. 


\section{Anexo \\ Argentina}

FUNDAMENTOS CONSTITUCIONALES

\begin{tabular}{|l|l|l|}
\hline DERECHO A LA PRIVACIDAD & DERECHO DE INFORMAR & $\begin{array}{l}\text { DERECHO A SER INFORMADO Y A RECTIFICAR } \\
\text { SU INORMACIÓN Y EL DERECHO DE ACCION } \\
\text { DE HABEAS DATA }\end{array}$ \\
\hline $\begin{array}{l}\text { Art. 19.- Las acciones privadas de los } \\
\text { hombres que de ningún modo ofendan al } \\
\text { orden y a la moral pública, ni perjudiquen a } \\
\text { un tercero, ...están exentas de la autoridad de } \\
\text { los magistrados. }\end{array}$ & $\begin{array}{l}\text { Art. 14.- Todos los habitantes gozan de los siguientes } \\
\text { derechos:...; de publicar sus ideas por la prensa sin } \\
\text { censura previa; ...de profesar libremente su culto;... }\end{array}$ & $\begin{array}{l}\text { Art. } \\
\text { servicios tienen derecho, en la relación de consumo, a } \\
\text { una información adecuada y veraz; }\end{array}$ \\
$\begin{array}{l}\text { Art. 42.- Los consumidores y usuarios de } \\
\text { bienes y servicios tienen derecho, en la } \\
\text { relación de consumo, a la protección de su } \\
\text { salud, seguridad e intereses económicos; }\end{array}$ & $\begin{array}{l}\text { Art. 43.- Toda persona podrá interponer acción de } \\
\text { amparo para tomar conocimiento de los datos a ella } \\
\text { referidos y de su finalidad, que consten en registros o } \\
\text { bancos de datos públicos, o los privados destinados a } \\
\text { proveer informes, en caso de falsedad o discriminación, } \\
\text { para exigir la supresión, rectificación, confidencialidad } \\
\text { o actualización de aquéllos. }\end{array}$ \\
\hline
\end{tabular}

\section{PRINCIPAL REGULACIÓN EN LA MATERIA}

\section{REGULACION}

Ley 25..326, Ley de Protección de Datos

Personales, Octubre 4 de 2000.

OBJETIVOS DE LA REGULACION

El objetivo de la Ley de Protección de los Datos Personales es:

La protección integral de los datos personales asentados en archivos, registros, bancos de datos, $\mathrm{u}$ otros medios técnicos de procesamiento de datos, sean éstos públicos, o privados destinados a dar informes, para garantizar el derecho al honor y a la intimidad de las personas, así como también el acceso a la información que sobre las mismas se registre de conformidad con lo establecido en el artículo 43, párrafo tercero de la Constitución Nacional.

\section{AMBITO DE LA REGULACION}

La Ley de Protección de Datos Personales es una ley nacional que regula el tratamiento de datos personales asentados en archivos, registros o bancos de datos, sean estos públicos, o privados destinados a proveer informes.

Por archivo, registro o banco de datos se entiende indistintamente, al conjunto organizado de datos personales que sean objeto de tratamiento o procesamiento, electrónico o no, cualquiera que fuere la modalidad de su formación, almacenamiento, organización o acceso.

Aplica tanto a los datos relativos a personas físicas como, en cuanto resulte pertinente, a los datos relativos a personas de "existencia ideal", es decir personas morales. 


\begin{tabular}{|l|l|l|}
\hline & & $\begin{array}{l}\text { La ley no aplica a las encuestas de opinión, mediciones } \\
\text { y estadísticas exoneradas conforme a la ley 17.622, } \\
\text { trabajos de prospección de mercados, investigaciones } \\
\text { científicas y médicas y actividades análogas, en la } \\
\text { medida en que los datos recogidos no puedan atribuirse } \\
\text { a una persona determinada o determinable. }\end{array}$ \\
\hline
\end{tabular}

INFORMACIÓN TRATADA POR LOS BURÓS DE CRÉDITO

TIPO DE INFORMACION TRATADA POR BURÓS

La Ley de Protección de Datos Personales se aplica al procesamiento (cualquier operación automatizada o no) de datos personales tanto de personas físicas como de personas morales. Se distinguen los siguientes tipos de datos personales:

Datos personales: Información de cualquier tipo referida a personas físicas o de existencia ideal determinadas o determinables (art. 2).

Datos sensibles: Datos personales que revelan origen racial y étnico, opiniones políticas, convicciones religiosas, filosóficas o morales, afiliación sindical e información referente a la salud o a la vida sexual.

Ninguna persona puede ser obligada a proporcionar datos sensibles. Los datos sensibles sólo pueden ser recolectados y objeto de tratamiento cuando medien razones de interés general autorizadas por ley o con finalidades estadísticas y científicas cuando no puedan ser identificados sus titulares.

Queda prohibida la formación de archivos, bancos o registros que almacenen información que directa o indirectamente revele datos sensibles, se exceptúan la Iglesia Católica, las asociaciones religiosas y las organizaciones políticas y sindicales (art.7).

\section{Datos relativos a la salud (art. 8)}

Los establecimientos sanitarios públicos o privados y los profesionales vinculados a la ciencias de la salud pueden recolectar y tratar los datos personales relativos a la salud física o mental de los pacientes que acudan a los mismos o que estén o hubieren estado bajo tratamiento de aquéllos, respetando los principios del secreto profesional.

No se exige consentimiento del titular para ceder datos de salud cuando sea

\section{SECRETO BANCARIO}

Ley de Entidades Financieras (Ley

No. 21.526)

21/02/77

título $V$, Art. $39-40$

El artículo 39 establece que las

entidades financieras no podrán

revelar las operaciones pasivas que

realicen.

Se exceptúan de tal deber los

informes que requieran:

Los jueces en causas judiciales

El Banco Central de la

República Argentina (BCRA) y

la Superintendencia de

Entidades Financieras y

Cambiarias

Organismos recaudadores de

impuestos nacionales,

provinciales o municipales

Las propias entidades para casos especiales autorizados por el

BCRA.

En el artículo 40 se establece que la información que reciba o recoja el BCRA, en ejercicio de sus funciones, vinculadas
Argentina

SECRETO FISCAL

La Ley 11.683, Ley Procedimiento

Tributario

(texto ordenado en 1998)

En el Artículo 101 se establece que el secreto Fiscal abarca:

-las declaraciones juradas, manifestaciones e informes que los responsables o terceros presentan a la Administración Federal de Ingresos Públicos (AFIP)

- y los juicios de demanda contenciosa en cuanto consignen dichas informaciones.

Los magistrados, funcionarios y empleados de la AFIP están obligados a mantener el secreto sin poder comunicarlo a persona, ni aun a solicitud del interesado, salvo a sus superiores jerárquicos.

El secreto no abarcará:

- Para el supuesto que, por desconocerse el domicilio del responsable, sea necesario recurrir a la notificación por edictos;

Para los organismos recaudadores siempre que las informaciones respectivas estén directamente vinculadas con la aplicación, percepción y fiscalización de los gravámenes; 
necesario por razones de salud pública, de emergencia o para la realización de estudios epidemiológicos, en tanto se preserve la identidad de los titulares de los datos mediante mecanismos de disociación adecuados.

Datos de carácter patrimonial (información crediticia) (art. 26)

En la prestación de servicios de información crediticia sólo pueden tratarse datos personales de carácter patrimonial relativos a la solvencia económica y al crédito, obtenidos de fuentes accesibles al público o procedentes de informaciones facilitadas por el interesado o con su consentimiento.

Pueden tratarse igualmente datos personales relativos al cumplimiento o incumplimiento de obligaciones de contenido patrimonial, facilitados por el acreedor o por quien actúe por su cuenta o interés.

Datos relativos a antecedentes penales o contravencionales (art.7)

Sólo pueden ser objeto de tratamiento por parte de las autoridades públicas competentes, en el marco de las leyes y reglamentaciones respectivas.

Quedan sujetos al régimen de la Ley los datos personales que por haberse almacenado para fines administrativos, deban ser objeto de registro permanente en los bancos de datos de las fuerzas armadas, organismos policiales o de inteligencia y aquéllos que fueron proporcionados a las autoridades administrativas y judiciales que lo requieran en virtud de disposiciones legales. (art.23) operaciones pasivas tendrá carácter estrictamente confidencial. El personal del banco, así como el personal que éste contrate para auditorías externas, deberá guardar dicha reserva.

\section{DERECHOS DE LOS CONSUMIDORES RESPECTO A SU INFORMACIÓN}

\begin{abstract}
- Para las empresas o entidades a quienes la AFIP haya encargado tareas administrativas, relevamientos de estadística y procesamiento de información. En estos casos, se les aplicará a dichas empresas lo referente al secreto fiscal.
\end{abstract}

En 1999 la AFIP presentó un Anteproyecto de Código Tributario. En dicho anteproyecto se relajaba el secreto fiscal al establecer en su artículo 29 que el secreto fiscal no alcanzaría las infracciones o incumplimientos de las obligaciones fiscales o tributarias detectadas mediante ejercicio de las facultades de verificación, fiscalización e investigación de la Autoridad Tributaria.

No obstante, hasta la fecha, el Código Tributario no ha sido promulgado, por lo que el secreto fiscal aún cubre las infracciones o incumplimientos de las obligaciones fiscales o tributarias.

Argentina

\section{En la Ley de Protección de Datos (2000) se establece:}

\section{Derecho de acceso de los cons umidores a información de su persona}

Toda persona puede solicitar información a la autoridad responsables de aplicar la ley relativa a la existencia de archivos, registros, bases o bancos de datos personales, sus finalidades y la identidad de sus responsables. El registro que se lleve al efecto será de consulta pública y gratuita. (art 13)

El titular de los datos, previa acreditación de su identidad, tiene derecho a solicitar y obtener información de sus datos personales incluidos en los bancos de datos públicos, o privados destinados a proveer informes. El responsable o usuario debe proporcionar la información solicitada dentro de los 10 días corridos de haber sido intimado fehacientemente. Vencido el plazo sin que se satisfaga el pedido, o si evacuado el informe, éste se estimara insuficiente, quedará expedita la acción de protección de los datos personales o de Habeas Data. (art.14)

El derecho de acceso sólo puede ser ejercido en forma gratuita a intervalos no inferiores a 6 meses, salvo que se acredite un interés legítimo al efecto. (art. 14) La información debe ser suministrada en forma clara, exenta de codificaciones y en su caso acompañada de una explicación, en lenguaje accesible al conocimiento medio de la población, de los términos que se utilicen. La información debe ser amplia y versar sobre la totalidad del registro perteneciente al titular, aun cuando el requerimiento sólo comprenda un aspecto de los datos personales. En ningún caso el informe podrá revelar datos pertenecientes a terceros, aun cuando se vinculen con el interesado. (art.15)

\section{Rectificación de información. (art.16)}



que sea titular, que estén incluidos en un banco de datos. El responsable o usuario del banco de datos, debe proceder a la rectificación, supresión o actualización de los datos personales del afectado, realizando las operaciones necesarias a tal fin en el plazo máximo de cinco días hábiles de recibido el reclamo del titular de los datos o advertido el error o falsedad. Durante el proceso de verificación y rectificación, el responsable o usuario del banco de datos deberá o bien bloquear el archivo, o consignar al proveer información relativa al mismo la circunstancia de que se encuentra sometida a revisión.

En el supuesto de cesión, o transferencia de datos, el responsable o usuario del banco de datos debe notificar la rectificación o supresión al cesionario dentro del $5^{\circ}$ día hábil de efectuado el tratamiento del dato.

La supresión no procede cuando pudiese causar perjuicios a derechos o intereses legítimos de terceros, o cuando existiera una obligación legal de conservar los datos.

La rectificación, actualización o supresión de datos personales inexactos o incompletos se debe efectuar sin cargo alguno para el sujeto investigado.

\section{Derecho de Acción de Protección de Datos (Capítulo VII)}

En adición a los derechos de acceso, rectificación, actualización y supresión que tiene el titular de los datos frente a los bancos de datos públicos, o privados destinados a dar informes, la ley contempla el derecho de ejercer la acción judicial de protección de datos o Habeas Data. Esta acción procede para tomar conocimiento de los datos personales almacenados en los bancos de datos o para exigir su rectificación, supresión, confidencialidad o actualización, después de que se exhaustó la vía administrativa. Dicha acción puede ser ejercida por el afectado, sus tutores y los sucesores de la persona física, por sí o por intermedio de apoderado y, en caso de ser persona ideal, por los representantes legales. La competencia para entender de la acción es el poder judicial.

La acción de Habeas Data se tramitará según las disposiciones de la Ley de Protección de Datos y por el procedimiento que corresponda a la acción de amparo común.

\section{Excepciones (art.17)}

Los responsables o usuarios de bancos públicos pueden, mediante decisión fundada, denegar el acceso, rectificación o supresión en función de la protección de la defensa de la Nación, del orden y la seguridad públicos, o de la protección de los derechos e intereses de terceros. La información sobre datos personales también puede ser denegada por los responsables de datos públicos cuando de tal modo pudieran obstaculizar actuaciones judiciales o administrativas en curso vinculadas a la investigación sobre el cumplimiento de obligaciones tributarias, el desarrollo de control de la salud o medio ambiente, la investigación de delitos penales y la verificación de infracciones administrativas.

Sin perjuicio de lo establecido, se deberá brindar acceso a los registros en cuestión en la oportunidad de que el afectado tenga que ejercer su derecho de defensa.

\section{Conocer de las SIs quien ha recibido reportes con información de su persona}

Los datos personales objeto de tratamiento sólo pueden ser cedidos para el cumplimiento de los fines directamente relacionados con el interés legítimo del cedente, del cesionario y con el previo consentimiento de titular de los datos, al que se le debe de informar sobre la finalidad de la cesión e identificar al cesionario o los elementos que le permitan hacerlo.

Con relación a la prestación de servicios de información crediticia, dado que en ciertas circunstancias no se requiere de previo consentimiento del titular de los datos, se establece que a solicitud de éste último, el responsable o usuario del banco de datos, le comunicará las informaciones, evaluaciones, y apreciaciones que sobre el mismo hayan sido comunicadas durante los últimos 6 meses y el nombre y domicilio del cesionario en el supuesto de datos obtenidos por cesión.

\section{Derecho a ser excluido de listados de ofertas}

El sujeto investigado podrá en cualquier momento solicitar el retiro o bloqueo de su nombre de los bancos de datos que tengan como finalidad: la recopilación de domicilios, reparto de documentos, publicidad o venta directa y otras actividades análogas. 
REGULACIÓN DE LOS BURÓS DE CRÉDITO Y AGENCIAS DE INFORMACIÓN (CONTROLADORES DE DATOS)

\begin{tabular}{|c|c|}
\hline $\begin{array}{c}\text { INICIO DE } \\
\text { OPERACIONES }\end{array}$ & \\
\hline $\begin{array}{l}\text { Inicio de Operaciones } \\
\text { 1.Todo archivo, registro, } \\
\text { base o banco de datos } \\
\text { público, y privado } \\
\text { destinado a proporcionar } \\
\text { informes debe inscribirse } \\
\text { en el Registro que al efecto } \\
\text { habilite el Organismo de } \\
\text { Control. } \\
\text { 2.El registro de archivos } \\
\text { de datos debe comprender } \\
\text { como mínimo la siguiente } \\
\text { información: } \\
\text { i. Nombre y domicilio } \\
\text { del responsable; } \\
\text { ii. Características } \\
\text { finalidad del archivo; } \\
\text { iii. Naturaleza de los datos } \\
\text { personales contenidos } \\
\text { en cada archivo; } \\
\text { iv. Forma de recolección } \\
\text { y actualización de } \\
\text { datos; } \\
\text { v. Destino de los datos y } \\
\text { personas físicas o de } \\
\text { existencia ideal a las } \\
\text { que pueden ser } \\
\text { transmitidos; } \\
\text { vi. Modo de } \\
\text { interrelacionar } \\
\text { información la } \\
\text { registrada; } \\
\text { vii. Medios utilizados para } \\
\text { garantizar la seguridad } \\
\text { de los datos, debiendo }\end{array}$ & 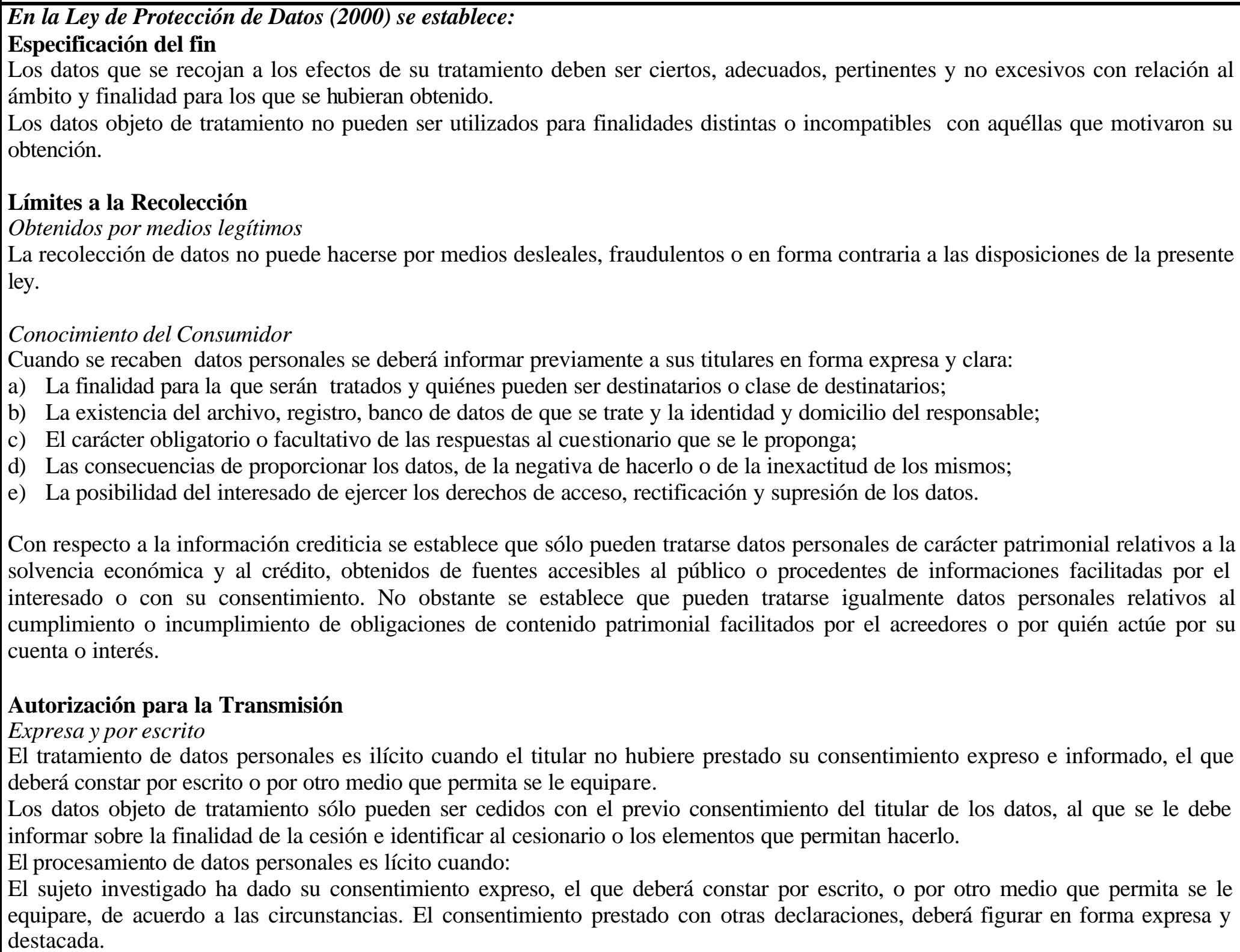 \\
\hline
\end{tabular}


detallar la categoría de

personas con acceso al tratamiento

viii. Tiempo

conservación de los

datos;

ix. Forma y condiciones en que las personas pueden acceder a los datos referidos a ellas y los procedimientos a realizar para la rectificación actualización de los datos.
No es necesario el consentimiento cuando:

a) Los datos se obtengan de fuentes accesibles al público;

b) Se recaben para el ejercicio de funciones propias de poderes del Estado;

c) Se trate de listados cuyos datos se limiten a nombre, documento nacional de identidad, identificación tributaria, ocupación, fecha de nacimiento, domicilio y número de teléfono.

d) Se trate de operaciones que realicen las entidades financieras y de las informaciones que reciban de sus clientes respetando el secreto bancario (art. 39 de la Ley 21.526)

La prestación de servicios de información crediticia no requeriría el previo consentimiento del titular de los datos a efectos de su cesión, ni ulterior comunicación de ésta, cuando estén relacionados con el giro de las actividades comerciales o crediticias de los cesionarios.

Implícita en transacciones iniciadas por el consumidor

No es necesario el consentimiento cuando los datos deriven de una relación contractual, científica o profesional del titular de los datos, y resulten necesarios para su desarrollo o cumplimiento.

Tampoco se necesita consentimiento para la cesión de datos personales cuando se realice entre dependencias de los órganos de Estado en forma directa, en la medida del cumplimiento de sus respectivas competencias, y cuando se traten de datos relativos a la salud y sea necesario por razones de salud pública emergencia o para estudios epidemiológicos.

\section{Límites al plazo de retención de los datos}

Los datos deben ser destruidos cuando hayan dejado de ser necesarios o pertinentes a los fines para los cuales hubiesen sido recolectados.

Para la prestación de servicios de información crediticia, sólo se podrán archivar, registrar o ceder los datos personales que sean significativos para evaluar la solvencia económico-financiera de los afectados durante los últimos 5 años. Dicho plazo se reduce a 2 años cuando el deudor cancele o de otro modo extinga la obligación, debiéndose hacer constar dicho hecho.

\section{Calidad de los datos}

Los datos deben ser exactos y actualizarse en caso de que ello fuera necesario.

Los datos total o parcialmente inexactos, o que sean incompletos, deben ser suprimidos, o en su caso completados por el responsable del archivo o base de datos, sin perjuicio de los derechos de rectificación y corrección establecidos en la ley.

\section{Regulación de Seguridad}

El responsable o usuario del archivo de datos debe adoptar las medidas técnicas y organizativas que resulten necesarias para garantizar la seguridad y confidencialidad de los datos personales, de modo de evitar su adulteración, pérdida, consulta o tratamiento no autorizado, y que permitan detectar desviaciones, intencionales o no, de información, ya sea que los riesgos provengan de la acción humana o del medio técnico utilizado.

Queda prohibido registrar datos personales en archivos, registros o bancos que no reúnan condiciones técnicas de integridad y 


\section{Responsabilidad del controlador}

Obligado al secreto profesional. Asimismo, debe atender a las solicitudes de los titulares de los datos, debe prever las medidas de seguridad y puede ser sancionado en caso de daños y perjuicios por la inobservancia de la ley.

El obligado puede ser relevado del deber del secreto por resolución judicial y cuando medien razones fundadas relativas a la seguridad pública, la defensa nacional o la salud pública.

El cesionario de los datos, es decir, el que los recibe, queda sujeto a las mismas obligaciones legales y reglamentarias del cedente y éste responderá solidaria y conjuntamente por la observancia de las mismas ante el organismo de control y el titular de los datos de que se trate.

\section{Sanciones}

Sin perjuicio de la responsabilidad por daños y perjuicios derivados de la inobservancia de la ley, y de las sanciones penales que correspondan, el organismo de control podrá aplicar las sanciones de apercibimientos, suspensión, multa de mil pesos a cien mil pesos, clausura o cancelación del archivo, registro o banco de datos.

También se observan sanciones penales como la pena de prisión de hasta 3 años cuando se inserte o proporcione a sabiendas información falsa. Dicho tiempo se puede aumentar si del hecho se derive perjuicio a alguna persona. Adicionalmente, también hay encarcelamiento si ilegítimamente se accede a un banco de datos personales. 


\section{Autoridades Administrativas}

Organo de Control.

La autoridad encargada de aplicar la ley es el Organo de Control, el cual depende del Poder Ejecutivo nacional. El Poder Ejecutivo nacional está encargado de reglamentar la ley , así como de establecer el Organo de Control. Dicho Organo debió de ser establecido a los ciento ochenta días de la promulgación de la ley; no obstante, a la fecha no lo ha establecido como resultado de las dificultades económicas por las que atraviesa el país.

Facultades y Responsabilidades:

- Asistir y asesorar a las personas acerca de los alcances de la ley y de los medios legales de que disponen para la defensa de los derechos que garantiza;

- Dictar las normas y reglamentaciones que se deberán observar en el desarrollo de las actividades comprendidas por la ley;

-Realizar un censo de archivos, registros o bancos de datos, y mantener registro permanente de los mismos. Toda persona puede solicitar al Organo de Control información sobre la existencia de los bancos de datos, sus finalidades y los responsables del mismo. Dicha consulta debe ser pública y gratuita.

-Controlar las normas sobre integridad y seguridad de los datos;

-Solicitar información a las entidades públicas o privadas, garantizando la seguridad y confidencialidad de la información y elementos suministrados.

-Imponer las sanciones administrativas que en su caso correspondan.

-Constituirse en querellante en las acciones penales que surjan por la violación de la ley;

-Vigilar el cumplimiento de los requisitos que deben cumplir los bancos de datos privados destinados a dar informes;

-Llevar un registro para inscribir los códigos de conducta de práctica profesional que les presente las asociaciones o entidades representativas o usuarios de bancos de datos de titularidad privada. El Organo de Control puede denegar la inscripción cuando considere que no se ajustan a las disposiciones legales y reglamentarias sobre la materia.

El director tendrá dedicación exclus iva en su función, encontrándose alcanzado por las incompatibilidades fijadas por ley para los funcionarios públicos y podrá ser removido por el Poder Ejecutivo por el mal desempeño de sus funciones.

\section{Autoridad Judicial}

Para que las personas puedan tomar conocimiento de sus datos personales y exigir la rectificación o supresión de los mismos, se ejerce la acción de Habeas Data ante los juzgados civiles.

Es competente para entender esta acción: el juez del domicilio del demandante; el del domicilio del demandado; el del lugar en el que el hecho o acto se exteriorice. Procede la competencia federal cuando la acción se interpone en contra de un archivo de datos públicos de organismos nacionales y cuando los archivos de datos se encuentren interconectados en redes interjurisdiccionales, nacionales o internacionales.

\section{Autorregulación}

Códigos de conducta:

Las asociaciones o entidades representativas de responsables o usuarios de bancos de datos de titularidad privada pueden elaborar códigos de conducta de práctica profesional, que establezcan normas para el tratamiento de datos personales que tiendan a asegurar y mejorar las condiciones de operación de los sistemas de información en función de los principios establecidos en la presente ley.

Dichos códigos deben ser inscritos en el registro que al efecto lleve el organismo de control, quien podrá denegar la inscripción cuando considere que no se ajustan a las disposiciones legales y reglamentarias sobre la materia. 
La primera organización dedicada al intercambio de información sobre consumidores se fundó en 1957.

A partir de 1994, el Banco Central de la República Argentina administra un buró de crédito el cual procesa dos bases de datos. Una es la "Central de Deudores del Sistema Financiero" y otra es la "Base de Cuenta Correntistas Inhabilitados".

Además existen burós nacionales como:

Veraz-Equifax (existe desde 1957, y desde 1994 reporta tanto información positiva como negativa),

Fidelitas-Experian, Dil (empresa argentina que desde 1974 produce Informes Comerciales)

Dun \& Bradstreet Argentina.

Además existen 110 burós de crédito privados regionales, los cuales se encuentran dispersos en todo el país y en general fueron creados por las cámaras de comercio del lugar.

\section{TIPOS DE SERVICIOS}

El buró de crédito del banco central administra dos bases de datos, la "Central de Deudores del Sistema Financiero" establecida mediante Comunicación "A 2729-293" y la "Base de Cuenta Correntistas Inhabilitados", regulada en la OPASI 2. La consulta de ambas bases de datos es posible vía Internet en la direccion www.bcra.gov.ar y mediante la venta de compact disk en forma mensual.

La Central de Deudores incluye a todos los deudores (personas físicas y/o morales) con deudas superiores a $\$ 50$ dólares de los Estados Unidos. Se informan dos tipos de cartera de clientes (deudas mayores a US\$200.000 se las identifica como cartera comercial, y el resto se lo considera cartera de consumo o vivienda). Las deudas se informan discriminadas por rubro y clasificadas según tipo de garantía. La información incluye una categorización de 1 hasta 6 , en donde se establece un número que marca el grado de calidad del riesgo, que en la cartera de consumos se marca según los días de atraso, y en la cartera comercial según criterios de evaluación preestablecidos por el BCRA. Por ejemplo: 1 normal, 2 con riesgo potencial (más de 31 días de atraso y hasta 90), 3 con problemas (entre 91 y 181 días de atraso), 4 con alto grado de insolvencia (entre 181 y 360 días de atraso), 5 irrecuperable (mas de un año de atraso), y 6) Irrecuperable por disposición técnica (más de 181 días de atraso en ex-entidades financieras).

Vía Internet cualquier persona puede acceder a la base del BCRA (www.bcra.gov.ar) para realizar consultas puntuales e individuales referidas a cualquier deudor, sin ningún tipo de restricciones y sin necesidad de identificación. Además, el BCRA suministra al publico un CD por \$10 dólares de los Estados Unidos con la ultima información disponible referida a:

1) clientes con deudas mayores a $\$ 50$ y que durante los últimos 24 meses haya estado alguna vez en situación crítica, o sea 3,4,5, ó 6 .

2) clientes que alguna vez en los últimos 24 meses hayan tenido deudas mayores a $\$ 200.000$, cualquiera que sea su situación.

En dichos CD se identifica al deudor y al acreedor, y se informa el monto de la calificación o deuda (el mayor), que el titular tiene en cada entidad, así como la clasificación otorgada por cada entidad y si hay o no garantía.

Burós Privados: También existe una gran diversidad de servicios que ofrecen los burós de crédito como: identificación de fraude de solicitudes de crédito, información sobre domicilios y teléfonos registrados, y sobre deudores en mora, reportes de evaluación de crédito, comerciales, pre-laborales y laborales, de antecedentes negativos legales, bancarios y comerciales, situación de cuentas por cobrar, listados para marketing, etc. 


\section{Anexo \\ Brasil}

FUNDAMENTOS CONSTITUCIONALES

\begin{tabular}{|l|l|l|}
\hline \multicolumn{1}{|c|}{$\begin{array}{c}\text { DERECHO A LA } \\
\text { PRIVACIDAD }\end{array}$} & \multicolumn{1}{|c|}{ DERECHO DE INFORMAR } & $\begin{array}{l}\text { DERECHO A SER INFORMADO Y A RECTIFICAR SU INFORMACIÓN Y EL DERECHO } \\
\text { DE ACCION DE HABEAS DATA }\end{array}$ \\
\hline $\begin{array}{l}\text { Art. 5, X.- Son inviolables la } \\
\text { intimidad, la vida privada, el } \\
\text { honor y la imagen de las } \\
\text { personas, asegurándose el } \\
\text { derecho a indemnización por } \\
\text { el daño material o moral } \\
\text { derivado de su violación; }\end{array}$ & $\begin{array}{l}\text { Art. 5, IV IX.- Es libre la } \\
\text { manifestación del pensamiento y y }\end{array}$ & $\begin{array}{l}\text { Art. 5 XIV.- Queda garantizado a todos el acceso a la información y salvaguardado el secreto } \\
\text { de las fuentes cuando sea necesario para el ejercicio profesional; }\end{array}$ \\
$\begin{array}{ll}\text { comunicación, sin censura ni de la actividad.. de } \\
\text { licencia. }\end{array}$ & $\begin{array}{l}\text { XXXIII.- Todos tendrán derecho a recibir de los órganos públicos informaciones de su interés } \\
\text { particular, o de interés colectivo o general, que serán entregadas en los términos que } \\
\text { establezca la ley.. }\end{array}$ \\
& $\begin{array}{l}\text { LXXII.- Se concederá acción de amparo (Habeas Data): } \\
\text { a) para asegurar el conocimiento de informaciones relativas a la persona del solicitante que } \\
\text { consten en registros o bancos de datos de entidades gubernamentales o de carácter público; } \\
\text { b) para la rectificación de datos, cuando no se prefiera hacerlo por procedimiento secreto, } \\
\text { judicial o administrativo; }\end{array}$ \\
\hline
\end{tabular}

\section{PRINCIPAL REGULACIÓN EN LA MATERIA}

\section{REGULACIÓN}

Lei No. 8.159 del 8 de enero de 1991 Disposiciones sobre la política nacional de archivos públicos y privados y de otras providencias

\section{Lei Ordinaria 9.507}

Regula el derecho de Acceso a Información y Disciplina el Proceso de Habeas Data. 12 de noviembre de 1997

Artículo 43 del Código de Protecao e Defesa do Consumidor, Decreto No. 2181

\section{OBJETIVOS DE LA REGULACIÓN}

Regula el tratamiento de archivos públicos, y de los privados identificados por el Poder Público como de interés público y social (por ejemplo, de fuentes relevantes para la historia y el desenvolvimiento científico nacional), en específico el acceso y secreto de los documentos públicos. Regula la organización y administración de las Instituciones Archivistas Públicas.

La Ley Ordinaria 9.507 tiene el objetivo de garantizar el: Derecho de Acceso a la información del consumidor.

Derecho a la rectificación de la información,

Regula el procedimiento del Habeas Data para:

1. Asegurar el conocimiento de información relativa a la persona del solicitante, contenida en bancos de datos de las entidades gubernamentales o de carácter público.

2. Rectificar datos, si el solicitante no prefiere hacerlo a través de procedimientos confidenciales, judiciales o administrativos

3. Anotar en el registro del interesado, la explicación o contestación acerca de la veracidad de datos no justificable o que esté en proceso judiciales o amigables pendientes

\section{AMB ITO DE LA REGULACIÓN}

Organos públicos, instituciones de carácter público y personas físicas

\section{Ley Ordinaria 9.507}

Registros o bancos de datos de carácter público. En dicha ley se establece que es de carácter público todo registro o banco de datos que contenga información que sea o pueda ser transmitida a terceros o que no sean de uso privado del órgano o entidad productora o depositaria de las informaciones.

Disposiciones sobre protección del consumidor y de otras providencias (art. 43) 
de 20 de marco de 1997.

\section{LEI-008078 de 11/09/1990}

(LEI ORDINÁRIA)

Resolución 2.390 del Banco

Central de Brasil del 22 de

mayo de 1997.
El Artículo 43, Disposiciones sobre protección del consumidor y de otras providencias tiene como objetivo:

Establecer los derechos de los consumidores en relación a información existente relativa a él en catastros, fichas, registros y sus datos personales y de consumo.

El objetivo de la Resolución $\mathbf{2 . 3 9 0}$ es la creación de la Central de Riesgos de Crédito. De acuerdo a esta medida las instituciones financieras deberán identificar e informar al Banco Central los clientes (personas físicas y jurídicas) que tengan un saldo deudor igual o superior a $\mathrm{R} \$ 50,000(\$ 25,627$ dólares de Estados Unidos a un tipo de cambio de 1.951 reales por dólar). El banco central pone a disposición de las instituciones financieras, con el permiso del titular de h cuenta, la deuda total del cliente.
Bancos de Datos y Catastros de Información de los Consumidores. Se establece que los Bancos de Datos y catastros relativos a los consumidores o servicios de protección del crédito son considerados entidades de carácter público

\section{Resolución 2.390 del Banco Central}

Central de Riesgos de Crédito del Banco

Central e instituciones financieras

\section{INFORMACIÓN TRATADA POR LOS BURÓS DE CRÉDITO}

\begin{tabular}{|l|}
\hline TIPO DE INFO. \\
\hline Los burós de crédito en \\
Brasil proveen \\
información positiva y
\end{tabular}

información positiva y

negativa

del

comportamiento de los consumidores, como los compromisos que ha adquirido en el mercado y sus hábitos de pago. También proveen información acerca de empresas chicas, medianas y grandes $\mathrm{y}$ empresas financieras. (VER

CUADRO

(VER

"SITUACIÓN

$\mathrm{DE}$

MERCADO, TIPO DE

SERVICIOS"')

La Ley 8.159 (1991)

define:

Archivos

Conjunto

\section{SECRETO BANCARIO}

Ley No.4.595 de1964, Art. 38 ( se revocó por la Ley Complementaria No. 105)

Ley Complementaria No. 105 del 10 de enero de 2001, Disposiciones sobre el secreto de las operaciones de instituciones financieras y de otras providencias.

Aplica a las siguientes instituciones financieras:

i) los bancos de cualquier especie; ii) distribuidores de valores inmobiliarios; iii) casa de cambio y de valores inmobiliarios; iv)sociedades de crédito, financiamiento e inversiones; ; v) sociedades de crédito inmobiliario; vi) administradoras de cartas de crédito; vii) sociedades de arrendamiento mercantil; viii) administradoras de mercado; ix)cooperativas de crédito; $x$ )asociaciones de ahorro y préstamo; xi) bolsa de valores o de mercado y futuros; xii) entidades de liquidación y compensación; xiii) otras sociedades que, por naturaleza de sus operaciones, sean consideradas por el Consejo Monetario Nacional. Además, también cubre a las empresas de fomento comercia 1 o factoraje.

Establece que las instituciones financieras deberán de conservar secreto sobre sus operacione activas, pasivas y servicios prestados.

1. La revelación de información protegida por el secreto con el consentimiento expreso del interesado

2. La transmisión a entidades de protección al crédito de informaciones en el registro de emisores de cheques sin fondos y de deudores incumplidos, observando las normas establecidas por e Consejo Monetario Nacional o por el Banco Central.

3. El intercambio de las informaciones entre instituciones financieras, para fines de registro, inclusive utilizando de intermediario a las centrales de riesgo, observando las normas establecidas públicos: por el Consejo Monetario Nacional o por el Banco Central

99

de 4. La transmisión de la información que las instituciones responsables de la retención y de la

Brasil

SECRETO FISCAL

Código Fiscal (Ley No. 5.172 de 25

de octubre de 1966)

Título IV,Art. 198

Dicho artículo fue modificado Lcp

$n^{\circ} 104$, de 10.1.2001

Se prohibe la divulgación por parte

de la Hacienda Pública y sus

funcionarios de información

obtenida en razón de su oficio sobre:

la situación económica y

financiera de los sujetos pasivos (contribuyente y responsable) o

de terceros

la naturaleza y estado de sus negocios o actividades

Se exceptúa de lo dispuesto en el artículo en los siguie ntes casos: cuando la autoridad judicial la requiera en el interés de la justicia;

cuando lo solicite la autoridad administrativa frente a un proceso administrativo iniciado, en el órgano o entidad respectiva, con el objeto de 
documentos producidos y recibidos por órganos públicos de ámbito federal, estatal, Distrito Federal y municipal en el ejercicio de sus actividades. Además, son también públicos los documentos producidos y recibidos por instituciones de carácter público o privadas encargadas de la gestación de servicios públicos.

\section{Archivos privados} identificados como de interés público y social: Considerados como conjuntos de fuentes relevantes para la historia y el desarrollo científico nacional. recolección de las contribuciones hacen a la Autoridad de Ingresos Federales, las informaciones necesarias para la identificación de los contribuyentes y los valores globales de las respectivas operaciones, en los términos y condiciones y en los plazos establecidos por el Ministerio de Estado de Hacienda.

5. Las comunicaciones a las autoridades competentes sobre las prácticas ilícitas penales o administrativas, incluyendo el aprovisionamiento de las informaciones sobre las operaciones que involucran recursos provenientes de cualquier práctica criminal;

El secreto también puede ser roto cuando sea necesario para la investigación de un ilícito, en cualquier fase de un proceso judicial.

La Ley 105 establece que el secreto se extiende al Banco Central de Brasil, no obstante dicho secreto, inclusive información de cuentas de depósito o de inversión, no aplica si el Banco Central está investigando ilícitos por parte de administradores o miembros de las instituciones financieras o cuando investiga a instituciones financieras sujetas a régimen especial.

Podrán solicitar este tipo de información de las instituciones financieras y del Banco Central:

El Poder Judicial; la información conserva su carácter de confidencial y sólo la pueden accesar las partes legítimas en cuestión.

El Poder Legislativo, para el ejercicio de sus competencias, manteniendo el secreto bancario.

Las Comisiones Parlamentarias investigadoras

Adicionalmente, establece que el Poder Ejecutivo debe disciplinar los criterios bajo los cuales las instituciones financieras informarán a la administración tributaria de la Unión, las operaciones financieras efectuadas por los usuarios de sus servicios. Esto incluye tanto información activa como pasiva. Dichas informaciones se restringen a aquéllas relacionadas con la identificación de los titulares de las operaciones y los montos globales de los movimientos mensuales, más queda prohibida la inserción de cualquier elemento que permita identificar el origen o naturaleza de los gastos efectuados a partir de ellos. Dicha información será protegida por el secreto tributario.

La violación del secreto constituye un crimen y está sujeta a una pena de uno a cuatro años de prisión y multas. investigar al sujeto pasivo a quien se refiere la información, por sospecha de práctica de infracción administrativa. El intercambio de información: la administración se debe llevar a cabo mediante procesos instaurados y la entrega debe ser hecha personalmente a la autoridad que lo solicita, la cual deberá de preservar el secreto.

El secreto tributario no abarca:

representaciones fiscales para fines penales.

Inscripciones en la Deuda Activa de la Hacienda Pública, es decir, deuda exigible.

Parcelamiento o moratoria

Artículo 199.

La Hacienda Pública de la Unión, los Estados, el Distrito Federal y los Municipios pueden prestarse mutuamente asistencia para la fiscalización de los tributos respectivos e intercambiarse informaciones, en la forma establecida, en carácter general o específico, por ley o convenio.

La Hacienda Pública de la Unión, en la forma establecida en tratados, acuerdos o convenios, podrá intercambiar información con estados extranjeros en interés de la recaudación y fiscalización de tributos. 


\section{Derecho Habeas Data}

Constitución Art. 5, LXXII, Se concede el Habeas Data:

1. Para asegurar el conocimiento de información relativa a su persona contenida en bancos de datos de entidades gubernamentales o de carácter público

2. Para la rectificación de datos, si el solicitante no prefiere hacerlo a través de procedimientos confidenciales, judiciales o administrativos.

Art. 5, LXXVII "Las acciones de Habeas Data son gratuitas".

\section{Acceso de los consumidores a su información}

Disposiciones sobre protección del consumidor y de otras providencias, (1990) Art. 43

El consumidor tiene acceso a la información existente en catastros, fichas registros y a los datos personales y de consumo archivados sobre él, así como sobre sus respectivas fuentes.

Ley $8.159(1990)$, art $4^{\circ}, 22^{\circ}$ y $23^{\circ}$.

Todos tienen derecho a recibir de los órganos público informaciones de su interés particular o de interés colectivo o general, contenida en documentos de archivos, que serán entregadas en el plazo de la ley, exceptuando aquéllas cuyo secreto sea imprescindible para la seguridad de la sociedad y del Estado, como para la inviolabilidad de la intimidad, de la vida privada, de la honra y de la imagen de las personas.

El acceso a los documentos protegidos por secreto referentes a la seguridad de la sociedad y del Estados será restringido por un plazo máximo de 30 años, contados a partir de su producción, pudiendo este plazo ser prorrogado, por una única vez, por un mismo periodo.

El acceso a los documentos protegidos por secreto referentes a la honra e imagen de las personas ser restringido a un plazo máximo de 100 años, contados a partir de su producción.

\section{Rectificación de información.}

Disposiciones sobre protección del consumidor y de otras providencias (1990), Art. 43

El consumidor, siempre que encuentre inexactitud en sus datos y catastros, podrá exigir su inmediata corrección, debiendo el responsable de la base da datos (archivista), en un plazo de 5 días útiles, comunicar los cambios a los destinatarios de las informaciones incorrectas.

\section{Conocer del buró quien ha recibido reportes con su información y derecho a ser excluido de listados de ofertas}

No se contemplan dichos derechos. 
REGULACIÓN DE LOS BURÓS DE CRÉDITO Y AGENCIAS DE INFORMACIÓN (CONTROLADORES DE DATOS)

\begin{tabular}{|c|c|}
\hline $\begin{array}{c}\text { INICIO DE } \\
\text { OPERACIONES }\end{array}$ & PRINCIPIOS PARA EL TRATAMIENTO \\
\hline $\begin{array}{ll}\text { No } & \text { hay } \\
\text { información } & \\
\text { acerca de un } \\
\text { registro }\end{array}$ & $\begin{array}{l}\text { Especificación del fin } \\
\text { En las Disposiciones sobre protección del consumidor y de otras providencias (1990), Art. 43, no se señala que los catastros, registros o } \\
\text { bancos de datos tienen que especificar un fin para el tratamiento de los datos. } \\
\text { Límites a la Recolección } \\
\text { Obtenidos por medios legítimos } \\
\text { En las Disposiciones sobre protección del consumidor y de otras providencias (1990), Art. 43, no se señala acerca de la obtención de los datos, } \\
\text { pero sí se establece que se le debe informar al consumidor. } \\
\text { Conocimiento del Consumidor } \\
\text { La apertura de un catastro, ficha y registro de datos personales o de consumo deberá de ser comunicada por escrito al consumidor, cuando no } \\
\text { sea solicitado por él. } \\
\text { Autorización para la Transmisión } \\
\text { En las regulaciones analizadas no se establece la autorización del consumidor como requisito para la transmisión. } \\
\text { Límites al plazo de retención de los datos } \\
\text { Los catastros de datos de consumo no pueden contener información negativa referentes a un periodo superior a cinco años. } \\
\text { Terminada la prescripción relativa a la cobranza de deudas del consumidor, no será proporcionada por los respectivos Sistemas de Protección } \\
\text { al Crédito, cualquier información que pueda impedir o dificultar el acceso al crédito de los proveedores. } \\
\text { Calidad de los datos } \\
\text { Disposiciones sobre protección del consumidor y de otras providencias(1990), Art. 43, establece que los catastros de datos de consumo deben } \\
\text { ser objetivos, claros y verdaderos y en lenguaje de fácil comprensión. } \\
\text { No se señala nada acerca de medidas de seguridad, responsabilidad del controlador ni apertura. Las sanciones están contempladas en cuanto a } \\
\text { que el Departamento de Protección y Defensa del Consumidor puede aplicar multas a quien viole el Código. }\end{array}$ \\
\hline
\end{tabular}


- Autoridad Administrativa

El Departamento de Protección y Defensa del Consumidor (DPDC) de la Secretaría de Derecho Económico del Ministerio de Justicia

En el Decreto No. 2.181 del 20 de marzo de 1997 se establecen las facultades del DPDC, entre las cuales están:

Recibir, analizar, evaluar y averiguar las consultas y denuncias presentadas por las personas jurídicas y consumidores individuales;

Representar al Ministerio Público competente en las medidas procesales, penales o civiles en el ámbito de sus atribuciones;

Llevar al conocimiento de los órganos competentes las infracciones de orden administrativas que violen los intereses de los consumidores;

Aplicar las sanciones administrativas a aquéllos que: i) impidan o dificulten el acceso gratuito del consumidor a su información de su persona en catastros, registros de datos personales y de consumo, así como a sus respectivas fuentes; ii) elaboren catastros de consumo con datos irreales o inexactos; iii) mantengan catastros con información negativa por un periodo superior al establecido, y; iv) dejen de corregir, inmediatamente y gratuitamente, la inexactitud de los datos en catastros cuando el consumidor lo solicite;

El DPFC también tiene la función de informar y concientizar al consumidor de sus derechos establecidos en el Código de Protección y Defensa del Consumidor.

En el Art. 43 del Código de Protección y Defensa del Consumidor se establece que los órganos públicos de defensa del consumidor mantendrán catastros actualizados de las reclamaciones fundamentadas contra proveedores de productos y servicios de información, debiendo divulgarlo públicamente y anualmente. La divulgación indicará si el reclamo fue atendido o no por el proveedor.

\section{Autoridad Sectorial}

El Banco Central es el encargado de la Central de Riesgos de Crédito Pública y dicta la reglamentación de dicha central; no obstante, en la Resolución 2.390 en la que se crea la Central de Riesgos no se contempla a centrales de riesgos privadas, por lo que no es claro de que el Banco Central regule dichas centrales.

\section{- Autoridad Judicial}

Según la Ley Ordinaria 9.507 compete resolver en primera instancia la demanda judicial sobre el Habeas Data:

a) Al Tribunal Supremo Federal contra actos del Presidente de la República, de las mesas de la Cámara de Diputados o senadores, del Tribunal de Cuentas de la Unión, del Procurador General de la República y del propio Tribunal Supremo;

b) Al Tribunal Superior de justicia contra los actos del Ministerio del Estado o del propio Tribunal;

c) A los Tribunales Regionales Federales contra actos del propio Tribunal o del juez federal;

d) Al juez federal contra actos de las autoridades federales, exceptuando los casos en que compete al Tribunal Federal;

e) A los Tribunales Estatales, según lo dispuesto en la Constitución del Estado;

f) Al juez estatal en los demás casos; 


\section{CENTRALES DE RIESGOS Y BURÓS DE CRÉDITO PRIVADOS}

Central de Riesgos de Crédito se crea en 1997. Es un órgano del Banco Central de Brasil.

SERASA es creada en 1968 por los bancos. Es el buró de crédito creado por los bancos y el más grande de Brasil y de América Latina.

Recolecta su información de "catastros" de protestos, distribuidores judiciales, juntas comerciales, Banco central, publicaciones oficiales y registros públicos, entre otros.

Lusoft, Intermediaria entre clientes y Serasa

Unnisa /Equifax Creada en diciembre de 1992. En 1994 se incorpora en una "joint venture" denominada Partech del Grupo Andrade Gutiérrez y Grupo Socma. En 1998 se asocia a Equifax. Es una empresa enfocada al negocio de operaciones de tarjetas de crédito y cualquier sistema de pago electrónico.

SCI- Seguridad en Crédito e Información. Creada en 1974 y actualmente Equifax. Provee informes sobre el comportamiento comercial de empresas u personas. Los informes pueden ser consultados con las más diversas finalidades, desde otorgamiento de un crédito e identificación de un cliente potencial hasta la contratación de un nuevo empleado. Recibe información de fuentes como: Notarios, Registro Nacional de Emisores de Cheques sin Fondos, Investigación de Quiebras y Concordatos, Acciones Civiles o Juntas Comerciales.

\section{TIPOS DE SERVICIOS}

\section{Central de Riesgos}

- Información de las personas (físicas o morales) con deudas ante instituciones financieras superiores a $\mathbf{R} \$ 50,000$.

SERASA: Da información acerca de consumidores, empresas grandes, medianas y chicas y empresas financieras. Algunos de los servicios que ofrecen en relación con los consumidores son:

RECHEQUE: Verificación de Cheques para ver si son robados, extraviados, cancelados, y sin fondos.

BURÓ DE CRÉDITO: Información positiva y negativa del comportamiento de los consumidores, como los compromisos que han adoptado en el mercado y sus hábitos de pago.

CONCENTRE: Banco de Datos con información de consumidores y empresas incluyendo: Protestos, Cheques sin Fondos, Acciones Judiciales, Deudas Financieras, Participación en empresas quebradas. Además de información de la Autoridad Fiscal, la Secretaria da Receita Federal.

PEFIN: Deudas Financieras que tenga con Instituciones Financieras y empresas de todos los sectores de la economía.

\section{UNNISA/EQUIFAX:}

Operación de la red de Tarjetas de Crédito

\section{SCI/Equifax:}

Empresarial: información de empresas (datos generales, pagos puntuales, protestos, quiebras y concordatos, concesiones de crédito etc)

Personal: informe con el perfil comercial de personas físicas (créditos, cheques sin fondos, pagos al contado, a plazo o con atraso)

Cheque: información de emisores de cheques sin fondos 


\section{Anexo \\ Chile}

FUNDAMENTOS CONSTITUCIONALES

\begin{tabular}{|c|c|c|}
\hline DERECHO A LA PRIVACIDAD & DERECHO A INFORMAR & \begin{tabular}{|l|llll} 
DERECHO A SER INFORMADO Y A RECTIFICAR SU & INFORMACIÓN & Y EL \\
DERECHO DE ACCION DE HABEAS DATA & & & \\
\end{tabular} \\
\hline $\begin{array}{l}\text { Art. } 19 \text { inciso } \mathbf{4}^{\mathbf{0}} \text {.- Derecho de respeto } \\
\text { y protección a la vida privada y } \\
\text { pública y a la honra de la persona y su } \\
\text { familia. } \\
\text { Inciso } \mathbf{5}^{\mathbf{0}} \text {-. Las comunicaciones y } \\
\text { documentos privados sólo pueden } \\
\text { interceptarse, abrirse o registrarse en } \\
\text { los casos y formas determinados por } \\
\text { la ley. }\end{array}$ & $\begin{array}{l}\text { Art. 19, inciso 12.- } \\
\text { Libertad de emitir opinión y } \\
\text { la de informar, sin censura } \\
\text { previa, en cualquier forma o } \\
\text { cualquier medio, sin } \\
\text { perjuicio de responder de los } \\
\text { delitos y abusos que se } \\
\text { cometan en el ejercicio de } \\
\text { estas libertades. }\end{array}$ & $\begin{array}{l}\text { Art. } 19 \text { inciso 4.- La infracción del derecho de respeto y protección a la vida privada y } \\
\text { pública y a la honra de la persona y su familia, cometida a través de un medio de } \\
\text { comunicación social, y que consistiere en la imputación de un hecho o acto falso, o que } \\
\text { cause injustificadamente daño o descrédito a una persona o a su familia, será constitutiva de } \\
\text { delito y tendrá la sanción que determine la ley. } \\
\text { Art. 20.- El que por causa de actos u omisiones arbitrarios o ilegales, sufra privación, } \\
\text { perturbación o amenaza en el legítimo ejercicio de los derechos y garantías establecidos en el } \\
\text { artículo } 19, . . \text { inciso cuarto, } 4 .^{\circ}, 5^{\circ}, 6 .^{\circ}, 9 \ldots \text { podrá recurrir a la Corte de Apelaciones. }\end{array}$ \\
\hline
\end{tabular}

PRINCIPAL REGULACIÓN EN LA MATERIA

\begin{tabular}{|l|l|}
\hline REGULACIÓN & OBJETIVOS DE LA REGULACIÓN \\
\hline Ley de & La Ley de Protección de Datos pretende dar una adecuada protección a las personas en relación \\
\hline
\end{tabular}

Protección de con:

Datos de

Carácter

Personal de

Agosto de 1999

1. El derecho a la privacidad, precaviendo eventuales intromisiones ilegítimas que pudieran afectarlo, en el ámbito del derecho civil.

2. El uso que terceros puedan hacer de sus datos de carácter personal.

Los principios generales de orden doctrinario que rigen la materia, expuestos en el informe acerca del proyecto a la Cámara de Senadores son los siguientes:

Los datos personales sólo pueden recolectarse por medios lícitos.

Los datos personales sólo pueden recolectarse, transmitirse y difundirse para la finalidad para la que se hubieran recogido.

Los antecedentes o hechos de la vida íntima o privada, que corresponden a la denominada "información sensible", son reservados, por lo que su publicidad requiere del consentimiento del afectado o estar autorizada expresamente por una ley excepcional.

La ley puede, excepcionalmente, autorizar la desviación del fin para el cual se recolectó el dato, sólo para evitar una amenaza inminente al orden público o una violación grave de derechos de terceros, declaradas por una resolución judicial.

En el Título Preliminar se establece que "Toda persona puede efectuar el tratamiento de datos personales, ...en todo caso deberá respetar el pleno ejercicio de los derechos fundamentales de los titulares de los datos y de las facultades que esta ley les reconoce."

AMBITO DE LA REGULACIÓN

La Ley de Protección de Datos regula el tratamiento de los datos de carácter personal en registros o bancos de datos por organismos públicos o por particulares y al responsable del tratamiento, es decir, el responsable del registro o banco de datos, persona natural o jurídica privada, o el respectivo organismo público.

El tratamiento de datos se define como, cualquier operación o conjunto de operaciones

o procedimientos técnicos, de carácter automatizado o no, que permitan recolectar, almacenar, grabar, organizar, elaborar, seleccionar, extraer, confrontar, interconectar, disociar, comunicar, ceder, transferir, transmitir o cancelar datos de carácter personal, o utilizarlos en cualquier otra forma. 
Ley General de Bancos Art.14 de Dic. 1997
En el Artículo 14 de la Ley General de Bancos se establece que con el objeto de permitir una evaluación habitual de las instituciones financieras por empresas especializadas, la Superintendencia deberá darles a conocer la nómina de los deudores de los bancos, los saldos de sus obligaciones y las garantías que hayan constituido. La Superintendencia debe aprobar la inscripción de dichas firmas especializadas en un registro especial que abrirá.

La Superintendencia mantendrá información permanente sobre esta materia para el uso de instituciones financieras.
En el 14 de la Ley General de Bancos se establece responsabilidades a la Superintendencia de Bancos e Instituciones financieras y a las instituciones financieras sometidas a su fiscalización.

INFORMACIÓN TRATADA POR LOS BURÓS DE CRÉDITO

\section{TIPO DE INFORMACIÓN TRATADA POR BURÓS \\ La Ley de Protección de Datos (1999) define los siguientes tipos de} información:

Datos de carácter personal: los relativos a cualquier información concerniente a personas físicas, identificadas o identificables.

Datos sensibles: datos personales que se refieren a las características físicas o morales de las personas, o a hechos o circunstancias de su vida privada o intimidad, tales como los hábitos personales, el origen racial, las ideologías y opiniones políticas, las creencias o convicciones religiosas, los estados de salud físicos o psíquicos (datos de salud) y la vida sexual.

No pueden ser objeto de tratamiento los datos sensibles, salvo que la ley lo autorice, exista consentimiento del titular o sean datos necesarios para la determinación $\mathrm{u}$ otorgamiento de beneficios de salud que correspondan a sus titulares.

\section{Datos de salud:}

(Agréganse los siguientes incisos segundo y tercero, nuevos, al artículo 127 del Código Sanitario) 'Las recetas médicas y análisis o exámenes de laboratorios clínicos y servicios relacionados con la salud son reservados. Sólo podrá revelarse su contenido o darse copia de ellos con el consentimiento expreso del paciente, otorgado por escrito.

Datos rebativos a obligaciones de carácter económico, financiero bancario o comercial.

La Ley de Protección de Datos sólo permite transmitir información crediticia negativa.

\section{SECRETO BANCARIO}

Ley General de Bancos (modificada por Ley $N^{\circ} 19.528$ )

Dic. 1997

Art. 154

El Secreto Bancario abarca:

Los depósitos y captaciones de cualquier naturaleza que reciban los bancos. Los bancos no podrán proporcionar antecedentes relativos a dichas operaciones sino a su titular o representante legal.

Las demás operaciones quedan sujetas a reserva y los bancos solamente podrán darlas a conocer a quien demuestre un interés legítimo y siempre que no sea previsible que el conocimiento de la información pueda ocasionar daño patrimonial al cliente.

En todo caso, los bancos podrán dar a conocer las operaciones señaladas en los incisos anteriores, en términos globales, no personalizados ni parcializados, sólo para fines estadísticos o de información cuando exista un interés público general comprometido, calificado por la Superintendencia.

\section{SECRETO FISCAL}

Código Tributario (1974, versión actualizada a junio 2001)

En el Artículo 30 se establece que las personas que, a cualquier título, reciban o procesen las declaraciones o giros quedan sujetas a obligación de reserva absoluta de todos aquellos antecedentes individuales de que conozcan en virtud del trabajo que realizan.

En el Artículo 168 se establece que el Servicio de Tesorería, a través de los funcionarios que designe el Tesoro General, tendrá acceso, para el solo objeto de determinar los bienes de contribuyente, a todas las declaraciones de impuestos del contribuyente, como asimismo a todos los demás antecedentes que obren en poder del Servicio de Impuestos Internos (SII), siendo aplicables en este caso la obligación y sanciones que el Código impone en relación al secreto de la documentación del contribuyente.

El Servicio de Impuestos Internos cuenta con un sistema (https://zeus.sii.cl/cvc/stc/stc.html) a través del cual se puede consultar cierta información de la situación tributaria de los siguientes contribuyentes:

que están incluidos en nómina de difícil fiscalización. 

cambio y pagarés protestados; cheques protestados por falta de fondos, por haber sido girados contra cuenta corriente cerrada o por otra causa; el incumplimiento de obligaciones derivadas de mutuos hipotecarios y de préstamos o créditos de bancos, sociedades financieras, administradoras de mutuos hipotecarios, cooperativas de ahorros y créditos, organismos públicos y empresas del Estado sometidas a la legislación común, y de sociedades administradoras de créditos otorgados para compras en casas comerciales.

Entre los bancos existe un convenio que les permite contar con información negativa y positiva.

\section{Datos personales relativos a condenas por delitos, infracciones} administrativas o faltas disciplinarias

Los organismos públicos que sometan a tratamiento datos personales relativos a condenas por delitos, infracciones administrativas o faltas disciplinarias, no podrán comunicarlos una vez prescrita la acción penal o administrativa, o cumplida o prescrita la sanción o la pena.

Exceptúanse los casos en que esa información les sea solicitada por los tribunales de Justicia u otros organismos públicos dentro del ámbito de su competencia, quienes deberán guardar respecto de ella la debida reserva o secreto.

- inconcurrentes a citaciones cursadas por diferencias detectadas en su declaración.

- los no ubicados en requerimientos hechos a domicilio

- inconcurrentes a requerimientos, habiendo sido notificados por la autoridad

La información disponible en la consulta del SII describe la situación del contribuyente, sólo en las causales que se indican y actualizadas a la fecha de consulta. Por tanto, esta información es parcial, ya que el contribuyente puede tener otras observaciones distintas a las que aparecen en esta consulta por parte del SII.

Adicionalmente, en los servicios prestado por Dicom Chile está un informe de la situación tributaria sobre personas naturales o jurídicas que están impedidas a timbrar boletas por alguna razón. También se publica información fiscal a través de una base de datos que contiene información de organismos estatales con antecedentes de contribuciones en cobranza, bienes raíces en cobranza, deudas vencidas, morosos formulario 21 , deudores de crédito fiscal y otras. 


\section{En la Ley de Protección de Datos (1999) se establece:}

\section{Acceso de los consumidores a su información y conocer del buró quien ha recibido reportes con su información}

Toda persona tiene derecho a exigir a quien sea responsable de un banco, que se dedique en forma pública o privada al tratamiento de datos personales, información sobre los datos relativos a su persona, su procedencia y destinatario, el propósito del almacenamiento y la individualización de las personas u organismos a los cuales sus datos son transmitidos regularmente. Si los datos personales están en un banco de datos al cual tienen acceso diversos organismos, el titular puede requerir información a cualquiera de ellos. El acceso a los datos será absolutamente gratuito.

Si el responsable del registro o banco de datos no se pronunciare sobre la solicitud del requirente dentro de dos días hábiles, o la denegare por una causa distinta de la seguridad de la Nación o el interés nacional, el titular de los datos tendrá derecho a recurrir al juez de letras en lo civil del domicilio del responsable, que se encuentre de turno según las reglas correspondientes. Se comienza el procedimiento del Habeas Data. (Art. 16 de la Ley de Protección de Datos de Carácter Personal)

\section{Rectificación de información.}

En caso de que los datos personales sean erróneos, inexactos, equívocos o incompletos, y así se acredite, el titular tendrá derecho a que se modifiquen.

Sin perjuicio de las excepciones legales, podrá, además, exigir que se eliminen, en caso de que su almacenamiento carezca de fundamento legal o cuando estuvieren caducos.

La modificación o eliminación de los datos serán absolutamente gratuitas, debiendo proporcionarse, además, a solicitud del titular, copia del registro alterado en la parte pertinente. Si se efectuasen nuevas modificaciones o eliminaciones de datos, el titular podrá, asimismo, obtener sin costo copia del registro actualizado, siempre que haya transcurrido a lo menos seis meses desde la precedente oportunidad en que hizo uso de este derecho. El derecho a obtener copia gratuita sólo podrá ejercerse personalmente.

Si los datos personales cancelados o modificados hubieren sido comunicados previamente a personas determinadas o determinables, el responsable del banco de datos deberá avisarles a la brevedad posible la operación efectuada. Si no fuese posible determinar las personas a quienes se les hayan comunicado, pondrá un aviso que pueda ser de general conocimiento para quienes usen la información del banco de datos.

El derecho de las personas a la información, modificación, cancelación o bloqueo de sus datos personales no puede ser limitado por medio de ningún acto o convención.

\section{Excepciones}

No podrá solicitarse información, modificación, cancelación o bloqueo de datos personales cuando ello impida o entorpezca el debido cumplimiento de las funciones fiscalizadoras del organismo público requerido (operador de banco de datos del sector público), o afecte la reserva o secreto establecidos en disposiciones legales o reglamentarias, la seguridad de la Nación o el interés nacional. Tampoco podrá pedirse la modificación, cancelación o bloqueo de datos personales almacenados por mandato legal, fuera de los casos contemplados en la ley respectiva.

\section{Derecho a ser excluido de listados de ofertas}

El titular puede oponerse a la utilización de sus datos personales con fines de publicidad, investigación de mercado o encuestas de opinión.

\section{Acción Adversa}

No se contempla en la legislación 
INICIO DE OPERACIONES

\section{Inicio de Operaciones}

*No hay un registro para

los registros o banco de datos privados, sólo se deben registrar los bancos de datos a cargo de organismos públicos y los que reciben información de la Superintendencia de Bancos e Instituciones

Financieras.

El Servicio de Registro Civil e Identificación llevará un registro de los bancos de datos personales a cargo de organismos públicos. Este registro tendrá carácter público y en él constará, respecto de cada uno de esos bancos de datos, el fundamento jurídico de su existencia, su finalidad, tipos de datos almacenados y descripción del universo de personas que comprende, todo lo cual será definido en un reglamento.

El organismo público responsable del banco de datos identificará cuando se inicien las actividades del banco, y comunicará cualquier cambio de los elementos indicados dentro de los quince días desde

\section{PRINCIPIOS PARA EL TRATAMIENTO}

\section{En la Ley de Protección de Datos (1999) se establece:}

Especificación del fin

La persona que autoriza debe ser debidamente informada respecto del propósito del almacenamiento de sus datos personales y su posible comunicación al público.

Los datos personales deben utilizarse sólo para los fines para los cuales hubieren sido recolectados, salvo que provengan o se hayan recolectado de fuentes accesibles al público.

\section{Límites a la Recolección}

Obtenidos por medios legítimos

El tratamiento de los datos personales sólo puede efectuarse cuando esta ley u otras disposiciones legales lo autoricen o el titular consienta expresamente en ello.

\section{Conocimiento del Consumidor}

La persona que autoriza debe ser debidamente informada respecto del propósito del almacenamiento de sus datos personales y su posible comunicación al público.

No obstante ello, la autorización no aplica a el tratamiento de datos personales ..., cuando sean de carácter económico, financiero, bancario o comercial.

\section{Autorización para la Transmisión}

Expresa y por escrito

El tratamiento de los datos personales sólo puede efectuarse cuando esta ley u otras disposiciones legales lo autoricen o el titular consienta expresamente en ello.

La autorización debe constar por escrito.

La autorización puede ser revocada, aunque sin efecto retroactivo, lo que también deberá hacerse por escrito.

\section{Datos que no requieren autorización:}

No requiere autorización el tratamiento de datos personales que provengan o que se recolecten de fuentes accesibles al público, cuando sean de carácter económico, financiero, bancario o comercial, se contengan en listados relativos a una categoría de personas que se limiten a indicar antecedentes tales como la pertenencia del individuo a ese grupo, su profesión o actividad, sus títulos educativos, dirección o fecha de nacimiento, o sean necesarios para comunicaciones comerciales de respuesta directa o comercialización o venta directa de bienes o servicios.

Tampoco requerirá de esta autorización el tratamiento de datos personales que realicen personas jurídicas privadas para el uso exclusivo suyo, de sus asociados y de las entidades a que están afiliadas, con fines estadísticos, de tarificación u otros de beneficio general de aquéllos.

El tratamiento de datos personales por parte de un organismo público sólo podrá efectuarse respecto de las materias de su 
Implícita en transacciones iniciadas por el consumidor

En la Ley de Protección de Datos de Carácter Personal no se contempla una autorización implícita de los consumidores.

\section{Límites al plazo de retención de los datos}

Los datos personales deberán ser eliminados o cancelados cuando su almacenamiento carezca de fundamento legal o cuando hayan caducado.

En ningún caso pueden comunicarse los datos personales relativos a obligaciones de carácter económico, financiero, bancario o comercial, que se relacionen con una persona identificada o identificable, luego de transcurridos siete años desde que la respectiva obligación se hizo exigible.

Tampoco se podrá continuar comunicando los datos relativos a dicha obligación después de transcurridos tres años del pago o de su extinción por otro modo legal.

\section{Calidad de los datos}

Los datos han de ser modificados cuando sean erróneos, inexactos, equívocos o incompletos.

Se bloquearán los datos personales cuya exactitud no pueda ser establecida o cuya vigencia sea dudosa y respecto de los cuales no corresponda la cancelación. El responsable del banco de datos personales procederá a la eliminación, modificación o bloqueo de los datos, en su caso, sin necesidad de requerimiento del titular.

En todo caso, la información debe ser exacta, actualizada y responder con veracidad a la situación real del titular de los datos.

\section{Regulación de Seguridad}

El responsable de los registros o bases donde se almacenen datos personales con posterioridad a su recolección deberá cuidar de ellos con la debida diligencia, haciéndose responsable de los daños.

\section{Responsabilidad del Controlador}

La persona natural o jurídica privada o el organismo público responsable del banco de datos personales deberá indemnizar el daño patrimonial y moral que causare por el tratamiento indebido de los datos, sin perjuicio de proceder a eliminar, modificar o bloquear los datos de acuerdo a lo requerido por el titular o, en su caso, lo ordenado por el tribunal.

\section{Sanciones}

Si el responsable del registro o banco de datos no se pronunciare sobre una solicitud del requirente de accesar o rectificar sus datos dentro de dos días hábiles, o la denegare por una causa distinta de la seguridad de la Nación o el interés nacional, el titular de los datos tendrá derecho a recurrir al juez de letras en lo civil del domicilio del responsable.

En caso de acogerse la reclamación, el juez fijará un plazo prudencial para dar cumplimiento a lo resuelto y podrá aplicar una multa de una a diez unidades tributarias mensuales. La falta de entrega de la información o el retardo en efectuar la modificación, serán castigados con multa de dos a cincuenta unidades tributarias mensuales $\mathrm{y}$, si el responsable del banco de datos requerido fuere un organismo público, el tribunal podrá sancionar al jefe del Servicio con la suspensión de su cargo, por un lapso de cinco a quince días. 
El juez tomará todas las providencias que estime convenientes para hacer efectiva la protección de los derechos que esta ley establece. El monto de la indemnización será establecido prudencialmente por el juez, considerando las circunstancias del caso y la gravedad de los hechos.

\section{AUTORIDADES Y SUS FACULTADES}

- Autoridad Administrativa

No se contemple dicha autoridad.

- Autoridad Judicial

La protección de los derechos establecidos en la Ley de Protección de Datos de Carácter Personal se delega a los tribunales. Si el responsable del registro o banco de datos no se pronunciare sobre la solicitud del titular para accesar su información o rectificarla, el titular de los datos tendrá derecho a recurrir al juez de letras en lo civil del domicilio del responsable, que se encuentre de turno según las reglas correspondientes.

La sentencia definitiva será apelable en ambos efectos, y el caso se va ante la Corte de Apelaciones respectiva.

En caso de que la causal invocada para denegar la solicitud del requirente fuere la seguridad de la Nación o el interés nacional, la reclamación deberá presentarse ante la Corte Suprema.

Además, en la ley se establece que el juez tomará todas las providencias que estime convenientes para hacer efectiva la protección de los derechos que esta ley establece. La prueba se apreciará en conciencia por el juez. 
*Superintendencia d Bancos e Instituciones Financieras. Institución Autónoma que se relaciona al Gobierno por el Ministerio de Hacienda. Por ley, cada mes los bancos y las sociedades financieras le tienen que reportar información positiva y negativa de la deuda de sus clientes. Dicha Superintendencia hace un reporte acerca de la deuda de cada tipo de crédito, de cada persona y compañía del sector bancario y lo manda de regreso a cada banco.

*DICOM (Equifax) Inicia sus operaciones en 1979. Es una Sociedad Anónima Cerrada que reúne y centraliza información que, según lo establece la ley, es de conocimiento público. Tiene un acuerdo con los bancos para incluir los reportes de la Superintendencia en su base de datos. Por ley, este tipo de información es sólo para los bancos y las instituciones financieras. Dicom no paga por la información consolidada de los bancos.

*SACOFI Sociedad Anónima Cerrada cuyos accionistas son los miembros de la Asociación de Bancos e Instituciones Financieras A.G. Proporciona información financiera a bancos

*Cámara de Comercio de Chile Publica un Boletín Comercial.

\section{TIPOS DE SERVICIOS}

Superintendencia: Registro de Deudores: información de deudores individuales y el monto de deuda que éstos tienen con los bancos y las sociedades financieras. Las deudas incluyen:

- el conjunto de obligaciones reales y contingentes de un deudor (directo o indirecto)

- las obligaciones vigentes y vencidas, manteniéndose la información de las operaciones castigadas durante 10 años. Este registro lo comparte la Superintendencia con los burós de crédito.

DICOM. Algunos de los servicios que ofrece son:

-Directorio de Empresas y Personas

-Perfil Comercial de Personas Físicas y Morales

-Boletín de Protestos

-Morosidad

-Impedidos de Abrir Cuenta Corriente

-Verificación de Cheques

-Boletín Laboral y Provisional

-Registro de Trabajos: Informa acerca de la dirección laboral, cargo, antigüedad laboral verificada en terreno. Aplicaciones: Confirmación de datos informados por el cliente.

-Registro de Causas Judiciales (Civiles o Laborales)

-Registro de Quiebras

-Situación Tributaria: Sobre personas naturales o jurídicas que está impedidas a timbrar boletas por alguna causal.

-Información Fiscal: antecedentes de contribuciones en cobranza, deudas vencidas, morosos formulario 21 , deudores de crédito fiscal.

SACOFI . Cuenta con una Central de Riesgos que proporciona la siguiente información: - Deuda de personas naturales y jurídicas en el sistema financiero

- Protestos históricos y vigentes;

- Infractores laborales;

-Impedidos de Abrir Cuentas Corrientes

Cámara de Comercio. El Boletín Comercial incluye:

-una nómina de documentos protestados

-pagarés protestados

-cheques protestados

-aclaración de los mismos. 


\section{Anexo \\ Colombia \\ FUNDAMENTOS CONSTITUCIONALES}

\begin{tabular}{|c|c|c|}
\hline $\begin{array}{l}\text { DERECHO A LA } \\
\text { PRIVACIDAD }\end{array}$ & $\begin{array}{l}\text { DERECHO A } \\
\text { INFORMAR }\end{array}$ & $\begin{array}{l}\text { DERECHO A SER INFORMADO Y A RECTIFICAR SU INFORMACIÓN Y EL DERECHO DE ACCION DE HABEAS } \\
\text { DATA }\end{array}$ \\
\hline $\begin{array}{l}\text { Art. 15.- } \\
\text { a la intimidad } \\
\text { personal y familiar } \\
\text { y a su } \text { buen } \\
\text { nombre. } \\
\text { Art. 21.- } \\
\text { garantiza Se } \\
\text { derecho a la honra. } \\
\begin{array}{ll}\text { La ley señalará la } \\
\text { forma de } \\
\text { protección. }\end{array}\end{array}$ & $\begin{array}{lr}\text { Art. 20.- } & \text { Se } \\
\text { garantiza a } & \text { toda } \\
\text { persona } & \text { la } \\
\text { libertad } & \text { de } \\
\text { expresar } & \text { y } \\
\text { difundir } & \text { su } \\
\text { pensamiento } & \text { y } \\
\text { opiniones, la de } \\
\text { informar } & \text { (y } \\
\text { recibir } & \\
\text { información } & \\
\text { veraz } & \mathrm{e} \\
\text { imparcial.) } & \end{array}$ & $\begin{array}{l}\text { Art. 15.-.Derecho a conocer, actualizar y rectificar las informaciones que se hayan recogido sobre ellas en bancos de } \\
\text { datos y archivos de entidades públicas y privadas. En la recolección, tratamiento y circulación de datos se respetarán la } \\
\text { libertad y demás garantías consagradas en la Constitución. } \\
\text { Art. 20.- Se garantiza a toda persona la libertad de (expresar y difundir su pensamiento y opiniones, la de informar y) } \\
\text { recibir información veraz e imparcial. } \\
\text { Art. 86.- Toda persona tendrá acción de tutela para reclamar ante los jueces, en todo momento y lugar, mediante un } \\
\text { procedimiento preferente y sumario, por sí misma o por quien actúe en su nombre, la protección inmediata de sus } \\
\text { derechos constitucionales fundamentales, cuando quiera que éstos resultaren vulnerados o amenazados por la acción o la } \\
\text { omisión de cualquier autoridad pública. La tutela es un procedimiento preferente y sumario (en ningún caso pueden } \\
\text { transcurrir más de } 10 \text { días entre la solicitud de tutela y su resolución)., altamente utilizado por los colombianos para } \\
\text { solicitar la modificación o exclusión de su información reportada en los Burós de Crédito. }\end{array}$ \\
\hline
\end{tabular}

PRINCIPAL REGULACIÓN EN LA MATERIA

\begin{tabular}{|c|c|c|}
\hline REGULACIÓN & BJETIVOS DE LA REGULACIÓN & \\
\hline $\begin{array}{l}\text { Ley ordinaria } \\
510 \text { (Art. } 110 \text { y } \\
114 \text { ) de 13/08/99. } \\
\text { Estos artículos } \\
\text { fueron } \\
\text { declarados } \\
\text { inexequibles } \\
\text { mediante } \\
\text { sentencia } \\
725 / 2000 \text { de la } \\
\text { Corte }\end{array}$ & $\begin{array}{l}\text { Determinar el alcance de la "intimidad informática" o Habeas Data, haciendo hincapié en el manejo que se le debe de dar a al } \\
\text { información crediticia de una persona. } \\
\text { Se establece que el núcleo del Habeas Data está integrado por el derecho de la autodeterminación informática y por la libertad, en } \\
\text { especial la libertad económica. Se entiende por autodeterminación informática la facultad de la persona a la cual se refieren los } \\
\text { datos, para autorizar su conservación, uso y circulación, de conformidad con las regulaciones legales. Con respecto a la libertad } \\
\text { económica, se senala que esta pudiera restringirse indebidamente en virtud de la circulación de datos que no sean veraces, o que no } \\
\text { haya sido autorizada por la persona concernida o por la ley. } \\
\text { Art. } 110 \text { Velar porque las personas encargadas de la conservación, el uso y la divulgación informática de la información de los } \\
\text { usuarios del sistema financiero se mantenga permanentemente actualizada, siguiendo ciertas reglas. Este artículo fue declarado } \\
\text { inexequible en sentencia } 725 / 00 \text { por la Corte Constitucional. } \\
\text { Art. } 114 \text { Establece reglas para la recolección, el tratamiento y la difusión de los datos personales por parte de los Bancos de Datos } \\
\text { Financieros o de Solvencia Patrimonial y Crediticia. Este artículo fue declarado inexequible mediante sentencia C-384/2000 de la } \\
\text { Corte Constitucional. } \\
\text { El fundamento para declarar inexequibles estos artículos, es el hecho que el art. } 152 \text { de la Constitución Política dispone que } \\
\text { mediante las leyes estatutarias el Congreso de la República regulará, entre otros temas, el correspondiente a los derechos y deberes } \\
\text { fundamentales de las personas y a los procedimientos y recursos para su protección. Los magistrados de la Corte Constitucional, } \\
\text { consideraron que los artículos } 110 \text { y } 114 \text { de la Ley } 510 \text { de } 1999 \text { (Ley Ordinaria), regulan un aspecto inherente al ejercicio del }\end{array}$ & $\begin{array}{l}\text { intidades } \\
\text { inancieras, } \\
\text { ancos de } \\
\text { atos } \\
\text { inancieros o } \\
\text { e Solvencia } \\
\text { atrimonial y } \\
\text { rediticia }\end{array}$ \\
\hline
\end{tabular}




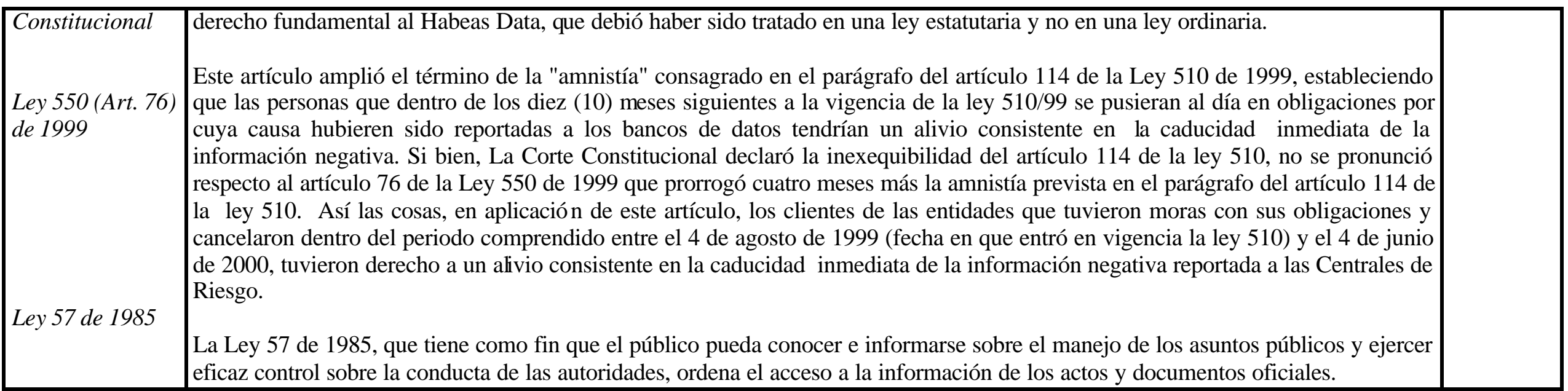

\section{INFORMACIÓN TRATADA POR LOS BURÓS DE CRÉDITO}

\section{TIPO DE INFORMACIÓN}

\section{TRATADA POR LOS BURÓS}

\section{En la Sentencia SU 089/95 se}

establece que el buen nombre es un concepto que difiere de la intimidad personal (pues ésta es secreta para los demás en tanto que aquél es público por naturaleza). Por lo anterior, se entiende que el comportamiento crediticio de una persona, si bien no pertenece a la esfera de la intimidad personal o familiar, guarda estrecha relación con el buen nombre tutelado en el artículo 15 constitucional. La fama del buen o mal pagador se origina en la forma en que usualmente la persona atiende sus obligaciones.

Asimismo, en la Sentencia se enumeran los datos pertenecientes a la intimidad personal o vida privada:

i) ideas y creencias religiosas, filosóficas, mágicas y políticas que el individuo desee sustraer del la com

\section{SECRETO FISCAL}

El artículo 583 del Decreto Tributario de1989 (versión actualizada del 2001) establece que:

Colombia no existe en materia financiera una ley que expresamente establezca el secreto bancario. No obstante, "la doctrina y la jurisprudencia admiten unánimemente la existencia de este deber de discreción, unas veces como resultado de los textos legales expresos que la consagran, y otras como fruto de un uso uniforme $y$ reiterado acerca de cuya obligatoriedad ha existido plena conciencia desde el principio mismo de la banca y de los profesionales de los negocios bancarios" (Concepto OJ-260 de noviembre 19 de 1982)

En el Numeral 4.1 del Capítulo Noveno, Título Primero de la Circular Externa 07 de 1996 de la Superintendencia, se establece la reserva bancaria como una de las obligaciones especiales de las entidades vigiladas por ella y se define como "el deber que tienen los funcionarios de las entidades financieras y aseguradoras de guardar reserva y discreción sobre los datos de sus clientes o sobre aquéllos relacionados con la situación propia de la compañía, que conozcan en desarrollo de su
"La información tributaria respecto de las bases gravables y la determinación privada de los impuestos que figuren en las declaraciones tributarias, tendrá el carácter de información reservada; por consiguiente, los funcionarios de la Dirección General de Impuestos Nacionales sólo podrán utilizarla para el control, recaudo, determinación, discusión y administración de los impuestos y para efectos de informaciones impersonales de estadística.

Los bancos y demás entidades que en virtud de la autorización para recaudar los impuestos y recibir las declaraciones tributarias, de competencia de la Dirección General de Impuestos Nacionales, conozcan las informaciones y demás datos de carácter tributario de las declaraciones, deberán guardar la más absoluta reserva con relación a ellos y sólo los podrán utilizar para los fines del procesamiento de la información, que demanden los reportes de recaudo y recepción, exigidos por el Ministerio de Hacienda y Crédito Público."

Excepciones (art. 583-587 y 693 del Decreto)

En los procesos penales cuando la correspondiente autoridad lo decrete como prueba

Para fines de control al lavado de activos, La Dirección de Impuestos 
conocimiento ajeno;

ii) aspectos concernientes a la vida amorosa o sexual;

iii) defectos o anomalías físicos o psíquicos no ostensibles;

iv) comportamiento del sujeto que no es conocido por extraños y que de ser conocido originaría críticas;

v) afecciones de la salud cuyo conocimiento menoscabe el juicio que para fines sociales $o$ profesionales formulen los demás acerca del sujeto;

vi)

contenido

comunicaciones escritas $u$ orales de tipo personal;

vii) la vida pasada del sujeto;

viii) orígenes familiares que lastimen la posición social y cuestiones concernientes a la filiación y los actos de estado civil;

ix) en general, todo dato, hecho o actividad personal no conocidas por otros, cuyo conocimiento por terceros produzca turbación moral o psíquica al afectado.

En la Sentencia se señala explícitamente que si un banco de datos, abusando de sus funciones, incluye entre la información sobre el deudor, datos que por su contenido pertenecen a la esfera de la íntima del individuo, podrá la persona cuya intimidad se vulnera exigir la exclusión de tales datos. Y si tal exclusión no se hace voluntariamente, acudir a tutela para proteger su derecho fundamental. profesión u oficio. Es pertinente recordar las consecuencias penales, laborales y administrativas que el incumplimiento a dicho precepto podría acarrear al infractor.'

En el OJ-321 de septiembre 29, 1976 de la Superintendencia Bancaria se establece que “...en general el banco está obligado a conservar el secreto acerca de todos los hechos de que tenga conocimiento del banquero en ejercicio de su profesión y en cuya reserva tenga interés el cliente"

La reserva además de comprender los datos relacionados en forma directa de la entidad financiera con el cliente, se extiende a los datos derivados de las relaciones jurídicas que lo vinculan con la institución financiera; es decir, comprende las operaciones realizadas entre los establecimientos de crédito y las personas naturales y jurídicas.

\section{Excepciones}

En el OJ-321 de septiembre 29, 1976 se establece que "el deber de discreción desaparece cuando se trata de hechos conocidos por la entidad en virtud de circunstancias ajenas a las relaciones directas con su cliente...igualmente dejará de tener vigencia la obligación en todos los supuestos en que no se encuentre un interés digno de ser amparado por este medio."

La Circular Externa 07 de 1996, la Superintendencia establece que no caen bajo el amparo de la reserva bancaria "conductas criminales, abusivas o contrarias a la buena fe que ha de regir el tráfico mercantil, o lo que es más grave aún, resultar encubierta información que facilite la labor de la administración de justicia y de los organismos que con ella colaboran en la lucha por el imperio de la moral y del derecho. Si no existe detrás del sigilo del

banquero, un interés legítimo de una tercera De lo anterior se desprende que se puede divulgar si el contribuyente se y Aduanas Nacionales (DIAN) deberá remitir, la información relativa a las declaraciones e investigaciones de carácter tributario

Para los efectos de liquidación y control de impuestos nacionales, departamentales o municipales, podrán intercambiar información sobre los datos de los contribuyentes, el Ministerio de Hacienda y las Secretarias de Hacienda Departamentales y Municipales

A los servicios de entidades privadas contratados por la Dirección General de Impuestos Nacionales para el procesamiento de datos, liquidación y contabilización de los gravámenes por sistemas electrónicos. Las entidades privadas con las cuales se contraten guardarán absoluta reserva acerca de las informaciones que se les suministren, y en los contratos respectivos se incluirá una caución suficiente que garantice tal obligación.

Por solicitud directa de los gobiernos extranjeros y sus agencias y con base en acuerdos de reciprocidad, se podrá suministrar información tributaria en el caso en que se requiera para fines de control fiscal o para obrar en procesos fiscales o penales. En tal evento, deberá exigirse al gobierno o agencia solicitante, tanto el compromiso expreso de su utilización exclusiva para los fines objeto del requerimiento de información, así como la obligación de garantizar la debida protección a la reserva que ampara la información suministrada. (Artículo modificado Ley 633/00 art. 43)

Además de las restricciones establecidas en ley para la divulgación de información tributaria, el derecho constitucional a la intimidad económica personal de las personas naturales puede presentar un límite (más no un obstáculo, según el Lic. Manuel José Cepeda Espinosa) al mismo. No obstante, dicha intimidad está a su vez limitada con base a: preservar el interés público, cumplir un deber y respetar los derechos de los demás.

Bajo la interpretación del Lic. Manuel José Cepeda Espinosa, basándose en dichas justificaciones, establece que "en aras de ayudar al cumplimiento del deber público de pagar impuestos, es posible divulgar con bajo riesgo jurídico, si una persona se encuentra a paz y salvo. En aras de promover la efectividad de los derechos de los ahorradores y el derecho a la información, es posible divulgar, con un riesgo mediano, si el contribuyente está, no sólo a paz y salvo, sino el monto de la obligación pendiente y el tiempo de la mora, siempre y cuando de dicha información no se pueda deducir la base gravable del tributo y otros datos sobre la situación económica del contribuyente" 
Información sobre arrendamiento La información reportada en los burós es generalmente información que reciben de las empresas inmobiliarias respecto al hábito de pago de los canones de arrendamiento por parte de los arrendatarias. persona que obtenga en esa discreción justa defensa contra la infidencia o la deslealtad, la utilización u observancia de esa práctica se convierte en un irresponsable ocultamiento que debe ser sancionado.... La reserva bancaria tampoco tiene vigencia cuando, ante las circunstancias previstas en el artículo 15 de la Constitución Política, la institución financiera se encuentra obligada a permitir el examen y registro de sus "papeles privados".

La Ley 57 de 1985, art.20, establece que las autoridades pueden acceder a los documentos de carácter reservado (que incluyen a los de las entidades financieras). "El carácter reservado de un documento no será oponible a las autoridades que lo soliciten para el debido ejercicio de sus funciones. Corresponde a dichas autoridades asegurar la reserva de los documentos que llegue a conocer." encuentra a paz y salvo con un riesgo bajo, aunque no inexistente. No obstante, a medida que se divulgue información de contendido económico el riesgo aumenta y se acerca a lo protegido bajo la reserva tributaria. Por lo que para transmitir información adicional a la de si el contribuyente está a paz y salvo, sin gran riesgo, se tiene que: i) emitir un norma expresa que regule la materia, o ii) establecer una práctica que lleve a que dicha información sea sólo la base para verificar si lo que dice el contribuyente que solicita un crédito es cierto o no, sin que ello implique una divulgación de datos económicos diferentes a los suministrados voluntariamente por la persona natural.

Cabe mencionar que existe un debate en Colombia acera de si los burós deben poder procesar o no información tributaria en el cual la DIAN expresó su interés. No obstante, el artículo 583 del Decreto Tributario no ha sido modificado, ni se ha emitido norma que regule la materia.

\section{DERECHOS DE LOS CONSUMIDORES RESPECTO A SU INFORMACIÓN}

\section{Acceso y Rectificación de información.}

\section{Art. 15 Constitucional}

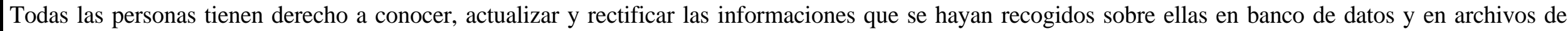
entidades públicas y privadas."

\section{En la Sentencia 089/95 se establece que:}

"El contenido del Habeas Data se manifiesta por tres facultades concretas que el artículo 15 constitucional reconoce a las persona a la cual se refieren los datos recogidos:

a) el derecho a conocer las informaciones que a ella se refieran;

b) el derecho a actualizar tales informaciones, es decir, a ponerlas al día, agregándoles los hechos nuevos;

c) el derecho a rectificar las informaciones que no correspondan a la verdad.

... Hay que aclarar que la actualización y la rectificación de los datos contrarios a la verdad, son, en principio, obligaciones de quien maneja el banco de datos; y que si él no las cumple, la persona concernida puede exigir su cumplimiento 
REGULACIÓN DE LOS BURÓS DE CRÉDITO Y AGENCIAS DE INFORMACIÓN (CONTROLADORES DE DATOS)

INICIO DE

Inicio de

Especificación del fin

No se señala

nada.

En la Ley 510, Art. 114 se establece que sólo se podrán registrar y ceder los datos que, según las normas o pautas de la Superintendencia Bancaria y de conformidad con el artículo 15 de la Constitución, se consideren relevantes para evaluar la solvencia económica de sus titulares. Como se señaló, este artículo fue declarado inexequible por la Suprema Corte de Justicia. (este artículo fue declarado inexequible mediante sentencia 725/2000 de la Corte Constitucional)

\section{Límites a la Recolección}

Obtenidos por medios legítimos

En la Sentencia_de la Corte Constitucional $\boldsymbol{S U}$ 089/95 se establece que:

“... el Habeas Data tiene que ver, además, con la manera como se manejen los datos. Al respecto el inciso 2 del artículo 15 Constitucional dispone:

En la recolección, tratamiento y circulación de datos se respetarán la libertad y demás garantías consagradas en la Constitución.

En consecuencia, los datos conseguidos, por ejemplo, por medios ilícitos no pueden ser parte de los bancos de datos y tampoco pueden circular."

\section{Conocimiento del Consumidor}

En la Sentencia de la Corte Constitucional $\mathbf{S U} 089 / 95$ se establece que: banco.'

"... para facilitar el conocimiento de los datos por la persona concernida, debe notificarse a ésta sobre la inclusión de tales datos en el

Con respecto a la recolección de la información, la Ley 510, Artículo 114 establece que las entidades o personas naturales que suministren regularmente datos financieros o sobre solvencia patrimonial y crediticia sólo podrán tratar automatizadamente datos personales obtenidos de fuentes accesibles al público o procedentes de informaciones recogidas mediante el consentimiento libre, expreso, informado y escrito de su titular. (El Artículo fue declarado inexequible por la Suprema Corte de Justicia)

En la Sentencia $\boldsymbol{S U} \mathbf{0 8 9 / 9 5}$ se señala que las instituciones de crédito, por manejar el ahorro público, ejercen una actividad de interés general, y un manejo prudente por parte de estas instituciones exige que obtengan información que permita prever qué suerte correrán los dineros dados en préstamo. Por ende, el deudor no tiene el derecho, con respecto a información crediticia, a impedir el suministro de la información veraz por tres razones: i)que se tratan de hechos que no tiene que ver solamente con él; ii) que no puede oponerse a que la entidad de crédito ejerza un derecho; que no se relaciona con asuntos relativos a su intimidad. Lo anterior, bajo el entendido que la circulación de esa información está condicionada a la autorización previa del interesado.

La interpretación que la Superintendencia Bancaria da a la autorización es la siguiente.

"Frente a la incertidumbre que plantea la determinación del carácter de reservado de los datos, para efectos de obtener acceso a los mismos... es aconsejable entonces contar con el consentimiento del sujeto a quien alude la información... No ocurre lo mismo cuando se trata de informaciones relativas a un interés que no sea digno de ser amparado por la reserva bancaria, la cual podría ser lícitamente suministrada por las entidades financieras...sin afectar el deber del sigilo propio de su actividad... Así, por ejemplo, podría suministrarse información respecto de la cartera morosa de los clientes, eventos en cuales se estaría obrando en principio en protección de los intereses de los empresarios e, igualmente, 
Asimismo, la Superintendencia concluye que, bajo su facultades de vigilar el sistema financiero, puede suministrar información respecto del comportamiento crediticio de los clientes del sector financiero a las entidades financieras vigiladas, sin autorización del titular de la información, sólo son el propósito de servir como elemento para el manejo y control de un riesgo inherente a la actividad financiera, sin que de esta forma pueda decirse que su acopio vulnera los derechos individuales.

\section{Autorización para la Transmisión \\ Expresa y por escrito}

En la Sentencia_de la Corte Constitucional SU $089 / 95$ se establece que:

“...el derecho a la información y la legitimidad de la conducta de las entidades que solicitan información de sus eventuales clientes, a las centrales de información que para el efecto se han creado, así como la facultad de reportar a quienes incumplan las obligaciones con ellos contraídas, tiene como base fundamental, la autorización que el interesado les otorgue para disponer de esa información, pues al fin y al cabo, los datos que se van a suministrar conciernen a él, y por tanto, le asiste el derecho, no sólo a autorizar su circulación, sino a rectificarlos o actualizarlos.

...Autorización que debe ser expresa y voluntaria por parte del interesado, para que sea realmente eficaz, pues de lo contrario no podría hablarse de que el titular de la información hizo uso efectivo de su derecho."

\section{Límites al plazo de retención de los datos}

En la Sentencia_de la Corte Constitucional SU 089/95 se establece que:

"hacia el pasado debe fijarse un límite razonable, pues no sería lógico ni justo que el buen comportamiento de los últimos años no borrara la mala conducta pasada.

En este orden de ideas, serían irrazonables la conservación, el uso y la divulgación informática del dato, si no se tuviera en cuenta la ocurrencia de todos los siguientes hechos:

a) Un pago voluntario de la obligación;

b) Transcurso de un término de dos años, término contado a partir del pago voluntario. Expresamente se exceptúa el caso en que la mora haya sido inferior a un año, caso en el cual, el término de caducidad sería igual al doble de la misma mora;

c) Que durante el término indicado, no se hayan reportado nuevos incumplimientos del mismo deudor, en relación con otras obligaciones;

d) Si el pago se ha producido en un proceso ejecutivo, es razonable que el dato, a pesar de ser público, tenga un término de caducidad, que podría ser de cinco años...

Se advierte expresamente que todo lo que se ha dicho sobre el término de caducidad refleja los criterios generales que la Corte estima razonable s a luz de la Constitución. Pero naturalmente, el legislador, al dictar la ley estatuaria correspondiente, podrá apartarse, determinando lo que el mismo estime razonable, siempre y cuando se ajuste a la Constitución"

El parágrafo del artículo 114 de la ley 510 establecía que "las personas que dentro de los seis (6) meses siguientes a la vigencia de la presente ley se pongan al día en obligaciones por cuya causa hubieren sido reportadas a los bancos de datos de que trata este artículo tendrán un alivio consistente en la caducidad inmediata de la información negativa, sin importar el monto de la obligación e independientemente de si el pago se produce judicial o extrajudicialmente." Sin embargo, dicho artículo fue declarado inexequible por la Suprema Corte de Justicia. No obstante, 
con el artículo 76 de la Ley 550 de 1999, la cual no se declaró inexequible, se estableció una amnistía de diez meses, por lo que se prorrogó cuatro meses más el plazo establecido en el parágrafo del art. 114 de la Ley 510.

Adicionalmente, el artículo 52 de la Ley 546 de 19999 "Sobre Regulación del Sistema de Financiación de Vivienda" establece que "los deudores de los créditos de vivienda individual a largo plazo que reestructuren sus créditos hipotecarios o entreguen sus vivie ndas en dación en pago con posterioridad al $1^{\circ}$ de enero de 1997 , tendrán derecho a que las entidades financieras los declaren a paz y salvo por el crédito respectivo y retiren sus nombres de las centrales de riesgo."

\section{Calidad de los datos}

En la Sentencia_de la Corte Constitucional SU 089/95 se establece que:

"La información debe corresponder a la verdad, ser veraz, pues no existe derecho a divulgar información que no sea cierta...La información para ser veraz debe ser completa."

En la Ley 510, Art. 114 se señala que los datos que recojan o sean objeto de tratamiento deber ser pertinentes, exactos y actualizados, de manera que correspondan verazmente a la situación real de su titular." (Artículo declarado inexequible por la Suprema Corte de Justicia).

Regulación de Seguridad, Responsabilidad del Controlador y Sanciones

No se contemplan dichas obligaciones en las regulaciones analizadas. 


\section{AUTORIDADES Y SUS FACULTADES}

\section{Autoridad Judicial}

La Corte Constitucional ha resuelto las controversias que se suscitan en el tema y ha emitido las sentencias correspondientes.

\section{Autoridad Administrativa}

Autoridad Sectorial

En la Ley 510, Art. 114 se establece que la Superintendencia Bancaria autoriza las tarifas para que los consumidores obtengan la información de su persona de los Banco s de Datos Financieros o de Solvencia Patrimonial y Crediticia. (Artículo declarado inexequible por la Suprema Corte de Justicia).

\section{SITUACIÓN DEL MERCADO DE BURÓS DE CRÉDITO}

\begin{tabular}{|l|}
\hline \multicolumn{1}{|c|}{ CENTRALES DE RIESGOS Y BURÓS DE CRÉDITO PRIVADOS } \\
\hline Central de Inteligencia Financiera (CIFIN) Central de Riesgos de la \\
Asociación Bancaria \\
Computec (Transunion), la cual tiene una central de información denominada \\
DataCrédito
\end{tabular}

DataCrédito.

Recientemente salió del mercado Covidata, afiliada de Dicom-Equifax,

con lo cual en el mercado colombiano sólo operan actualmente las dos centrales mencionadas anteriormente.

La Superintendencia Bancaria recolecta información y tiene una base datos propia pero al contrario del Banco Central de la República de Argentina no la distribuye por si misma sino a través de CIFIN y DataCrédito.

La Superintendencia tiene un convenio (firmado en 1995) en virtud del cual la Superintendencia le proporciona a CIFIN y DataCrédito información relacionada con la calificación y clasificación de endeudamiento de las personas con entidades del sector financiero a cambio de lo cual CIFIN y DataCrédito le traspasan información adicional sobre el comportamiento de las personas usuarias del sistema financiero. 


\section{Anexo \\ México}

\section{FUNDAMENTOS CONSTITUCIONALES}

\begin{tabular}{|c|c|c|}
\hline DERECHO A LA PRIVACIDAD & DERECHO A INFORMAR & $\begin{array}{lccccccc}\text { DERECHO } & \text { A } & \text { SER } & \text { INFORMADO } & \text { Y } & \text { A } & \text { RECTIFICAR } & \text { SU } \\
\text { INFORMACIOON } & \text { Y } & \text { EL DERECHO DE } & \text { DCCIÓN DE HABEAS DATA } \\
\end{array}$ \\
\hline $\begin{array}{l}\text { Art. 16.- Establece que nadie puede ser } \\
\text { molestado en su persona, familia, domicilio, } \\
\text { papeles o posesiones, sino en virtud de } \\
\text { mandamiento escrito de la autoridad } \\
\text { competente, que funde y motive la causa legal } \\
\text { del procedimiento; } \\
\text { Art. 7.- Consagra la libertad de escribir y } \\
\text { publicar escritos sobre cualquier materia, sin } \\
\text { más límites que el respeto a la vida privada, a la } \\
\text { moral y a la paz pública. }\end{array}$ & $\begin{array}{l}\text { Art. 6.- La manifestación de las ideas } \\
\text { no será objeto de ninguna inquisición } \\
\text { judicial o administrativa, sino en caso } \\
\text { de que ataque la moral, los derechos } \\
\text { de tercero, provoque algún delito o } \\
\text { perturbe el orden público;... El } \\
\text { derecho a la información será } \\
\text { garantizado por el Estado. }\end{array}$ & $\begin{array}{l}\text { Art. 6. -.. El derecho a la información será garantizado por el Estado. } \\
\text { Este derecho del individuo incluye el derecho a ser informado. No ha } \\
\text { sido reglamentado a la fecha. }\end{array}$ \\
\hline
\end{tabular}

PRINCIPAL REGULACIÓN EN LA MATERIA

\begin{tabular}{|c|c|c|}
\hline REGULACIÓN & OBJETIVOS DE LA REGULACIÓN & AMBITO DE LA REGULACIÓN \\
\hline $\begin{array}{l}\text { El artículo } 33 \text { de la Ley para Regular } \\
\text { las Entidades Financieras (LRAF) y la } \\
\text { Reglas Generales a las que deberán } \\
\text { sujetarse las Sociedades de } \\
\text { Información Crediticia de 1995, } \\
\text { reformadas en } 1997 .\end{array}$ & $\begin{array}{l}\text { El objetivo de las Reglas es regular a las } \\
\text { Sociedades de Información Crediticia (SICs), } \\
\text { que son burós de crédito que prestan el servicio } \\
\text { de información sobre operaciones activas y } \\
\text { otras de naturaleza análoga, realizadas por } \\
\text { entidades financieras. }\end{array}$ & $\begin{array}{l}\text { La regulación se enfoca sólo al ámbito financiero. Sólo comprende la } \\
\text { información crediticia. No está regulado el procesamiento de información } \\
\text { para propósitos de empleo, información médica, arrendamiento, ofertas } \\
\text { en firme, etc. }\end{array}$ \\
\hline
\end{tabular}


INFORMACIÓN TRATADA POR LOS BURÓS DE CRÉDITO

\begin{tabular}{|c|c|c|}
\hline $\begin{array}{c}\text { TIPO DE } \\
\text { INFORMACIÓN } \\
\text { TRATADA POR } \\
\text { BURÓS }\end{array}$ & SECRETO BANCARIO & SECRETO FISCAL \\
\hline 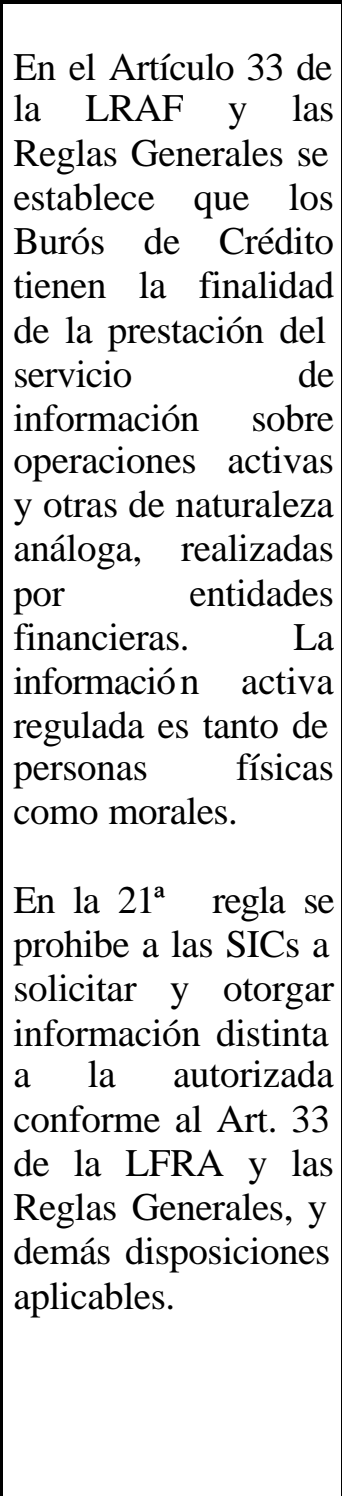 & $\begin{array}{l}\text { Ley de Instituciones de Crédito Título VI, Art. } 117 \text { (18/07/90; última reforma aplicada } \\
\text { 19/09/91) } \\
\text { El artículo } 117 \text { establece que las instituciones de crédito, sus funcionarios y empleados, en } \\
\text { ningún caso podrán dar noticias o información de los: } \\
-\quad \text { Depósitos, } \\
\text { - } \quad \text { servicios } \\
\text { - o cualquier tipo de operación } \\
\text { sino al depositante, deudor, titular o beneficiario que corresponda, a sus representantes legales } \\
\text { o autorizados para disponer de la cuenta o intervenir en la operación o servicio. } \\
\text { No están sujetos al secreto la autoridad judicial en virtud de un juicio en que el titular sea parte } \\
\text { o el acusado; y las autoridades hacendarias federales para fines fiscales } \\
\text { Art. 118: Con la salvedad de la información que sea solicitada por la CNBV, la violación del } \\
\text { secreto propio de las operaciones a que se refiere la fracción XV del artículo 46, incluso ante las } \\
\text { autoridades o tribunales en juicios o reclamaciones que no sean aquéllos entablados por el } \\
\text { Fideicomitente o Fideicomisario, comitente o mandante, contra la institución o viceversa, } \\
\text { constituirá a ésta en responsabilidad civil por los daños y perjuicios ocasionados. } \\
\text { Ley para Regular las Agrupaciones Financieras (18/07/90; última reforma 19/01/99) } \\
\text { Art. } 33 \text { (Excepción al Secreto Bancario) } \\
\text { Las entidades financieras podrán proporcionar información a empresas que tengan por objeto la } \\
\text { prestación del servicio de información sobre operaciones activas (operaciones crediticias y otras } \\
\text { de naturaleza análoga) } \\
\text { Artículo } 33-a \text { a: Con excepción de la información que proporcionen sobre operaciones activas a } \\
\text { sus usuarios, las disposiciones relativas al secreto bancario les serán aplicables a las SICs, a sus } \\
\text { funcionarios y empleados. } \\
\text { La obligación del secreto bancario a que se refiere el párrafo anterior, también es aplicable a los } \\
\text { usuarios de la información crediticia, así como a sus funcionarios y empleados, respecto de } \\
\text { dicha información. No se considerará que existe violación al secreto bancario cuando una } \\
\text { entidad financiera proporcione información sobre operaciones activas a alguna sociedad de } \\
\text { información crediticia. }\end{array}$ & $\begin{array}{l}\text { Código Fiscal de la Federación, Arts.69 y } \\
63 \\
\text { (31/12/1981; última reforma aplicada } \\
31 / 12 / 2000) \\
\text { El artículo } 69 \text { establece que el personal } \\
\text { oficial que intervenga en los diversos } \\
\text { trámites relativos a la aplicación de las } \\
\text { disposiciones tributarias estará obligado a } \\
\text { guardar absoluta reserva en lo concerniente } \\
\text { a las: } \\
\text { - Declaraciones y datos suministrados } \\
\text { por los contribuyentes o terceros } \\
\text { relacionados, así como los obtenidos en } \\
\text { el ejercicio de comprobación. } \\
\text { Dicha reserva no comprenderá la } \\
\text { información relativa a los créditos } \\
\text { fiscales exigibles de los contribuyentes, } \\
\text { que las autoridades fiscales proporcionen } \\
\text { a las sociedades de información crediticia } \\
\text { que obtengan autorización de la } \\
\text { Secretaría de Hacienda y Crédito Público } \\
\text { de conformidad con la Ley de } \\
\text { Agrupaciones Financieras (agregado en } \\
\text { diciembre de 2000) y los casos que señalen } \\
\text { las leyes fiscales y aquéllos casos en que } \\
\text { deban suministrarse datos a: } \\
\text { - Funcionarios encargados de la } \\
\text { administración y defensa de los intereses } \\
\text { fiscales nacionales; } \\
\text { Autoridades judiciales en procesos de } \\
\text { orden penal; } \\
\text { Tribunales competentes que conozcan } \\
\text { de pensiones alimenticias; }\end{array}$ \\
\hline
\end{tabular}


Ley del Mercado de Valores (02/01/75, última reforma aplicada 19/09/91) Art. 25, 72

En el Art. 25 y 72 se establece que los agentes de valores y las instituciones para el depósito de valores no podrán dar información de las operaciones que realicen o en las que intervengan, salvo las que le solicite el cliente o sus representantes legales o quien este autorizado de intervenir.

(Lo anterior no aplica a información solicitada por la autoridad judicial en un juicio en que el titular sea parte o acusado.)

No obstante lo anterior, las instituciones de crédito, las casas de bolsa y las instituciones para el depósito de valores están obligadas de proporcionar a la CNBV toda clase de información y documentos que, en ejercicio de sus funciones de inspección y vigilancia, ésta les solicite.
La reserva tampoco comprende el supuesto previsto en el artículo 63 de este Código.

En el Art. 63 se establece que los hechos que se conozcan con motivo del ejercicio de comprobación o que consten en los expedientes $\mathrm{o}$ documentos de las autoridades fiscales podrán servir para motivar las resoluciones de la SHCP o cualquier otra autoridad $\mathrm{u}$ organismo descentralizado competente en materia de contribuciones fiscales. En este caso no se viola el secreto fiscal. 
Acceso de los consumidores a su información

Según el Art.33 de la LRAF, las personas que realicen alguna gestión financiera ante usuarios de información crediticia, pueden solicitar a través del propio usuario de que se trate, los datos que éste haya obtenido de la SIC.

Según el Artículo 16 de la Ley Federal de Protección al Consumidor (LFPC), las empresas dedicadas a la investigación de crédito o recopilación de información sobre consumidores con fines mercadotécnicos están obligadas a informar gratuitamente a cualquier persona que lo solicite, si mantienen información acerca de ella. Si existe información, deben ponerla a su disposición, e informarle acerca de qué información ha compartido con terceros y la identidad de esos terceros, así como las recomendaciones que hayan efectuado. La respuesta a cada solicitud deberá darse dentro de los 30 días siguientes a su presentación.

\section{Rectificación de la Información}

Según el Art. $33^{\mathrm{a}}$ de la LRAF, las aclaraciones respecto de los datos que un usuario haya obtenido de una SIC, se deben realizar por los interesados ante los acreedores respectivos, quienes, en su caso, llevarán a cabo las gestiones conducentes ante la SIC de que se trate.

Según el Artículo16 de la LFPC, si existe ambigüedad o inexactitud en la información, la empresa (dedicada a la investigación información sobre consumidores con fines mercadotécnicos) debe efectuar de inmediato las correcciones que fundamentadamente indique la persona afectada, e informar las correcciones a los terceros que hayan recibido dicha información.

\section{Conocer del buró quien ha recibido reportes con su información}

No se contempla este derecho en la regulación.

\section{Derecho a ser excluido de listados de ofertas}

Dado el esquema de autorización que se establece en las Reglas Generales, no es posible que las SICs provean de listados a los usuarios para que éstos realicen ofertas en firme. Por ello, el Art.17 de la LFPC dice que el consumidor puede exigir a proveedores específicos y a agencias de investigación de crédito o de mercadotecnia, no ser molestado en su domicilio o lugar de trabajo para ofrecerle bienes y servicios, o para realizar dichas investigaciones, salvo autorización expresa del propio consumidor.

\section{Acción Adversa}

No se contempla en la legislación.

\section{REGULACIÓN DE LOS BURÓS DE CRÉDITO)}

\section{INICIO DE OPERACIONES} \begin{tabular}{|l|l|}
\hline De acuerdo con el Art.33 y la $8^{\mathrm{a}}$ y $9^{\mathrm{a}}$ & Especificación del Fin \\
\hline
\end{tabular}

de las Reglas Generales, para que una entidad pueda organizarse y operar como SIC, se requiere la autorización del Gobierno Federal, que compete otorgar a la SHCP discrecionalmente, oyendo la opinión del Banco de México y de la CNBV.

La $9^{a}$ Regla establece que la solicitud
La $15^{\mathrm{a}}$ de las Reglas Generales establece que las SICs sólo pueden llevar a cabo las actividades necesarias para la realización de su objeto, así como las análogas y conexas que autorice el Banco de México.

En la Ley de Protección al Consumidor se establece que queda prohibido a las empresas dedicadas a la investigación de crédito o de mercadotecnia y a sus clientes, utilizar la información con fines diferentes a los crediticios o mercadotécnicos.

\section{Límites a la Recolección}

Obtenidos por medios legítimos, Conocimiento del Consumidor

No se contempla en la regulación. 
para constituirse como SIC deberá contener lo siguiente:

Relación de accionistas indicando el capital que cada uno de ellos suscribirá y pagará, así como, en su caso, su curricula vitarum;

Relación de los consejeros y principales funcionarios de la SIC, i. incluyendo aquellos que ocupen cargos con la jerarquía inmediata inferior a la del director general , así como su curricula vitarum;

Proyecto de estatutos;

Programa General Funcionamiento, que comprenda por lo menos:

- La descripción de bs sistemas y procesos de recopilación y manejo de información;

- Las características de lo productos y servicios que prestarán a los usuarios;

- Las políticas de prestación de servicios con que pretenden operar;

- Las medidas de seguridad y control a fin de evitar el manejo indebido de la información;

- Las bases de organización;

- El programa detallado inversión a tres años;

- El calendario de apertura de oficinas y plazas en que se ubicarán; y

- La demás información y documentación que le solicite la SHCP.

La escritura constitutiva de las SICs y cualquier modificación a la misma, deberá someterse a la aprobación previa de la SHCP. Una vez aprobada,

\section{Autorización para la Transmisión}

Expresa y por escrito

Según la $3^{\mathrm{a}}$ de las Reglas Generales, los usuarios (personas físicas o morales, así como las autoridades administrativas y judiciales en sus respectivas competencias) deberán contar con la autorización expresa y por escrito de cada uno de los sujetos investigados, conteniendo su firma autógrafa, y en donde deberá constar de manera fehaciente que conocen la naturaleza y alcance de la información que se solicitará para obtener información relacionada con:

Personas físicas, $y$

Personas morales con créditos totales inferiores a cien mil UDIS.

Los usuarios que realicen consultas relacionadas con personas morales con créditos totales superiores a cien mil UDIS, no requerirán de la autorización expresa y por escrito del sujeto investigado.

Las SICs sólo pueden dar información a los usuarios que tengan autorización original (expresa y por escrito) del sujeto investigado.

Las autoridades judiciales y hacendarias federales en materia fiscal, podrán solicitar información a las SICs aún sin contar con la autorización del sujeto investigado.

Implícita en transacciones iniciadas por el consumidor

No se contempla en la regulación.

\section{Calidad de Datos}

No se contempla en la regulación.

\section{Regulación de Seguridad}

En la $20^{\mathrm{a}}$ de las Reglas Generales se establece que la SICs deberán adoptar las medidas de seguridad y control que resulten necesarias para evitar el manejo indebido de la información (acto u omisión tendiente a causar o que cause daño o perjuicio, en su persona o patrimonio al sujeto del que se posea la información).

\section{Responsabilidad de los administradores de las SICs}

En la $4^{\mathrm{a}}$ de las Reglas Generales se señala que la autoridad puede inhabilitar para desempeñar un empleo cargo o comisión dentro del sistema financiero mexicano, por un periodo de seis meses a diez años, a aquellos funcionarios o empleados de las SICs que cometan alguna violación a las disposiciones relativas al secreto bancario. Además debe repara daños y perjuicios.

Adicionalmente, en la $6^{\text {a }}$ de las Reglas Generales se establece que las SICs deberán de supervisar que los usuarios cumplan con lo señalado en el Art. 33 de la LRFA y las Reglas y demás disposiciones aplicables, en particular en lo relativo a la obligación de guardar el secreto bancario.

\section{Sanciones}

La facultad de sancionar de las distintas autoridades que regulan a las Sociedades de Información Crediticia es limitada. No se establecen sanciones por los daños y perjuicios sufridos por los consumidores. La Comisión Nacional Bancaria, que 
supervisa burós de crédito así como a sus usuarios, tiene facultades de sanción genéricas limitadas a los burós de crédito asî Público de Comercio.

como a sus usuarios que son entidades financieras. Los usuarios que no son entidades financieras no pueden ser sancionados por esta comisión por caer fuera de su ámbito de aplicación. La SHCP tiene la facultad de autorizar la

Según la $10^{\mathrm{a}}$ Regla, sólo podrán operar como SICs las Sociedades anónimas mexicanas cuyos constitución de nuevos burós y solamente puede revocar la autorización, lo cual es una sanción extrema que es poco accionistas, consejeros y principales funcionarios de los dos niveles superiores de la Sociedad, sean personas de reconocida calidad moral y, tratándose de los dos últimos, cuenten con la capacidad técnica necesaria.

aplicable. El Banco de México tiene la facultad de regular la operación de los burós de crédito pero no dispone de mecanismo de sanción alguno para hacer valer sus disposiciones.

\section{AUTORIDADES Y SUS FACULTADES}

México

\section{- Autoridades Administrativas}

\section{Autoridades Sectoriales}

Secretaría de Hacienda y Crédito Público (SHCP)

La SHCP expidió las "Reglas Generales a las que deberán sujetarse las Sociedades de Información Crediticia."

La SHCP, oyendo la opinión de Banco de México y de la Comisión Nacional Bancaria y de Valores, autoriza la constitución de Sociedades de Información Crediticia, así como también puede revocar dicha autorización.

\section{Banco de México}

Las SICs deben sujetarse en sus actividades a las disposiciones de carácter general que expida el Banco de México. Esta autoridad dictó las "Disposiciones de carácter general a las que se sujetarán las Sociedades de Información Crediticia para proporcionar su base de datos a otras Sociedades de Información Crediticia.”

\section{Comisión Nacional de Banca y Valores}

Las SICs están sujetas a la inspección y vigilancia de la Comisión Nacional Bancaria y de Valores (CNBV).

Facultades y Responsabilidades:

Capacidad regulatoria: dicta disposiciones generales; además, dicta la forma y los términ os en los que se debe conservar la autorización.

Capacidad de sanción: Puede inhabilitar para desempeñar un empleo en el sistema financiero mexicano, a aquellos funcionarios o empleados de las Sociedades que violen las disposiciones relativas al secreto bancario. Además, puede quitarles el carácter de usuarios a aquellos clientes que violen el secreto bancario, así como remover a los miembros del Consejo de Administración de la SIC cuando considere que no reúnen los requisitos necesarios o incurran en violaciones a las disposiciones aplicables.

Las SICs deben proporcionar toda clase de información y documentos que el Banco de México o cualquiera de las Comisiones encargadas de la inspección y vigilancia de las entidades financieras les soliciten, con el propósito de que tales órganos cumplan con sus funciones. 
CENTRALES DE RIESGOS Y BURÓS DE CRÉDITO PRIVADOS

En 1930, la Asociación Mexicana de Bancos formó el Departamento de Información de Créditos Duplicados.

En 1964 se creó el Senicreb.

En los años setenta los bancos establecieron la primera sociedad de información de crédito al consumo la "Central de Informes y Cobranzas"

En 1993 se constituye la primera SIC con el nombre de "Comcred".

Senicreb es operada por el Banco de México, sólo procesa información positiva y negativa de acreditados con deudas mayores a 200 mil pesos (alrededor de 20 mil dólares).

Opera un buró privado:

El Buró de Crédito, controlado por los principales bancos, procesa información negativa y positiva. (asociado con TransUnion para información sobre personas físicas y con Dun \& Bradstreet para personas morales); y

Equifax, empresa que en tres años y medio sólo logró obtener una operación incipiente y que tuvo que cerrar a principios del 2000.

Además, existe NCSI, una empresa que entre otros servicios ofrece información sobre usuarios morosos de telefonía de larga distancia a los

operadores de larga distancia.
El Senicreb es un servicio para los bancos comerciales, para la banca de desarrollo $\mathrm{y}$ otros intermediarios no financieros.

El Buró de Crédito ofrece servicios de información crediticia.

NCSI ofrece información sobre los clientes morosos del servicio telefónico de larga distancia. 


\section{Anexo \\ Perú}

FUNDAMENTOS CONSTITUCIONALES

\begin{tabular}{|c|c|c|}
\hline DERECHO A LA PRIVACIDAD & DERECHO A INFORMAR & \begin{tabular}{|l|c|c|} 
DERECHO A SER INFORMADO Y A RECTIFICAR SU & INFORMACIÓN & EL \\
DERECHO DE ACCIÓN DE HABEAS DATA & & \\
\end{tabular} \\
\hline 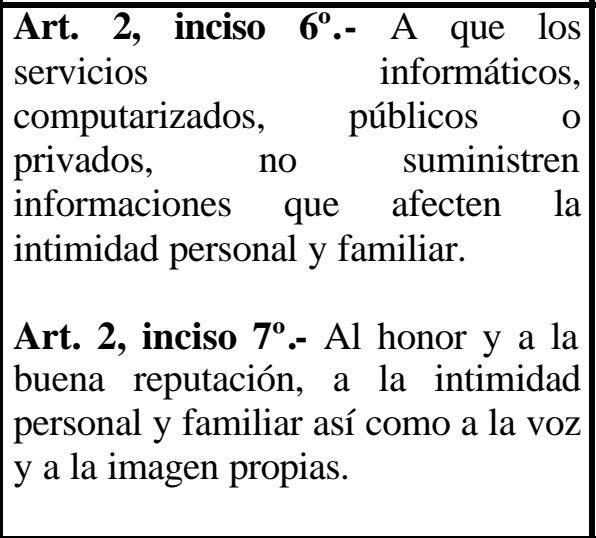 & $\begin{array}{l}\text { Art. 2, inciso } 4^{\mathbf{0}} \text {.- Toda Persona } \\
\text { tiene derecho: } \\
\text { A las libertades de información, } \\
\text { opinión, expresión y difusión } \\
\text { del pensamiento mediante la } \\
\text { palabra oral o escrita, por } \\
\text { cualquier medio de } \\
\text { comunicación social, sin previa } \\
\text { autorización ni censura ni } \\
\text { impedimentos algunos, bajo las } \\
\text { responsabilidades de la ley. }\end{array}$ & $\begin{array}{l}\text { Art. 2, inciso } \mathbf{5}^{\circ} \text {.- A solicitar sin expresión de causa la información que requiera y a } \\
\text { recibirla de cualquier entidad pública, en el plazo legal, con el costo que suponga el } \\
\text { pedido. Se exceptúan las informaciones que afecten la intimidad personal y las que } \\
\text { expresamente se excluyan por ley o por razones de seguridad nacional. } \\
\text { El secreto bancario y la reserva tributaria pueden levantarse a pedido del juez, del Fiscal } \\
\text { de la Nación, o de una comisión investigadora del Congreso con arreglo a ley y siempre } \\
\text { que se refieran al caso investigado. } \\
\text { Art. 200.- Son garantías constitucionales: } \\
\text { 3. La Acción de Habeas Data, que procede contra el hecho u omisión, por parte de } \\
\text { cualquier autoridad, funcionario o persona, que vulnere o amenaza los derechos a que se } \\
\text { refiere el Art. } 2 \text { inciso 5) y 6) de la constitución. }\end{array}$ \\
\hline
\end{tabular}

\section{PRINCIPAL REGULACIÓN EN LA MATERIA}

\begin{tabular}{|c|c|c|}
\hline & & \\
\hline $\begin{array}{l}\text { ales Privadas de } \\
\text { nación de } \\
\text { os y de } \\
\text { ción al titular de } \\
\text { ormación. } \\
01\end{array}$ & $\begin{array}{l}\text { er cómo se debe llevar a cabo la tramitaci } \\
\text { le Habeas Data, en tanto se dicte la Ley esp } \\
\text { les judiciales competentes ante las cuales } \\
\text { consentida o ejecutariada; iii) disposiciones } \\
\text { a supletoria para la tramitación y conocir }\end{array}$ & $\begin{array}{l}\text { Dichas CEPRIS tratan información de } \\
\text { riesgos relacionada tanto a personas } \\
\text { naturales como a personas jurídicas. } \\
\text { No se consideran CEPIRS, para efectos } \\
\text { de la Ley, a las entidades de la } \\
\text { Administración Pública que tengan a su } \\
\text { cargo registros o bancos de datos que } \\
\text { almacenen información con el propósito } \\
\text { de darle publicidad con carácter } \\
\text { general, sin importar la forma como se } \\
\text { haga pública dicha información. }\end{array}$ \\
\hline
\end{tabular}


Agosto 1998

Dicho proyecto no se aprobó por lo que a la fecha está archivado en el Congreso.

Ley No. 26702, Ley General del Sistema Financiero y del Sistema de Seguros y Orgánica de la Superintendencia d Banca y Seguros. $N$. 26702 (Art. 158-160) 06/12/96 exceptuarse del mencionado derecho de acceso.

Establecer reglas especiales para regular las instancias y los plazos para que los interesados agoten la vía administrativa. Si dicha vía se agota, el interesado puede cursar el requerimiento por conducto notarial con el fin de interponer la demanda de Habeas Data.

Los artículos 158-160 de la Ley No. 26702 tienen como objetivos:

Establecer la organización de las Centrales de Riesgos e información que contendrá. Establecer la obligación de las empresas de los sistemas financiero o de seguros de suministrar periódica y oportunamente la información relevante.

Establecer centrales de riesgo privadas.
El Proyecto de Ley No. 3903 regula a la administración pública, la cual comprende a las entidades a las que se refiere el Art. 1 de la Ley de Normas Generales de Procedimientos Administrativos de Perú.

Regula a la Central de Riesgos de Crédito de la Superintendencia Bancaria e instituciones financieras

INFORMACIÓN TRATADA POR LOS BURÓS DE CRÉDITO

Perú

\section{TIPO DE INFORMACIÓN TRATADA POR BURÓS \\ La Ley que Regula las CEPIRS distingue entre los}

siguientes tipos de información:

\section{Información de Riesgos}

Relacionada con obligaciones o antecedentes financieros, comerciales, tributarios, laborales, de seguros o cualquier otra información de una persona natural o jurídica vinculada a las características, históricas y presentes, de su pasivo ( información sobre los créditos que tenga la persona).

Las operaciones pasivas de las empresas del sistema financiero con sus clientes (es decir, la información activa de la persona) está protegida por el secreto bancario.

\section{Información Sensible}

Referida a las características físicas, morales o emocionales de una persona natural, o a hechos o circunstancias de su vida afectiva o familiar, tales como los hábitos personales, las ideologías y opiniones políticas, las creencias o convicciones religiosas, los estados de salud físicos o psíquicos y la vida sexual $u$ otras análogas que afecten su intimidad

\section{SECRETO BANCARIO}

Ley General del Sistema Financiero y del Sistema de Seguros y

Orgánica de la Superintendencia de Banca y Seguros (09/12/96, modificada el 06/05/99)

(Art. 140) Alcance del secreto bancario. Está prohibido a las empresas del sistema financiero, así como a sus directores y trabajadores, suministrar cualquier información sobre las operaciones pasivas con sus clientes, a menos que medie autorización escrita de éstos.

También se encuentran obligados a observar el secreto bancario: El Superintendente y los trabajadores de la Superintendencia, salvo que se trate de la información respecto a los titulares de las cuentas corrientes cerradas por el giro de cheques sin provisión de fondos. Los directores y trabajadores del Banco Central; Los directores y trabajadores de las sociedades de auditoría y de las empresas clasificadoras de riesgo.

No rige esta norma tratándose de movimientos sospechosos de lavado de dinero, en cuyo caso se deberá de comunicar dichos movimientos al Fiscal.

El artículo 142 indica la información no comprendida dentro del Secreto Bancario. Información de carácter global, particularmente en los siguientes casos:

\section{SECRETO FISCAL}

Decreto Supremo $N^{\circ}$ 135-99-EF

(Publicado el 19 de agosto de 1999)

Libro 2, Título III, Art.85

Tendrá carácter de información reservada:

la cuantía y la fuente de las rentas

los gastos

la base imponible

cualesquiera otros datos relativos a ellos

contenidos en las declaraciones e informaciones que obtengan por cualquier medio de los contribuyentes, responsables o terceros.

La reserva no abarca:

las exhibiciones de documentos y declaraciones que ordene:

el Poder Judicial en los procedimientos sobre: tributos, 
Dicha información no puede estar contenida en los bancos de datos de las CEPIRS ni ser difundida en sus reportes de crédito.

\section{Información Tributaria}

Las obligaciones tributarias de la persona natural o jurídica están incluidas en la categoría de información de riesgo. Cabe notar que la reserva tributaria no abarca la deuda exigible de las personas. Es decir, su transmisión de parte de las CEPIRS no requiere consentimiento.

Las CEPIRS no podrán contener en sus bancos de datos ni difundir en sus reportes de crédito información que viole el secreto bancario o la reserva tributaria
Cuando sea proporcionada por la Superintendencia al Banco Central y a las empresas del sistema para uso estadístico o formulación de política monetaria;

Cuando se suministre a bancos e instituciones financieras del exterior con los que se mantenga corresponsalía;

Cuando lo soliciten las sociedades de auditoría o firmas especializadas en clasificación de riesgos;

Cuando lo requieran personas interesadas en la adquisición de no menos del 30\% del capital accionario de la empresa.

No se viola el secreto cuando se divulga información sobre las sumas recibidas de los distintos clientes para fines de liquidación de la empresa.

El secreto Bancario tampoco rige cuando sea requerida por:

- Jueces y tribunales en juicios en el que sea parte el cliente;

- Fiscal de la Nación, en los casos de presunción de enriquecimiento ilícito de funcionarios o servidores públicos o de quienes hayan administrado dinero del Estado;

- Fiscal de la Nación o gobernador de un país con el que tengan convenio de combatir el tráfico ilícito de drogas, terrorismo, lavado de dinero o de activos, y operaciones ejecutadas por personas involucradas en actos delictivos.

- Presidente de una Comisión investigadora del poder legislativo, en relación con hechos que comprometan el interés público;

El Superintendente en ejercicio de sus facultades de supervisión;

Los que accedan a dicha información secreta deben mantenerla con

dicho carácter en tanto ésta no resulte incompatible con el interés público. alimentos, disolución de la sociedad conyugal o en los procesos penales.

el Fiscal de la Nación en los casos de presunción de delito;

la Comisión de Fiscalización o Comisiones Investigadoras del Congreso siempre que se refiera al caso investigado.

Tampoco puede incluirse dentro de la reserva tributaria:

- La publicación que realice la Administración tributaria de los contribuyentes, los tributos determinados por los citados contribuyentes, los montos pagados, deudas tributarias materia de fraccionamiento y/o aplazamiento, y su deuda exigible (la deuda exigible dará lugar a las acciones de coerción para su cobranza).

- La reserva tributaria no impide que se difundan montos de deuda tributaria (deuda exigible). 


\section{Derecho de acceso de los consumidores a su propia información}

Los titulares podrán acceder, una vez al año o cuando la información contenida en los bancos de datos haya sido objeto de rectificación, a la información crediticia que les concierne que estuviese registrada en los bancos de datos administrados por las CEPIRS. Esta información será acompañada de una reseña explicativa de los derechos desarrollados en el presente Título, así como de los procedimientos para hacerlos valer. La información podrá ser obtenida por el titular de la información:

a) De forma gratuita , mediante la visualización en pantalla de los datos o;

b) Mediante el pago de una suma de dinero, que no excederá de los costos necesarios para la emisión del documento correspondiente, mediante un escrito, copia o fotocopia, en forma legible e inteligible, sin utilizar claves o códigos que requieran de dispositivos mecánicos para su adecuada comprensión.

La información a que se refiere este artículo incluirá, a solicitud del titular, la identidad de las fuentes de información registrada en los bancos de datos, con excepción de las fuentes de acceso público y la identidad de todas las personas que obtuvieron un reporte de crédito sobre el titular en los últimos doce meses, así como la fecha en que se emitieron tales reportes

\section{Modificación, Supresión y Rectificación de información}

En caso de considerar que la información contenida en los bancos de datos es ilegal, inexacta, errónea o caduca, el titular de dicha información podrá solicitar que ésta sea revisada por cuenta y costo de las CEPIRS y, de ser el caso, que se proceda a su modificación o cancelación. La solicitud para la revisión de la información deberá ser interpuesta por escrito, acompañando los medios probatorios que acrediten que el solicitante es el titular de la información. En dicha solicitud se precisará los datos concretos que se desea revisar, acompañando la documentación que justifique el pedido. Dentro del plazo de siete (7) días útiles desde la presentación de la solicitud, las CEPIRS informarán por escrito al titular de la información si su pedido es procedente o si ha sido denegado. Alternativamente, dentro del mismo plazo, las CEPIRS podrán prorrogar hasta por catorce (14) días útiles adicionales el plazo para emitir una decisión definitiva, debiendo para ello, hasta que finalice el plazo, difundir que dicha información es materia de revisión. Vencidos los plazos mencionados en el párrafo precedente, el titular de la información que no hubiese recibido una comunicación por escrito que responda de manera definitiva su solicitud, entenderá denegado su pedido.

En caso que se verifique que la información contenida en los bancos de datos es ilegal, inexacta, errónea o caduca, la CEPIR, a su cuenta y costo, enviará comunicaciones rectificatorias, a quienes les hubiera proporcionado dicha información en los doce meses anteriores a la fecha en que se verifique el problema.

Las CEPIRS establecerán los procedimientos internos necesarios para brindar una eficiente, efectiva y oportuna atención a las solicitudes de revisión presentadas, así como los mecanismos de comunicación y coordinación adecuados con las fuentes de las que recolecta la información.

\section{Derecho de Acción de Protección de Datos (Habeas Data)}

Los titulares de la información que no sean considerados consumidores para efectos del Decreto Legislativo N $^{\circ} 716$, Ley de Protección al Consumidor, podrán solicitar judicialmente la tutela de los derechos enunciados en este Subtítulo en la vía del Proceso Sumarísimo.

Para poder interponer una demanda con el fin de que se modifique, cancele o rectifique una información de riesgos que se considere ilegal, inexacta, errónea o caduca, el titular de dicha información deberá previamente obtener un pronunciamiento por parte de la CEPIRS, expreso o tácito, denegando una solicitud de revisión de o rectificación.

En contraste, los titulares de la información que sí son considerados consumidores, después de haber sido denegado el acceso, modificación o rectificación a sus datos, interponen la demanda frente al INDECOPI.

\section{Conocer del buró quien ha recibido reportes con su información}


La información a incluirá, a solicitud del titular, la identidad de las fuentes de información registrada en los bancos de datos, con excepción de las fuentes de acceso público y la identidad de todas las personas que obtuvieron un reporte de crédito sobre el titular en los últimos doce meses, así como la fecha en que se

emitieron tales reportes

Derecho a ser excluido de listados de ofertas

No está especificado en la Ley

\section{Acción Adversa}

No está especificado en la Ley 
REGULACIÓN DE LOS BURÓS DE CRÉDITO Y AGENCIAS DE INFORMACIÓN (CONTROLADORES DE DATOS)

INICIO DE OPERACIONES

\section{Las CEPIRS pueden constituirse bajo Especificación del fin}

cualquiera de las formas permitidas por

la Ley General de Sociedades.

Las CEPIRS deberán contar como mínimo, con las siguientes características de organización y funcionamiento:

a) Personal directivo y técnico de reconocida solvencia moral $y$ económica;

b) Infraestructura informática adecuada para el debido tratamiento de la Información recolectada;

c) Procedimientos internos para una eficiente, efectiva y oportuna atención de consultas, quejas y reclamos, cuando sea el caso; $y$,

d) Controles internos que proporcionen seguridad en el desarrollo de sus actividades, así como procedimientos de validez de la información procesada.

Están impedidos de ser accionistas, directores, gerentes o funcionarios que tengan capacidad de decisión dentro de las CEPIRS:

a) Los impedidos para ser directores y gerentes de conformidad con la Ley General de Sociedades;

b) Los condenados por delitos dolosos; c) Los declarados en proceso de insolvencia, mientras dure éste;

d) Los que registren protestos de documentos en los últimos cinco años;

\section{Autorización}

\section{PRINCIPIOS PARA EL TRATAMIENTO}

La información recolectada solo podrá ser utilizada para los fines señalados en la ley.

Las CEPIRS podrán recolectar información de riesgos directamente de los titulares, debiendo previamente informarles a éstos de modo expreso, preciso e inequívoco la existencia del banco de datos, la finalidad de la recolección de la información y los potenciales destinatarios de ésta.

\section{Límites a la Recolección}

Obtenidos por medios legítimos

La recolección de información no podrá efectuarse por medios fraudulentos o ilícitos.

Las CEPIRS sólo podrán recolectar información de riesgos para sus bancos de datos tanto de fuentes públicas como de fuentes privadas, sin necesidad de contar con la autorización del titular de la información.

Las CEPIRS puede celebrar contratos privados directamente con la persona natural o jurídica que tenga o haya tenido relaciones civiles, comerciales, administrativas, bancarias, laborales o de índole análoga con el titular de la información, siempre y cuando ésta se refiera a los actos, situaciones, hechos, derechos y obligaciones materia de tales relaciones o derivadas de éstas y que no constituyan violación del secreto profesional Igualmente podrán celebrar contratos privados directamente con las entidades de la Administración Pública que recolecten o utilicen información de riesgos en el ejercicio de sus funciones y competencias legalmente establecidas, salvo que tal información haya sido declarada o constituya un secreto comercial o industrial.

\section{Autorización para la Transmisión}

Las CEPIRS podrán difundir a terceras personas, de manera onerosa o a título gratuito, la información de riesgos que contengan en sus bancos de datos. Para tales efectos, las CEPIRS podrán implementar en la forma que estimen conveniente, procedimientos automatizados para la transmisión, comunicación o acceso de datos a terceros, así como el registro obligatorio de éstos, debiendo cautelar los derechos de los titulares de la información. No se requiere autorización explícita o implícita por parte del titular de datos para la transmisión de datos.

\section{Límites al plazo de retención de los datos}

La información será conservada durante el plazo legal establecido o, en su defecto, durante el tiempo necesario para los fines para los que fue recolectada.

Las CEPIRS no podrán contener en sus bancos de datos ni difundir en sus reportes de crédito la siguiente información: - Información referida al incumplimiento de obligaciones de naturaleza civil, comercial o tributaria, cuando (i) hayan transcurrido cinco (5) años desde que la obligación fue pagada o extinguida en forma total o (ii) haya prescrito el plazo legal para exigir su cumplimiento, lo que suceda primero;

Información referida a sanciones exigibles de naturaleza tributaria, administrativa u otras análogas, de contenido económico, cuando (i) hayan transcurridos cinco (5) años desde que se ejecutó la sanción impuesta al infractor o se 
e) Los que, como directores o gerentes de una persona jurídica, hayan resultado administrativamente responsables por actos que han merecido sanción grave; f) Los que, directa o indirectamente, tengan créditos vencidos por más de ciento veinte (120) días, o que hayan ingresado a cobranza judicial; $y$,

g) Los que sean titulares, socios o accionistas de empresas vinculadas, a los que se refiere el literal $b$ ) del artículo $54^{\circ}$ de la Ley del Impuesto General a las Ventas e Impuesto Selectivo al Consumo, que tengan créditos vencidos por más de ciento veinte (120) días, o que hayan ingresado a cobranza judicial. extinguió por cualquier otro medio legal, o (ii) haya prescrito el plazo legal para exigir su ejecución, lo que suceda primero;

- Información referida a la insolvencia o quiebra del titular de la información, cuando haya transcurrido cinco (5) años desde que se levantó el estado de insolvencia o desde que se declaró la quiebra; o,

\section{Calidad de los datos}

La información será lícita, exacta, veraz y actual de forma tal que responda a la situación real del titular de la información en determinado momento. Si la información resulta ser ilícita, inexacta, errónea o caduca, en todo o en parte, deberán

adoptarse las medidas correctivas, según sea el caso, por parte de las CEPIRS, sin perjuicio de los derechos que

corresponden a los titulares de dicha información; y,

\section{Regulación de Seguridad}

Las CEPIRS deberán adoptar las medidas de índole técnica y administrativa destinadas a garantizar la seguridad de la información que manejen, a fin de evitar su alteración, pérdida, tratamiento o acceso no autorizado.

\section{Responsabilidad de las CEPIRS y de los usuarios de las CEPIRS}

La responsabilidad civil de las CEPIRS por los daños ocasionados al titular por efecto del tratamiento o difusión de información, será objetiva. Las CEPIRS podrán repetir contra las fuentes proveedoras de información cuando el daño sea ocasionado como consecuencia del tratamiento de información realizada por éstas.

Igualmente existe responsabilidad por parte de los usuarios o receptores de información de riesgos proporcionada por las CEPIRS, en caso de utilización indebida, fraudulenta o de modo que cause daños al titular de la información, misma que se determinará conforme a las normas de responsabilidad civil y penal a que hubiese lugar. Sin perjuicio de lo anterior, las CEPIRS podrán repetir contra los usuarios o receptores de información en caso de haber asumido responsabilidad frente al titular de la información o terceros, en los supuestos antes indicados en que esté involucrada la responsabilidad de los usuarios o receptores de información.

\section{Sanciones}

La INDECOPI puede establecer sanciones administrativas e imponer a las CEPIRS que incurran en alguna infracción a la presente Ley las siguientes medidas correctivas:

a) La modificación o cancelación de la información de riesgos registrada en sus bancos de datos; y,

b) La rectificación de la información comercial de riesgos difundida en el mercado, por cuenta y costo del infractor, en la forma que determine la Comisión.

Adicionalmente a las sanciones administrativas a que hubiera lugar respecto de las CEPIRS, la INDECOPI también puede imponer sanciones a las fuentes proveedoras de la información que incurran en alguna infracción a la presente Ley y, en general, a terceras personas que, directa o indirectamente, han proporcionado información de riesgos a las CEPIRS que resulte ilegal, inexacta, errónea o caduca, la modificación, actualización, rectificación o cancelación de la información de riesgos antes indicada que se encuentre registrada en sus bases de datos. 
- Autoridad Administrativa

La Superintendencia de Banca y Seguros tiene a su cargo la Central de Riesgos Pública.

De acuerdo con la Ley que Regula las CEPIRS la Comisión de Protección al Consumidor del Instituto Nacional de Defensa de la Competencia y de la Protección

de la Propiedad Intelectual-INDECOPI es el órgano administrativo competente para conocer de las infracciones tipificadas en el artículo precedente e imponer las sanciones administrativas y las medidas correctivas a las que hubiere lugar. Para tales efectos, la Comisión aplicará el procedimiento único contemplado en el título

V del Decreto Legislativo No 807 - Facultades, Normas y Organización del INDECOPI.

\section{- Autoridad Judicial}

El Habeas Data se tramita ante el Juez de Primera Instancia en lo Civil de turno del lugar en donde tiene su domicilio el demandante, o donde se encuentren ubicados los archivos o en el que corresponda al domicilio del demandado, sea esta persona natural o jurídica, pública o privada, a ele cción del demandante.

Si la afectación de derechos se origina en archivos federales, conocerá de la demanda la Sala Civil de turno de la Corte Superior de Justicia respectiva, la que encargará a un Juez de Primera Instancia en lo civil su trámite. 


\begin{tabular}{|c|c|}
\hline $\begin{array}{l}\text { CENTRALES DE RIESGOS Y BURÓS DE CRÉDITO } \\
\text { PRIVADOS }\end{array}$ & $\overline{\mathrm{CIOS}}$ \\
\hline $\begin{array}{l}\text { La Superintendencia comienza la entrega de la } \\
\text { información de riesgo crediticio a las empresas del } \\
\text { sistema financiero en el año de } 1967 \text { con el documento } \\
\text { denominado "Boletín de Deudores". Luego, a partir de } \\
\text { 1991, se crea el área de Central de Riesgos de la } \\
\text { Superintendencia de Banca y Seguros (SBS). } \\
\text { La Central de la SBS comparte la siguiente información } \\
\text { con las centrales de riesgo privadas: } \\
\text { (i) deudas consolidadas mayores que \$ } 5000 \text { dólares } \\
\quad \text { de los Estados Unidos. } \\
\text { (ii) deudas de consumo a partir de Un Nuevo Sol; } \\
\text { (iii) cierre de cuentas corrientes; } \\
\text { (iv) anulación de tarjetas de crédito. } \\
\text { Las Centrales de Riesgos privadas inician sus } \\
\text { operaciones en 1995. Actualmente operan dos Centrales } \\
\text { de Riesgo Privadas: } \\
\text { - Infocorp S.A. Se crea en 1995 por el Banco de } \\
\text { Crédito del Perú, Banco Wiese y Equifax a través de } \\
\text { DICOM, una filial de Equifax en Chile. Equifax } \\
\text { tiene el } 51 \% \text { del capital social y los bancos el } 49 \% \text {. } \\
\text { - Certicom S.A. } \\
\text { - En mayo de 2000 cerró sus operaciones el Buró de } \\
\text { Privado Riesgo Cero. Esta empresa estaba } \\
\text { asociada a TransUnion. } \\
\text { - } \\
\text { - } \\
\text { - Las Cámaras de Comercio envían información a los } \\
\text { Burós de Crédito privados. }\end{array}$ & $\begin{array}{l}\text { Infocorp } \\
\text { Servicios: } \\
\text { - Directorio de personas, } \\
\text { - Deuda SBS, o sea mayor a } \$ 5,000 \text { USD de personas naturales o jurídicas del sistema financiero. } \\
\text { (Deuda Directa: vigente, vencida y judicial y Contingente. También garantías, intereses y comisiones } \\
\text { por cobrar, créditos otorgados, monto, número de acreedores) } \\
\text { - Cuentas corrientes cerradas } \\
\text { - Tarjetas de Crédito Anuladas } \\
\text { - Boletín de Protestos (letras, pagarés y "warrants") } \\
\text { - Deudas de consumo, o sea menor que } \$ 5,000 \text { dólares de los Estados Unidos. } \\
\text { - Sistema Consolidado de Morosidad, deudas vencidas o en cobranza judicial } \\
\text { - } \quad \text { Indicador de Consultas } \\
\text { - Directorio SUNAT y Negativo SUNAT, datos de las personas en el padrón del RUC y deudas } \\
\text { tributarias en cobranza coactiva y omisiones a la declaración. } \\
\text { - } \quad \text { Verificación de Trabajo y Domicilio } \\
\text { - } \quad \text { Representante legal } \\
\text { - Protesto por girados } \\
\text { - Consolidada SBS x Deudor } \\
\text { - } \quad \text { Actividad comex (comercio exterior) } \\
\text { - } \quad \text { Revisión de Reclamos } \\
\text { Cabe destacar que en verificación de trabajo incluye la verificación de trabajadores dependientes e } \\
\text { independientes, en la cual se recoge datos del titular como sueldo, antigüedad, cargo y datos de la } \\
\text { empresas en donde trabaja o del que es propietario (como actividad económica, número de trabajadores, } \\
\text { datos del inmueble, etc.) Además, si es una persona independiente también se incluyen pagos de AFP, } \\
\text { IPSS y la SUNAT, entre otros. } \\
\text { Certicom } \\
\text { Servicios de información de: } \\
\text { - Endeudamientos consolidados mayores que } \$ 5,000 \text { dólares de los Estados Unidos, anulación de } \\
\text { tarjetas de crédito y cierre de cuentas corrientes (información proporcionada por la SBS) } \\
\text { - Protestos de letras, pagares y "warrants" y sus regularizaciones (información proporcionada por la } \\
\text { - Cámara de Comercio de Lima) } \\
\text { - } \quad \text { Enorosidad comercial (información proporcionada las casas comerciales) } \\
\text { bancos) } \\
\text { - Cobranzas coactivas (in información proporcionada por la SUNAT) }\end{array}$ \\
\hline
\end{tabular}




\section{Anexo \\ Estados Unidos}

PRINCIPAL REGULACIÓN EN LA MATERIA

\begin{tabular}{|c|c|c|}
\hline REGULACIÓN & OBJETIVOS DE LA REGULACIÓN & AMBITO DE LA REGULACIÓN \\
\hline $\begin{array}{l}\text { El Freedom of } \\
\text { Information } \\
\text { (FOIA) de } 1966 \text { y } \\
\text { Enmiendas. } \\
\begin{array}{l}\text { Modificado en enero } 2 \\
\text { de } 1991 .\end{array}\end{array}$ & $\begin{array}{l}\text { El FCRA tiene como objetivos: } \\
\text { i. } \quad \text { proteger la privacidad de la información de los reportes del consumidor y } \\
\text { ii. } \quad \text { garantizar que la información que ofrecen las agencias de información } \\
\text { ("burós de crédito") sea tan veraz y precisa como sea posible. } \\
\text { iii. hacer que los burós de crédito adopten procedimientos razonables para } \\
\text { apoyar el comercio permitiendo el flujo del crédito al consumo, las decisiones de } \\
\text { contratación de personal, las de los seguros y otras necesidades de información, de } \\
\text { tal forma que la información proporcionada por los burós de crédito sea justa para } \\
\text { el consumidor, y se respete la confidencialidad, veracidad, relevancia y uso } \\
\text { apropiado de dicha información. } \\
\text { El FOIA tiene como objetivo normar el acceso a la información que obra en poder } \\
\text { del gobierno. } \\
\text { Establece lineamientos para regular la relación entre las autoridades que tienen la } \\
\text { información pública y las personas que la solicitan. Establece los procedimientos } \\
\text { para dirimir disputas por la vía administrativa o bien por la vía judicial. }\end{array}$ & $\begin{array}{l}\text { El FCRA regula la industria de agencias de } \\
\text { reportes del consumidor que incluye a los burós } \\
\text { de crédito. } \\
\text { El FOIA regula a las "agencias" } \\
\text { gubernamentales, definidas como: cualquier } \\
\text { departamento ejecutivo, departamento militar, } \\
\text { corporación gubernamental, corporación } \\
\text { controlada por el gobierno o cualquier otro } \\
\text { establecimiento en la rama ejecutiva del } \\
\text { gobierno, que tengan información pública en su } \\
\text { poder. }\end{array}$ \\
\hline $\begin{array}{l}\text { El Título V de la Ley } \\
\text { Gramm-Leach-Bliley } \\
\text { (Octubre 1999) } \\
\text { modificada por el } \\
\text { Financial Information } \\
\text { Privacy Protection Act } \\
\text { (Mayo 2000) }\end{array}$ & $\begin{array}{l}\text { Establecer la obligación por parte de las instituciones financieras de respetar la } \\
\text { privacidad de sus clientes y proteger la seguridad y confidencialidad del la } \\
\text { información personal no-pública de sus clientes. }\end{array}$ & $\begin{array}{l}\text { La Ley Gramm-Leach-Bliley aplica a todas la } \\
\text { instituciones financieras, como están definidas en } \\
\text { la sección 4k del Bank Holding Company Act de } \\
\text { 1956. En general, "Institución Financiera" } \\
\text { significa cualquier institución dedicada a } \\
\text { negocio de proveer servicios financieros a } \\
\text { clientes que mantienen un crédito, depósito, } \\
\text { fideicomiso o cualquier cuenta financiera o } \\
\text { relación con la institución. } \\
\text { Incluye: Instituciones de depósito, intermediarios } \\
\text { de la Bolsa (broker o dealer), compañía de } \\
\text { inversión, compañías de seguros, compañías } \\
\text { financieras o de crédito, compañías que expiden } \\
\text { tarjetas de crédito u operador de un sistema de } \\
\text { tarjetas de crédito, agencias de reportes del } \\
\text { consumidor que compilan y mantienen archivos } \\
\text { de los consumidores a nivel nacional. }\end{array}$ \\
\hline
\end{tabular}




\begin{tabular}{|l|l|l|}
\hline & & $\begin{array}{l}\text { No incluye: A cualquier persona o entidad en } \\
\text { relación a la actividad financiera sujeta a la } \\
\text { jurisdicción de la Commodity Futures Trading } \\
\text { Commission, así como a cualquier entidad que } \\
\text { opera bajo el Farm Credit Act de 1971. } \\
\text { Cabe notar que las mismas reglas establecidas en } \\
\text { el Título V de la Gramm-Leach-Bliley, se aplican } \\
\text { a los terceros, sean o no instituciones financieras, } \\
\text { que reciban la información personal no-pública } \\
\text { de las instituciones financieras. }\end{array}$ \\
\hline
\end{tabular}

\section{INFORMACIÓN TRATADA POR LOS BURÓS DE CRÉDITO}

Estados Unidos

Bajo el Fair Credit Reporting Act (1997) se distingue la siguiente información:

Reporte del consumidor: se refiere a cualquier comunicación, oral o escrita, de cualquier información de un consumer reporting agency ("burós de crédito") con referencia a la calidad, situación o capacidad crediticia, el carácter, la reputación general, características personales o modo de vida, que sea usada o vaya a ser usada o recolectada total o parcialmente para el propósito de servir como un factor para establecer la elegibilidad de un consumidor para obtener crédito, seguro, y empleo, entre otros.

Hay diferentes tipos de reportes del consumidor, como:

Reporte de crédito: contiene 4 tipos de información:

Información que identifica de quién es el reporte, y contiene datos como el nombre, último domicilio, estado civil, número de seguridad social, fecha de nacimiento, nombre del cónyuge, número de personas dependientes, domicilio anterior e información laboral;

Información crediticia del consumidor, la cual incluye: número de cuentas, nombre del acreedor, el monto del último pago, el límite de crédito y de tiempo de pago de la cuenta;

Información de origen público;

- Información de todos aquellos acreedores que hayan obtenido una copia del reporte de crédito.

El reporte de crédito no incluye ninguna información acerca del carácter, estilo de vida, religión, origen nacional, afiliación política, preferencias sexuales, amigos o parientes, de la persona. Los burós de crédito tampoco deberán transmitir o recolectar información del historial médico de la persona.

Reporte de investigación: son reportes detallados que incluyen entrevistas con los vecinos o conocidos del consumidor (sujeto investigado), acerca de su estilo de vida, carácter y reputación. Estos reportes podrán ser usados en conexión con solicitudes de seguro o empleo.. El consumidor (sujeto investigado) deberá ser notificado por escrito cuando alguna compañía solicite un reporte de este tipo. La notificación deberá explicar su derecho a pedir cierta información del reporte a la eompañ́a en la eual hizo su solicitud. Si es rechazada tal solicitud, puede obtener información adicional del buró de crédito y en este caso el buró de crédito no tiene que revelar las fuentes de información. 
Reporte para propósitos de empleo: aquél que tiene el propósito de evaluar un consumidor para un empleo, promoción, renuncia o retención como empleado. Para hacer un reporte para propósitos de empleo se le tiene que notificar por escrito al consumidor que se va a hacer dicho reporte y que el consumidor autorice por escrito que se haga ese reporte.

Información médica: La que se obtiene de médicos, hospitales, clínicas o instituciones médicas. Para obtenerla se requiere del consentimiento del individuo a quien se refiere la información.

El Título V de la Ley Gramm-Leach-Bliley (1999), modificado por el Financial Information Privacy Protection Act (2000) tiene como objetivo proteger la información personal no-pública en poder de las entidades financieras, la cual se define como:

A. Cualquier información que identifique a una persona, incluyendo el Número del Seguro Sociat

Provista por el consumidor a la institución financie ra en una solicitud o de otra manera, para obtener un producto o servicio de una institución financiera.

Resultante de una transacción entre la institución financiera y un consumidor que involucre un producto o servicio financiero,

Obtenida por una institución financiera mientras provee un producto o servicio financiero al consumidor, sin incluir a la información que está disponible públicamente.

B. Cualquier lista, descripción o agrupamiento de uno o más consumidores de la institución financiera que se derive utilizando cualquier información no-pública en adición a la que sí es pública. No incluye las listas, descripciones o agrupamientos de consumidores que se derive sin usar información personal nopública.

Por ende, la definición de información personal no-pública incluye la información pasiva y activa de las instituciones financieras. 


\section{DERECHOS DE LOS CONSUMIDORES RESPECTO A SU INFORMACIÓN}

\section{Derecho de acceso de los consumidores a su información y a conocer del buró quién ha recibido reportes con su información}

De acuerdo al FCRA, ante la solicitud del consumidor, la consumer reporting agency debe informarle de todo lo que contiene su reporte, y darle una lista de todo aquél que haya solicitado su reporte durante el último año (dos años para solicitudes relacionadas de empleo).El consumidor tiene derecho a recibir un reporte gratis cuando una compañía toma una acción adversa contra un consumidor y éste solicita el reporte dentro de los 60 días de tener conocimiento de ello. Además,

tiene derecho a recibir un reporte gratis al año si:

está desempleado y planea buscar trabajo en un plazo no mayor que 60 días,

recibe asistencia social, $\mathrm{o}$

-.st reporte es erróneo a causa de fraude.

EL FCRA establece un precio tope, de \$8 USD, al cobro que un buró de crédito puede hacer a un consumidor que solicita su reporte.

El Derecho de Acceso de los consumidores a su información que está en manos de las instituciones financieras se regula por el Título V de la Gramm-LeachBliley(1999), modificado por el Financial Information Privacy Protection Act (2000). Dicho acceso se establece de manera muy genérica y amplia (no establece plazos y procedimientos) y se deja a las autoridades el emitir regulaciones adicionales en la materia.

En general, ante la solicitud del consumidor, una institución financiera debe hacer disponible al consumidor la información sobre él que tenga bajo su control y que esté razonablemente disponible. No obstante, la institución financiera no está obligada a dar acceso al consumidor a información resultado de un algoritmo usado para derivar calificaciones de crédito o de riesgo, así como predicciones. Tampoco está obligada a crear nuevos archivos para cumplir con el requerimiento del consumidor o a dar información integrada, de alguna manera, para cumplir con esfuerzos de prevención de fraude, lavado de dinero u otras conductas fraudulentas. Finalmente, no está obligada a dar acceso a información que se requiera conservar como confidencial por un ley federal.

En la Ley no se establece el cargo que una institución financiera puede imponer al consumidor por dar el acceso. Solamente establece que debe ser razonable y el consumidor debe de ser informado del mismo antes de obtener el acceso.

\section{Rectificación de información.}

De acuerdo al FCRA, para corregir errores el consumidor puede contactar tanto al buró de crédito como al proveedor de información, quiénes tienen la responsabilidad de corregir información inexacta o incompleta. Para hacer que se corrija la información que él considere incorrecta, debe:

informar por escrito al buró de crédito qué información cree que es incorrecta, identificando claramente cada punto del reporte en el que no esté de acuerdo y especificando si solicita corrección o eliminación de esa información.

informar por escrito al acreedor (o a otro proveedor de información) que disputó algún punto de su reporte.

Una vez informado, el buró debe reinvestigar la información en cuestión, generalmente dentro de 30 días. También debe mandar toda la información que el consumidor provee acerca de la disputa al proveedor de dicha información, el cual también debe de reinvestigar las cuestiones y si encuentra que la información es incorrecta, debe notificarlo a todos los burós de crédito en la nación para que corrijan el archivo del consumidor.

Cuando la reinvestigación se haya completado, el buró de crédito debe darle al consumidor los resultados por escrito y una copia gratis de su reporte, si la disputa resulta en algún cambio al reporte. Si el reporte contiene información errónea, el buró de crédito deberá corregirla; si un punto está incompleto, deberá completarlo.

Si el consumidor lo solicita, el buró de crédito debe enviar notificaciones de corrección a todo aquel que haya recibido su reporte en los pasados 6 meses (los que hayan solicitado empleo, pueden hacer que se mande una copia del reporte corregido a todo aquél que hubiera recibido una copia durante los últimos 2 años).

Si la reinvestigación no resuelve la disputa del consumidor, éste puede pedir que el buró de crédito incluya una declaración de disputa en su archivo, y ésta deberá quedar registrada en los reportes que sobre dicho consumidor efectúen en el futuro. 
Con respecto a la información en manos de instituciones financieras, la Gramm-Leach-Bliley establece que las instituciones deben dar al consumidor la oportunidad de disputar la precisión de la información que la institución tenga sobre él y a presentar evidencia a su favor. La institución deberá de corregir o borrar información identificada por el consumidor como incompleta o inexacta.

\section{Derecho a ser excluido de listados de ofertas}

En la sección 604 del FCRA se señala que el consumidor tiene el derecho de que su nombre y dirección se excluyan de las listas que proveen los burós de crédito para las ofertas en firme de crédito o seguro (transacción no iniciada por el consumidor).

\section{Acción Adversa}

La persona que toma tal acción (como una negación o cancelación de seguro o incremento de tasas de interés) debe:

informar al consumidor cual buró de crédito le proporcionó el reporte (incluyendo nombre, dirección y teléfono del buró de crédito, y el teléfono gratuito para burós de crédito nacionales);

entregar una declaración de que el buró de crédito que proporcionó el reporte no tomó la decisión y no asume la responsabilidad por la acción adversa y que no puede dar las razones específicas por las que se tomó tal acción;

mencionar los derechos del consumidor de reclamar si la información que el buró de crédito entregó, fuera incompleta o imprecisa y el derecho a recibir un reporte gratis del buró de crédito.

En el caso de que la acción adversa sea respecto a una solicitud de crédito por parte del consumidor, el Equal Credit Opportunity Act (ECOA) obliga a que los acreedores especifiquen porque fue tomada esa acción si el consumidor pregunta. Además, el ECOA también obliga a los acreedores a tomar en cuenta información adicional que el consumidor pudiera facilitarles acerca de su historial crediticio.

\section{Otros derechos del consumidor}

El consumidor puede hacer que se incluya información adicional. Aunque los burós de crédito no tienen la obligación de incluir la información extra que provea el consumidor, generalmente los burós de crédito adicionan información de cuentas verificables.

\begin{tabular}{|c|c|}
\hline \multicolumn{2}{|c|}{ REGULACIÓN DE LOS BURÓS DE CRÉDITO Y AGENCIAS DE INFORMACIÓN (CONTROLADORES DE DATOS) } \\
\hline $\begin{array}{c}\text { INICIO DE } \\
\text { OPERACIONES }\end{array}$ & \begin{tabular}{|l} 
PRINCIPIOS PARA EL TRATAMIENTO \\
\end{tabular} \\
\hline $\begin{array}{l}\text { Inicio de } \\
\text { Operaciones } \\
\text { No existen requisitos } \\
\text { para que una sociedad } \\
\text { se pueda conformar } \\
\text { como consumer } \\
\text { reporting agency } \\
\text { ("buró de crédito"). } \\
\text { Basta con que al } \\
\text { operar se ajusten a la } \\
\text { regulación del FCRA } \\
\text { y cumplan con las } \\
\text { obligaciones y } \\
\text { responsabilidades que }\end{array}$ & $\begin{array}{l}\text { Especificación del Fin } \\
\text { EL FCRA en la sección } 604 \text { establece los propósitos permisibles de los reportes de los burós de crédito. } \\
\text { Límites a la Recolección } \\
\text { Obtenidos por medios legítimos } \\
\text { El FCRA no dice nada específicamente en esta materia. } \\
\text { Conocimiento del Consumidor } \\
\text { Se requiere informar al consumidor antes de efectuar un reporte con propósitos de empleo. } \\
\text { Se requiere la autorización del consumidor para la recolección de información médica. } \\
\text { Para la elaboración de reportes de investigación, el solicitante del reporte tiene que informar al consumidor de que pidió la preparación de } \\
\text { dicho reporte dentro de los } 3 \text { días de haber efectuado dicha solicitud. Asimismo, a solicitud por escrito del consumidor el solicitante del } \\
\text { reporte debe de informar de manera completa y precisa la naturaleza y el ámbito de la investigación que solicitó. El Buró de Crédito no } \\
\text { puede elaborar un reporte de investigación a menos que el solicitante cumpla con su obligación de informar al consumidor. }\end{array}$ \\
\hline
\end{tabular}


conocimiento de sus clientes sus políticas y prácticas con respecto a la transmisión de información personal no-pública a terceros afiliados y no afiliados, incluyendo las categorías de datos que se pueden transmitir y la categoría de personas a las que se le puede transmitir, así como a la protección de dicha información.
El buró deberá proporcionarle al consumidor, con cada notificación por escrito que haga al mismo, un resumen por escrito de todos los derechos que tiene el consumidor; y, en caso de que un buró de crédito recopile y mantenga archivos de consumidores nacionalmente, deberá incluir un número telefónico gratuito establecido por la agencia en donde presten servicio a los consumidores durante días hábiles.

\section{Autorización para la Transmisión}

\section{Expresa y por escrito}

Los burós de crédito podrán proporcionar reportes del consumidor en los siguientes casos:

1.Transaceiones iniciadas por el consumidor:

Cuando el consumidor solicita un crédito o seguro; se considera que éste autoriza de manera implícita al otorgante de crédito o seguro para que pueda obtener un reporte acerca de él. Por tanto, no es necesaria la firma autógrafa del consumidor.

Cuando el consumidor solicita un empleo, la autorización deberá ser explícita; es decir, expresa y por escrito, conteniendo su firma autógrafa.

\section{Implícita en transacciones iniciadas por el consumidor}

2.Transacciones no iniciadas por el consumidor:

- Un buró de crédito puede entregar un reporte del consumidor en conexión con cualquier transacción de crédito o seguro no iniciada por el consumidor, sólo si el consumidor autoriza de forma explícita a la agencia a proporcionar el reporte a tal persona.

Se permite la venta de listados de consumidores para realizar "ofertas en firme" (cualquier oferta de crédito o seguro, que se haga efectiva si el consumidor así lo decide, y que está basada en información de un reporte del consumidor, de tal forma que el consumidor al que se le hace la oferta cumple con los criterios específicos establecidos para la selección). No se requiere la autorización explícita pero hay ciertos límites a la información que las agencias pueden desplegar. Esta información incluye:

- el nombre y la dirección del consumidor,

- un identificador que no sea único del consumidor y que sea usado por la persona sólo para verificar la identidad del consumidor, y - otra información del consumidor con excepción de aquélla que identifique experiencias específicas del consumidor con sus acreedores $\mathrm{u}$ otras entidades.

El consumidor puede ordenar a los burós de crédito, no ser incluido en los listados. Los burós de crédito no deberán incluir en las listas de crédito o seguro no solicitado a los consumidores (sujetos investigados) que así lo hayan manifestado. Las ofertas en firme deben incluir un número telefónico gratuito para que los consumidores hablen, si es que desean que su nombre y dirección sean eliminados de las listas por dos años; si se llena una forma que el buró de crédito proporciona para este propósito serán eliminados permanentemente.

Si se quiere obtener información médica o de un reporte de investigación, es necesario que el consumidor dé su autorización explícitamente

En relación a la información personal no-pública que controlan las instituciones financieras, las reglas de transmisión de dicha información establecidas en el Título V de la Ley Gramm-Leach-Bliley (1999), modificado por el Financial Information Privacy Protection Act (2000) son las siguientes:

A. Una institución no puede transmitir información personal no-pública a un tercero afiliado o no-afiliado de la misma, excepto si dicha institución:

1) le ha provisto al consumidor una clara notificación escrita, en medio electrónico o de cualquier forma que sea permitida por las 
regulaciones, de las categorías de información que pueden ser transmitidas a un tercero, y

2) le ha dado la oportunidad al consumidor, antes de la transmisión, de señalar que la información no se transmita al tercero. Dicho derecho a negar la transmisión debe poderse ejercer por el consumidor utilizando los mismos medios de comunicación a través de los cuáles le llegó la notificación o cualquier medio que le sea conveniente al mismo.

Lo anterior se traduce en que si una institución hace la notificación y no recibe una negativa por parte del consumidor, puede transmitir la información personal a un tercero afiliado o no afiliado. No obstante, a tal regla se le imponen algunas restricciones relacionadas con información de los hábitos de consumo del consumidor, información de salud e información de los números de las cuentas del consumidor para propósitos de mercadotecnia. A este respecto se establece que:

A. Una institución financiera, la cual provee al consumidor un servicio de envío o recepción de pagos o transferencias ya sea por cheque, tarjeta de débito o crédito u otro instrumento similar, no puede transferir a un tercero afiliado o no afiliado una lista del las transacciones que realiza el consumidor o una descripción de los hábitos de consumo, intereses, preferencias u otras características del mismo.

B. Adicionalmente, una institución financiera no puede transmitir a un tercero afiliado o no-afiliado una lista de consumidores que contenga o se derive de información de salud que identifique individualmente a un consumidor.

Sólo se puede transmitir información de hábitos de consumo o de salud si la institución le requirió claramente al consumidor su consentimiento afirmativo por escrito o por medios electrónicos o cualquier otra forma permitida por la regulación, y recibió dicho consentimiento.

Adicionalmente, al tomar la decisión de si ofrecer o proveer, y en qué términos, un servicio o producto financiero, una institución financiera no puede obtener o recibir de un tercero afiliado o no-afiliado información de salud que identifique individualmente a un consumidor, excepto cuando la institución financiera:

Ha requerido claramente el consentimiento afirmativo por escrito, por medios electrónicos o a través de cualquier otra forma permitida por la regulaciones, para la transferencia y uso de esa información en relación a un producto o servicio financiero particular, y ha recibido dicho consentimiento afirmativo del consumidor.

Requiere de antemano esa misma información de salud a todos los consumidores como un requerimiento o condición para proveer el producto o servicio financiero.

Para el uso de telemarketing, mercadotecnia directa por correo o cualquier mercadotecnia por correo electrónico, una institución financiera no puede transmitir, excepto a una consumer reporting agency, el número de una cuenta, o cualquier número o código de acceso de una cuenta de tarjeta de crédito, o cualquier cuenta de transacción de un consumidor a un tercero afiliado o no-afiliado

Las reglas de transmisión que se discutieron en los párrafos anteriores también aplican a los terceros afiliados o no-afilidos que reciben la información personal no-pública en cuanto a la re-transimisión o re-uso de la misma.

Circunstancias en las cuales la institución financiera puede divulgar a terceros, información personal no pública de sus clientes:

Las instituciones financ ieras, así como los terceros afiliados o no-afiliados que hayan recibido información, pueden libremente transmitir la información personal no-pública, (es decir, no requieren obtener ni la negativa del consumidor en relación a la transmisión, ni el consentimiento afirmativo del mismo) en los siguientes casos:

A. Cuando sea necesaria para efectuar, administrar o reforzar una transacción requerida y autorizada por el consumidor (ya sea que lo esté 
llevando a cabo la propia institución financiera o terceros contratados), o en relación con:

Dar servicio o procesar un producto o servicio financiero requerido o autorizado por el consumidor (autorización implícita).

Mantener o dar servicio a una cuenta que el consumidor tenga con la institución financiera o como parte de un programa de tarjetas de crédito de marca privada.

Llevar acabo una bursatilización propuesta o actual, una venta en el mercado secundario o transacciones similares relacionadas a las transacciones del consumidor.

- Desempeñar, en nombre de la institución financiera, servicios o funciones relacionados con los clientes de la institución financiera, por ejemplo, aplicar mercadotecnia de los productos y servicios a dichos clientes.

B. Con el consentimiento o bajo la dirección del propio consumidor.

C. Para proteger o prevenir un fraude, para control del riesgo institucional o resolver las disputas o dudas del consumidor, y a los representantes legales del consumidor.

D. Para proveer información a: (i) las organizaciones que aconsejan en la calificación de seguros; (ii) fondos o agencias de garantía; (iii) calificadoras financieras; (iv) personas que evalúan el cumplimiento con estándares de la industria.

E. Está permitido o requerido bajo otras leyes en concordancia con el Right to Financial Privacy Act de 1978.

F. A la Secretaría del Tesoro (Secretary of the Treasury) cuando esté establecido en la ley, a una autoridad de seguros de Estado o a la Comisión Federal de Comercio (Federal Trade Commission), así como para una investigación relacionada con el bien público.

G. A una consumer reporting agency en concordancia con el FCRA o cuando la información se obtuvo de un reporte de consumo obtenido de una consumer reporting agency.

H. En la venta, fusión, transferencia o intercambio de todo o parte de un negocio, si la transmisión de la información personal no-pública se refiere únicamente a los consumidores de dicho negocio.

I. Por mandato de ley.

J. Para facilitar el servicio al cliente, por ejemplo el mantenimiento y la operación de centros de llamadas.

K. A los abogados, contadores y auditores de la institución financiera.

\section{Límites al plazo de retención de los datos (FCRA 1997)}

No se borra la información de las bases de datos de los burós de crédito, para el otorgamiento de créditos de 150 mil dólares o más, seguros de vida con cobertura igual o superior a 150 mil dólares, o de empleo con salarios anuales de 75 mil dólares o mayores. Los reportes incluyen toda la información disponible. En los otros casos la información se reporta hasta por 7 años, tales como de juicios y sentencias, incumplimiento de obligaciones fiscales, cuentas por cobrar, registros de arrestos, denuncias y condenas de delitos, mientras que en caso de quiebra se reporta hasta por 10 años.

\section{Regulación de Calidad}

El FCRA (sección 623) obliga a los proveedores de información a entregar información exacta y a corregir y actualizar la información.

\section{Regulación de Seguridad}

El tema de seguridad en la industria se maneja a través de estándares desarrollados por la ACB (Associated Credit Bureaus). La ACB trabajó conjuntamente con las compañías de "software" líderes en el mercado, para desarrollar el ACB Security Certification Program, el cual establece estándares para el acceso de "software", incluyendo:

Que no haya códigos de acceso preinstalados;

Eliminación de códigos de acceso;

Que el despliegue de los códigos de acceso de los burós de crédito sea restringido;

Niveles de seguridad y "passwords" de usuarios; 
"Password" de puerta trasera asegurado (secured backdoor password)

Mensajes de Alerta;

Protección contra copiado del "software":

Códigos de acceso "protegidos".

La ACB certifica que los productos de "software", para el acceso a los datos, cumplan voluntariamente con los estándares de seguridad de la industria. La certificación será otorgada sólo a aquellos burós de crédito que estén en completo acuerdo con los estándares de seguridad de la ACB o que tengan controles aceptables que sean equivalentes.

La Ley Gramm-Leach-Bliley establece que las agencias o autoridades correspondientes deberán establecer para las instituciones financieras bajo su jurisdicción los estándares apropiados relacionados con los mecanismos administrativos, técnicos o físicos para salvaguardar la información. Lo anterior, de tal manera que se asegure la confidencialidad y seguridad de los archivos e información de los clientes, se proteja contra amenazas o daños a la seguridad e integridad de los archivos y se proteja contra el acceso o uso no-autorizado de la información que puede resultar en daños o inconveniencia substancial al cliente.

\section{Responsabilidad del controlador}

(Sección 617, FCRA) Toda persona que es negligente en cumplir cualquiera de los requerimientos establecidos en el FCRA con relación a los consumidores, es responsable por resarcir los daños y prejuicios que les haya ocasionado a éstos y pagar los costos legales en los que se incurran.

\section{Sanciones}

Un empleado de un buró de crédito que intencionalmente y con conocimiento provee información contenida en los archivos del buró a una persona no autorizada a recibir dicha información será sancionado de acuerdo a lo establecido en el Título 18 del United States Code y encarcelada por no más de dos años. (Sección 620, FCRA)

La Ley Gramm-Leach-Bliley establece sanciones para el acceso fraudulento a información financiera. Dichas sanciones pueden ser tanto administrativas como penales. Establece que las violaciones a la protección de privacidad de la información financiera de los consumidores (Sección 521 del Título V de la Ley) pueden ser multadas monetariamente, o con hasta 5 años de prisión, o ambas.

\section{Transparencia del controlador de datos}

Tiene que tener un número sin costo para atender las consultas de los consumidores. 


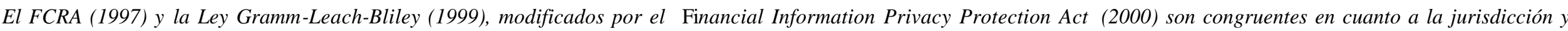
papel que juegan las autoridades.

Federal Trade Commission (FTC) (en general, la FTC tiene funciones de protección al consumidor y de competencia)

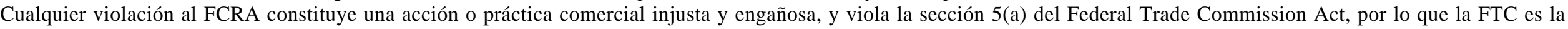
autoridad con respecto a cualquier "consumer reporting agency".

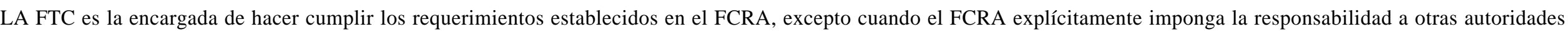
sectoriales.

Facultades y Responsabilidades:

capacidad procesal

poderes de investigación, como requerir que se haga un reporte, requerir la producción de documentos y requerir que un testigo se presente.

capacidad de hacer cumplir la ley

capacidad regulatoria en cuanto a que puede emitir reglas procesales para hacer cumplir los requerimientos de la ley.

capacidad de comenzar una acción civil en una corte de distrito de los Estados Unidos contra la persona que viole el FCRA. La corte es la que sanciona.

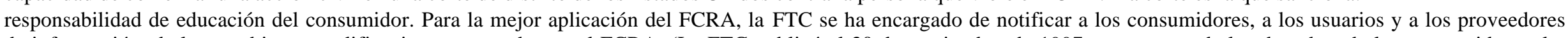

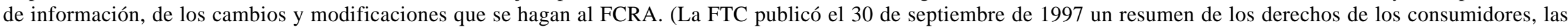

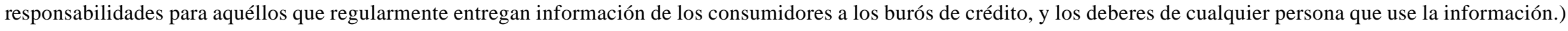

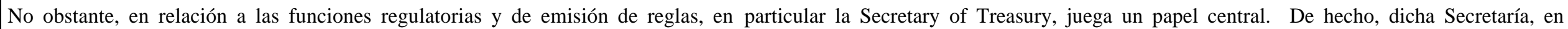

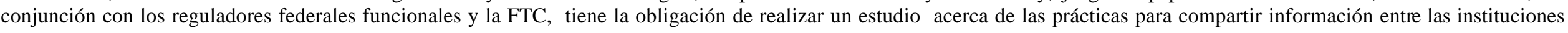

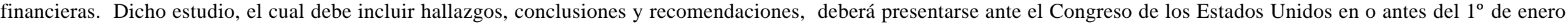
de 2002.

\section{Autoridades Sectoriales (Sección 621, Subsección b)}

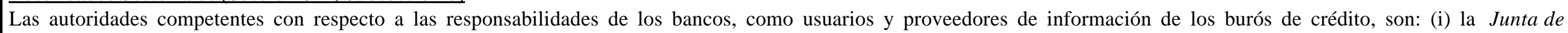

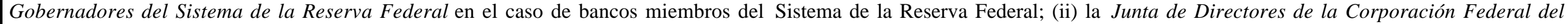

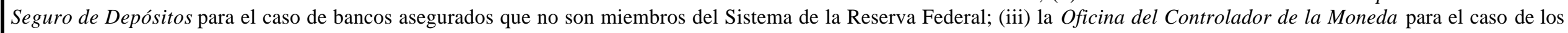
bancos nacionales y las sucursales de bancos extranjeros.

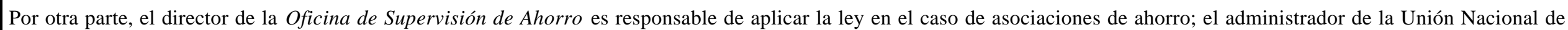

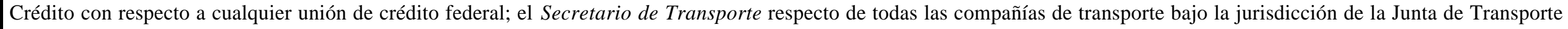

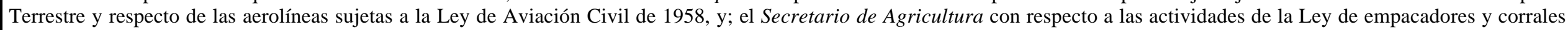

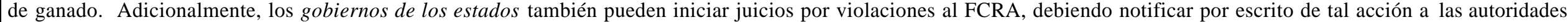
federales.

\section{Autoridad Judicial}

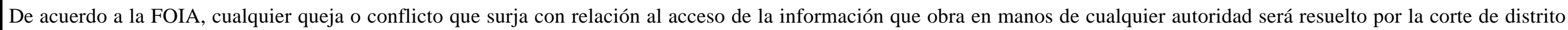
en el cual resida el demandante, o en el domicilio donde tenga su principal negocio o bien en el lugar que se ubiquen las bases de datos de la autoridad.

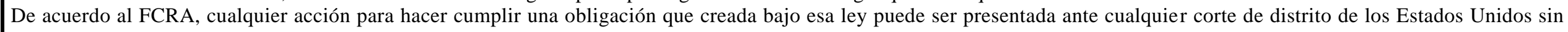
importar el monto de la controversia, o ante cualquier otra corte de una jurisdicción competente, dentro de los dos años en que el daño se hizo. 
Actualmente existen alrededor de 500 burós regionales y especializados inscritos en la ACB, y 3 burós con cobertura nacional (Equifax, Trans Union y Experian).

Los servicios que se ofrecen son muy diversos, por ejemplo: reportes crediticios, de investigación, con propósitos de empleo, seguro, arrendamiento, para otorgar fianzas, credit scoring o valuación de crédito, valuación de riesgo, y listados para prescreening $\mathrm{u}$ ofertas en firme.

\section{Anexo \\ Canadá}

PRINCIPAL REGULACIÓN EN LA MATERIA

\begin{tabular}{|c|}
\hline REGULACIÓN \\
\hline Personal Information Protection and Electronic \\
Documents Act, (PIPEDA) Bill C-6 04/13/2000, que \\
entró en vigor en 01/01/2001, \\
la cual incluye como su Anexo los Principios \\
establecidos en el Estándar Nacional de Canadá \\
denominado, "Código Modelo para la Protección de \\
Información Personal, CAN/CSA-Q830-96”.
\end{tabular}

Información Personal, CAN/CSA-Q830-96”.

Sector Público Federal

Se regula al sector público federal que cuente con información personal o no personal.

Access to Information Act y el Privacy Act (1983)

\section{Sector Público Provincial}

Se regula al sector público provincia 1 que cuente con información personal o no personal.

- Alberta(1995) El ámbito de la legislación se extendió a organismos de salud (oct.1998),

universidades (enero 1999) y gobiernos municipales y jefaturas policiacas (oct. 1999).)

\section{OBJETIVO}

El objetivo de la PIPEDA es:

Establecer, en una era en que la tecnología facilita la circulación y el intercambio de información, reglas para gobernar la recolección, uso y transmisión de información personal de manera que se reconozcan:

1. El derecho de privacidad del individuo con respecto a su información.

2. La necesidad de las No aplica a:

organizaciones para recolectar, usar - Las instituciones de gobierno a las cuales se aplica el Privacy y transmitir información personal Act.

para propósitos que una persona - El individuo que recolecte, use o transmita información para razonable consideraría apropiados uso personal o doméstico y no la recolecte, use o transmita para la circunstancias. para cualquier otro propósito.

Cualquier organización que recolecte, use o transmita la información personal para propósitos periodísticos, artísticos y literarios y no la recolecte, use o transmita para otros propósitos.

La PIPEDA no regula al sector público, sino al privado, y no obstante, actualmente no regula y no puede regular a todo el sector privado de Canadá. En enero de 2001, solamente los siguientes negocios están obligados a cumplir con la Ley: 
- British Colombia (1993),

- Manitoba (1998)

- New Brunswick (1978)

- Newfoundland (1982)

- NW(1997)

- Nueva Scotia (1993)

- Ontario(1988)

- Quebec (1982)

- Saskatchewan (1991)

- Yukon(1996)

Además de la Ley que regula al sector público, British Columbia, Manitoba, Quebec, Newfoundland y Saskatchewan tienen una ley que da a los residentes protección civil en caso de una violación de su privacidad territorial y personal

\section{Sector Privado Provincial}

- Quebec: "Act Respecting the Protection of Personal Information in the Private Sector". telecomunicaciones, teledifusión, aerolíneas, compañías de transporte, y cualquier compañía que venda información personal a través de las fronteras de las provincias o internacionales.

Después de 3 años, h Ley va a aplicarse a todas las actividades comerciales del sector privado, incluyendo compañías bajo jurisdicción provincial o territorial

En los últimos 30 años el gobierno federal y los gobiernos provinciales de Canadá han aprobado diversas regulaciones con respecto a la privacidad del individuo. La PIPEDA es un esfuerzo por reconciliar dicha regulación. No obstante, dado que es una regulación federal, queda en manos de las provincias y los territorios promulgar una legislación "substancialmente similar" en los siguientes 3 años de la fecha en que entra en vigencia la PIPEDA. Terminados los 3 años. en caso que las provincias o territorios no promulguen una ley de protección de datos, la PIPEDA se aplica automáticamente al sector de menudeo, manufactura, empresas de renta de videos, y a casi todos los negocios que traten directamente con el consumidor final. No se aplica a gobiernos provinciales, municipalidades, universidades, escuelas y hospitales.

\section{INFORMACIÓN TRATADA POR LOS BURÓS DE CRÉDITO}

Canadá

\section{TIPO DE INFORMACIÓN TRATADA POR BURÓS}

Información Personal: Información acerca de un individuo identificable, pero que no incluye el nombre, título o dirección de trabajo o número telefónico de trabajo de un empleado de una organización.

Información Sensible Cierta información, por ejemplo, los datos médicos y los de ingreso casi siempre se consideran sensibles. Cualquier información puede ser sensible dependiendo del contexto.

\section{Información de Salud Personal}

i) información concerniente a la salud física o mental de un individuo;

ii) información concerniente a los servicios de salud provistos al individuo;

iii) información concerniente a la donación por parte del individuo de cualquier parte corporal o substancia corporal del individuo o información que derive de una prueba o examen de una parte o substancia corporal del individuo.

iv) información que se recolecta incidentalmente para la provisión de un servicio de salud para un individuo. 


\section{Derecho de acceso de los consumidores a su propia información (Principio 9 $^{\circ}$ )}

A solicitud, un individuo debe ser informado de la existencia, uso y cesión de su información personal y deberá tener acceso a ella. Se alienta a las organizaciones indicar la fuente de la información.

La organización que tenga los datos deberá de responder a la solicitud del individuo dentro de un tiempo razonable y con el mínimo o ningún costo para él. En ciertas circunstancias, la organización que tiene los datos no puede proveer acceso a toda la información personal que tenga del individuo. Dichas excepciones deben ser limitadas y específicas y o las razones se deben de dar al individuo ante la solicitud.

La solicitud de acceso se debe hacer por escrito , para lo cual puede contar con ayuda de la organización. La organización debe responder a la solicitud a más tardar en treinta días de recibida. Dicho plazo se puede extender bajo ciertas circunstancias. Si la organización no responde en el tiempo establecido se considera que negó la solicitud de acceso. Si responde dentro del plazo permitido y se niega la solicitud, deberá informar al individuo las razones y cualquier procedimiento que tenga bajo la ley para responder a la negación.

\section{Excepciones}

Se excluye del acceso la información que es prohibitivamente costosa proveer, información que contiene referencias a otros individuos, información que no se puede dar por razones legales, de seguridad, información comercial propietaria o aquélla sujeta a un litigio judicial.

La organización no está requerida a dar acceso a información personal sólo si:

La información está protegida por el privilegio de solicitante-cliente

Al hacerlo se revelaría información comercial confidencial

El hacerlo podría razonablemente amenazar la vida o seguridad de otro individuo

La información se generó en el curso de un proceso formal de resolución de disputas.

\section{Rectificación de información. (Principio $9^{\circ}$ del Código Modelo para la Protección de Datos)}

Un individuo debe poder cuestionar la precisión y cobertura de la información y modificarla apropiadamente. Cuando un individuo demuestra exitosamente que la información no es precisa o no está completa, la organización modificará la información requerida. La modificación puede incluir la corrección, supresión, o adición de información. Cuando sea apropiado, las modificaciones deberán de comunicarse a terceros que tienen acceso a la información en cuestión.

\section{Conocer del buró quien ha recibido reportes con su información (Principio 9 ${ }^{\circ}$ )}

La organización deberá dar cuenta del uso que se ha hecho o se está haciendo de la información personal que requiera el individuo y dar cuenta de los terceros a los cuáles se les ha transmitido. Al dar cuenta de los terceros a los cuales se ha transmitido la información, se deberá ser lo más específico posible. De no poderse proveer una lista de las organizaciones a las cuales se transmitió la información, se deberá, al menos, dar una lista de las posibles organizaciones a las cuales se pudo haber transmitido.

Derecho a ser excluido de listados de ofertas

No está especificado en la PIPEDA

Acción Adversa

No está especificada en la PIPEDA 
REGULACIÓN DE LOS BURÓS DE CRÉDITO Y AGENCIAS DE INFORMACIÓN (CONTROLADORES DE DATOS)

INICIO DE OPERACIONES

\section{Principio 80}

La organización deberá hacer accesible la información al específica en relación a sus políticas y prácticas de manejo de información.

Entre la información que deberá hacerse accesible está:

a) Nombre o título, y la dirección de la persona que es responsable de las políticas y practicas de la organización y a quién se le pueden enviar las quejas y preguntas.

b) Los medios de obtener acceso a la información personal que tenga bajo su control.

c) Una descripción del tipo de información personal que controla organización, así como el uso general de la misma.

d) Una copia de cualquier folleto o información que explique las políticas de la organización, estándares y códigos

e) Qué información personal se hace disponible organizaciones

relacionadas subsidiarias)

\section{Especificación del fín (Principio $\mathbf{2}^{\mathbf{0}}$ )}

PRINCIPIOS PARA EL TRATAMIENTO

Los propósitos para los cuales la información es recolectada deben ser identificados y documentados por la organización antes o al mismo tiempo que la información se recolecte.

$\mathrm{Si}$ alguna información recolectada va a ser usada para un fin no identificado previamente, el nuevo fin debe ser identificado antes de ser usada. Excepto cuando el nuevo fin se requiera por ley, el consentimiento del individuo debe ser requerido antes de que la información se use para tal fin.

La recolección de la información personal debe limitarse a aquélla que sea necesaria para los fines identificados por la organización. (Principio $4^{\mathrm{o}}$ )

No se puede usar o transmitir información personal para fines distintos para los cuales se recolectó, excepto con el consentimiento del individuo o si así lo requiere la ley.

\section{Límites a la Recolección (Principio $2^{\circ}$ y $4^{\circ}$ )}

Obtenida por medios legítimos

La información debe ser recolectada por medios justos y legales.

\section{Conocimiento del Consumidor}

El conocimiento y consentimiento del individuo se requiere para la recolección, uso y transmisión de la información personal, excepto cuando no es apropiado. Circunstancias en las que no es apropiado son, por ejemplo, cuando medien razones legales (e.g. prevención de fraude o para hacer cumplir la ley), médicas (e.g.. el individuo es menor de edad, está seriamente enfermo o mentalmente incapacitado), de seguridad o sea imposible o impráctico buscar el consentimiento.

En la PIPEDA se establece que se puede recolectar información personal sin consentimiento cuando:

a) la recolección es claramente en el interés del individuo y no se puede obtener el consentimiento en el tiempo adecuado;

b) es razonable esperar que la recolección con el conocimiento o consentimiento del individuo comprometería la disposición y precisión de la información, y la recolección es razonable para los propósitos relacionados a la investigación de un incumplimiento a un acuerdo o a una ley de Canadá o alguna de sus provincias;

c) La recolección es únicamente para fines periodísticos, artísticos o literarios;

d) La información está disponible públicamente o esta recolección queda establecida en la regulación.

\section{Autorización para el Uso y Transmisión (Principio $2^{\circ}$ )}

El consentimiento para el uso y transmisión de datos se puede obtener en el momento de la recolección de la información. En ciertas circunstancias, el consentimiento para el uso y transmisión se puede obtener después de que la información se recolectó, pero antes de que se use (por ejemplo, cuando el fin para la que se va a usar no estaba identificado anteriormente).

La forma del consentimiento requerida por la organización puede variar dependiendo de las circunstancias y el tipo de información. Para determinar el tipo de consentimiento requerido la organización debe de tomar en cuenta qué tan sensible es la 
El individuo puede dar su consentimiento de diversas formas, entre las cuáles están incluidas:

a) Una forma firmada por el individuo que busque el consentimiento e informe al individuo del uso que tendrá esa información;

b) Oralmente cuando la información se recolectó por teléfono;

c) En el momento que el individuo use un producto o servicio.

\section{Expresa y por escrito}

En general, una organización debe obtener consentimiento expreso cuando la información se considere sensible.

Implícita en transacciones iniciadas por el consumidor

El consentimiento implícito es apropiado cuando la información sea menos sensible.

Una organización puede usar información personal sin el conocimiento o consentimiento del individuo cuando:

a) puede ser útil en la investigación de un incumplimiento de las leyes de Canadá, provincia o jurisdicción extranjera y va a ser usada en dicha investigación;

b) es usada con el fin de actuar en una emergencia en la cual la vida, salud o seguridad de un individuo se ve amenazada;

c) es usada para fines estadísticos o de investigación. En tal caso se debe de asegurar la confidencialidad.

Una organización puede transmitir información personal sin el conocimiento o consentimiento del individuo cuando la transmisión se haga:

a) a un notario que representa a dicha organización;

b) para el propósito de recuperar una deuda que tenga el individuo con dicha organización;

c) para cumplir con una citación u orden judicial u orden hecha por una corte, o para cumplir con las reglas de corte relacionadas a la producción de archivos;

d) a una institución o cuerpo de investigación gubernamental que haya requerido la información y probado su autoridad legal para obtenerla dado que sospecha que se relaciona con la seguridad nacional o se requiere para administrar o hacer valer la ley;

e) a una persona que requiere de la información por una emergencia en la cual la vida, salud o seguridad de un individuo está en peligro. La organización debe informar al titular de los datos, si está vivo, de dicha transmisión lo más pronto posible después de ceder la información;

f) es usada para fines estadísticos o de investigación. En tal caso se debe de asegurar la confidencialidad;

g) cien años después de haberse creado el archivo con esa información o veinte años después de muerto el titular de los datos;

h) de información disponible públicamente o que esté establecido en la regulación.

\section{Límites al plazo de retención de los datos}

La Información Personal se debe retener por el tiempo necesario para cumplir con los fines.

Las organizaciones deberán de desarrollar lineamientos o aplicar procedimientos con respecto a la retención de datos personales, los cuales deberán contener el mínimo y el máximo periodo de retención.

Información Personal que se utilizó para tomar una decisión acerca de un individuo se debe conservar el suficiente tiempo para permitir al individuo accesar su información después de que la decisión se tomó.

Información personal que ya no se requiera para cumplir con el fin especificado debe ser destruida, borrada o hacerla anónima. 


\section{Calidad de los datos}

La Información Personal debe ser tan precisa, completa y a la fecha como sea necesario para los fines para los cuales va a ser usada.

\section{Regulación de Seguridad}

La información personal deberá de ser protegida por mecanismos de seguridad apropiados a que tan sensible sea la información. Los mecanismos de seguridad deberán de proteger a la información personal contra pérdida o robo, así como contra acceso,

transferencia, copia o modificaciones no autorizados. Los métodos de protección deben incluir medidas físicas, organizacionales y tecnológicas.

\section{Responsabilidad del controlador (Principio $1^{\circ}$ )}

Una organización es responsable de la información personal bajo su control y deberá asignar a un individuo o individuos que sean responsables para la observancia y cumplimiento de los principios establecidos en el código, anexados a la PIPEDA.

La organización es responsable de la información personal en su posesión o custodia, incluyendo la información que ha sido transferida a un tercero para procesar. La organización deberá usar medios contractuales u otros medios para proveer un nivel de protección comparable mientras la información está siendo procesada por un tercero.

\section{Sanciones}

No están especificadas en la PIPEDA. 
Autoridades Administrativas

El encargado de recibir y resolver las quejas por parte de los individuos en contra de las organizaciones que contravengan la PIPEDA, es el Comisionado de

Privacidad Federal. Esta autoridad se crea en el Privacy Act (1983).

El comisionado puede:

1. Recibir quejas por parte de los individuos.

2. Si considera que existen bases razonables para investigar la cuestión planteada por el individuo, puede iniciar una queja con relación a ella, y tiene que avisar a la organización en contra de quien se hizo la queja.

3. Conducir una investigación en relación a la queja para lo cual puede:

i) Requerir la presencia de personas ante el Comisionado y obligarlos a dar evidencia oral o escrita bajo juramento

ii) Administrar juramentos

iii) Recibir y aceptar evidencia u otra información que considere adecuada, independientemente de si sea aceptada o no en la corte

iv) Entrar a las instalaciones de la organización si es necesario para satisfacer los requerimientos de seguridad que deben tener las mismas.

v) Conversar en privado con cualquier persona que se encuentre en las instalaciones de la organización.

vi) Examinar o obtener copias de archivos que encuentre en las instalaciones de la organización.

4. Resolver quejas por medio de mecanismos de resolución de disputas, tales como mediación o conciliación.

5. Debe preparar, dentro del año de recibida la queja, un reporte que contenga sus hallazgos y recomendaciones, cualquier acuerdo al que hayan llegado las partes, el requerimiento por parte del Comisionado de que la organización le haga saber las acciones tomadas o propuestas para instrumentar las recomendaciones. Dicho reporte se debe de enviar sin demora a las partes interesadas.

6. Realizar auditorías a las organizaciones en relación a sus prácticas para el manejo de información personal.

En todo lo anterior, el Comisionado deberá de mantener la confidencialidad de la información, excepto cuando esté en el interés público hacer pública dicha información. Además, el Comisionado deberá presentar ante el Parlamento un reporte anual.

El Governor in Council es el órgano regulatorio.

\section{Autoridad Judicial}

La persona que sometió la queja puede, después de recibir el reporte del Comisionado, solicitar una audiencia frente a la Corte, la cual puede ordenar a la organización en cuestión corregir sus prácticas para cumplir con lo establecido en la ley y notificar las acciones tomadas o propuestas para corregir sus prácticas, así como indemnizar a dicha persona por cualquier daño incurrido, incluyendo la humillación que éste haya sufrido. 


\section{Anexo \\ Unión Europea}

PRINCIPAL REGULACIÓN EN LA MATERIA

\begin{tabular}{|l|l|}
\hline REGULACIÓN & OBJETIVOS DE LA REGULACIÓN \\
\hline
\end{tabular}

La Directiva de La Directiva (95/46/CE) tiene como objetivos:

la Comunidad

Europea

$(95 / 46 / C E)$ que

entró en vigor

en octubre de

1998. personales. i. Garantizar la protección de las libertades y de los derechos fundamentales de las personas físicas, $\mathrm{y}$, en particular, del derecho a la intimidad, en lo que respecta al tratamiento de los datos

ii. Evitar que se restrinja o prohiba la libre circulación de datos personales entre los Estados miembros por motivos relacionados con la protección garantizada.

En particular se buscan los siguientes principios:

1. Que los datos personales sean tratados de manera leal y lícita;

2. Que los datos personales sean recogidos con fines determinados, explícitos y legítimos, y no sean tratados posteriormente de manera incompatible con dichos fines (a menos que se trate de datos con fines históricos, estadísticos o científicos);

3. Que los datos personales sean adecuados, pertinentes y no excesivos con relación a los fines para los que se recaben y para los que se procesen posteriormente;

4. Que los datos personales sean exactos y, cuando sea necesario, actualizados; deberán tomarse todas las medidas razonables para que los datos inexactos o incompletos, con respecto a los fines para los que fueron recogidos o para los que fueron procesados posteriormente, sean suprimidos o rectificados;

5. Que los datos personales sean conservados en una forma que permita la identificación de los interesados durante un período no superior al necesario para los fines para los que fueron recogidos o para los que se procesen ulterior mente.
AMBITO DE LA REGULACIÓN

La Directiva (95/46/CE) es aplicable a

toda la Unión Europea.

Regula el tratamiento total o parcialmente automatizado de datos personales, así como el tratamiento no automatizado de datos personales contenidos o destinados a ser incluidos en un fichero.

Se exceptúa el tratamiento:

i) efectuado en el ejercicio de actividades no comprendidas en el ámbito de aplicación del Derecho comunitario (seguridad pública, la defensa, la seguridad del Estado y las actividades del Estado en materia penal).

efectuado por una persona física en el ejercicio de actividades exclusivamente personales domésticas.

\section{INFORMACIÓN TRATADA POR LOS BURÓS DE CRÉDITO}

Datos Personales; son aquéllos referentes a toda información de personas físicas (como un número de identificación o uno o varios elementos específicos característicos de su identidad física, fisiológica, psíquica, económica, cultural o social).

\section{Datos Personales Sensitivos;}

Información como el origen racial o étnico, las opiniones políticas, las convicciones religiosas o filosóficas, la membresía en sindicatos, así como el procesamiento de los datos relativos a la salud o a la sexualidad.

Se prohibe el tratamiento de este tipo de datos a menos que:

a) se cuente con el consentimiento explícito del sujeto investigado, salvo en los casos en los que la legislación del Estado miembro disponga que la prohibición establecida en el apartado 1 no pueda levantarse con el consentimiento del interesado.

b) el tratamiento sea necesario para respetar las obligaciones y derechos específicos del responsable del tratamiento en materia de Derecho laboral,

c) el tratamiento sea necesario para salvaguardar el interés vital del interesado o de otra persona, en el supuesto de que el interesado esté física o jurídicamente incapacitado para dar su consentimiento, 
d) el tratamiento se refiera a datos que el interesado haya hecho manifiestamente públicos o sean necesarios para el reconocimiento, ejercicio o defensa de un derecho en un procedimiento judicial.

\section{Datos de Salud}

No se requiere de consentimiento cuando el tratamiento de datos resulte necesario para la prevención o para el diagnóstico médicos, la prestación de asistencia sanitaria o tratamientos médicos o la gestión de servicios sanitarios, siempre que dicho tratamiento de datos sea realizado por un profesional sanitario sujeto al secreto profesional, sea en virtud de la legislación nacional, o de las normas establecidas por las autoridades nacionales competentes, o por otra persona sujeta asimismo a una obligación equivalente de secreto.

\section{Datos relativos a infracciones, condenas penales o medidas de seguridad}

El tratamiento de estos datos sólo podrá efectuarse bajo el control de la autoridad pública o si hay previstas garantías específicas en el Derecho nacional. Sin embargo, sólo podrá llevarse un registro completo de condenas penales bajo el control de los poderes públicos. Los Estados miembros podrán establecer que el tratamiento de datos relativos a sanciones administrativas o procesos civiles se realice asimismo bajo el control de los poderes públicos. 
Derecho de acceso de los consumidores a su información

Los sujetos investigados tienen derecho a obtener del controlador de datos, libremente, sin restricciones y con una periodicidad razonable y sin retrasos ni gastos excesivos:

- la confirmación de la existencia o inexistencia del tratamiento de datos que le conciernen, así como información por lo menos de los fines de dichos tratamientos, las categorías de datos a que se refieran;

la comunicación, en forma inteligible, de los datos objeto de los tratamientos, así como la información disponible sobre el origen de los mismos;

el conocimiento de la lógica utilizada en los procesos automatizados de los datos que le conciernen;

la notificación a quienes se hayan comunicado los datos, de toda rectificación, suspensión o bloqueo efectuado, (si no resulta imposible o supone un esfuerzo desproporcionado).

\section{Rectificación de información.}

Un sujeto investigado puede solicitar la rectificación, supresión o el bloqueo de los datos que le conciernen cuyo tratamiento no se ajuste a las disposiciones de la Directiva, en particular a causa del carácter incompleto o inexacto éstos. También puede solicitar la notificación a los terceros a quienes se hayan comunicado los datos de toda rectificación, supresión o bloqueo efectuado, si no resulta imposible o supone un esfuerzo desproporcionado.

\section{Excepciones}

Se puede limitar el alcance de las obligaciones y los derechos previstos en el apartado 1 del artículo 6, en el artículo 10, en el apartado 1 del artículo 11, y en los artículos 12 y 21 cuando tal limitación constituya una medida necesaria para la salvaguarda de:

a) la seguridad del Estado;

b) la defensa;

c) la seguridad pública;

d) la prevención, la investigación, la detección y la represión de infracciones penales o de las infracciones de la deontología en las profesiones reglamentadas;

e) un interés económico y financiero importante de un Estado miembro o de la Unión Europea, incluidos los asuntos monetarios, presupuestarios y fiscales;

f) una función de control, de inspección o reglamentaria relacionada, aunque sólo sea ocasionalmente, con el ejercicio de la autoridad pública en los casos a que hacen referencia las letras c), d) y e);

g) la protección del interesado o de los derechos y libertades de otras personas.

\section{Conocer del buró quien ha recibido reportes con su información}

Los sujetos investigados tienen derecho a obtener del controlador de datos, libremente, sin restricciones y con una periodicidad razonable y sin retrasos ni gastos excesivos, los destinatarios o las categorías de destinatarios a quienes se comuniquen dichos datos.

\section{Derecho a ser excluido de listados de ofertas}

Un individuo tiene el derecho de oponerse, previa petición y sin gastos, al tratamiento de los datos de carácter personal que le conciernan respecto de los cuales el responsable prevea un tratamiento destinado a la prospección; o ser informado antes de que los datos se comuniquen por primera vez a terceros o se usen en nombre de éstos a efectos de prospección, y a que se le ofrezca expresamente, el derecho de oponerse, sin gastos, a dicha comunicación o utilización.

\section{Acciones Adversas}

Un individuo tiene derecho a no verse sometido a una decisión con efectos jurídicos sobre ellos que le afecte de manera significativa, basada únicamente en el procesamiento automatizados de datos destinado a evaluar aspectos como su rendimiento laboral, calidad crediticia, confiabilidad, conducta, etc. Ello, a menos que dicha decisión se haya adoptado en el marco de la celebración de un contrato o una ley que establezca medidas que garanticen el interés legítimo, o esté autorizada por el sujeto investigado.

\section{Otros Derechos}

\section{Derecho de oposición.}

El sujeto investigado tiene derecho oponerse, al menos en los casos contemplados en las letras e) y f) del artículo 7, en cualquier momento y por razones legítimas propias de su situación particular, a que los datos que le conciernan sean objeto de tratamiento, salvo cuando la legislación nacional disponga otra cosa. 
REGULACIÓN DE LOS BURÓS DE CRÉDITO Y AGENCIAS DE INFORMACIÓN (CONTROLADORES DE DATOS)

INICIO DE OPERACIONES

\section{Inicio de Operaciones}

Se requiere que los controladores de datos notifiquen a la Autoridad de Protección de Datos, antes de llevar a cabo un proceso. La información que deberá figurar en la notificación (como mínimo) es la siguiente:

El nombre y domicilio del controlador de datos y, en su caso, de su representante,

El propósito(s) del proceso,

Una descripción de los sujetos investigados y del tipo de datos que se procesan,

Una descripción de los usuarios a los que se les pueden comunicar los datos,

Las transferencias de datos personales previstas a terceros países,

Una descripción general que permita evaluar de modo preliminar si las medidas adoptadas, resultan adecuadas para garantizar la seguridad del proceso.

Se puede eximir de la obligación de notificación o disponer una simplificación de la misma en ciertas circunstancias (Artículo 18, inciso 2 de la Directiva). Adicionalmente, se puede disponer que no se notifiquen aquellos tratamientos cuya única finalidad sea la de llevar un registro que esté destinado a facilitar información al público y estén abiertos a la consulta por el público en

PRINCIPIOS PARA EL TRATAMIENTO

\section{Especificación del fín}

Los Estados miembros dispondrán que los datos personales sean:

- Recogidos con fines determinados, explícitos y legítimos, y no sean tratados posteriormente de manera incompatible con dichos fines; no se considerará incompatible el tratamiento posterior de datos con fines históricos, estadísticos o científicos, siempre y cuando los Estados miembros establezcan las garantías oportunas;

- Adecuados, pertinentes y no excesivos con relación a los fines para los que se recaben y para los que se traten posteriormente;

\section{Límites a la Recolección}

Obtenidos por medios legítimos

(38) Considerando que el tratamiento leal de datos supone que los interesados deben estar en condiciones de conocer la existencia de los tratamientos y, cuando los datos se obtengan de ellos mismos y contar con una información precisa y completa respecto a las circunstancias de dicha obtención;

Los datos personales deben ser tratados de manera leal y lícita;

\section{Conocimiento del Consumidor}

(39) Considerando que determinados tratamientos se refieren a datos que el responsable no ha recogido directamente del interesado; que, por otra parte, pueden comunicarse legítimamente datos a un tercero aún cuando dicha comunicación no estuviera prevista en el momento de recabar los datos del propio interesado; que, en todos estos supuestos, debe informarse al interesado en el momento del registro de los datos o, a más tardar, al comunicarse los datos por primera vez a un tercero;

(40) Considerando, no obstante, que no es necesario imponer esta obligación si el interesado ya está informado, si el registro o la comunicación están expresamente previstos por la ley o si resulta imposible informarle, o ello implica esfuerzos desproporcionados, como puede ser el caso para tratamie ntos con fines históricos, estadísticos o científicos; que a este respecto pueden tomarse en consideración el número de interesados, la antigüedad de los datos, y las posibles medidas compensatorias;

El responsable del tratamiento deberá comunicar a la persona de quien se recaben los datos que le conciernan, por lo menos:

a) la identidad del responsable del tratamiento y, en su caso, de su representante;

b) los fines del tratamiento de que van a ser objeto los datos;

c) cualquier otra información tal como: los destinatarios o las categorías de destinatarios de los datos, el carácter obligatorio o no de la respuesta y las consecuencias que tendría para la persona interesada una negativa a responder, la existencia de derechos de acceso y rectificación de los datos que le conciernen, en la medida en que, habida cuenta de las circunstancias específicas en que se obtengan los datos, dicha información suplementaria resulte necesaria para garantizar un tratamiento de datos leal respecto del interesado. 
Cuando los datos no hayan sido recabados del interesado, el responsable del tratamiento deberá, desde el momento del registro o a más tardar, en el momento de la primera comunicación de datos, comunicar al interesado:

a) la identidad del responsable del tratamiento y, en su caso, de su representante;

b) los fines del tratamiento de que van a ser objeto los datos;

c) cualquier otra información tal como la ya mencionada.

Estas disposiciones no se aplicarán, en particular para el tratamiento con fines estadísticos o de investigación histórica o científica, cuando la información al interesado resulte imposible o exija esfuerzos desproporcionados o el registro o la comunicación a un tercero estén expresamente prescritos por ley.

\section{Autorización para la Transmisión}

\section{Expresa y por escrito}

El tratamiento de datos personales puede efectuarse si el interesado ha dado su consentimiento (manifestación de voluntad, libre, específica e informada, mediante la que el interesado consienta el procesamiento de sus datos personales) de forma inequívoca.

Implícita en transacciones iniciadas por el consumidor

El tratamiento de datos personales puede efectuarse si es necesario para la ejecución de un contrato en el que el interesado sea parte o para la aplicación de medidas precontractuales adoptadas a petición del interesado.

Los controladores de datos podrán transmitir datos personales en los siguientes casos:

1.Que el sujeto haya dado su consentimiento explícito, o

2 No se requiere consentimiento explícito para la transmisión cuando ello:

a) es necesario para la ejecución de un contrato en el que el interesado sea parte o para la aplicación de medidas precontractuales adoptadas a petición del interesado,

b) es necesario para el cumplimiento de una obligación jurídica a la que esté sujeto el responsable del tratamiento,

c) es necesario para proteger el interés vital del interesado,

d) es necesario para el cumplimiento de una misión de interés público o inherente al ejercicio del poder público conferido al responsable del tratamiento o a un tercero a quie n se comuniquen los datos,

e) es necesario para la satisfacción del interés legítimo perseguido por el responsable del tratamiento o por el tercero o terceros a los que se comuniquen los datos, siempre que no prevalezca el interés o los derechos y libertades fundamentales del interesado.

\section{Límites al plazo de retención de los datos}

Los datos personales deben ser conservados en una forma que permita la identificación de los interesados durante un período no superior al necesario para los fines para los que fueron recogidos o para los que se traten ulteriormente.

Los Estados miembros establecerán las garantías apropiadas para los datos personales archivados por un período más largo del mencionado, con fines históricos, estadísticos o científicos.

\section{Calidad de los datos}

Los datos deben ser exactos y, cuando sea necesario, actualizados; deberán tomarse todas las medidas razonables para que los datos inexactos o incompletos, con respecto a los fines para los que fueron recogidos o para los que fueron tratados posteriormente, sean suprimidos o rectificados; 


\section{Regulación de seguridad}

El responsable del tratamiento debe aplicar las medidas técnicas y de organización adecuadas, para la protección de los datos personales contra la destrucción, accidental o ilícita, la pérdida accidental y contra la alteración, la difusión o el acceso no autorizados.

El responsable del tratamiento, en caso de tratamiento por cuenta del mismo, deberá elegir a un encargado del tratamiento que reúna garantías suficientes en relación con las medidas de seguridad técnica y de organización de los tratamientos que deban efectuarse, y se asegure de que se cumplen dichas medidas.

\section{Responsabilidad del controlador}

Corresponderá a los responsables del tratamiento garantizar el cumplimiento de los principios relativos al tratamiento de datos..

Toda persona que sufra un perjuicio como consecuencia de un tratamiento ilícito o de una acción incompatible con las disposiciones nacionales adoptadas en aplicación de la Directiva, tiene derecho a obtener del responsable del tratamiento la reparación del perjuicio sufrido. El responsable del tratamiento podrá ser eximido parcial o totalmente de dicha responsabilidad si demuestra que no se le puede imputar el hecho que ha provocado el daño.

\section{Sanciones}

Los Estados miembros adoptarán las medidas adecuadas para garantizar la plena aplicación de las disposiciones de la Directiva y determinarán, en particular, las sanciones que deben aplicarse en caso de incumplimiento de las disposiciones adoptadas en ejecución de la Directiva.

\section{Apertura}

Los Estados miembros adoptarán las medidas necesarias para garantizar la difusión de los tratamientos.

La autoridad de control llevará un registro de los tratamientos notificado. El registro podrá ser consultado por cualquier persona.

En lo que respecta a los tratamientos no sometidos a notificación, que los responsables del tratamiento u otro órgano designado por los Estados miembros comuniquen, en la forma adecuada, a toda persona que lo solicite, información determinada. 


\section{- Autoridades Administrativas}

\section{Autoridad de Control}

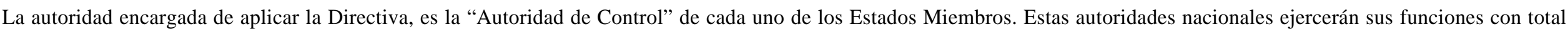

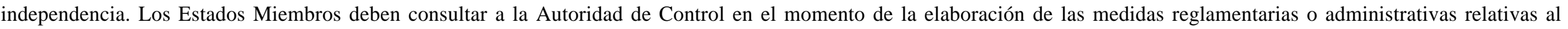
tratamiento de datos de carácter personal.

Facultades y Responsabilidades:

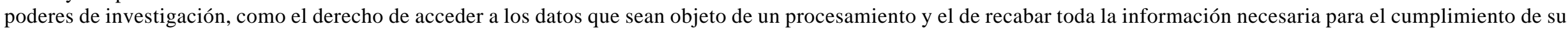
misión de control;

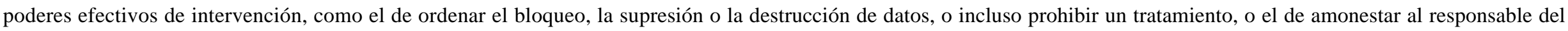
tratamiento o el someter la cuestión a los parlamentos;

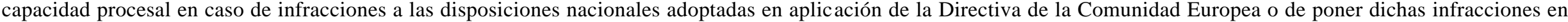
conocimiento de la autoridad judicial.

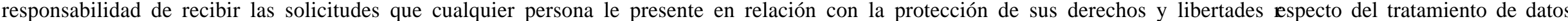
personales. Asimismo, atenderá las solicitudes de verificación de la legalidad de un tratamiento.

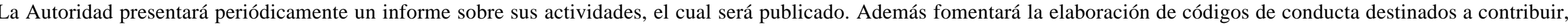
en función de las particularidades de cada sector, a la correcta aplicación de las disposiciones nacionales.

Grupo de Protección de las Personas

Dicho Grupo tiene carácter consultivo e independiente.

Facultades y Responsabilidades:

estudiar toda cuestión relativa a la aplicación de las disposiciones nacionales;

emitir un dictamen destinado a la Comisión sobre el nivel de protección existente dentro de la Comunidad y en terceros países;

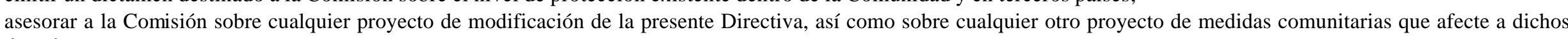
derechos

emitir un dictamen sobre los códigos de conducta elaborados a escala comunitaria.

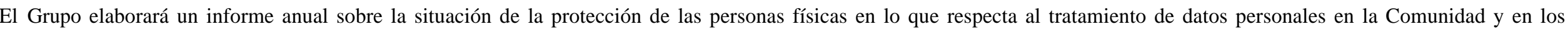
terceros países, y lo transmitirá al Parlamento Europeo, al Consejo y a la Comisión. Dicho informe será publicado

Comisión de la Comunidad Europea

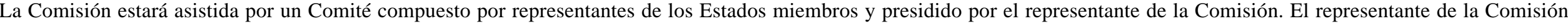

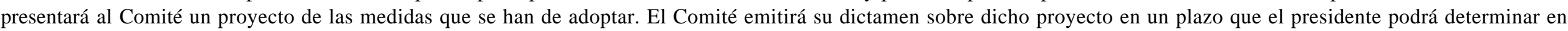
función de la urgencia de la cuestión de que se trate. La Comisión adoptará las medidas que serán de aplicación inmediata.

\section{- Autoridad Judicial}

Sin perjuicio del recurso administrativo que pueda interponerse, en particular ante la autoridad de control, toda persona dispone de un recurso judicial en caso de violación de los derechos que le garanticen las disposiciones legales. 

Equifax, creada en 1994; maneja sólo información negativa.

- $\quad$ En el verano de 1999, el buró de crédito de Experian e Informa iniciaron operaciones.

\section{REINO UNIDO \\ Los burós de crédito tienen sus inicios en los años sesenta.}

Actualmente hay dos burós de crédito privados que han estado en el mercado desde los años ochenta (hace 10 años había 4):

- Experian la exCCN, maneja un buró de crédito de información positiva y negativa.

Equifax (resultado de la adquisición de Grattan y Uapt-Inforlink). maneja información positiva y negativa.

\section{TIPOS DE SERVICIOS}

Se ofrecen servicios como calificación de riesgo, bases de

datos de morosidad y demandas por falta de pago, y de 